NUREG / CR-0570

App., Vol. 2

\title{
Technology, Safety and Costs of Decommissioning a Reference Low-Level Waste Burial Ground
}

Appendices

Prepared by E.S. Murphy, G.M. Holter

Battelle-Pacific Northwest Laboratory

Prepared for

U.S. Nuclear Regulatory

Commission 


\section{NOTICE}

This report was prepared as an account of work sponsored by an agency of the United States Government. Neither the United States Government nor any agency thereof, or any of their employees, makes any warranty, expressed or implied, or assumes any legal liability or responsibility for any third party's use, or the results of such use of any information. apparatus product or process disclosed in this report, or represents that its use by such third party would not infringe privately owned rights.

Available from

GPO Sales Program

Division of Technical Information and Document Control

U. S. Nuclear Regulatory Commission

Washington, D. C. 20555

Printed copy price: $\$ 6.50$

and

Nationa] Technical Information Service Springfield, Virginia 22161 
NUREG / CR-0570

App., Vol. 2

\section{Technology, Safety and Costs of Decommissioning a Reference Low-Level Waste Burial Ground}

Manuscript Completed: June 1980

Date Published: June 1980

Prepared by E.S. Murphy, G.M. Holter

Pacific Northwest Laboratory

Richland, WA 99352

Prepared for Office of Standards Development U.S. Nuclear Regulatory Commission

Washington, D.C. 20555

NRC FIN No. B2136 


\section{STUDY CONTRIBUTORS}

STUDY LEADER

E. S, Hurphy

APPENDIX A - REFERENCE SITE DETAILS

W. E. Kennedy, Jr.

R. B. McPherson

RPPENDIX B - WASTE INYENTORY DETAILS

E. S. Murphy

APPENDIX C - RADIATION DOSE METHODOLOGY

R. B. McPherson

W. E. Kennedy, Jr.

B. A. Napier

J. F. Washburn

APPENDIX D - ENYIRONMENTAL SURVEILLANCE AND RECORDS MAINTENANCE DETAILS

G. M. Holter

APPENDIX E - PAYMENTS NEEDED TO FINANCE DECOMIISSIONING

P. L. Hendrickson

E. S. Murphy

APPENDIX F - SITE/WASTE STABILIZATION DECOMMISSIONING ACTIYITY DETAILS

G. M. Holter

J. O. Skolrud (a)

APPENDIX G - WASTE RELOCATION DECOMMISSIONING

J. R. LaRiviere(b) ACTIVITY DETAILS

R. R. Jackson $\{b$ )

E. 5. Murphy

i.. R. Schneller (b)

(a) Associated with Exxon Nuclear Company, inc. (b)Associated with Science Applications, Inc.
APPENDIX H - COST ASSESSMENT DETAILS

E. S. Murphy

G. H. Holter (b)

R. R. Jackson (b) (b)

M. R. Schnel ier
J. O. Skolrud

APPENDIX I - RADIOLOGICAL SAFETY DETAILS

W. E. Kennedy, Jr.

G. R. Hoenes

F. J. Borst

L. W. Brackenbush

B. A. lapier

K. L. Soldat $(b)$
R. R. Jackson

EDITOR

D. R. Payson 
• 


\section{REPORT CONTENTS OUTLINE}

VOLUME I

SECTION 3 - INTRODUCTION

SECTION 2 - SUMMARY

SECTION 3 - REVIEW OF BURIAL GROUND EXPERIENCE

SECTION 4 - DECOMMISSIONING ALTERNATIVES AND STUDY APPROACH

SECTION 5 - REGULATORY CONSIDERATIONS FOR DECOMMISSIONING

SECTION 6 - ALTERNATIVE APPROACHES TO FINANCING DECOMMISSIONING

SECTION 7 - CHARACTERISTICS OF THE REFERENCE BURIAL GROUNDS

SECTION 8 - ANALYSIS OF RELEASE CONDITIONS USING PATHWAY METHODOLOGY

SECTION 9 - ENVIRONMENTAL SURVEILLANCE AND RECORDS MAINTENANCE

SECTION 10 - SITE/WASTE STABILIZATION ACTIVITIES

SECTION 11 - WASTE RELOCATION ACTIVITIES

SECTION 12 - DECOMMISSIONING COSTS

SECTION 13 - PUBLIC, OCCUPATIONAL, AND TRANSPORTATION SAFETY

SECTION 14 - DISCUSSION OF RESULTS

SECTION 15 - FACILITATION OF DECOMMISSIONING

SECTION 10 - GLOSSARY

VOLUME 2

APPENDIX A - REFERENCE SITE DETAILS

APPENDIX B - WASTE INVENTORY DETAILS

APPENDIX C - RADIATION DOSE METHODOLOGY

APPENDIX D - ENVIRONMENTAL SURVEILLANCE AND RECORDS MAINTENANCE DETAILS

APPENDIX E - PAYMENTS NEEDED TO FINANCE DECOMMISSIONING

APPENDIX $F$ - SITE/WASTE STABILIZATION DECOMMISSIONING ACTIVITY DETAILS

APPENDIX G - WASTE RELOCATION DECOMMISSIONING ACTIVITY DETAILS

APPENDIX $H$ - COST ASSESSMENT DETAILS

APPENDIX I - RADIOLOGICAL SAFETY DETAILS 


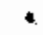




\section{CONTENTS}

STUDY CONTRIBUTORS

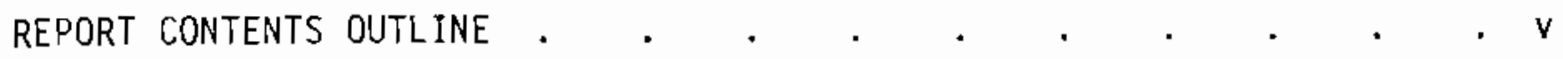

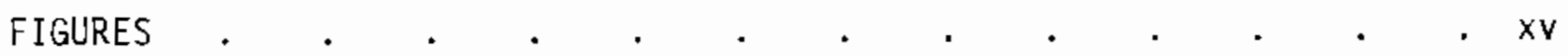

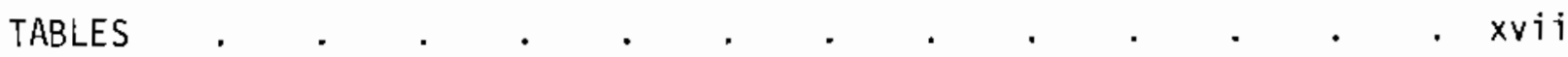

APPENDIX A - REFERENCE SITE DETAILS . . . . . . . . . . A-1

A.l LOCATION OF MAXIMUM-EXPOSED INDIVIDUAL . . . . .

A.2 FOOD CONSUMPTION PARAMETERS . . . . . . . . . . A-

A.3 DEMOGRAPHY . . . . . . . . . . . . . . A-4

REFERENCES . . . . . . . . . . . . . . . . . A-5

APPENDIX B - WASTE INVENTDRY DETAILS . . . . . . . . . B-l

B.1 WASTE INVENTORY DATA FOR CONMERCIAL SITES . . . . . B-1

B.2 REFERENCE BURIAL GROUND INVENTORY DETAILS . . • . . B-4

B.3 CALCULATION OF WASTE INVENTORY AT SitE CLOSURE $\quad \cdot \quad \cdot \quad \cdot \quad$ B-7

B.3.1 Radioactive Decay. . . . . . . . . B-9

B.3.2 Growth of Radioactive Daughters . . . . . B-10

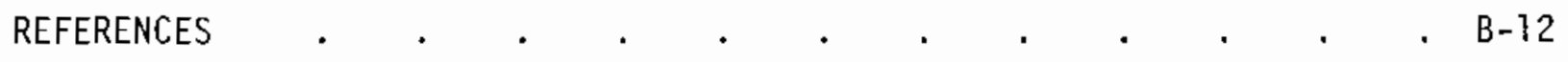

APPENDIX C - RADIATION DOSE METHODOLOGY . . . . . . . . . C-1

C. 1 DEFINITIONS AND TERMINOLOGY . . . . . . . . C-1

C.2 RADIONUCLIDE TRANSPORT AND DISPERSION . . . . . . $\mathrm{C}-3$

C.2.1 Surface Erosion . . . . . . . . . . . C-4

C.2.2 Mass-Loading . . . . . . . . . . . . C -7

C.2.3 Air Concentration from Resuspension . . . . C-8

C.2.4 Percolation, Groundwater Migration, and Overland
Flow . . . . . . . . C-10

C.2.4.1 Assumptions and Basic Data for the Eastern
Site. . . . . . . . . . . . . 
- C.2.4.2 Assumptions and Basic Data for the Western

Site. . . . . . . $\mathrm{C}-20$

C.2.4.3 Uncertainties . . . . . . . . . C-21

C.3 MOdels for estimating RAdiation doSE tO PEOPLE * . . . C-22

C.3.1 Dose from Ingestion of Food . . . . . . . C-25

C.3.1.1 Deposition Directly from Air . . . . C $\mathrm{C}-26$

C.3.1.2 Deposition by Irrigation . . . . . C C-26

C.3.1.3 Concentration in Vegetation. . . . . C-27

C.3.1.4 Concentration in Animal Products . . . . C-29

C.3.2 Oose from Orinking Water . . . . . . C-30

C.3.3 Dose from Aquatic Food Ingestion. . . . . . C-30

C.3.4 Inhalation Radiation Dose . . . . . . . . C-31

C.3.5 External Radiation Dose . . . . . . C-32

C.4 DETERMINATION OF MAXIMUM ANNUAL RADIATION DOSE . . . C-32

C.5 CALCULATED MAXIMUM ANNUAL RADIATION DOSES AT THE REFERENCE

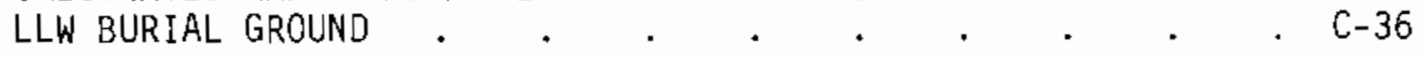

C.5.1 Dose Calculations for the Western Site . . . C-36

C.5.2 Dose Calculations for the Eastern Site . . . C -47

REFERENCES . . . . . . . . . . . . . C-44

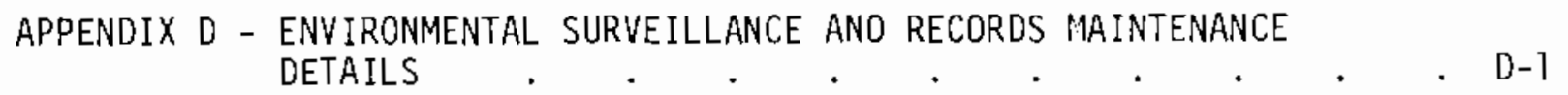

0.1 TYPICAL ENVIRONMENTAL MONITORING RESULTS FROM A COMMERCIAL

LLW SITE . . . . .

0.2 ENVIRONMENTAL SAMPLING PROCEDURES . . . . . . . . $0-3$

D.2.1 Water Sampling . . . . . . . . D-4

0.2 .2 Soil Sampling . $\quad . \quad . \quad . \quad . \quad . \quad . \quad . \quad D-4$

D.2.3 Vegetation Sampling . . . . . . . . $D-4$

0.2 .4 Small Mammal Sampling . . . . . . . . . . $0-6$ 
0.2.5 Air Sampling. . . . . . . . . . . . D . . . . .

0.2.6 TLD Exposure Sampling . . . . . . . . D-8

D.3 RADIOACTIVE SHIPMENT RECORD FORM . . . . . . . . . D-8

REFERENCES . . . . . . . . . . . . . . D- 17

APPENDIX E - PAYMENTS NEEDED TO FINANCE DECOMMISSIONING . . . E-1

E.1 BASES AND ASSUMPTIONS . . . . . . . . . . . . E-T

E.2 PAYMENT SCHEDULES FOR THE SINKING FUND OPTION . . . E-3

E.2.1 Sinking Fund Payments . . . . . . . . E-5

E.2.2 Provision for Premature Site Closure . . . . E-8

E.3 PREPAYMENT OF ANTICIPATED DECOMMISSIONING COSTS . . . E-8

E.4 PAYMENT OF DECOMMISSIONING COSTS WHEN INCURRED . . . E-10

REFERENCES . . . . . . . . . . . . . E-11

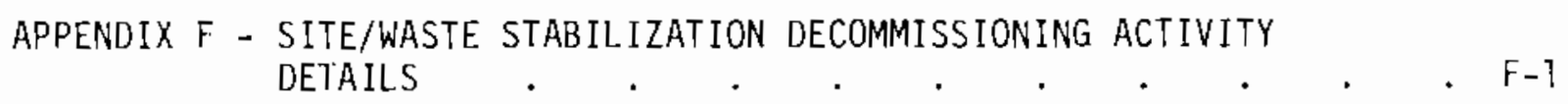

F.1 RADIONUCLIDE RELEASE MECHANISMS AND PROSPECTIVE SITE/WASTE

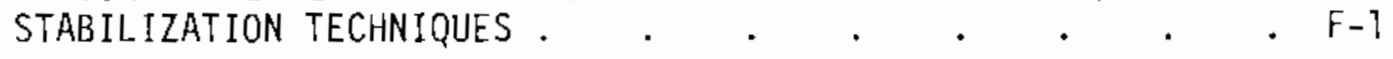

F.1.1 Radionuclide Release Mechanisms . . . . . F-1

F.1.1.1 Geomorphological Release Mechanisms . . . F-2

F.1.1.2 Hydrological Release Mechanisms . . . F-5

F.1.1.3 Biological Release Mechanisms . . . . F-7

F.1.1.4 Human Activity Release Hechanisms . . . F-9

F.1.1.5 Other Considerations . . . . . . F-10

F.1.2 Prospective Site/Waste Stabilization Techniques . . F-i1

F.2 quality assurance . . . . . . . . . . . . . F-28

F.2.1 Methods Review . . . . . . . . F-29

F.2.2 Procurement Document Control . . . . . F-29

F.2.3 Work Instructions, Procedures, and Drawings . . F-29

F.2.4 Document Control . . . . . . . . F-30 
F.2.5 Identification and Control of Procured Items . . F-30

F.2.6 Special Procedures . . . . . . . F-30

F.2.7 Inspection and Testing. . . . . . . . F-30

F.2.8 Calibration. . . . . . . . . F -30

F.2.9 Shipping and Receiving. . . . . . . F-31

F.2.10 0perating Status . . . . . . . . F-31

F.2.11 Nonconformance and Corrective Action . . . . F-3]

F.2.12 Special Quality Records . . . . . . . F-31

F.2.13 Quality Auditing . . . . . . . . F -31

REFERENCES

APPENOIX G - WASTE RELOCATION DECOMMISSIONING ACTIVITY OETAILS . . G-1

G.1 DETAILS OF SLIT TRENCH EXCAVATION ALTERNATIVES . . . . G-1

G.1.1 Core Orilling and Sampling Procedures. . . . G-1

G.1.2 Hydraulic Excavation . . . . . . . G-2

G.1.3 Pneumatic Excavation . . . . . . . G-5

G.1.4 Polar Crane . . . . . . . . . G-7

G.1.5 Mobile Gantry Crane . . . . . . . G-8

G.1.6 Mobile Gantry Crane in Enclosed Structure . . . G-9

G.2 DETAILS OF ENCLOSURE REQUIREMENTS FOR TRU WASTE REMOVAL . G-10

G.2.1 Lightweight Metal Building . . . . . . G-11

G.2.2 Air Support Weather Shield (ASWS) . . . . G-12

G.2.3 Mobile, Remotely Controlled Manipulator . . . G-12

G.3 DETAILS OF BURIAL TRENCH EXCAVATION ALTERNATIVES . . . G-14

G.3.T Excavation from Above the Trench . . . . . G-15

G.3.2 Excavation from Within the Trench . . . . G-16 
G.4 PACKAGING AND SHIPPING OF RADIOACTIVE MATERIALS . . . G-18

G.4.1 Packaging of Radioactive Materials . . . . G-18

G.4.1.1 Packaging of Waste Exhumed from a S7it . . G-18
Trench

G.4.1.2 Packaging of Transuranic-Contaminated
Waste. . . . . G-19

G.4.1.3 Packaging of Waste Exhumed from a Burial . . G-19
Trench . . . . . .

G.4.2 Shipping of Radioactive Materials . . . . G-21

REFERENCES . . . . . . . . . . . . . G-23

APPENDIX H - COST ASSESSMENT DETAILS . . . . . . . . . $\mathrm{H}-\mathrm{T}$

H.1 COMPILATION OF UNIT COST FACTORS . . . . . . $\mathrm{H}-\mathrm{l}$

H.1.1 Unit Manpower Costs . . . . . . . H-1

H.1.2 Unit Waste Managenent Costs . . . . . . $\mathrm{H}-1$

H.1.2.1 Unit Shipping Container Costs . . . , $\mathrm{H}-1$

H.1.2.2 Unit Transportation Costs . . . . . $\mathrm{H}-\hat{3}$

H.1.2.3 Unit Waste Disposal Costs . . . . . H-5

H.I.3 Unit Costs of Equipment, Materials, and Supplies - $\mathrm{H}-7$

H.1.4 Unit Costs of Environmental Services . . . . H-7

H.2 COST ASSESSMENT DETAILS FOR STABILIZATION $\quad \cdot \quad \cdot \quad \cdot \quad \cdot \quad \mathrm{H}-7$

H.2.1 Stabilization Activity Details and Assumptions . . H-7

H.2.2 Manpower Details for Stabilization . . . . H-16

H.2.2.1 Support Staff Manpower Requirements . . . H-17

H.2.2.2 Decommissioning Worker Manpower Requirements . H-18

H.2.3 Equipment and Material Oetails for Stabilization . H-18

H.3 COST DETAILS FOR LONG-TERM CARE . . . . . . . . H-18

H.3.1 Manpower Details for Long-Term Care . . . . H-23

H.3.2 Long-Term Care Details and Assumptions . . . H-23 
H.3.2.7 Environmental Monitoring Details . . . H-23

H.3.2.2 Site Maintenance Details . . . . . . H-26

H.4 COST ASSESSMENT DETAILS FOR WASTE RELOCATION . . . . H-26

H.4.l Manpower Requirements and Costs for Waste

H.4.2 Material and Equipment Cost Details for Waste H-27

H.4.3 Waste Management Cost Details for Waste
Relocation H-38

REFERENCES . . . . . . . . . . . . . . . . . . H-41

APPENDIX I - RADIOLOGICAL SAFETY DETAILS . . . . . . . . . I-1

I. 1 RADIOLOGICAL PUBLIC SAFETY . . . . . . . . I-3

I.1.1 Airborne Radioactive Releases from Routine Waste
Relocation Operations. . . . . . I-5

I.1.7.] Relocation of Wiaste from a Slit Trench . . I-6

I.1.1.2 Relocation of TRU Waste from a Burial
Trench . . . . . I-10

I.1.1.3 Relocation of all the Waste from a Burial
Trench . . . . . I-13

I.1.2 Airborne Radioactive Releases from Routine Site
Stabilization Operations . . . . . I-15

I.1.3 Airborne Radioactive Releases from Postulated
Decomissioning Accidents . . . . . I-15

I.T.4 Calculated Public Radiation Doses . . . . I-23

I. 2 OCCUPATIONAL SAFETY . . . . . . . . . . . . . I-24

I.2.1 Relocation of High Beta-Gamma Radioactivity Waste
from a Slit Trench . . I-3l

I.2.1.1 Core Drilling and Sampling . . . . I-3I

1.2.1.2 Overburden Removal . . . . . . . I-33

I.2.1.3 Sheet Piling Installation. . . . . . I-34 
1.2.1.4 Trench Excavation and Waste Exhumation . . I-34

I.2.2 Relocation of TRU Waste from a Burial Trench . . 1-37

I.2.2.1 Core Drilling and Sampling . . . . I-37

I.2.2.2 Overburden Removal . . . . . . I-39

I.2.2.3 Sheet Piling Installation . . . . . I-39

I.2.2.4 Trench Excavation and Waste Exhumation . . I-40

I.2.3 Relocation of the Waste from a Single Burial Trench . I-42

1.2.3.1 Core Drilling and Sampling . . . . I-42

I.2.3.2 Overburden Removal . . . . . . I-44

I.2.3.3 Trench Excavation and Waste Exhumation . . I-44

I.2.4 Occupational Exposure from Site Stabilization Operations....... . . . I .45

I.2.5 Occupationa1 Exposure from Long-Term Care
Operations
. . . . . . . . . . I-46

I.3 TRANSPORTATION SAFETY . . . . . . . . . . . I-46

I.3.1 Assumptions for Routine Transportation Calculations . I-47

I.3.2 Assumptions for Postulated Transportation Accidents . I-50

I.3.3 Calculations of Airborne Radioactive Concentration During Transportation Accidents . . . . . I-54

I.4 REFERENCE RADIONUCLIDE INVENTORIES . . . . . . . . I-55 REFERENCES . . . . . . . . . . . . . . . . . . . . I-61 
,

-

$+$ 


\section{FIGURES}

A.1-1 Average $\left(x / Q^{\circ}\right)$ Values Versus Distance in a Sector from the Generic Site. . . . . . . . . A-2

C.2-l Potential Technetium-99 Concentration in Ground Water Versus Distance . . . . . . . . C $\mathrm{C}-15$

C.2-2 Potential Thorium-232 Concentration in Ground Water Versus Distance . . . . . . . . . . C-15

C.2-3 Predicted Technetium-99 Concentration in the Ground Water Versus Time at the Surface Stream . . . . . . C-16

C.2-4 Predicted Thorium-232 Concentration in the Ground Water Versus Time at the Surface Stream . . . . . . . . C-16

C.2-5 Estimated Release of ${ }^{14} \mathrm{C}$ into the Surface Stream from Overland Flow . . . . . . . . . . C Cl7

C.2-6 Predicted Technetium-99 Concentration in the Ground Water Versus Time at the Surface Stream (using 100-year and 1000-year leach times)

D.2-1 Example Environmenta\} Sampling Record Form . . . . . . D-5

D.2-2 Example Air Sampling Record Form . . . . . . . . . D-7

D.3-1 Example Radioactive Shipment Record Form . . . . . . D-9

G. 1-1 Hydraulic Excavation of Slit Trench . . . . . . . G-3

G.1-2 Pneumatic Excavation of Slit Trench . . . . . . . G-5

G.1-3 Excavation of Slit Trench Using Polar Crane . . . . . G-7

G. 1-4 Excavation of S1it Trench Using Gantry Crane . . . . . G-8

G.1-5 Excavation of S1it Trench Using Gantry Crane in Enclosed
Structure . . . . . . . . . . G-9

G.2-1 Plan of Lightweight Metal Enclosure for TRU Waste Exhumation . G-11

G.2-2 Plan of Air-Support Weather Shield and Lightweight Metal Enclosure for TRU Waste Exhumation . . . . . G-13

G.3-1 Waste Relocation from a Conventional Burial Trench by Excavation from Above the Trench . . . . . . . G-15 
G.3-2 Waste Relocation from a Conventional Burial Trench by Excavation from Within the Trench . . . . . . G-77

G.4-1 Characteristics of a Super Tiger Overpack . . . . . . G-20

G.4-2 Radiation Dose Rate Limits for Exclusive-Use Vehicles . . G-22

I.3-1 Pasquil1 Type $F$ Centerline $x / Q^{\prime}$ Values for Building-Wake Modifjcation Factors Versus Downwind Distance . . . . . . . I-56 


\section{TABLES}

A.2-1 Parameters Used for Calculation of Radiation Doses from

Consumption of Foods . . . . . . . . . A-3

A.3-1 Population Distribution Around the Generic Sites . . . A-4

B.1-1 Annual National Total Waste Disposal at the Six Commercial Waste Buriai Facilities . . . . . . . . B-2

B.1-2 Radioactive Waste Buried at Commercial Sites as of

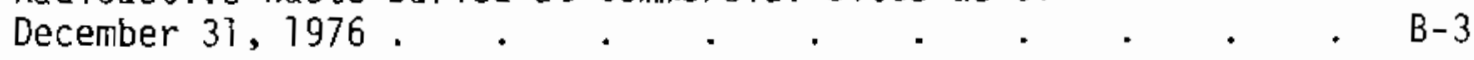

B.1-3 Comparison of Annual Volumes of Radioactive Waste Buried at the Six Commercial Sites, 1974-1977 . . . . . . B-3

B.2-1 Radionuclide Concentrations in Low-Level Waste for Use in Estimating Total Burial Site Inventories . . . . . B-6

B.2-2 Comparison of the Isotopic Composition of the Generic Waste Inventory with Waste Inventories at Commercial LLW Burial Grounds.

C.1-1 Solubility Class Assumptions for the Waste Inventory. . . C-4

C.2-1 Parameter Values Used in Estimating Water Erosion for the Eastern Site. . . . . . . . . . . C 6

C.2-2 Parameter Values Assumed for Estimating Wind Erosion . . . C-6

C.2-3 Distribution Coefficients . . . . . . . . C-12

C.2-4 Predicted Radionuclide Concentrations in the Well Water Beneath the Eastern Burial Site. . . . . . . C-18

C.2-5 Predicted Radionuclide Release Rates to the Surface Water Stream from Groundwater Migration and Overland Flow at the Eastern Site. . . . . . . . . C-19

C.5-1 Maximum Annual Doses to Maximum-Exposed Individual from Conditional Release of Western Site - Excavation Prohibited . C-38

C.5-2 Maximum Annual Doses to Maximum-Exposed Individual from Release of Western Site - Excavation Permitted . . . . C-39

C.5-3 Maximum Annual Doses to Maximum-Exposed Individual from Release of Western Site - Overburden Removed by Erosion 
C.5-4 Maximum Annual Doses to the Maximum-Exposed Individual from Unrestricted Release of the Western Site with the Radionuclide Inventory of Table $8.4-2$

C.5-5 Contributions to Maximum Annual Doses to Maximum-Exposed Individual from Water Pathways - Eastern Site . . . . C-42

C.5-6 Maximum Annual Doses to the Maximum-Exposed Individual from Unrestricted Release of the Eastern Site with the Radionuclide Inventory of Table 8.4-2

D.1-1 Typical Envirommental Monitoring Results for a Commercial LLW Burial Ground.

D.1-2 Typical Direct Radiation Exposure Readings for a Commercial LLW Burial Ground . . . . . . . . . . D-3

E.1-T Stabilization and Long-Tern Care Costs . . . . . . E-2

E.2-1 Sinking Fund Terminal Values Required to Finance Site Stabilization and Long-Term Care. . . . . . . E-5

E.2-2 Example Annual Sinking Fund Payments for Site Stabilization and Long-Term Care . . . . . . . . . E-6

E.2-3 Uniform Annual Sinking Fund Payments . . . . . . . E-9

E.3-1 Required One-Time Payments for Prepayment of Decommissioning Costs

G.2-1 Conceptual Functions of a Mobile, Remotely Controlled Manipulator. . . . . . . . . . . G-14

H.1-1 Unit Saiaries for Decommissioning Staff . . . . . . . H-2

H.1-2 Unit Costs for Shipping Containers Used in this Study . . H-2

H.7-3 Transportation Rates for Legal-Size and Weight Shipments (Effective April 1, 1978) . . . . . . . H-4

H. 1-4 Additional Charges when Gross Shipment Weight Exceeds 20.41 MT, Based on Rates for the State of Washington . . . H-5

H.1-5 Schedule of Disposal Charges for Shallow-Land Burial . . . . H-6

H.1-6 Unit Charges for Contractor Equipment . . . . . . . H-8

H.1-7 Unit Costs for Materials and Expendable Equipment . . . H-9

H.1-8 Postulated Unit Costs of Environmental Sample Analyses . . H-10 
H.2-1 Estimated Support Staff Manpower Requirements for Burial

Ground Stabilization . . . . . . . . . H-19

H.2-2 Estimated Decommissioning Worker Manpower Requirements

for Burial Ground Stabilization. . . . . . . H-20

H.2-3 Equipment and Material Requirements and Costs for

Stabilization of the Western Site . . . . . . H-2l

H.2-4 Equipment and Material Requirements and costs for

Stabilization of the Eastern Site . . . . . H-22

H.3-1 Annual Manpower Requirements for Long-Term Care of the Arid Western Site Following Site Stabilization by the

Minimal or Modest Plan... . . . . . H-24

H.3-2 Annual Manpower Requirements for Long-Term Care of the Arid Western Site Following Site Stabilization by the Complex Plan.

H.3-3 Annual Manpower Requirements for Long-Term Care of the Humid Eastern Site Following Site Stabilization by the Minimal or Modest Plan. . . . . . . . . . H-25

H.3-4 Annual Manoower Requirements for Long-Term Care of the Humid Eastern Site Following Site Stabilization by the Complex Plan . H-25

H.4-1 Manpower Requirements and Costs for S1it Trench Exhumation Western Site. . . . . . . . . . . H-28

H.4-2 Manpower Requirements and Costs for S7it Trench Exhumation Eastern Site. . . . . . . . . . . H-29

H.4-3 Manpower Requirements and Costs for TRU Waste Exhumation Western Site. . . . . . . . . . . H-30

H.4-4 Manpower Requirements and Costs for TRU Waste Exhumation Eastern Site. . . . . . . . . . . H-3l

H.4-5 Manpower Requirements and Costs for Relocation of the
Waste from One Trench - Western Site. . H-32

H.4-6 Manpower Requirements and Costs for Relocation of the
Waste from One Trench - Eastern Site. . . H-32

H.4-7 Contractor's Equipment Costs for Excavation of a S1 it Trench. H-33

H.4-8 Costs of Expendable Equipment and Supplies for Excavation of a Slit Trench. . . . . . . . . H-34 
H.4-9 Contractor's Equipment Costs for Exhumation of TRU Waste . . H-35

H.4-10 Costs of Expendabie Equipment and Supplies for Exhumation of TRU Waste. . . . . . . . . . . . H-36

H.4-11 Contractor's Equipment Costs for Relocation of Waste from One Burial Trench. . . . . . . . . . H-37

H.4-12 Costs of Expendable Equipment and Supplies for Relocation of Waste from One Burial Trench. . . . . . . H H

H.4-13 Waste Management Requirements and Costs for Exhumation of a Slit Trench. . . . . . . . . . H

H.4-14 Waste Management Requirements and Costs for Exhumation of TRU Waste. . . . . . . . . . . H-39

H.4-15 Waste Management Requirements and Costs for Relocation of the Waste from an Entire Burial Trench . . . . . H-40

I.1-1 Wind and Mechanical Resuspension Data for Routine Airborne Releases from Waste Relocation Operations at the Reference LLW Burial Ground

1.1-2 Calculated Airborne Releases from Routine Waste Relocation operations at the Reference LLW Burial Grounds . . . . . I-8

I.1-3 Postulated Accidents During Decommissioning Operations at the Reference LLW Buriai Ground . . . . . . . . I-16

1.1-4 Radiation Doses to the Maximum-Exposed Individual from Airborne Releases During Routine Waste Relocation Dperations at the Western Site

I.1-5 Radiation Doses to the Maximum-Exposed Individual from Airborne Releases During Routine Waste Relocation Operations at the Eastern Site . . . . . . . . . I-26

I. 1-6 Radiation Doses to the Population Residing Within $80 \mathrm{kin}$ from Airborne Releases During Routine Waste Relocation operations at the Western Site . . . . . . . . I-27

1.1-7 Radiation Doses to the Population Residing Within $80 \mathrm{~km}$ from Airborne Reieases During Routine Waste Relocation Operations at the Eastern Site . . . . . . . . I-28

I.1-8 Radiation Doses to the Maximum-Exposed Individual from Airborne Releases from Decommissioning Accidents 
I.2-1 Occupational Doses and Data for Slit Trench Waste

Relocation Operations . . . . . . . . . I-32

1.2-2 Occupational Doses and Oata for Partial Trench (TRU)

Waste Exhumation/Relocation... . . . . . I-38

I.2-3 Occupational Ooses and Oata for Exhumation of the Waste
from One Burial Trench. . I-43

1.3-1 Waste Shipping Requirements. . . . . . . . I-47

1.3-2 Direct Radiation Ooses to Transportation Workers and Members of the General Public Ouring Routine Transport

of Exhumed Waste. . . . . . . . . . . I-49

I.3-3 Transportation Accident Severity Categories . . . . 1-51

I.3-4 Minor Offsite Transportation Accidents . . . . . I-52

I.3-5 Severe Offsite Transportation Accidents . . . . . I-53

I.3-6 Onsite Transportation Accident . . . . . . . I-53

I.4-1 Reference Radionuclide Inventory 1, 30-Year-01d S1 it Trench
Waste/Soil Mixture

I.4-2 Reference Radionuclide Inventory 2, 1-Year-01d Slit Trench Waste/Soil Mixture . . . . . . . . . I-57

I.4-3 Reference Radionuclide Inventory 3, Average Waste/Soil Radioactivity at Site Closure . . . . . . . I-59

I.4-4 Reference Radionuclide Inventory 4, TRU Waste Activity at Site Closure Associated with $40 \mathrm{~g}$ of Pu Isotopes . . . I-60 

APPENDIX A

\section{REFERENCE SITE DETAILS}

Supporting material necessary to evaluate the radiological safety impacts of decommissioning activities at the reference low-level waste (LLW) site is presented in this appendix. The location of the maximum-exposed individual in relation to the reference site is described in Section A.T. Parameters used for the calculation of radiation doses from the consumption of foods grown on a decommissioned site are given in Section A.2. Demographic characteristics of the reference site are presented in section A.3. For the calculation of radiological safety impacts, the parameters discussed here are assumed to apply to both the arid western site and the humid eastern site.

\section{A. 1 LOCATION OF MAXIMUM-EXPOSED INDIVIDUAL}

To determine use 1 imitations for public use of a decomissioned burial site (Section 8 of Volume 1), the maximum-exposed individual is assumed to live and work on the decommissioned site. To determine public safety impacts of decommissioning activities (Section 13 of Volume 1), the maximum-exposed individual is assumed to reside $1 \mathrm{~km}$ from the site, where the atmospheric dilution factor is estimated to be $7.5 \times 10^{-6} \mathrm{sec} / \mathrm{m}^{3}$ for a ground-level release. This dilution factor is derived by multiplying the average dilution factor for a ground-level release, taken from Figure A.1-1, by 2.5 to adjust for the maximum sector. The atmospheric dilution factor for a large population group is calculated to be $2.4 \times 10^{-9} \mathrm{sec} / \mathrm{m}^{3}$ for a ground-level release.

\section{A.2 FOOD CONSUMPTION PARAMETERS}

Parameters used to calculate radiation doses from the consumption of foods grown on a decommissioned site are listed in Table A.2-1. Only that fraction of the diet grown locally and consumed by the maximum-exposed individual is shown in the table. For the arid western site, the irrigation rate 


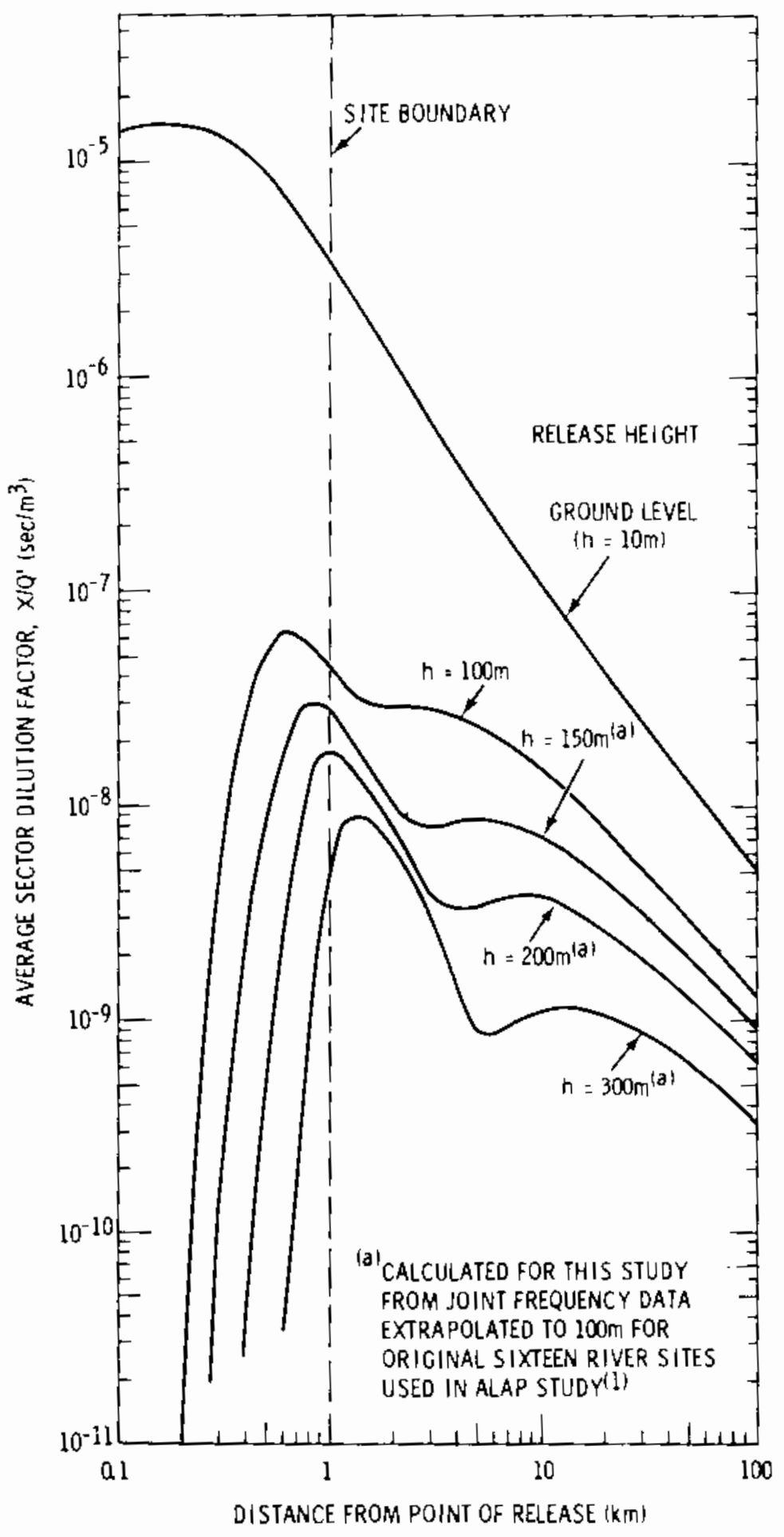

FIGURE A.1-1. Average $\left(X / Q^{\prime}\right)$ Values versus Distance in a Sector from the Generic Site 
TABLE A.2-1. Parameters Used for Calculation of Radiation Doses from Consumption of Foods

\begin{tabular}{|c|c|c|c|c|}
\hline Food & $\begin{array}{r}\text { Growing } \\
\text { Period } \\
\text { (days) }\end{array}$ & $\begin{array}{l}\text { Yield } \\
\left(\mathrm{kg} / \mathrm{m}^{2}\right) \\
\end{array}$ & $\begin{array}{r}\text { Holdup } \\
\text { (days) }\left(\begin{array}{l}\text { a }) \\
\end{array}\right.\end{array}$ & $\begin{array}{c}\text { Consumption } \\
(\mathrm{kg} / \text { year })(\mathrm{b})\end{array}$ \\
\hline Leafy Vegetables & 90 & 1.5 & 1 & 30 \\
\hline Other Above-Ground Vegetables & 60 & 0.7 & 1 & 30 \\
\hline Potatoes & 90 & 4.0 & 10 & 110 \\
\hline Other Root Vegetables & 90 & 5.0 & 1 & 72 \\
\hline Berries & 60 & 2.7 & $\mathrm{i}$ & 30 \\
\hline Melons & 90 & 0.8 & 1 & 40 \\
\hline Orchard Fruit & 90 & 1.7 & 10 & 265 \\
\hline Wheat & 90 & 0.72 & 10 & 80 \\
\hline Other Grain & 90 & 1.4 & 1 & 8 \\
\hline Eggs & 90 & $0.84^{(c)}$ & 2 & 30 \\
\hline$M i\rceil k$ & 30 & $1.3^{(c)}$ & 2 & $274^{(d)}$ \\
\hline Beef & 90 & $0.84^{(c)}$ & 15 & 40 \\
\hline Pork & 90 & $0.84^{(c)}$ & 15 & 40 \\
\hline Poultry & 90 & $0.84^{(c)}$ & 2 & 18 \\
\hline Fish & & & 1 & 20 \\
\hline Crustacea & & & 1 & 10 \\
\hline Molluscs & & & 1 & 10 \\
\hline Drinking water & & & 0.5 & $730^{(d)}$ \\
\hline
\end{tabular}

(a) Time between harvest and consumption.

(b) Only that fraction of the diet grown locally, and therefore potentially contaminated, is listed. Consumption by the maximum-exposed individual is assumed.

(c) Yield of animal feeds (i.e., grain or pasture grass).

(d) Units of liters/year.

is assumed to be $150 \mathrm{2} / \mathrm{m}^{2}$ per month for 8 months out of the year. Because of the high average rainfall at the eastern site, irrigation is not required. 


\section{A. 3 DEMOGRAPHY}

Existing LLW burial sites in the United States are all located in rural areas having relatively low population densities. For this study, in order to caiculate public safety impacts of decommissioning activities, a generic population distribution is assumed that is common to both the arid western and humid eastern sites. The population distribution is summarized in Section 7.5 of Volume 1 . Details are given in Table A.3-1. The total population within a circie with an $80-\mathrm{km}$ radius is 3.52 million.

TABLE A.3-1. Population Distribution Around the Generic Sites

\begin{tabular}{|c|c|c|c|c|c|}
\hline $\begin{array}{l}\text { Distan } \\
\text { Faciitit }\end{array}$ & $\begin{array}{l}\text { ice from } \\
\text { ies }(\mathrm{km})\end{array}$ & $\begin{array}{c}\text { Population } \\
\text { Density } \\
\text { (persons } / \mathrm{km}^{2} \text { ) }\end{array}$ & $\begin{array}{l}\text { Total Population } \\
\text { in Annulus (a) }\end{array}$ & $\begin{array}{l}\text { Cumu } \\
\text { Popu }\end{array}$ & $\begin{array}{l}\text { lative } \\
\text { lation }\end{array}$ \\
\hline 0 & -1.6 & -- & 10 & & 10 \\
\hline 1.6 & $-\quad 3.2$ & 87 & $2130^{(b)}$ & & $140^{(b)}$ \\
\hline 3.2 & -4.8 & 129 & 5230 & & 370 \\
\hline 4.8 & -6.4 & 139 & 7940 & 15 & 300 \\
\hline 6.4 & -8.0 & 160 & 11700 & 27 & 000 \\
\hline 8.0 & -16 & 746 & 89300 & 116 & 000 \\
\hline 16 & -32 & 154 & 375000 & 491 & 000 \\
\hline 32 & -48 & 216 & 878000 & 1370 & 000 \\
\hline 48 & -64 & 181 & 1030000 & 2400 & 000 \\
\hline 64 & -80 & 154 & 1120000 & 3520 & 000 \\
\hline
\end{tabular}

(a) It is assumed that $1 / 16$ of the population resides within each of the 16 sectors.

(b) Totals are rounded to three significant figures. 


\section{REFERENCES}

i. U.S. AEC, Final Environmental Statement Concerning Proposed Rule-making Action: Numerical Guides for Design Objectives and Limiting Conditions for Operation to Meet the Criteria "As Low As Practicable" for Radioactive Material in Light-Water-Cooled Nuclear Power Reactor Effluents, Wash-1258, Directorate of Regulatory Standards, Volume 1 of 3 , Figure $6 \mathrm{~B}-1$, p. 6B-43 and Figure 6C-8, p. 6C-12, July 1973. 

APPENDIX B

\section{WASTE INVENTORY DETAILS}

This appendix presents supporting material for the reference radioactive waste inventory shown in Table 7.3-3 of Volume 1. Waste inventory data for existing commercial sites are summarized in Section B.1. The bases for the inventory shown in Table 7.3-3 are discussed in Section B.2. The method used to calculate the inventory at burial ground closure is described in Section B.3.

\section{B.1 WASTE INVENTORY DATA FOR COMMERCIAL SITES}

Data on radioactive waste buried at the six conmercial $L L W$ burial grounds in the United States are shown in Tables B.1-1 and B.1-2. Table B.1-1 shows annual total radioactive waste disposal at the six sites through $\mathrm{CY}-1976$. Table 8.1-2 shows total waste buried at each of the sites as of January 1, 1977. Data for both tabies are based on Reference 1.

As shown in Table B.1-2, byproduct and special nuclear material (SNM) activity concentrations at the six commercial sites vary by about an order of magnitude. Richland, Washington, and Morehead, Kentucky, have the highest reported byproduct activity concentrations and Sheffield, Illinois, has the lowest reported byproduct activity concentration. Beatty, Nevada, has the nighest reported SNM activity concentration and Sheffield, Illinois, and West valley, New York, have the lowest reported SNM activity concentrations. The average specific activity (not corrected for decay) of buried byproduct material at the six sites is $8.95 \mathrm{ci} / \mathrm{m}^{3}$.

During 7977 about $72,000 \mathrm{~m}^{3}$ of waste was received at the commercial sites, ${ }^{(2)}$ as shown in Table B.7-3. Most of the increase in waste volume was accommodated at the Barnwell site because of the closing of the West valley site and the 10 cents per pound excise tax imposed by the State of Kentucky on wastes to be buried at the Morehead site. No increase in waste volume was noted at Beatty and only a small increase at Richland. This is probably because of the relative geographic isolation of the western sites from 
TABLE B.T-1. Annual National Total waste Disposal at the Six Commercial Waste Burial Facilities (a)

\begin{tabular}{|c|c|c|c|c|c|c|c|c|}
\hline \multirow[b]{2}{*}{ Year } & \multirow[b]{2}{*}{ Volume $\pi_{1}^{3}$} & \multicolumn{2}{|c|}{ Byproduct Material (b) } & \multicolumn{3}{|c|}{ Special Nuclear Material(c) } & \multicolumn{2}{|c|}{ Source Material ${ }^{(0)}$} \\
\hline & & & $\mathrm{ci} / \mathrm{m}^{3}$ & & & $9 / m^{2}$ & $\mathrm{~kg}$ & $\mathrm{~kg} / \mathrm{m}^{3}$ \\
\hline 1962 & 1860 & N.A. ${ }^{(e)}$ & $N, A,\{e\}$ & & 319 & 0.17 & 296 & 0.16 \\
\hline 1963 & 6240 & 29618 & 4.75 & 43 & 215 & 6.93 & 13264 & 2.13 \\
\hline 1964 & 13100 & 165060 & 12.60 & 187 & 073 & 14.28 & 15993 & 1.22 \\
\hline 1965 & 13120 & 91864 & 7.00 & 341 & 359 & 26.03 & 23025 & 1.75 \\
\hline 1966 & 16190 & 106773 & 6.59 & 19 & 751 & 1.22 & 39359 & 2.43 \\
\hline 1967 & 19370 & 94624 & 4.89 & 42 & 170 & 2.18 & 30229 & 1.56 \\
\hline 1968 & 19640 & 116772 & 5.95 & 30 & 172 & 1.54 & 22459 & 1.74 \\
\hline 1969 & 21360 & $122 \quad 209$ & 5.72 & 47 & 687 & 2.23 & 89281 & 4.18 \\
\hline 1970 & 25000 & 163811 & 6.55 & 69 & 392 & 2.78 & 41296 & 1.65 \\
\hline 1971 & 29300 & 792883 & 27.06 & 101 & 512 & 3.46 & 70983 & 2.42 \\
\hline 1972 & 37300 & 321449 & 8.62 & 153 & 389 & 4.11 & 98455 & 2.64 \\
\hline 1973 & 47040 & 402406 & 8.55 & 181 & 607 & 3.86 & 114866 & 2.44 \\
\hline 1974 & 53380 & $568 \quad 134$ & 10.64 & 167 & 662 & 3.14 & $125 \quad 432$ & 2.35 \\
\hline 1975 & 57390 & 455751 & 7.94 & 143 & 653 & 2.50 & 160462 & 2.80 \\
\hline 1976 & 62820 & 355789 & 5.66 & 148 & 486 & 2.36 & 106068 & 1.69 \\
\hline TOTALS & 423100 & $3787 \quad 133$ & 8.95 & 1677 & 547 & 3.96 & $95] 468$ & 2.25 \\
\hline
\end{tabular}

(a) The data in this table are from Reference 1.

(b) Byproduct material (reported in curies) refers to any radioactive material (except source material and special nuclear material) obtained during the production or use of source or special nuclear material and includes fission products and other radioisotopes.

(c) Special nuclear material (reported in grams) refers to plutonium, $233 \mathrm{U}$, uranium containing more than the natural abundance of the isotope 235 , or any materia? artificialiy enriched with any of the foregoing substances. Special nuclear material does not include source material.

(d) Source material (reported in kilograms) refers to thorium, natural or depleted uranium, or any combination thereof. Source material does not include special nuclear material.

(e) N.A. - Not Available. 


\section{TABLE B.1-2. Radioactive Waste Buried at Commercial Sites as of December 31, 1976}

\begin{tabular}{|c|c|c|c|c|c|c|c|}
\hline & $\begin{array}{c}\text { Barnwel l, } \\
\text { South Carolina }\end{array}$ & $\begin{array}{l}\text { Beatty, } \\
\text { Nevada }\end{array}$ & $\begin{array}{l}\text { Morehead, } \\
\text { Kentucky. }\end{array}$ & $\begin{array}{l}\text { Richland, } \\
\text { Washington }\end{array}$ & $\begin{array}{l}\text { Sheffield, } \\
\text { Illinois }\end{array}$ & $\begin{array}{l}\text { West Valley, } \\
\text { New York }\end{array}$ & $\begin{array}{l}\text { Averages } \\
\text { or Iotals } \\
\end{array}$ \\
\hline $\begin{array}{l}\text { Date of Initial } \\
\text { Operation }\end{array}$ & 1971 & 1962 & 1965 & 1965 & 1967 & 1963 & \\
\hline $\begin{array}{l}\text { Status as of } \\
\text { January } 1,1979\end{array}$ & Open & Open & $\begin{array}{l}\text { Closed by } \\
\text { State }\end{array}$ & Open & $\begin{array}{l}\text { Filied to } \\
\text { Licensed } \\
\text { Capacity }\end{array}$ & $\begin{array}{l}\text { Closed by } \\
\text { site Operator }\end{array}$ & \\
\hline Burial Area $\left(\mathrm{m}^{2}\right)$ & 1090000 & 324000 & 1340000 & 405000 & 82000 & 89000 & \\
\hline $\begin{array}{l}\text { Buried Waste } \\
\text { Volume }\left(\mathrm{m}^{3}\right)\end{array}$ & $85 \quad 440$ & 53800 & 134900 & 13500 & 69000 & 66520 & 423200 \\
\hline $\begin{array}{l}\text { Total Byproduct } \\
\text { Activity (Ci) }\end{array}$ & $422 \quad 476$ & 132318 & 2139225 & $468 \quad 824$ & 46512 & 577778 & 3787133 \\
\hline $\begin{array}{l}\text { Byproduct Specific } \\
\text { Activity }\left(\mathrm{Ci} / \mathrm{m}^{3}\right)\end{array}$ & 4.94 & 2.46 & 15.86 & 34.73 & 0.67 & 8.69 & 8.95 \\
\hline $\begin{array}{l}\text { Total Special } \\
\text { Nuclear Material } \\
\text { (g) }\end{array}$ & $427 \quad 407$ & 683669 & 403609 & 57698 & 49609 & $55 \quad 555$ & 1677547 \\
\hline $\begin{array}{l}\text { SNM Concentration } \\
\left(\mathrm{g} / \mathrm{m}^{3}\right)\end{array}$ & 5.00 & 12.71 & 2.99 & 4.27 & 0.72 & 0.84 & 3.96 \\
\hline $\begin{array}{l}\text { Total Source } \\
\text { Material (kg) }\end{array}$ & 143015 & 40813 & $228 \quad 673$ & 11586 & 80908 & $446 \quad 473$ & 951468 \\
\hline $\begin{array}{l}\text { Source Material } \\
\text { Concentraion } \\
\left(\mathrm{kg} / \mathrm{m}^{2}\right)\end{array}$ & 1.67 & 0.76 & 1.70 & 0.86 & 1.17 & 6.71 & 2.25 \\
\hline
\end{tabular}

TABLE B.1-3. Comparison of Annual Volumes of Radioactive Waste Buried at the Six Commercial Sites, 1974-1977(a)

Volume of Radioactive Waste Buried Annually $\left(\mathrm{m}^{3}\right)$

\begin{tabular}{|c|c|c|c|c|c|c|c|}
\hline Year & $\begin{array}{l}\text { Barnwell, } \\
\text { South Carolina }\end{array}$ & $\begin{array}{r}\text { Beatty, } \\
\text { Nevada } \\
\end{array}$ & $\begin{array}{l}\text { Morehead, } \\
\text { Kentucky }\end{array}$ & $\begin{array}{l}\text { Richland, } \\
\text { Washington }\end{array}$ & $\begin{array}{l}\text { Sheffield, } \\
\text { Illinois }\end{array}$ & $\begin{array}{l}\text { West valley, } \\
\text { New York }\end{array}$ & Totals \\
\hline 1974 & 18019 & 4103 & 8897 & 1411 & $12 \quad 373$ & $53 \quad 377$ & 53377 \\
\hline 1975 & 17829 & 4943 & 17109 & 1500 & 14116 & $1899^{(b)}$ & 57386 \\
\hline 1976 & 28829 & 3864 & $13783^{(c)}$ & 2867 & 13480 & $\cdots$ & 62823 \\
\hline 1977 & $46 \quad 564$ & 4742 & 423 & 2380 & 17644 & $\ldots$ & 71753 \\
\hline
\end{tabular}

(a)Data for the years 1974 to 1976 are from Reference 1. Data for the year 1977 are from Reference 2.

(b) Receipt and burial of wastes suspended on March 11, 1975.

(c) Only $845 \mathrm{~m}^{3}$ of waste was buried at Morehead after the 104 per pound excise tax went into effect on July $1,1976$. 
locations where the waste is generated. (As of December 31, 1977, 60 of the 651 icensed commercial nuclear reactors were located in the eastern, southeastern and central regions of the nation.)

As of January 1, 1979, the burial grounds at West Valley, New York, and Morehead, Kentucky, are closed, and the site at Sheffield, Illinois, is filled to 1 icensed capacity (see Section 3 of Volume 1). The state of South Carolina has imposed a ceiling of $2.1 \times 10^{6}$ cubic feet per year $\left(5.95 \times 10^{4}\right.$ cubic meters per year) on radioactive wastes buried at the Barnwell site. While officials from South Carolina have stated that this burial limitation will initially be somewhat flexibie to avoid causing hardship to utilities, it is probable that the two western sites will experience significant increases in volumes of waste buried at these sites.

\section{B.2 REFERENCE BURIAL GROUND INVENTORY DETAILS}

Published information about radionuclide concentrations in buried waste at commercial LLW burial grounds is limited. A computer study (3) has been made of radioactive shipment records for waste buried at the Morehead, Kentucky, site. The study provides an estimate of the radioactivity at the site as of 1974. An estimate of the isotopic composition of radioactive waste buried at West Valiey is contained in an EPA report ${ }^{(4)}$ dealing with waste migration problems at the site in northwestern New York State. Because a significant fraction of the radioactivity at the West Valley site is listed as "mixed fission products" or "mixed and miscellaneous," the report is of limited use. Data on the isotopic composition of byproduct material buried in Trench 14 at the Sheffield, Illinois, site have been provided to the NRC ${ }^{(5)}$ by the site operator.

Because data on radionuclide concentrations in waste buried at conmercial sites are limited, and because significant variations in isotopic concentrations exist between sites for which data are reported, a generic waste inventory is used in this study. The radionuciide inventory used in this report (i.e., the inventory shown in Table 7.3-3 of Volume 1) is derived from an unpublished NRC estimate of the average radionuclide concentrations in commercial radioactive waste. The NRC waste inventory estimate is shown in 
Table B.2-1. A normalization factor, based on $9.0 \mathrm{ci} / \mathrm{m}^{3}$ for the average specific activity of byproduct waste, is applied to the NRC data to obtain the activity concentrations shown in Table 7.3-3 of Volume 1 . This byproduct specific activity normalization factor is derived from inventory data for commercial sites, presented in Table B.1-2.

To obtain the isotopic concentrations shown in Table B.2-1, both fuelcycle and non-fuel-cycle wastes are included. Three significant assumptions are made. First, the waste is assumed to be composed of $60 \%$ fuel-cycle waste and $40 \%$ non-fuel-cycle waste. (1) Second, isotopes with half lives less than 50 days, or with only one or two pieces of evidence supporting their presence at low concentrations in wastes from operating light water reactors (LWR), are excluded from consideration. Finally, decay during transport to a shallowland burial ground is neglected, and in some cases concentrations are based on records that neglected decay during storage at the source.

Fuel-cycle waste comes predominantly from LWR operation. (6) Supportive fuel-cycle facilities, such as $U_{6}$ conversion plants, gaseous diffusion plants, and fuel fabrication plants produce relatively sma 11 quantities of waste in supporting a reference reactor for 1 year, compared to the amounts generated by the reactor. The reference reactor is an LWR rated at 1000 MWe and is postulated to operate at $80 \%$ of capacity. It is assumed that the LWR generating system is composed of pressurized water reactors and boiling water reactors, at a plant ratio of $2: 1$.

In determining isotopic concentrations for fuel-cycle waste, LWR decommissioning wastes are included by substituting a decommissioning waste radionuclide concentration whenever it exceeds the average concentration for waste from operating LWRs.

Non-fuel-cycle waste radionuclide concentrations are estimated by using concentration averages from Reference 7 . This study pertains exclusively to institutional waste sources (hospitals, universities, clinics, etc.) and therefore neglects industrial and government laboratory waste sources. However, the authors of the Reference 7 study estimate that these other non-fuelcycle sources are contributing less than $6 \%$ of the waste volume currently 
TABLE B.2-1. Radionuclide Concentrations in Low-Leve? Waste for Use in Estimating Total Burial Site Inventories (unpubrished estimate made by the NRC)

\begin{tabular}{|c|c|c|}
\hline I so tope & $\begin{array}{l}\text { Average Activity } \\
\text { in Waste }\left(\mathrm{Ci} / \mathrm{m}^{3}\right)\end{array}$ & Source of Waste \\
\hline${ }^{3} \mathrm{H}$ & $1.2 \times 10^{-1}$ & Non-fuel Cycle \\
\hline $14 \mathrm{C}$ & $3.8 \times 10^{-3}$ & Non-fuel Cycle \\
\hline $35 s$ & $8.6 \times 10^{-4}$ & Non-fuel cycle \\
\hline${ }^{5} \mathrm{Cr}$ & $4.3 \times 10^{-1}$ & LWR Operations \\
\hline $54 \mathrm{Mn}$ & $2.5 \times 10^{-1}$ & LHR Operations \\
\hline $55 \mathrm{Fe}$ & $4.3 \times 10^{-1}$ & LWR Operations \\
\hline${ }^{58} \mathrm{Co}$ & $4.3 \times 10^{-1}$ & LHR Operations \\
\hline${ }^{50} \mathrm{CO}$ & $1.3 \times 10^{0}$ & LWR 0ecommissioning \\
\hline $59 \mathrm{Ni}$ & $1.3 \times 10^{-2}$ & LWR Deconmissioning \\
\hline${ }^{63} \mathrm{Ni}$ & $2.4 \times 10^{0}$ & LWR Decommissioning \\
\hline${ }^{65} \mathrm{Zn}$ & $2.0 \times 10^{-2}$ & LWR Operations \\
\hline${ }^{90} \mathrm{Sr}$ & $4.8 \times 10^{-3}$ & LWR Operations \\
\hline $94 \mathrm{Nb}$ & $1.4 \times 10^{-4}$ & LWR Decommissioning \\
\hline $952 r$ & $2.0 \times 10^{-2}$ & LWR Operations \\
\hline${ }^{99} \mathrm{TC}$ & $3.2 \times 10^{-5}$ & LWR Operations \\
\hline $106 \mathrm{Ru}$ & $2.0 \times 10^{-2}$ & LWR Operations \\
\hline $124 \mathrm{Sb}$ & $5.0 \times 10^{-3}$ & LWR Operations \\
\hline $125 \mathrm{Sb}$ & $5.0 \times 10^{-3}$ & LWR Operations \\
\hline 1251 & $1.5 \times 10^{-3}$ & Non-fuel Cycie \\
\hline 1291 & $6.4 \times 10^{-5}$ & LWR Operations \\
\hline $134 \mathrm{Cs}$ & $4.8 \times 10^{-1}$ & LWR Operations \\
\hline $135 \mathrm{Cs}$ & $3.2 \times 10^{-5}$ & LWR Operations \\
\hline $137 \mathrm{Cs}$ & $8.6 \times 10^{-1}$ & LWR Operations \\
\hline $144 \mathrm{Ce}$ & $2.0 \times 10^{-2}$ & LWR Operations \\
\hline $152 \mathrm{Eu}$ & $4.8 \times 10^{-5}$ & LHR Operations \\
\hline $154 \overline{E U}$ & $4.8 \times 10^{-4}$ & LWR Operations \\
\hline $155 \mathrm{EU}$ & $4.8 \times 10^{-4}$ & LWR operations \\
\hline $226 \mathrm{Ra}$ & $1.2 \times 10^{-4}$ & Burial Ground Records \\
\hline $230 \mathrm{Th}$ & $7.1 \times 10^{-5}$ & Burial Ground Records \\
\hline $232 \mathrm{Th}$ & $8.4 \times 10^{-6}$ & Burial Ground Records \\
\hline $235 \mathrm{U}$ & $3.2 \times 10^{-5}$ & Buria] Ground Records \\
\hline $238 U$ & $7.1 \times 10^{-4}$ & Burial Ground Records \\
\hline $237 \mathrm{~Np}$ & $4.6 \times 10^{-8}$ & LWR Operations \\
\hline $238 \mathrm{pu}$ & $3.2 \times 10^{-4}$ & LWR Operations \\
\hline $239 \mathrm{pu}$ & $4.3 \times 10^{-5}$ & LWR Operations \\
\hline $240 \mathrm{Pu}$ & $6.7 \times 10^{-5}$ & LWR Operations \\
\hline $241 \mathrm{Pu}$ & $1.6 \times 10^{-2}$ & LHR operations \\
\hline $242 \mathrm{Pu}$ & $2.4 \times 10^{-7}$ & LWR Operations \\
\hline $241 \mathrm{Am}$ & $3.0 \times 10^{-5}$ & LHR Operations \\
\hline $242 \mathrm{Am}$ & $1.6 \times 10^{-6}$ & LWR Operations \\
\hline $243 \mathrm{Am}$ & $2.1 \times 10^{-6}$ & LWR Operations \\
\hline $242 \mathrm{Cm}$ & $2.5 \times 10^{-3}$ & LWR Operations \\
\hline $243 \mathrm{Cm}$ & $6.0 \times 10^{-7}$ & LHR Operations \\
\hline${ }^{244} \mathrm{Cm}$ & $1.9 \times 10^{-4}$ & LWR Operations \\
\hline
\end{tabular}


going to commercial burial sites. A comprehensive study of radionuclide concentrations in industrial and government laboratory low-level waste has not been published.

In addition to the consideration of individual types of low-level waste generators, the concentrations of ${ }^{226} \mathrm{Ra}$ and a few isotopes associated with source material are estimated from records at shallow-land burial sites. It should be noted that many shipments of source material and ${ }^{226} \mathrm{Ra}$ are from industrial and government laboratory sources, thus their influence, while not specifically identified, is directly affecting these concentration estimates.

Because of the national policy deferring the reprocessing of power reactor fuel, wastes generated from reprocessing and plutonium fuel fabrication are not considered in the estimates. Uranium mines and mills are also not included since radioactive wastes from these operations are normally disposed of near the facilities themselves and not at commercial burial grounds.

The contribution of various isotopes to the total byproduct activity is shown in Table B.2-2 for the generic waste inventory used in this study and for waste inventories reported for three commercial sites. Large variations exist in the isotopic concentrations of the waste buried at the different commercial sites. The percentage of ${ }^{63} \mathrm{Ni}$ activity is much higher for the generic inventory than it is for commercial burial ground inventories. Nickel-63 is postulated to be a constituent of LWR decomissioning waste. Reactor decommissioning waste is not buried at the commercial sites for which data are given in Table B.2-2.

\section{B.3 CALCULATION OF WASTE INVENTORY AT SITE CLOSURE}

This section describes methods for calculating the radioactive waste inventory of the reference burial ground at the time of site closure.

Table 7.3-3 of Volume 1 shows both the undecayed inventory for a single trench (i.e., the radioactivity in the waste at the time the waste is buried) and the total radioactive inventory at the time of site closure. The site is assumed to contain 180 identical trenches, with six trenches being filled during each of the 30 years of burial ground operation. The radioactive inventory at the time of site closure is calculated on the basis that there 
TABLE B.2-2. Comparison of the 1sotopic Composition of the Generic Waste Inventory with Waste Inventories at Commercial LLW Burial Grounds

\begin{tabular}{|c|c|c|c|c|c|}
\hline \multirow[b]{2}{*}{ Isotope } & \multirow[b]{2}{*}{$\begin{array}{c}\text { Half Life } \\
\text { (years) }\end{array}$} & \multicolumn{4}{|c|}{ Percent of Byproduct Activity } \\
\hline & & $\begin{array}{c}\text { Generic } \\
\text { Inventory }(a)\end{array}$ & $\begin{array}{l}\text { Morehead } \\
\text { Kentucky (b) }\end{array}$ & $\begin{array}{l}\text { Sheffield } \\
\text { Illinois(c) }\end{array}$ & $\begin{array}{l}\text { West Vailey } \\
\text { New York (d) }\end{array}$ \\
\hline${ }^{3} \mathrm{H}$ & $1.2 \times 10^{1}$ & 1.8 & 9.0 & 0.64 & 33.4 \\
\hline${ }^{14} \mathrm{C}$ & $5.7 \times 10^{3}$ & 0.056 & 3.6 & 0.82 & 0.13 \\
\hline $\begin{array}{l}{ }^{3} \mathrm{H}+{ }^{14} \mathrm{C} \\
22 \mathrm{Na}\end{array}$ & $2.6 \times 10^{0}$ & & 0.004 & & \\
\hline $35 \mathrm{~s}$ & $2.4 \times 10^{-1}$ & 0.013 & & & \\
\hline${ }^{5} \mathrm{Cr}$ & $7.6 \times 10^{-2}$ & 6.3 & & 1.5 & \\
\hline $54 \mathrm{Mn}$ & $8.3 \times 10^{-1}$ & 3.7 & & 4.4 & \\
\hline $5.5 \mathrm{Fe}$ & $2.6 \times 10^{0}$ & 6.3 & 0.02 & & \\
\hline${ }^{59} \mathrm{Fe}$ & $1.2 \times 10^{-1}$ & & & 0.67 & \\
\hline${ }^{57} \mathrm{Co}$ & $7.4 \times 10^{-1}$ & & & 0.11 & \\
\hline${ }^{58} \mathrm{Co}$ & $2.0 \times 10^{-1}$ & 6.3 & & 3.4 & \\
\hline${ }^{60} \mathrm{Co}$ & $5.3 \times 10^{0}$ & 19.1 & 14.8 & 32.2 & 22.6 \\
\hline${ }^{59} \mathrm{Ni}$ & $8.0 \times 10^{4}$ & 0.19 & $T R(e)$ & & \\
\hline${ }^{63} \mathrm{Ni}$ & $9.2 \times 10^{1}$ & 35.2 & 0.0002 & & \\
\hline$E 5 \mathrm{Zn}$ & $6.7 \times 10^{-1}$ & 0.29 & & 0.97 & \\
\hline $86 \mathrm{Rb}$ & $5.1 \times 10^{-2}$ & & & 10.8 & \\
\hline${ }^{90} \mathrm{Sr}$ & $2.8 \times 10^{1}$ & 0.07 & 1.1 & 0.70 & 4.6 \\
\hline${ }^{94} \mathrm{Nb}$ & $2.0 \times 10^{4}$ & 0.002 & & & \\
\hline${ }^{95} \mathrm{Zr}$ & $1.8 \times 10^{-1}$ & 0.29 & & 0.39 & \\
\hline${ }^{99} \mathrm{TC}$ & $2.1 \times 10^{5}$ & 0.0005 & 0.001 & 0.24 & \\
\hline $106 \mathrm{Ru}$ & $1.0 \times 10^{0}$ & 0.29 & & 0.05 & \\
\hline $124 \mathrm{Sb}$ & $1.6 \times 10^{-1}$ & 0.073 & & i. 6 & \\
\hline $1255 b$ & $2.7 \times 10^{0}$ & 0.073 & 0.16 & & \\
\hline $125 I$ & $1.6 \times 10^{-1}$ & 0.022 & & 1.5 & 0.07 \\
\hline $129 \mathrm{I}$ & $1.7 \times 10^{7}$ & 0.0001 & $T R(e)$ & & 0.07 \\
\hline$\because 31$ & $2.2 \times 10^{-2}$ & & & 3.2 & \\
\hline $134 \mathrm{Cs}$ & $2.0 \times 10^{0}$ & 7.0 & $T R(e)$ & 4.9 & \\
\hline $135 \mathrm{Cs}$ & $3.0 \times 10^{6}$ & 0.0005 & $T R(e)$ & & \\
\hline $137 \mathrm{Cs}$ & $3.0 \times 10^{1}$ & 12.6 & 3.5 & $3\} .2$ & 0.01 \\
\hline${ }^{144} \mathrm{Ce}$ & $7.8 \times 10^{-1}$ & 0.29 & & & \\
\hline $147 \mathrm{Pm}$ & $2.6 \times 10^{0}$ & & 0,18 & & \\
\hline $152 E u$ & $1.3 \times 70^{1}$ & 0.0007 & $\operatorname{TR}(e)$ & & \\
\hline $154 E$ & $1.6 \times 10^{1}$ & 0.007 & 2.2 & & \\
\hline 155 EU & $1.8 \times 10^{0}$ & 0.007 & & & \\
\hline $207 \mathrm{Bi}$ & $3.0 \times 10^{1}$ & & 64.8 & & \\
\hline $210 \mathrm{pb}$ & $2.0 \times 10^{i}$ & & 0.001 & & \\
\hline $216 \mathrm{PO}$ & $3.8 \times 10^{-1}$ & & & 0.75 & \\
\hline $226 \mathrm{Ra}_{\mathrm{a}}$ & $1.6 \times 10^{3}$ & 0.0018 & 0.69 & & 0.001 \\
\hline$M F P(f)$ & & & & & 6.2 \\
\hline Misc. & & & & & 19.5 \\
\hline
\end{tabular}

(a) From Table B.2-1.

(b) From Reference 3.

(c) From Reference 5 .

(d) From Reference 4.

(e) Trace $(<0.007 \%)$.

(f) Mixed Fission Products. 
is no migration of radioactivity away from the trenches and that changes in inventory come about solely as a result of filling the trenches and subsequent radioactive decay.

For most radioisotopes in the waste inventory, a decrease in activity with time comes as a result of simple decay to a stable daughter nuclide. Section B.3.1 describes the calculation of radioactivity at site closure for these isotopes.

For a few isotopes (notably $241 \mathrm{Am}$ and $238 \mathrm{pu}$ ), the activity during burial both increases as a result of isotope buildup from the radioactive decay of a relatively short-lived precursor and decreases as a result of decay. A calculation of the radioactivity at site closure must take account of the buildup in activity that results from precursor decay. This case is described in Section B.3.2.

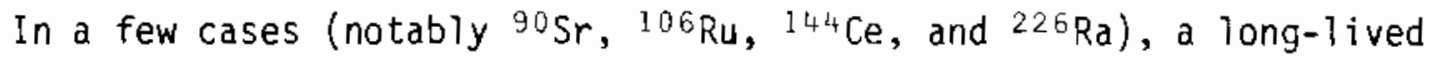
parent decays to a very short-lived daughter. For these isotopes, the daughter isotope is also included in Table 7.3-3, and the activity of the daughter at site closure is approximated as being equal to that of the parent.

\section{B.3.1 Radioactive Decay}

The activity of a radioactive sample at time $t$ is related to the initial activity of the same sample by the equation:

$$
A_{n}(t)=A_{n o} e^{-\lambda_{n} t}
$$

where:

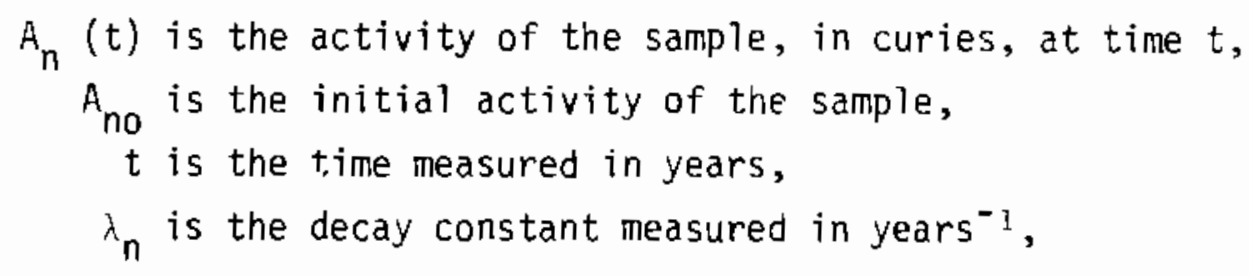
and the subscript $n$ is used to designate a particular species of radionuclide. 
For this study, let $A_{\text {no }}$ be the initial activity of the $n$ 'th isotope in the waste buried in one trench. Since six trenches are assumed to be filled per year for each of 30 years, the total activity of this isotope present in the burial ground at the time of site closure can be approximated by:

$$
A_{n}=6 A_{n o} \sum_{t} e^{-\lambda_{n} t}
$$

where $t$ takes successively the values of $0.5 \mathrm{yr}, 1.5 \mathrm{yr}, \ldots, 28.5 \mathrm{yr}$, $29.5 \mathrm{yr}$.

\section{B.3.2 Growth of Radioactive Daughters}

The following analysis applies to cases where a radioactive nuciide (the parent nuciide) decays to another radioactive nuciide (the daughter nuclide), which in turn decays to a stable end product. The analysis is used, for example, to determine the ${ }^{241}$ Am activity present in the waste at site closure where this activity results both from the burial of waste containing $241 \mathrm{Am}$ and from the presence in the waste of $241 \mathrm{Pu}$ that decays to $241 \mathrm{Am}$. It also applies to the growth of $238 \mathrm{pu}$ from the decay of $242 \mathrm{Cm}$ and to several other radioactive parent-daughter chains in the waste inventory.

The parent-daughter system is described by the differential equations:

$$
\begin{aligned}
& \frac{d N_{1}}{d t}=-\lambda_{1} N_{1} \\
& \frac{d N_{2}}{d t}=\lambda_{1} N_{1}-\lambda_{2} N_{2}
\end{aligned}
$$

The subscript 1 refers to the parent nuclide, the subscript 2 refers to the daughter nuclide, $N$ is the number of radioactive nuclei in the waste sample, and $\lambda$ is the decay constant.

Equations B. 3 and B. 4 can be integrated ${ }^{(8)}$ to give:

$$
N_{1}(t)=N_{10} e^{-\lambda_{1} t}
$$




$$
N_{2}(t)=\frac{\lambda_{1}}{\lambda_{2}-\lambda_{1}} N_{10}\left(e^{-\lambda_{1} t}-e^{-\lambda_{2} t}\right)+N_{20} e^{-\lambda_{2} t}
$$

where $N_{10}$ and $N_{20}$ represent the number of parent and daughter nuclei present in the waste sample at time $t=0$.

From equation B.6, the daughter nuclide activity in a single trench at time $t$, measured in curies, is given by

$$
A_{2}(t)=\frac{\lambda_{2}}{\lambda_{2}-\lambda_{1}} A_{10}\left(e^{-\lambda_{1} t}-e^{-\lambda_{2} t}\right)+A_{20} e^{-\lambda_{2} t}
$$

where $A_{10}$ is the initial radioactivity, in curies, of the parent nuclide and $A_{20}$ is the initial radioactivity, in curies, of the daughter nuclide in a single trench when the waste is buried.

The total radioactivity of the daughter isotope present in the burial ground at the time of site closure can be approximated by:

$$
A_{2}=6 \frac{\lambda_{2}}{\lambda_{2}-\lambda_{2}} A_{10} \sum_{t}\left(e^{-\lambda_{2} t}-e^{-\lambda_{2} t}\right)+6 A_{20} \sum_{t} e^{-\lambda_{2} t}
$$

where $t$ takes successively the values of $0.5 \mathrm{yr}, 1.5 \mathrm{yr}, 2.5 \mathrm{yr}, \ldots, 28.5 \mathrm{yr}$, $29.5 \mathrm{yr}$. 


\section{REFERENCES}

1. W. F. Holcomb, "A Summary of Shallow Land Burial of Radioactive Wastes at Commercial Sites Between 1962 and 1976, with Projections, "Nuclear Safety, Vol. 19, No. 1, p. 50, January-February 1978.

2. SECY-78-256, Nuclear Regulatory Commission memorandum on "Low-Level Waste Disposal Capacity," May 12, 1978.*

3. U. Gat, J. D. Thomas and D. T. Clark, "Radioactive Waste Inventory at the Maxey Flats Nuclear Waste Burial Site," Health Physics, Vol. 30, p. 281, March 1976.

4. P. A. Giardina, M. F. DeBonis and J. Eng, Surmary Report on the Low-Leve? Radioactive Waste Burial Site, West Valley, New York (1963-1975), EPA-902/4-77-0TD, U.S. Environmenta1 Protection Agency, New York, NY, October 1977.

5. Letter from T. S. Baer, Vice-President, Nuclear Engineering Company to W. P. Bishop, Associate Director for Waste Management, Division of Fuel Cycle and Material Safety, U.S. Nuclear Regulatory Commission, dated November 1, 1977.

6. T. B. Mullarkey et al., A Survey and Evaluation of Handling and Disposing of Solid Low-level Nuclear Fuel Cycle wastes, AIF/NESP-008, Atomic Industrial Forum, Inc., Washington, DC, October 1976.

7. R. L. Andersen et al., Institutional Radioactive Wastes, NUREG/CR-0028, Prepared by the University of Maryland at Baltimore for the U.S. Nuclear

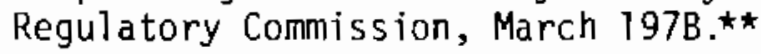

8. I. Kaplan, Nuclear Physics, Second Edition, Addison-Wesley Publishing Co., Inc., p. 239, Reading, MA, 1964.

*Available in the Nuclear Regulatory Commission Public Document Room for inspection and copying for a fee.

$\star \star$ Available for purchase from the NRC/GPO Sales Program, U.S. Nuciear Regulatory Commission, Washington, D.C. 20555, and the National Technical Information Service, Springfield, Virginia 22161. 
APPENDIX C

RADIATION DOSE METHOOOLOGY

Results of radiation dose calculations are presented in Sections 8 and 13 of this report. The calculated doses are used in the anaiysis of release conditions for the reference low-level waste (LLW) burial grounds, and to estimate the safety impacts of decommissioning operations. This appendix contains details of the assumptions, models, and parameter values used to support the dose calculations.

Oefinitions and terminology are given in Section C.1. Assumptions, models, and parameter values used to determine radionuclide source terms from air and water pathways are described in Section C.2. Models that use these source terms and estimate radiation dose to people are described in section C. 3 . The methodology for calculating the maximum annual radiation dose received by a maximum-exposed individual is described in Section C.4. Calculated maximum annual radiation doses at the reference eastern and western sites are presented in Section C.5.

\section{1 DEFINITIONS AND TERMINOLOGY}

The following definitions and terminology apply for the airborne and waterborne release of radionuclides:

\section{Chronic Release}

A chronic release occurs over a long time span (e.g., months to years).

\section{Acute Release}

An acute release is of short duration. Accident analyses summarized in Section 13 are based on acute releases. The meteorological model used for these analyses assumes that an acute release is of less than 8 hours duration.

\section{Organs of Reference}

These include the total body, thyroid glands, lungs, bone, and the lower large intestine (LLI) of the GI-tract. These are the internal organs of the human 
body for which radiation doses are calculated. The total body is the head and trunk of the human body, including active blood-forming organs, lens of eyes, and gonads.

\section{Exposure Pathways}

The potentiai routes by which people may be exposed to radionuciides or radiation are called exposure pathways. Exposure pathways considered in this study are inhalation of radioactive particulates, external exposure from the waste, and ingestion of food products, drinking water, and aquatic animals containing radionuclides.

\section{Maximum-Exposed Individual}

This individual receives the maximum radiation dose to an organ of reference. The maximum-exposed individual is assumed to reside at the location where the highest radiation exposure is received. Maximized exposure pathway parameters are used.

\section{Collective Dose}

The collective dose is the summation of radiation dose equivalents received by all individuals in the population of concern. It is calculated by multiplying the dose to the average individual by the population distribution discussed in Appendix A. Average parameter values are used for the exposure pathways.

First-Year Dose

This radiation dose equivalent is accumulated during the year of the release period.

\section{0-Year Committed Dose Equivalent}

This is the first-year dose equivalent plus the dose accumulated for the next 49 years from the radionuclides that are deposited within the human body during the year of the release period.

Annual Dose

This is the radiation dose equivalent calculated during any year for continuous exposure. It is the sum of the doses received by the total body 
or an organ of reference during the year of interest from all pathways, including the doses resulting in that year from intake of radionuclides during previous years.

\section{Maximum Annual Dose}

The maximum annual dose is the largest of the $n$ annual doses calculated to occur during an n-year exposure period following the start of continuous exposure. The maximum annual dose is further defined in Section C.4. To determine disposition criteria for a decommissioned facility, the maximum annual dose to each organ of reference is compared separately with an assumed annual dose limit.

\section{Class $W$ and $Y$ Material}

These consist of radionuclides that are slowiy removed from the pulmonary region of the lungs, either by gradual dissolution in extracellular fluids or in particulate form by translocation to the GI-tract, blood, or lymphatic system. Class $w$ represents material with maximum clearance half-times in the lungs from a few days to a few months, and Class $Y$ is used to describe material with maximum clearance half-times ranging from 6 months to several years.

\section{Class D Material}

Radionuclides in this class are dissolved upon contact with extracellular fluids and translocated to the biood. Class $D$ material is expected to exhibit maximum clearance half-times of less than 1 day. (1)

These definitions apply for all dose calculations performed for and reported in this study. Table $\mathrm{C.1-1}$ gives the solubility class assumed for each element considered in this study.

\section{C.2 RADIONUCLIDE TRANSPORT AND DISPERSION}

The models used to estimate local atmospheric concentrations from resuspension and to estimate liquid releases into a neaby river from groundwater migration and overland flow are described in this section. Surface erosion must occur to expose the waste before resuspension becomes important. The equations used to predict surface erosion are described first. 
TABLE C.1-1. Solubility Class Assumptions for the Waste Inventory $(a)$

\begin{tabular}{|c|c|c|}
\hline Element & $\begin{array}{c}\text { Solubility Ciass } \\
\text { (A)I Other Organs/Lungs and GI-LLI) }\end{array}$ & Reference \\
\hline Tritium & 0 & $\operatorname{TGLM}(1)$ \\
\hline Carbon & 0 & TGLM \\
\hline Chromium & $W / Y$ & TGLM \\
\hline Manganese & $D / W$ & NLREG/CR-0150 (2) \\
\hline Iron & $W / Y$ & NUREG/CR-0150 \\
\hline Cobalt & $W / Y$ & NUREG/CR-OT50 \\
\hline Nickel & $w$ & TGLM \\
\hline Zinc & $W / Y$ & TGLM \\
\hline Strontium & $0 / Y$ & NUREG/CR-0150 \\
\hline Zirconium & $W / Y$ & NUREG/CR-0150 \\
\hline Technetium & $D / W$ & NUREG/CR-0150 \\
\hline Rutheni um & y & NULREG/CR-0150 \\
\hline Iodine & D & NUREG/CR-0150 \\
\hline Cesium & 0 & NUREG/CR-0150 \\
\hline Cerium & $W / Y$ & TGLM \\
\hline Radium & $W$ & TGLM \\
\hline Thorium & $W / Y$ & TGLM \\
\hline Úranium & $w / Y$ & TGLM \\
\hline Neptunium & Y & $E P A-520 / 4-77-016^{(3)}$ \\
\hline Plutonium & y & EPA-520/4-77-016 \\
\hline Americium & $w$ & Assumed \\
\hline Curium & Y & $E P A-520 / 4-77-016$ \\
\hline
\end{tabular}

(a)For use in the Task Group Lung Model inhalation calculations.

\section{C.2.1 Surface Erosion}

Two geologic processes for surface erosion are considered in this study: water and wind. Both result in a decrease in the overburden and eventual surface exposure of the buried waste.

The annual soil loss due to water erosion can be predicted using the universal soit loss equation. ${ }^{(4-6)}$

$$
A=R K L S C P
$$


where:

A - estimated soil loss, tons/acre/yr

$R$ - rainfall factor; a measure of the erosivity of annual rainfall, tons/acre/yr

$K$ - soil-erodibility factor; a measure of the erosion susceptibility of a particular soil type (dimensioniess)

LS - topographic factor representing the combined effects of slope, length, and steepness (dimensionless)

C - cover and management factor (dimensionless)

- supporting practices factor (dimensionless).

Water erosion is not considered to be a significant soil removal mechanism for the western site. In an arid region, soil loss from water erosion is negligible compared to soil loss from wind erosion, assuming runoff from thaw and snowmert is smail. (5)

The values of the factors most representative of the eastern site are presented in Table C.2-1. Using the values given in Table C.2-1, the estimated annual soil loss at the eastern site from water erosion is calculated to be 52 tons/acre. Assuming a soil density of $1490 \mathrm{~kg} / \mathrm{m}^{3}$, the erosion rate of the overburden is estimated to be $8 \mathrm{~mm} / \mathrm{yr}$. Over the long term (200 years), erosion effects of individual rainstorms are expected to be small compared to the soil loss calculated using Equation C.?.

Potential annual soil loss from wind erosion that could occur from a given agricultural field is expressed as: (7)

$E=f^{\prime}\left(I^{\prime}, k^{\prime}, C^{\prime}, L^{\prime}, V\right)$

where:

E amount of erosion, tons/acre/yr
I' - soil erodibility index, tons/acre/yr 


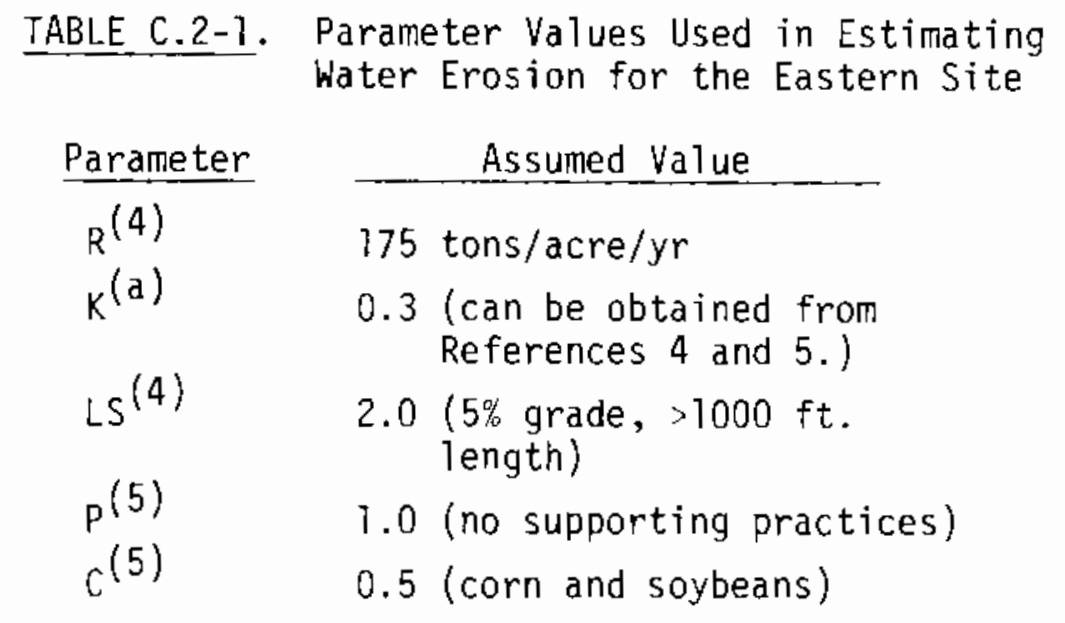

(a) Inquiry, U.S. Department of Agri-
culture, Soij Conservation Service, Chicago River Basin Station.

$k^{\prime}$ - soil ridge roughness factor (dimensionless)

$C^{\prime}$ - climatic factor, percent

$L^{\prime}$ - field length along the prevailing wind erosion direction, ft

$\checkmark$ - equivalent quantity of vegetative cover, ib/acre.

Values of these parameters and tables to evaluate Equation C.2 are given in Reference 7. The values assumed for this study are listed in Table C.2-2 for the two sites. It is assumed that $100 \%$ of the particles have diameters less than $0.8 \mathrm{~mm}$.

TABLE C.2-2. Parameter Values Assumed for Estimating Wind Erosion

\begin{tabular}{|c|c|c|c|}
\hline \multirow[b]{2}{*}{ Parameter } & \multicolumn{2}{|c|}{ Assumed Value } & \multirow[b]{2}{*}{ Reference } \\
\hline & Eastern Site & Western Site & \\
\hline$I^{\prime}$ & 310 tons/acre/yr & 310 tons/acre/yr & Table 3 of Reference 7 . \\
\hline$k^{1}$ & 0.6 & 0.6 & $\begin{array}{l}\text { Soil ridge roughness of } 1 \text { inch from } \\
\text { Figure } 7 \text { of Reference } 7 \text {. }\end{array}$ \\
\hline$C^{\prime}$ & $7.5 \%$ & $56 \%$ & $\begin{array}{l}\text { Value for eastern site from Figures } \\
1]-22 \text { of Reference } 7 \text {. Value for } \\
\text { western site calculated using } \\
\text { Equation } 1 \text { on page } 605 \text { of Reference } 8\end{array}$ \\
\hline$L^{\prime}$ & $>3000 \mathrm{ft}$ & $>3000 \mathrm{ft}$ & Assumed from site dimensions \\
\hline V & $3000 \mathrm{ib} / \mathrm{acre}$ & $3000 \mathrm{lb} / \mathrm{acre}$ & $\begin{array}{l}\text { Figures } 8,9 \text {, and } 10 \text { of Reference } 7 \text {, } \\
\text { assuming a crop yield of } 3 \mathrm{~kg} / \mathrm{m}^{2} \text {. }\end{array}$ \\
\hline
\end{tabular}


The annual soil losses from wind erosion predicted for the western and eastern sites are 40 tons/acre and 3 tons/acre, respectively. The value for the western site includes the contribution from the frequent dust storms. These soil losses correspond to erosion rates of $6 \mathrm{~mm} / \mathrm{yr}$ and $0.5 \mathrm{~mm} / \mathrm{yr}$ for the western and eastern sites, assuming a soil density of $1490 \mathrm{~kg} / \mathrm{m}^{3}$.

The total surface erosion rates from both water and wind are calculated to be $6 \mathrm{~mm} / \mathrm{yr}$ for the western site and $8.5 \mathrm{~mm} / \mathrm{yr}$ for the eastern site. For this study, because of the approximate nature of these values, an average erosion rate of $7 \mathrm{~mm} / \mathrm{yr}$ is assumed for both sites. This erosion rate is used to predict the removal of overburden by geomorphological processes. The estimated time for removal of $3 \mathrm{~m}$ of overburden is about 400 years.

\section{C.2.2 Mass-Loading}

A simple method of predicting the average local concentration of resuspended radioactive material is the mass-loading approach. This method uses the product of the surface soil radionuclide concentration and the average mass loading of the atmosphere. In the absence of data for a particular site, a value of $1 \times 10^{-4} \mathrm{~g} / \mathrm{m}^{3}$ has been suggested for predictive purposes. $(3,9,10)$ This value is used in this report for the annual average mass-loading factor. Annual arithmetic averages around the United States vary from $9 \times 10^{-6}$ to $7.9 \times 10^{-5} \mathrm{~g} / \mathrm{m}^{3}$.

The mass-loading factor for the breathing zone of individuals producing resuspension by mechanical disturbance is assumed to be $1 \times 10^{-2} \mathrm{~g} / \mathrm{m}^{3}$. This is a factor of 100 times the annual average mass-loading factor and is in agreement with other reported values used for similar situations. (12-14) Ten percent of the resuspended particles are assumed to be of respirable size, with diameters less than $10 \mu \mathrm{m}$. Although this mass-loading factor is not a maximum value, it is considered to be reasonabiy conservative for the excavation scenario devised. The exposure time for higher mass-loading factors is expected to be less than the 2,000 hours assumed for our scenario, which would probably result in a similar intake. 


\section{C.2.3 Air Concentration from Resuspension}

The annual average local air concentration, $\bar{x}$, from resuspension (in $\left.\mathrm{pCi} / \mathrm{m}^{3}\right)$ is calculated with equation C.3.

$$
\bar{X}_{i}=C_{s i} M L / \rho
$$

where:

$$
\begin{aligned}
C_{s i} \text { - the concentration of radionuclide } i \text { in the soil } \\
\text { that is available for resuspension, } \mathrm{pCi} / \mathrm{m}^{3} \\
\mathrm{ML} \text { - Mass-loading factor, } \mathrm{g} / \mathrm{m}^{3} \\
0 \quad \text { - soil density, } \mathrm{g} / \mathrm{m}^{3} \text {; for wind resuspension of the } \\
\text { topsoil, a soil density of } 1.49 \mathrm{~g} / \mathrm{cm}^{3} \text { is used } \\
\text { ("surface density" of } 224 \mathrm{~kg} / \mathrm{m}^{2} \text { divided by a } 15 \mathrm{~cm} \\
\text { plow depth). (15) For excavation, a bulk soil } \\
\text { density of } 1.7 \mathrm{~g} / \mathrm{cm}^{3} \text { is given in Section } 7 \text { of } \\
\text { Volume } 1 .
\end{aligned}
$$

The soil concentration, $C_{s i}$, for the wind erosion calculation includes radionuclides from irrigation deposits and any radioactive waste present in the top $0.15 \mathrm{~m}$ of soil. This contamination is assumed to be uniformly mixed in the top $0.15 \mathrm{~m}$ of soil. For excavation, the concentration of radioactive waste in the soil down to a depth of $3.5 \mathrm{~m}$ is used for $C_{s i}$. The soil concentration contribution from the buried radioactive waste is calculated with Equation C.4.

$$
c_{s i}=f c_{t i}+c_{o f}
$$

where:

$f$ - the fraction of the radioactive waste concentration in the waste trench that is estimated to be in the volume of soil under consideration (dimensionless)

$c_{t i}$ - the concentration of radionuclide $i$ in the waste trenches, $\mathrm{pCi} / \mathrm{m}^{3}$; given in Table $8.2-1$ for the time of site closure 
$C_{\text {of }}$

- radionuclide concentration in the soil caused by overland flow, $\mathrm{pCi} / \mathrm{m}^{3}$; calculated in Section C.2.4.

The $f$ parameter changes with time due to erosion of the overburden. The fraction of the buried radioactive waste in the top $0.15 \mathrm{~m}$ of soil, $f_{l}$, is calculated by Equation C.5.

$$
f_{1}=n_{W} w /(15 \times 18)
$$

where:

$h_{w}$ - the height of the waste layer in the top $15 \mathrm{~cm}$ of soil, $\mathrm{cm}$

$W$ - the average width of the portion of the waste trench in the top $15 \mathrm{~cm}$ of soil, $\mathrm{m}$

15 - the plow layer, cm

18 - width of the waste trench pius the separation distance between trenches, $m$.

The height of the waste layer, $h_{w}$, is determined using the erosion rate calculated in Section C.2.1.

The fraction of waste in the excavated soil (top $3.5 \mathrm{~m}$ ), $\mathrm{f}_{2}$, is calculated using Equation C.6.

$$
f_{2}=D\left(\frac{W+W^{\prime}}{2}\right) / 63
$$

where:

D the height of the waste contained in the top $3.5 \mathrm{~m}$ of soil, $m$

W width of the top of the waste trench, m

$W^{\prime} \quad$ - width of the bottom of the waste trench contained in the top $3.5 \mathrm{~m}$ of soil, $\mathrm{m}$

63 - width of the waste trench plus the separation distance between trenches multiplied by $3.5 \mathrm{~m}, \mathrm{~m}^{2}$. 


\section{C.2.4 Percolation, Groundwater Migration, and Overland Flow}

This section presents the models, assumptions, and data used in estimating the transport of radionuclides away from the burial ground by water. The geometries assumed for the two sites (eastern and western) are presented in Section 7 of volume 1, Figures 7.2-1, 7.4-1, and 7.4-4.

The site characteristics necessary to simulate groundwater migration and overland flow are soil composition, permeability, porosity, sorptive (ion exchange) properties, groundwater velocity, distance to surface water, size and shape of area, evapotranspiration rate, and precipitation. The site characteristics assumed for the western and eastern sites are given in Tables 7.4-1 and 7.4-3 respectively. The burial ground is assumed to be located above the water table, up groundwater gradient from a flowing surface stream. The radionuclide concentrations in the aquifer below the burial ground are estimated, and the discharge rates of radionuciides into the surface stream are determined for two cases. The first case is the discharge rate for radionuclides that leach from the waste to the water table and then migrate via the aquifer to the surface stream. The second case is the transport of radionuciides out of the waste trenches to the surface and then to the surface stream via overland flow. The water transport of radionuclides away from the burial ground depends on the total inventory buried, not on the radionuclide concentration in the waste trenches. The total waste inventory used for these calculations is given in Table 8.4-7, Section 8 .

The model used for these simulations is the MMT (Multicomponent Mass Transport) model originally developed by Ahlstrom, et al. (16) Ahlstrom derived the MMT model from a heat transport model developed by Eliason and Foote. (17) The model assumes a constant groundwater velocity and a constant dispersion coefficient. It accounts for a linear adsorption isopleth with a slope described by the empirical distribution coefficient, $k_{d}$, and for the effect of decay of parent radionuclides to their daughters (decay chains). The empirical distribution coefficient is defined as the quantity of adsorbed material per mass of soil divided by the quantity of dissolved material per volume of water. 
Because of the great difficulty of direct field measurement of $k_{d}$, values determined by laboratory measurement are normally used in calculations of water transport of radionuclides. However, the validity of applying laboratory values to field situations is often questionable. Measured values of the distribution coefficient are strongly dependent on the physical and chemical conditions of measurement. Among other variables, mineralogy, particle size, nature of solution, and chemical nature of radioactive species are important. In the absence of site-specific field data, conservative values based on laboratory measurements are recommended for use in transport calcuiations.

The $k_{d}$ values assumed for the eastern and western sites are 1 isted in Table C.2-3 for each element of the reference waste inventory. Values are based on published data for Hanford and Sheffield whenever possible. Distribution coefficients from other studies are listed in the table for comparison.

\section{C.2.4.1 Assumptions and Basic Data for the Eastern Site}

The first step in simulating groundwater migration is to calculate the groundwater velocity for both the unsaturated zone above the water table and the saturated zone below the water table. The pore velocities are calculated using Darcy's Law:

$$
q=\frac{k}{n_{e}}\left(\frac{d h}{d x}\right)
$$

where:

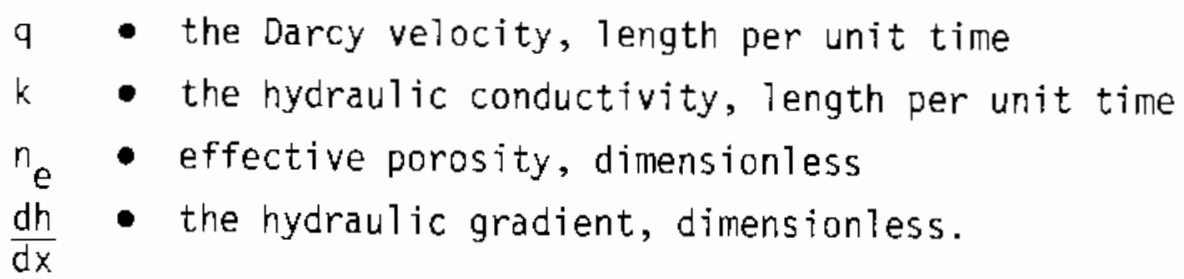

For the unsaturated zone the gradiert is assumed to be one. At the eastern site, the unsaturated zone has a water content near saturation. To be conservative, the hydraulic conductivity is assumed to be equal to the saturated hydraulic conductivity given in Table 7.4-3. The velocity is calculated for the saturated zone from the average gradient and saturated 


\section{TABLE C.2-3. Distribution Coefficients}

\begin{tabular}{|c|c|c|c|c|c|c|c|c|c|c|}
\hline \multirow[b]{4}{*}{ Element } & \multicolumn{10}{|c|}{$k_{d}(1 / k g)$} \\
\hline & \multicolumn{2}{|c|}{$\begin{array}{l}\text { Values Assumed for } \\
\text { This Study?a) } \\
\end{array}$} & \multicolumn{8}{|c|}{ Values Used in Other Studies } \\
\hline & \multirow{2}{*}{$\begin{array}{l}\text { Western } \\
\text { site }\end{array}$} & \multirow{2}{*}{$\begin{array}{c}\text { Eastern } \\
\text { Site }\end{array}$} & \multirow{2}{*}{$\operatorname{ARHCO}(b)$} & \multirow{2}{*}{$\begin{array}{r}\text { NECCO } \\
\text { May(c) }\end{array}$} & \multirow{2}{*}{$\begin{array}{l}\text { NECO } \\
\text { June }(d)\end{array}$} & \multirow{2}{*}{$\begin{array}{l}\text { Dames and } \\
\text { Moore (e) }\end{array}$} & \multicolumn{2}{|c|}{ Leddicotte $e^{(f)}$} & \multirow{2}{*}{\multicolumn{2}{|c|}{$\begin{array}{c}\text { Staley }(g) \\
\text { Silt and } \\
\text { Sand Clay }\end{array}$}} \\
\hline & & & & & & & Dry site & Humid Site & & \\
\hline H & 0 & 0 & & & & 0 & 0 & 0 & 0 & 0 \\
\hline$c$ & 0 & 0 & & & & 2 & & & & \\
\hline $\mathrm{Cr}$ & 10 & 50 & & & & & & & 10 & 100 \\
\hline Mn & 100 & 200 & & & & & & & 10 & 100 \\
\hline $\mathrm{Fe}$ & 100 & 200 & & & & 150 & & & 150 & 1500 \\
\hline Co & 2000 & 350 & & $\begin{array}{r}138- \\
593\end{array}$ & $700-800$ & 75 & 1000 & 2500 & 100 & 1000 \\
\hline $\mathrm{Ni}$ & 70 & 70 & & & & 80 & & & 100 & 1000 \\
\hline $\mathrm{Zn}$ & 50 & 50 & & & & & & & & \\
\hline Sr & 20 & 10 & $5-38$ & $\begin{array}{l}3.4- \\
17.3\end{array}$ & $3.4-6$ & 20 & 10 & 50 & 2 & 20 \\
\hline $\mathrm{Zr}$ & 500 & 500 & & & & 2000 & & & & \\
\hline TC & 0 & 0 & $\ll 1$ & & & 0 & & & 0.1 & 1 \\
\hline Ru & 400 & 30 & $26-750$ & & & & & & & \\
\hline 1 & 0 & 0 & & & & 0 & 5 & 25 & 0.1 & 1 \\
\hline$C_{5}$ & 100 & 40 & $12-200$ & $\begin{array}{r}3939- \\
9429\end{array}$ & $27-50$ & 200 & 1000 & 2500 & 20 & 200 \\
\hline $\mathrm{Ce}$ & 200 & 200 & & & & & & & & \\
\hline Ra & 100 & 80 & & $\begin{array}{r}222- \\
367\end{array}$ & $\begin{array}{r}2000- \\
4200\end{array}$ & 100 & & & & \\
\hline Th & 1000 & 1000 & & & & 15000 & & & & \\
\hline$U$ & 20 & 30 & $<1$ & & & 3000 & & & & \\
\hline$N p$ & 10 & 15 & & & & 15 & & & 70 & 700 \\
\hline $\mathrm{Pu}$ & 200 & 200 & 200 & & & 2000 & 1000 & 2500 & 200 & 2000 \\
\hline Am & 1200 & 500 & 1200 & & & 2000 & 1000 & 2500 & 70 & 700 \\
\hline $\mathrm{Cm}$ & 500 & 500 & & & & 600 & 1000 & 2500 & 70 & 700 \\
\hline
\end{tabular}

(a)Based on reported values for Hanford, washington, and Sheffield, Illinois, whenever data are available.

(b)R. C. Arnett, D. J. Brown and R. G. Baca, Hanford Groundwater Transport Estimates for Hypothetical Radioactive Waste Incidents, ARH-LO-162, AtTantic Richfield Hanford Company, Richland, Wa., June 1977.

(c) Sheffield, Low-Level Radioactive Waste Disposal Site - Report of Additional Investigations Conducted During February and March, 1978, Nuclear Engineering Company, Inc. Louisville, Kentucky, Revised May 5 , 1978. (Distribution coefficients for sands.)

(d) Sheffield, Illinois Low-Level Radioactive Waste Disposal Site - Responses to Questions, Nuclear Engineering Company, Inc., Washington, $D \bar{C}$, June 29, 1978. (Distribution coefficients for loess, till, and shale.)

(e)A. E. Aikens, Jr., R. E. Berlin, J. Clancy and 0. 1. Oztunali, Generic Methodology for Assessment of Radiation Doses from Groundwater Migration of Radionuclides in LWR Wastes in Shallow Land Burial Trenches, AIF/NESP-013, Prepared by Dames and Moore for Atomic Industria] Forum, Inc., January 1979. (Estimated values for a typical desert soil.)

$(f) G$. $W$. Leddicotte and $W$. A. Rodger, "Suggested Quantity and Concentration Limits to be Applied to Key Isotopes in Shallow Land Burial," in M. W. Carter, et al. "Management of Low-Level Radioactive Waste, Vol. 2, New York, Pergamon Press, 1979.

(g) G. B. Staley, G.P. Turi and D. L. Schreiber, "Radionuclide Migration from Low-Level Waste: A Generic Overview," in M. W. Carter, et al., Management of Low Level Radioactive Waste, vol. 2, New York, Pergamon Press, 1979. (Distribution coefficients for sand were selected to be near the low end of the range of values reported in NUREG-0140. $k_{d}$ values were increased by a factor of 10 for silt, clay, loess, and till.) 
hydraulic conductivity given for the site. Using the distance from the waste trenches to the water table $(10 \mathrm{~m})$ and the distance from the burial ground to the surface stream $(1 \mathrm{~km})$, a water travel time to the surface stream through the aquifer is calculated to be about 270 years. The dispersion coefficient used is $3.5 \mathrm{~m}^{2} / \mathrm{yr}$, which was arrived at from comparisons of model predictions with envirommental measurements. (16)

Leach rates are influenced by many factors. These include the characteristics of the radionuclide and of the waste material, the properties of the leachant, frequency of leachant changing, leaching time, and temperature. Specific field data on the leachability of radionuclides from waste buried in LLW burial grounds are not available. Published leach rate data come mainly from laboratory experiments in which small samples are leached by distilled water or by actual or simulated disposal-environment water. Laboratory leach rate data are summarized in a recent Brookhaven National Laboratory report. Reference 19 reports ieach rates for cement monoliths that range from $10^{-1}$ to $10^{-9} \mathrm{~g} / \mathrm{cm}^{2}-$ day.

Because leach rates are not we 11 known, only two leach times are used in this study to predict radionuclide release from the buried waste. A leach time of 1000 years is assumed for reactor decommissioning waste (i.e., for ${ }^{60} \mathrm{Co},{ }^{59} \mathrm{Ni}$, and $63 \mathrm{Ni}$ in structural material) and a leach time of 100 years is assumed for leaching of radionuclides from all other waste forms. These values are mid-points of ranges assumed in Reference 18 for decommissioning wastes and reactor wastes. These leach times are considered conservative, although research is needed to develop a quantitative understanding of leaching of radioactive waste.

Overland flow is modeled assuming the burial ground is inundated by a water table that intersects the soil surface at the burial ground. This is necessary because the unsaturated zone existing at the site is close to saturation and thus the prevailing driving force for movement of the water is gravity. Therefore, movement of the radionuclides to the surface would be extremely unikely without this assumption. 
To use MMT for the overland flow case, one more assumption is necessary. Two cases can be envisioned: one where the water table essentially takes the shape of the ground surface; the second where all the water flowing through the burial ground arrives at the surface and forms a small stream. The second case is the more conservative and provides the basis for the overland flow model in this study. Thus, it is assumed that all the water flowing through the burial ground arrives at the surface and flows overland in a small stream to the river $1 \mathrm{~km}$ distant. Sorption is assumed to be insignificant during overland flow. This is equivalent to assuming that the sediment load in the stream that flows along the ground is small and that no significant sorption occurs on the ground surface. Since no significant sorption is assumed to occur, it is far too conservative to assume leach times from the waste forms of 100 or 1000 years. Preliminary data from the Waste Isolation Safety Assessment Program (20) indicate that leach times are probably on the order of 10,000 years. Therefore, this more realistic leach time is used for the overland flow case.

The groundwater results from the MMT model are in terms of concentration ( $\mathrm{AC} i / \mathrm{ml}$ ) versus time, and concentration versus distance 100 years after site closure to obtain a maximum concentration in the ground water. Examples are shown in Figures $C .2-1$ through $C .2-4$ for a radionuclide with a $k_{d}$ value of 0 , ${ }^{99} \mathrm{Tc}$, and for a radionuclide with a $k_{d}$ value of $1,000,232 \mathrm{Th}$. The first two curves show maximum concentration in the ground water versus distance, which is used for calculating the potential concentration in the well water. The next two curves give the predicted groundwater concentrations versus time at the surface stream located $1 \mathrm{~km}$ from the burial ground. These concentrations are multiplied by the groundwater flow, calculated to be $8.5 \times 10^{6} \mathrm{l} / \mathrm{yr}$ for an assumed groundwater velocity of $3.7 \mathrm{~m} / \mathrm{yr}$ and cross section of $2.3 \times 10^{3} \mathrm{~m}^{2}$ for the affected aquifer, to arrive at the radionuclide release rates into the surface stream. The overland flow results are given in $\mathrm{Ci} / \mathrm{yr}$ released to the surface stream. An example is shown in Figure $\mathrm{C} .2-5$ for ${ }^{14} \mathrm{C}$. The estimated radionuclide concentrations in the well water, and the estimated radionuclide release rates into the surface stream by groundwater migration and overland flow, are given in Tables C.2-4 and C.2-5 for each radionuclide of the waste inventory. Uniform and complete mixing from a point source are 


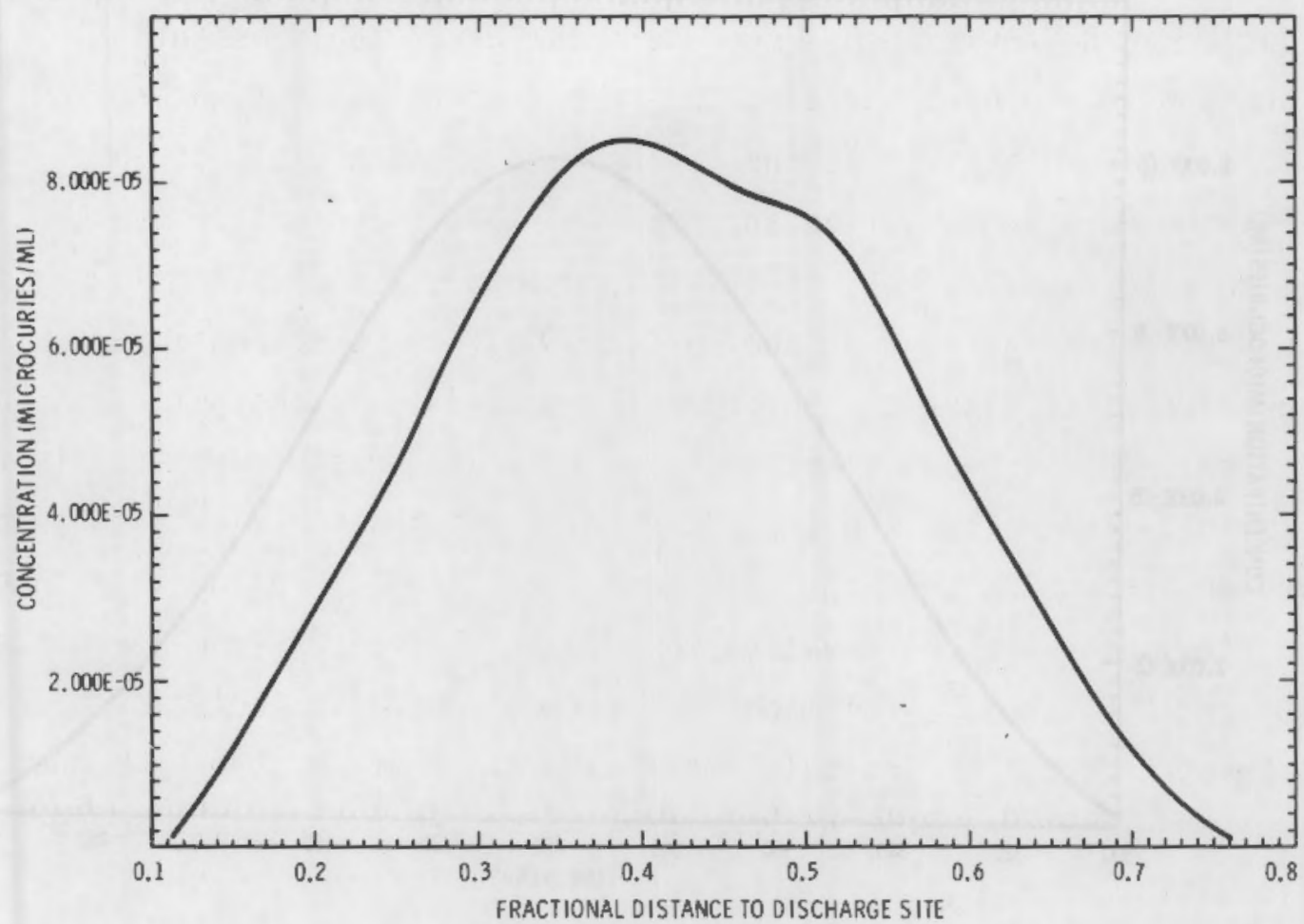

FIGURE C.2-1. Potential Technetium-99 Concentration in Ground Water Versus Distance

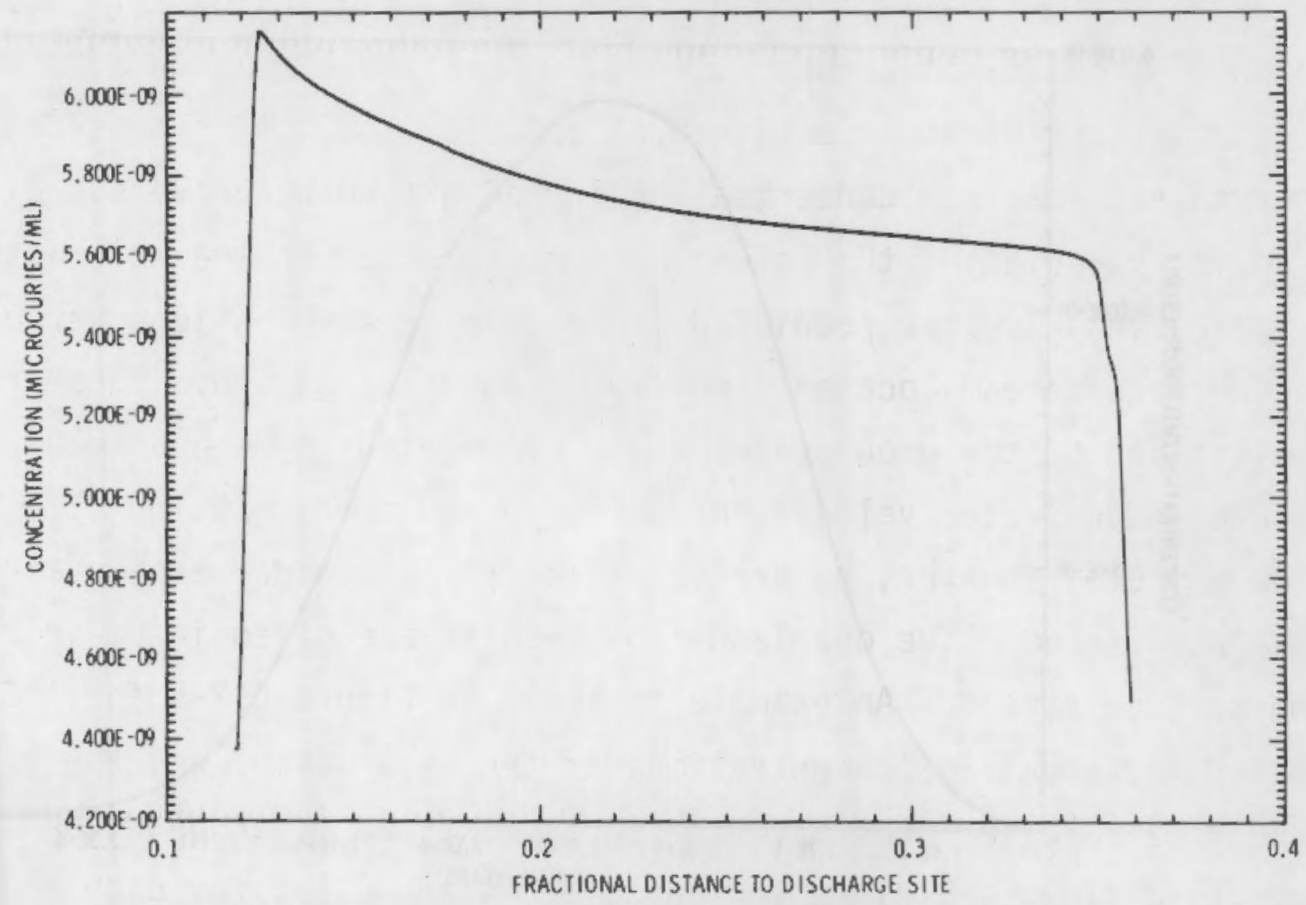

FIGURE C.2-2. Potential Thorium-232 Concentration in Ground Water Versus Distance 


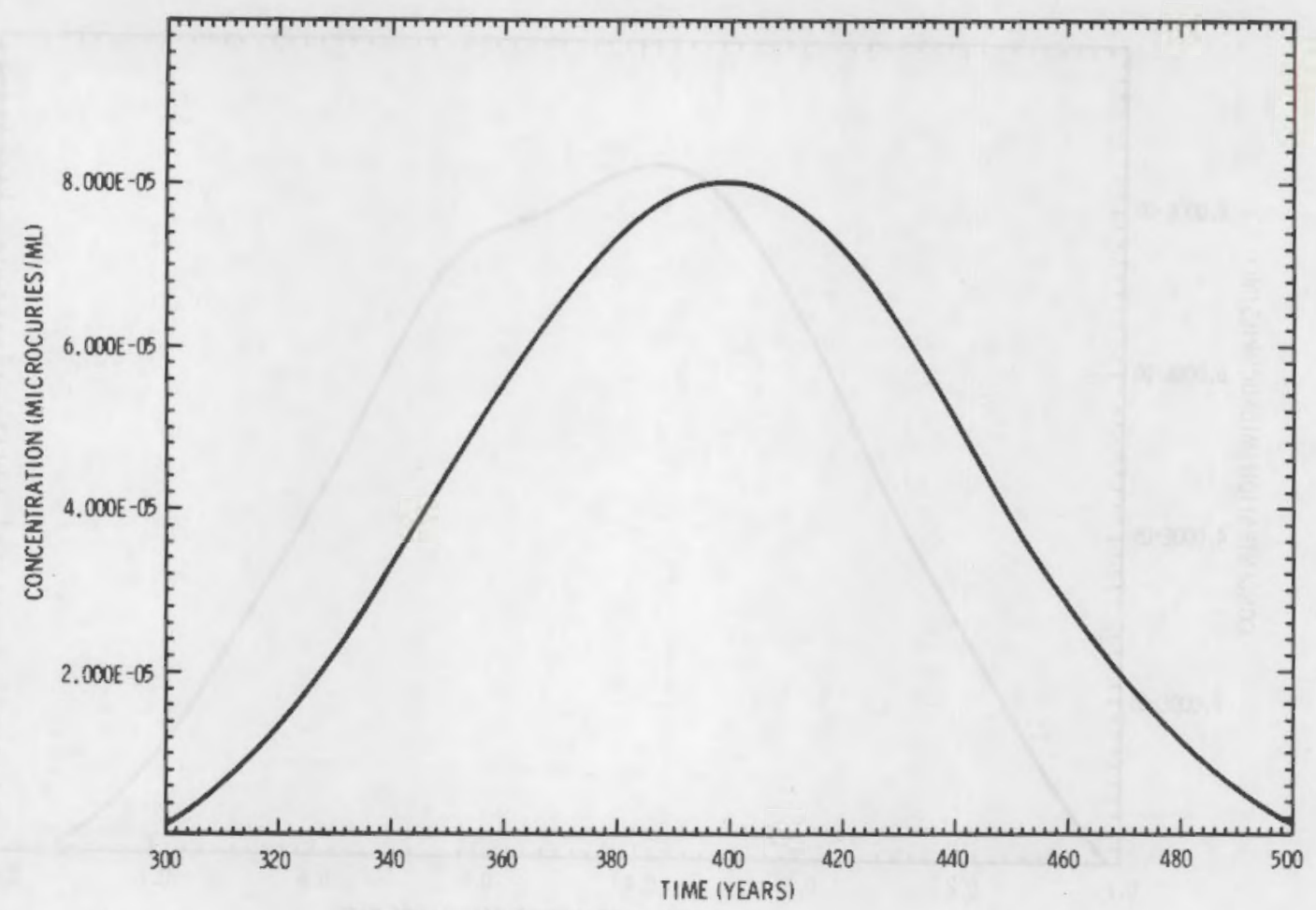

FIGURE C.2-3. Predicted Technetium-99 Concentration in the Ground Water Versus Time at the Surface Stream

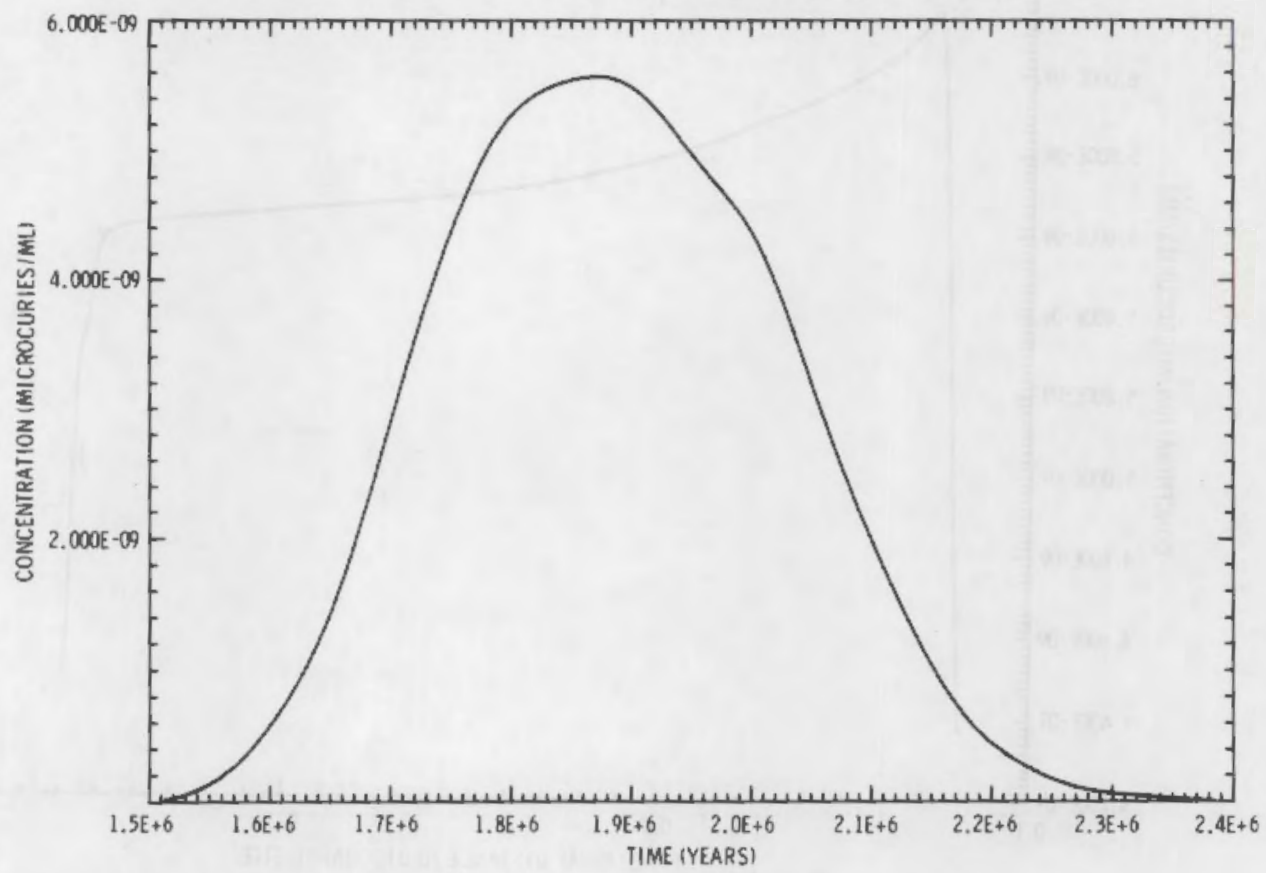

FIGURE C.2-4. Predicted Thorium-232 Concentration in the Ground Water Versus Time at the Surface Stream 

TABLE C.2-4. Predicted Radionuclide Concentrations in the Well Water Beneath the Eastern Burial Site

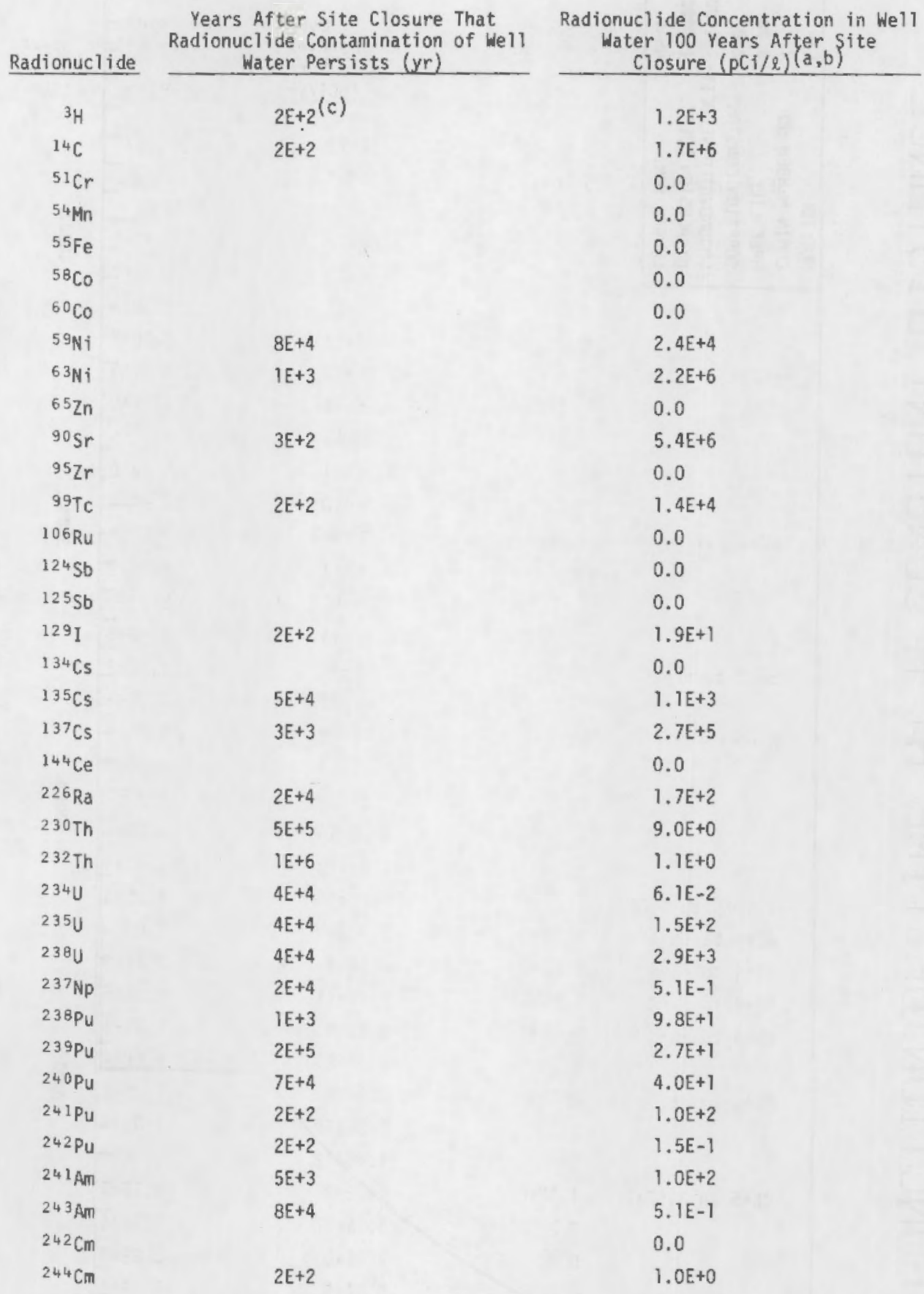

(a)Calculated on the assumption that leaching to ground water begins immediately after site closure.

(b) Source terms for dose calculations at any time after site closure are obtained by applying the appropriate radioactive decay factor.

(c) Notation: $2 \mathrm{E}+2$ is equivalent to $2 \times 10^{2}$. 
IABLE C.2-5. Predicted Radionuclide Release Rates to the Surface Water Stream from Groundwater Migration and Overland Flow at the Eastern Site

\begin{tabular}{|c|c|c|c|c|}
\hline \multirow[b]{2}{*}{ Radionuclide } & \multicolumn{2}{|c|}{$\begin{array}{l}\text { Release to Surface Water } \\
\text { From Groundwater Migration }\end{array}$} & \multicolumn{2}{|c|}{$\begin{array}{l}\text { Overland Flow Results } \\
\text { in the First Year After Site Closure }\end{array}$} \\
\hline & $\begin{array}{l}\text { Time Period Since } \\
\text { Site closure (yr) }\end{array}$ & PCi/yr & $\begin{array}{l}\text { Release to Surface } \\
\text { Water (pci/yr) }\end{array}$ & $\begin{array}{l}\text { Ground } \\
\text { Contamination }\left(\mathrm{pC} i / \mathrm{m}^{2}\right)\end{array}$ \\
\hline${ }^{3} \mathrm{H}$ & $3 E+2$ to $5 E+2$ & $1.5 E+12^{(a)}$ & $1.1 E+13$ & $1.6 \mathrm{E}+7$ \\
\hline $1+C$ & $3 E+2$ to $5 E+2$ & $5.9 E+13$ & $7.6 \mathrm{E}+11$ & $1.7 E+6$ \\
\hline${ }^{51} \mathrm{Cr}$ & & $0.0^{(b)}$ & 0.0 & 0.0 \\
\hline $54 \mathrm{Mn}$ & & 0.0 & 1. $9 E+12$ & $2.7 E+6$ \\
\hline${ }^{55} \mathrm{Fe}$ & & 0.0 & $1.0 \mathrm{E}+13$ & $1,4 E+7$ \\
\hline${ }^{58} \mathrm{Co}$ & & 0.0 & $5.1 E+11$ & 7. $3 E+5$ \\
\hline${ }^{80} \mathrm{Co}$ & & 0.0 & $6.2 E+13$ & $8.8 E+7$ \\
\hline${ }^{59} \mathrm{Ni}$ & $8 E+4$ to $1,2 E+5$ & $6.6 \mathrm{E}+11$ & $2.5 E+12$ & $3.6 \mathrm{E}+6$ \\
\hline $63 \mathrm{Ni}$ & & 0.0 & $4.3 E+14$ & 6. $I E+8$ \\
\hline${ }^{65} \mathrm{Zn}$ & & 0.0 & $1.2 \mathrm{E}+17$ & 1. $7 \mathrm{E}+5$ \\
\hline${ }^{90} \mathrm{Sr}$ & & 0.0 & $9.3 E+11$ & 1. $3 E+6$ \\
\hline $95 \mathrm{Zr}$ & & 0.0 & $2.0 E+10$ & $2.9 E+4$ \\
\hline${ }^{99} \mathrm{Tc}$ & $3 E+2$ to $5 E+2$ & $5.8 \mathrm{E}+11$ & $6.5 E+9$ & $9.3 E+3$ \\
\hline $106 \mathrm{Ru}$ & & 0.0 & $3.8 \mathrm{E}+11$ & $5.5 E+5$ \\
\hline $1: 4 b$ & & 0.0 & $3.8 E+9$ & $5.5 E+3$ \\
\hline $125 \mathrm{Sb}$ & & 0.0 & $1.3 E+11$ & $1.9 E+5$ \\
\hline 1291 & $3 E+2$ to $5 E+2$ & $1.2 E+11$ & $1.3 E+9$ & $1.9 E+3$ \\
\hline $134 \mathrm{Cs}$ & & 0.0 & $9.4 \mathrm{E}+12$ & $1.3 E+7$ \\
\hline${ }^{35} \mathrm{Cs}$ & $6 E+4$ to $B E+4$ & 4. $9 E+10$ & $6.8 E+10$ & $9.7 E+4$ \\
\hline${ }^{137} \mathrm{Cs}$ & & 0.0 & 1. $2 E+14$ & $1.7 E+8$ \\
\hline${ }^{144} \mathrm{Ce}$ & & 0.0 & 0.0 & 0.0 \\
\hline $226 \mathrm{Ra}$ & & 0.0 & 2. $1 E+10$ & $3.0 E+4$ \\
\hline $230 \mathrm{Th}$ & & 0.0 & $1.4 \mathrm{E}+10$ & $2.0 E+4$ \\
\hline $232 \mathrm{Th}$ & $1.5 E+6$ to $2.2 E+6$ & $4.6 E+7$ & $1.6 \mathrm{E}+9$ & $2.3 E+3$ \\
\hline $234 \mathrm{U}(\mathrm{C})$ & $4 E+4$ to $6 E+4$ & $2.5 E+6$ & 0.0 & 0.0 \\
\hline $235 \mathrm{U}$ & $4 E+4$ to $6 E+4$ & $6.4 \mathrm{E}+9$ & $5.5 E+9$ & $9.3 \mathrm{E}+3$ \\
\hline $238 \mathrm{U}$ & $4 E+4$ to $6 E+4$ & $1.3 \mathrm{E}+11$ & $1.4 E+11$ & $2.0 E+5$ \\
\hline $2.37 \mathrm{~Np}$ & $2 E+4$ to $3 E+4$ & $5.9 E+7$ & $9.2 E+6$ & $1.3 E+1$ \\
\hline $238 \mathrm{Pu}$ & & 0.0 & $5.0 E+10$ & $8.5 E+4$ \\
\hline $233 \mathrm{Pu}$ & $2 E+5$ to $3 E+5$ & $2.5 E+7$ & $8.5 E+9$ & $1.2 E+4$ \\
\hline $240 \mathrm{Pu}$ & & 0.0 & $1.3 E+10$ & $1.9 E+4$ \\
\hline $241 \mathrm{Pu}$ & & 0.0 & $1.6 E+12$ & $2.3 E+6$ \\
\hline $242 \varphi_{u}$ & $2 E+5$ to $3.5 E+5$ & $4.9 E+6$ & $4.7 E+7$ & $6.7 E+1$ \\
\hline $241 \mathrm{Am}$ & & 0.0 & $5.1 E+10$ & 7. $3 E+4$ \\
\hline $243 \mathrm{Am}$ & & 0.0 & $4.0 E+8$ & $5.8 \mathrm{E}+2$ \\
\hline $242 \mathrm{Cm}$ & & 0.0 & $9.4 E+9$ & 1. $3 E+4$ \\
\hline $244 \mathrm{Cm}$ & & 0.0 & $2.1 E+10$ & $3.0 E+4$ \\
\hline
\end{tabular}

(a) Notation: $1.5 E+12$ is equivalent to $1.5 \times 10^{12}$.

(b) Negligible due to radioactive decay during travel time between initial leaching from the waste forms and arriyal at the surface stream.

(c) Daughter of $238 \mathrm{U}$. 
assumed for calculating resulting radionuclide concentrations in the surface water stream. Thus, the average radionuclide concentration in the surface stream $(\mathrm{pCi} / \hat{\mathrm{x}}$ ) equals the release rate $(\mathrm{pCi} / \mathrm{yr}$ ) divided by the annual flow of the surface stream (l/yr), given in Section 7 as $220 \mathrm{l} / \mathrm{sec}$. Ground contamination from overland flow is calculated by dividing the release rate by the burial ground surface area $\left(7 \times 10^{5} \mathrm{~m}^{2}\right)$.

The results for groundwater transport represent conservative leach times of 100 years and 1000 years, whereas the results for the overland transport case represent a more reaiistic leach time of 10,000 years. (20) The results must be viewed in terms of probability of occurrence. The probability of transport through the ground water is much greater than the probability of overland transport.

To obtain radionuclide concentrations in drinking water from a well drilled into the shale beneath the burial site (Table C.2-4), the groundwater concentrations are further diluted by a factor of 5.5 to account for the full groundwater flow of $4.7 \times 10^{7}$ \&/yr underneath the site. (See Table 7.4-3.)

Since the groundwater concentrations in Table C.2-4 represent maximum concentrations at any location 100 years after site closure, this method of determining radionuclide concentrations in drinking water is believed to produce conservative results.

\section{C.2.4.2 Assumptions and Basic Data for the Western Site}

The same methods described for modeling groundwater transport at the eastern site are applicable for the western site. Because of the extremely dry soils at the western site, the unsaturated hydraulic conductivity is, on the average, $3.5 \times 10^{-0} \mathrm{~cm} /$ day. Soil moisture from precipitation is returned to the atmosphere by evaporation before it has had a chance to percolate downward to any significant depth. Using the mean depth to ground water at the western site of $60 \mathrm{~m}$, a travel time for water from the reference burial ground to the aquifer below the site is predicted to be 470 million years. In the Waste Isolation Safety Assessment Program, (20) the consequence analyses are carried to 2 million years. Even if the conductivity is increased by 2 orders of magnitude, the water travel time is still longer than 2 million years. Therefore, the groundwater transport case is not modeled. 
The probability for overiand flow is essentially nonexistent for the western site. Since sand is the most prevalent surficial material and the uncompacted soil at the site has a relatively high permeability, the water infiltration rate is too high to allow any overland flow. The climatological data on precipitation and rainfalt intensity for the western site, given in Section 7 , also eliminate any potential for overland flow. The climatological data indicate that it is extremely improbable that the water table would rise the 60-m distance up to the waste trenches at any future time.

\section{C.2.4.3 Uncertainties}

Many uncertainties exist in the hydrologic data used to model radionuclide migration via the water pathway.

One uncertainty involves the value of hydraulic conductivity used in the equation to calculate the groundwater flow velocity. Several methods are used to measure hydraulic conductivity in aquifers. Various assumptions are inherent in all the methods, and values obtained by different methods at a given location may vary by an order of magnitude. aquifer is also spatially variant.

Two parameters in the transport equation have uncertainties in them: the dispersion coefficient and the distribution coefficient. Both of these parameters can be measured with relative ease in the laboratory, but it is difficult to measure them in the field due to many practical problems. However, because measured values of these parameters are strongly dependent on the physical and chemical conditions of measurement, the application of laboratory values to field situations is of questionable validity. Examples of distribution coefficient $\left(K_{d}\right)$ values reported in the literature are shown in Table C.2-3.

Finaliy, as discussed in Section C.2.4.1, there are order-of-magnitude - uncertainties in leach rates and leach times used to describe the leaching of radionuclides from buried waste. Because of this, conservative values are chosen for the leach times used in this study.

An example of the effect of a change in leach time on radionuclide concentration in the surface stream is shown in Figure C.2-6 for a long-lived 


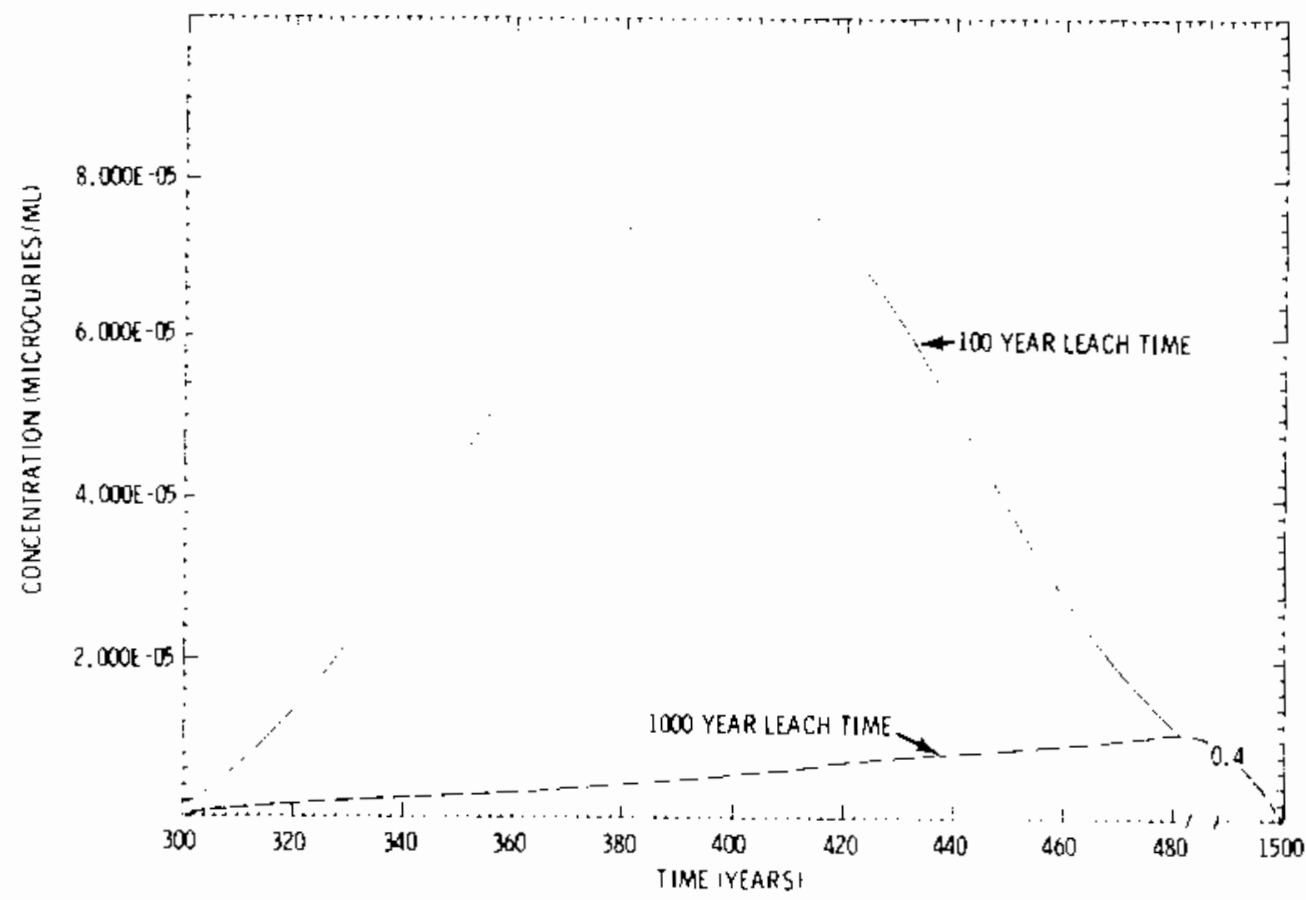

FIGURE C.2-6. Predicted Technetium-99 Concentration in the Ground Water versus Time at the Surface Stream (using 100year and 1000-year leach times)

radionuclide with a small $K_{d}$ value. The nuclide chosen is 99 Tc $\left(K_{d}=0\right)$. Increasing the assumed leach time by an order of magnitude results in almost an order of magnitude decrease in the maximum radionuclide concentration in the ground water at the point of discharge to the surface stream. It also results in a significant postponement of the time when this concentration attains its maximum value. For a radionuclide with a large $k_{d}$ value, such as $230 \mathrm{Th}$, neither the maximum radionuclide concentration nor the time when the concentration attains its maximum value are significantiy affected by an order of magnitude increase in leach time.

\section{3 MODELS FOR ESTIMAIING RADIATION DOSE TO PEOPLE}

The fundamental relationship for the calculation of radiation dose to people from exposure pathways is given for any radionuclide in Equation C.9.

$$
R_{i p r}=C_{i p} U_{p} D_{i p r}
$$


where:

$$
\begin{array}{ll}
R_{i p r} & \text { - Radiation dose equivalent or committed dose equivalent } \\
& \text { from radionuclide } i \text { via exposure pathway } p \text { to organ } r \\
C_{i p} & \text { - concentration of radionuclide } i \text { in the media of exposure } \\
& \text { pathway } p \text {; for inhalation, } c_{i p} \text { is replaced with the term } \\
& \bar{x}_{i} \text {, which represents the average airborne concentration } \\
& \text { - exposure rate or intake rate associated with exposure } \\
U_{p} & \text { pathway } p \\
& \text { radiation dose equivalent or comitted dose equivalent } \\
& \text { factor for a given radionucijde } i \text {, exposure pathway } p \text { and } \\
& \text { organ } r \text { that converts a given concentration of the radio- } \\
& \text { nuclide and the intake rate of that radionuclide to the } \\
& \text { radiation dose equivalent or committed dose equivalent. }
\end{array}
$$

Specific equations for each exposure pathway are derived from Equation C.9. The principal difference among the exposure pathways is the manner in which the radionuclide concentrations in water, air, soil, or food products are calculated as an integral part of the computerized models used in this study. 15,21$)$ The concentrations are functions of such parameters as the radionuclide release rates, resuspension, deposition rates, irrigation rates, root uptake parameters, bioaccumulation, atmospheric dispersion, and water migration and dispersion.

The usage parameter $\left(U_{p}\right.$ in Equation C.9) assigns hours of external exposure and intake rates of contaminated foods, water, and air to the radiation dose equation. Average adult usage parameter values are the basis for the collective radiation dose estimates, whereas maximum adult usage values are used in developing the disposition criteria and for calculating the dose to the maximum-exposed individual.

Equations for calculating the internal radiation dose equivalent or committed dose equivalent factors $\left(D_{i p r}\right.$ in Equation C.9) for ingestion are derived from those given by the International Comission on Radiological Protection (ICRP) for body burdens and Maximum Permissible Concentrations (MPC) of each radionuclide. (21-25) Internal dose factors for the adult not found in the literature are calculated in a manner similar to that discussed in Reference 25 . Effective decay energies for the nuclides are calculated from the ICRP model, 
which assumes that all of a given radionuclide is in the center of a spherical organ with an appropriate effective radius. Dose equivalent factors for inhalation are calculated using the computer code DACRIN. (26) This code incorporates the ICRP Task Group Lung Mode ${ }^{(1)}$ to calcuiate the dose equivalent to the lung and other organs of reference. Dose equivalent factors are calculated for Translocation Class D, $W$ and $Y$ material. A particle size of $1 \mu \mathrm{m}$ diameter is assumed. Radiation dose equivalent factors have units of mrem in the first year per $\mathrm{pC} i$ taken into the body during that year either via ingestion or inhalation. Radiation committed dose equivalent factors have units of mrem/50-yr per $\mathrm{pC} i$ taken into the body in the first year.

External doses from gamma radiation are calculated for three contributors: activation products buried in steel canisters, radionuclides deposited on the ground by irrigation with contaminated water and by overland flow, and radionuclides evenly distributed in a subsurface trench. Dose contributions from exposure to bodies of water and shoreline contaminated by liquid releases are considered negligible in comparison with these three.

Cylindrical steel canisters buried end to end in a trench are modeled as one long cylindrical source with a slab shield of soil. The total-body dose rate factors are calculated for a point $1 \mathrm{~m}$ above ground level at a depth of $50 \mathrm{~mm}$ of tissue at the center of the trench. The dose rate factors are generated by the shielding code ISOSHLD ${ }^{(27)}$ for each overburden depth considered. Dose rate factors are calculated in $\mathrm{rem} / \mathrm{hr}$ for a given inventory of activation products.

Radionuclides deposited on the ground from irrigation with contaminated water and from overland flow are assumed to be evenly distributed in the top $0.15 \mathrm{~m}$ of soil due to plowing, along with any of the subsurface waste plowed into the upper layer of soil. The dose rate factors are calculated for a point $1 \mathrm{~m}$ above the ground at a tissue depth of $50 \mathrm{~mm}$. The shielding code ISOSHLD is used to generate the dose rate factors in rem $/ \mathrm{hr}$ per $\mathrm{Ci} / \mathrm{m}^{3}$.

The radionuclides distributed in a subsurface trench are represented by a rectangular solid source with uniform source strength, shielded by a variable thickness of soil. The soil thickness is assumed to be greater than $0.15 \mathrm{~m}$ 
(plow layer), since any radioactive waste entering the top $0.15 \mathrm{~m}$ of soil is mixed and considered with the radionuclides deposited on the surface by irrigation and overland flow. The dimensions of the subsurface source are such that it is essentially a semi-infinite slab source. Dose rate factors for exposure $1 \mathrm{~m}$ above the surface are in units of rem $/ \mathrm{hr}$ per $\mathrm{pCi} / \mathrm{m}^{3}$. Factors are radionuclide (and therefore energy) specific. These factors are generated by the shielding code ISOSHLD. A separate dose rate factor is required for each radionuclide for each different surface-soil shield thickness. The soil thickness is assumed to be constant for a given 50-year dose period.

The 50-year committed dose equivalent for the external exposure pathways associated with ground contamination and with the buried waste is equal to the first-year dose.

\section{C.3.1 Dose From Ingestion of Food}

The annual radiation dose in mrem, $R_{v r}$, to a person consuming vegetation grown on the contaminated site is given by Equation C. 10 .

$$
R_{v r}=\sum_{i=1}^{n} c_{i v} U_{v} D_{i r}
$$

Similarly, the annual radiation dose equivalent in mrem, $R_{a r}$, to a person consuming a particular contaminated animal product is given by Equation $C .11$.

$$
R_{a r}=\sum_{i=1}^{n} c_{i a} U_{a} D_{i r}
$$

where:

$$
\begin{aligned}
& C_{i v}, C_{i a} \text { - the concentration of radionuclide } i \text { in the vegetable or } \\
& \text { animal product, } \mathrm{pCi} / \mathrm{kg} \text { or } \mathrm{pCi} / \mathrm{l} \\
& U_{v}, U_{a} \text { - annual consumption of contaminated vegetable or animal } \\
& \text { products, } \mathrm{kg} \text { or } \ell
\end{aligned}
$$


Dir - radiation dose equivalent factor for ingestion discussed in Section C.2, $\mathrm{mrem} / \mathrm{pCi}$.

Exposure from routine releases is assumed to be a 1-year chronic ingestion at a uniform rate. Specific values of the consumption parameters $U_{v}$ and $U_{a}$ are taken from WASH-1258 ${ }^{(28)}$ for both the maximum-exposed individual and the population. This exposure pathway is not considered for an acute release.

Models used for estimating the transfer of radionuclides from air to plants (through leaves and soi1) to farm products and animal products were originaliy derived by Soldat. (24) A more detailed treatment of this topic is folind in Reference 15.

\section{C.3.T.1 Deposition Directly from Air}

Equation C.12 is used to describe the deposition of resuspended airborne particulate radionuclides directly onto food products and on to the ground.

$$
d_{i}^{a}=86,400 \bar{x}_{i} v_{d i}
$$

where:

$$
\begin{array}{ll}
d_{i}^{a} & \text { - deposition rate or flux of radionuclide } i, \mathrm{pCi} /\left(\mathrm{m}^{2}-\text { day }\right) \\
86,400 & \text { - }
\end{array}
$$
Reference 29.

\section{C.3.1.2 Deposition by Irrigation}

The deposition rate in $\mathrm{pC} i / \mathrm{m}^{2}-d a y, d_{j}^{i}$, for radionuclide $i$, from irrigation water onto the ground is defined by Equation C.13. 


$$
d_{i}^{i}=C_{i w} I
$$

where:

$c_{i w}$ - concentration of radionuclide $i$ in the water used for irrigation, $\mathrm{pCi} / \mathrm{e}$; calculated in Section C.2.4.

I - irrigation rate; the amount of water sprinkled on a unit area of field in 1 day, $2 /\left(\pi^{2}-\right.$ day $)$; given in Appendix $A$.

\section{C.3.1.3 Concentration in Vegetation}

The concentration of radioactive material in vegetation resulting from direct deposition onto plant foliage, uptake of radioactive waste, and uptake of radionuclides previously deposited on the soil is determined by Equation C.14.

$$
\begin{aligned}
C_{i v} & =\left[\frac{\left(d_{i}^{a}+d_{i}^{i}\right) r T_{v}\left(1-\exp \left[{ }^{-\lambda} E i t^{t}\right]\right)}{Y_{v} \lambda_{E j}}+\frac{\left.d_{j}^{i} f_{t} B_{v i}(]-\exp \left[\lambda_{i} t_{b}\right]\right)}{p \lambda_{i}}\right. \\
& +\frac{0.75 f_{t} C_{s i}{ }^{B} v i}{p}+\frac{f_{w} C_{t i}{ }^{B} v i}{\rho} \mid \exp \left(-\lambda_{i} t_{h}\right)
\end{aligned}
$$

where:

$c_{i v}$ - concentration of radionuclide $i$ in the edible portion of the vegetation, $\mathrm{pCi} / \mathrm{kg}$

$\mathrm{d}_{\mathrm{i}}$ - previously defined (see Equations C.12 and C.13), pCi/(n ${ }^{2}-$ day)

$r$ - fraction of deposition retained on the vegetation (dimensionless), taken to be 0.25

$T_{v}$ - factor for translocation of externally deposited radionuciides to the edible parts of the vegetation (dimensionless). For simplicity, this parameter is assumed to be independent of the radionuclide and is assigned values of 1 for leafy vegetables and fresh forage and 0.1 for ali other produce, including grain. (Reference 23 lists values for this parameter, which vary with radionuclide.) 
$\lambda_{j}$

${ }^{\lambda} \mathrm{Ei}_{\mathrm{i}}$

W

Y

B vi

$t_{b}$

to be 50 years for irrigation

$t_{e}$

- time of exposure of above-ground vegetation to contamination during growing season, days

$f_{t}$ - fraction of the roots in the plow layer of soil (dimensionless)

$t_{h}$ - holdup time between harvest and food consumption, days

P soil "surface density," $\mathrm{kg}$ (dry soil) $/ \mathrm{m}^{2}$; a value of 224 $\mathrm{kg} / \mathrm{m}^{2}$ is used assuming the contaminated ground is plowed to a depth of $15 \mathrm{~cm}^{(15)}$

$\mathrm{C}_{s i}$ - concentration of radionuclide $i$ available for plant uptake from the waste contained in the plow layer (top $15 \mathrm{~cm}$ of soil), $\mathrm{pC} / / \mathrm{m}^{3} ; \mathrm{calcu}$ ated in Section C.2.3

0.15 - plow layer, m

$f_{w}$ - fraction of the roots that penetrate the waste trenches (dimensionless); assumed to be 0.01 when the overburden depth is greater than $? \mathrm{~m}$, and 0.10 when the overburden is between 0 and $1 \mathrm{~m}$

$C_{t i}$ - concentration of radionuclide $i$ available for plant uptake in the waste trenches, $\mathrm{pCi} / \mathrm{m}^{3}$; given in Table 8.2.3-1 for the time of site closure

P - bulk soil density of subsurface material, $\mathrm{kg} / \mathrm{m}^{3}$; given in Section 7 as $1.7 \times 10^{3} \mathrm{~kg} / \mathrm{m}^{3}$. 
The first term inside the brackets of Equation C. 14 relates to the concentration resulting from direct deposition of resuspended material and irrigation on foliage during the growing season. (Irrigation is not considered for the reference sites of this study.) The second term relates to the plant uptake from the soil and reflects the deposition from irrigation for the past 50 years. The third and fourth terms account for uptake of waste material contained in the top $0.15 \mathrm{~m}$ of soil and below this layer, respectively. Specific values used for the parameters in Equation C. 14 are found in References 15,28 , and 29.

Under certain conditions, plants may have deep, extensive root systems. The depths to which roots can penetrate are dependent on plant species, soil characteristics, soil moisture profile, time, and other site-specific factors. Many plants are known to have root systems that exceed depths of $2 \mathrm{~m} .{ }^{(30)}$ The question of whether and to what degree roots will penetrate into buried waste is not clear and should be researched. The values assigned to $f_{w}$ in this study are chosen arbitrarily.

\section{C.3.7.4 Concentration in Animal Products}

The radionuclide concentration in animal products such as meat, miik, and eggs is dependent on the amount of contaminated forage or feed eaten by the animal. This concentration is described by Equation C.15.

$$
c_{i a}=s_{i a}\left[c_{i F} Q_{F}+c_{i a w} Q_{a w}\right]
$$

where:

$$
\begin{aligned}
C_{i a} \text { - concentration of radionuclide } i \text { in the animal product, } \mathrm{pCi} / \mathrm{kg} \\
\\
\text { or } \mathrm{pCi} / \hat{x}
\end{aligned}
$$

$S_{i a}$ - transfer coefficient of radionuclide $i$ from daily intake of the animal to the edible portion of the animal product, $\mathrm{pCi} / \mathrm{l}(\mathrm{mi} / \mathrm{k})$ per $\mathrm{pCi} /$ day or $\mathrm{pCi} / \mathrm{kg}$ (animal product) per $\mathrm{pCi} / \mathrm{day}$

$c_{i f}$ - concentration of radionuclide $i$ in feed or forage, $\mathrm{pCi} / \mathrm{kg}$; calculated from Equation C.14 
$Q_{F}$ - animal consumption rate of contaminated feed or forage, $\mathrm{kg} /$ day

$C_{i a w}$ - concentration of radionuclide $i$ in the water consumed by animals, $\mathrm{pC} i / \ell$; assumed to be the same as the irrigation water, $\mathrm{C}_{i w}$

$Q_{a w}$ - consumption rate of the contaminated water by the animal, l/day.

Specific values for the parameters used in Equation C.15 are found in References 15, 28, and 29. For parameters where data are lacking, comparisons are made with biological data from chemically similar elements.

\section{C.3.2 Dose from Drinking water}

The dose $R_{w r}$ in mrem, from ingestion of water containing radionuclides, is calculated from Equation C. 16 .

$$
R_{w r}=U_{w} \sum_{i=1}^{n} c_{i d w} \exp \left(-\lambda_{i} t_{h}\right) D_{i r}
$$

where:

$U_{w}$ - annual consumption of contaminated drinking water, $\ell$

$C_{i d w}$ - the concentration of radionuclide $i$ in the drinking water, $\mathrm{pCi} / \ell$; assumed to be well water

$\lambda_{j}$ - radiological decay constant for radionuclide $i$, days ${ }^{-1}$

$t_{h}$ - transit time required for radionuclide to reach the point of exposure, days

$D_{\text {ir }}$ - radiation dose equivalent factor for ingestion discussed in Section C.3, mrem/pCi.

\section{C.3.3 Dose from Aquatic Food Ingestion}

Concentrations of radionuclides in aquatic foods are directly related to the concentrations of the radionuclides in water. Equilibrium ratios between the two concentrations, called bioaccumulation factors, are taken from Reference 21 . The dose $R_{a f r}$ in mrem, from consumption of aquatic foods containing radionuclides, is calculated from Equation C.17. 


$$
R_{a f r}=U_{a f} \sum_{i=1}^{\pi} c_{i w} B_{i} \exp \left(-\lambda_{i} t_{h}\right) D_{i r}
$$

where:

$U_{a f}$ - annual consumption of contaminated aquatic foods, $\mathrm{kg}$

$C_{i w}$ - the concentration of radionuclide $i$ in the water, $\mathrm{pCi} / \ell$

$\mathrm{B}_{i}$ - the bioaccumulation factor for radionuclide $\mathrm{i}, \mathrm{pCi} / \mathrm{kg}$ per $\mathrm{pCi} / \mathrm{\ell}$

Dir - radiation dose equivalent factor for ingestion discussed in Section C.3, $\mathrm{mrem} / \mathrm{pCi}$

$\lambda_{j}$ - radiological decay constant for radionuclide $i$, days ${ }^{-1}$

$t_{h}$ - holdup time-between harvest and food consumption, days.

\section{C.3.4 Inhalation Radiation Dose}

The inhalation dose, $R_{h r}$ in mrem, is calculated using Equation C.18.

$$
R_{h r}=\sum_{i=1}^{n} D_{i r} \bar{x}_{i} V T
$$

where:

$D_{\text {ir }}$ - radiation dose equivalent or committed dose equivalent factor for inhalation discussed in Section C.3, $\mathrm{mrem} / \mathrm{pCi}$ or $\mathrm{mrem} / 50-\mathrm{yr}$ per $\mathrm{pCi}$

$\bar{x}_{j}$ - the annual average airborne concentration of radionuclide $i$, $\mathrm{pC} \mathbf{i} / \mathrm{m}^{3}$

$\checkmark$ - ventilation rate of exposed individual, $\mathrm{m}^{3} / \mathrm{sec}$. Human ventilation rates for three time periods are derived from ICRP recommendations: ${ }^{(31)} 3.3 . \times 10^{-4} \mathrm{~m}^{3} / \mathrm{sec}$ for the period $0-8$ hours, $2.3 \times 10^{-4} \mathrm{~m}^{3} / \mathrm{sec}$ for $8-24$ hours, and $2.7 \times 10^{-4} \mathrm{~m}^{3} / \mathrm{sec}$ for greater than 24 hours 
$T$ - time of exposure to the airborne radionuclide concentration, seconds. A year's exposure of $3.16 \times 10^{7}$ seconds is assumed for inhalation of resuspended radionuclides. A working year of 2,000 hours $\left(7.20 \times 10^{6}\right.$ seconds) is used for the excavation scenario.

The inhalation dose model presented in Equation $\mathrm{C} .18$ is consistent with the ICRP Task Group Lung Model. (1)

\section{C.3.5 External Radiation Dose}

Annual doses resulting from exposure to surface and subsurface soil contamination and to buried canisters of waste (slit trench) are calculated using Equation C.9 and the external dose rate factors discussed in Section C. 3 . These dose rate factors are calculated for a point located $? \mathrm{~m}$ above the ground. An exposure period of 8,766 hours per year is assumed. The surface soil contamination increases with time from irrigation with contaminated water. (However, irrigation is not considered for the reference sites of this study.) Daughter build-in through chain decay is accounted for. The fraction of subsurface soil (the soil below the plow layer) that is contaminated waste material is assumed to be 0.8. This is based on 15-m-wide trenches separated by 3-m spaces of soil. The subsurface waste also undergoes chain decay with time. Additional methodology used to calculate doses to workers during decomissioning operations is discussed in Section 13 of volume 1.

\section{C.4 DETERMINATION OF MAXIMUM ANNUAL RADIATION DOSE}

The method used in this study to analyze release conditions for a decommissioned LLW burial ground is based on a comparison of the calculated maximum annual dose received by a maximum-exposed individual with an established annual dose limit. The maximum-exposed individual is assumed to live and work on the decommissioned site; to consume all of his food from crops and animal products grown on the site; and to drink water from a well drilled on the site. In the absence of regulatory guidance on permissible dose limits from a decommissioned burial ground, an annual dose limit of 50 mrem to the maximum-exposed individual is assumed for the purpose of demonstrating the methodology. 
Caiculation of the maximum annual dose to an organ of reference requires the dose equivalent from exposure during the year of interest. It also requires a detailed accounting of the doses resulting in the year of interest from intake of radionuclides during previous years. For continuous exposure to a radioactively decaying source, the year in which the annual dose reaches a maximum depends on the chemical and physical characteristics of the radionuclides in the source, the organ of reference, and the exposure pathway. If internal exposure from inhalation or ingestion is the dominant dose contributor, the maximum annual dose may not occur in the first year. The annual dose to internal body organs from internally deposited radionuclides tends to increase for a time after the start of continuous exposure to a radioactively decaying source until a maximum is reached. The annual dose then tends to decrease with time due to radioactive decay, a decrease in the exposure-pathway-dependent radionuclide concentrations, and biological elimination of radionuclides deposited in the organ.

The calculated first-year dose from ingested or inhaled radionuclides will most likely underestimate the maximum annua? dose, and therefore does not provide the best comparison to an annual dose limit. It is also not appropriate to compare a committed radiation dose equivalent, accounting for 50 -years of dose conmitment, to an annual dose timit. Therefore, an extension of the general dose relationship given in Equation C.9 is required to calculate annual doses for a period of years, from which the maximum value is then selected.

The derivation of a general expression describing annual dose calculations is illustrated by considering the annual dose equations for the first 3 years of a continuous exposure to radiation. The annual dose for the first year to an organ of reference is simply the summation of the radiation dose equivalents from all internal and external exposure pathways.

The second-year annual dose to an organ of reference is the summation of the radiation dose equivalents from all exposure pathways during the second year and the dose equivalent delivered during the second year from radionuclides internally deposited in that organ during the first year. For the second year, the annual dose is calculated by the mathematical expression: 


$$
A_{2}=R_{2}^{*}+\left(R_{1,2}-R_{1,1}\right)
$$

where:

$A_{2}$ - the annual dose during the second year from all exposure pathways to the organ of reference, mrem

$R_{2}^{*}$ - the radiation dose equivalent in the second year to the organ of reference from all internal and external exposure pathways from intake and exposure in the second year of continuous exposure, mrem

$R_{1,2}$ - the committed dose equivalent to the organ for the first two years from radionuclides internally deposited during intake from exposure pathways in the first year, mrem

$\mathrm{R}_{1,1}$ - the radiation dose equivalent to the organ of reference for the first year from radionuclides internally deposited during intake from exposure pathways in the first year (no external component to the dose equivalent), mrem.

The term in parentheses in Equation C.19 is the expression for the dose equivalent to the organ of reference from radionuclides deposited in the organ in the first year. It is found by subtracting the first-year dose equivalent from internally deposited radionuclides from the two-year committed dose equivalent.

The third-year annual dose to an organ of reference is the summation of the radiation dose equivalents from all exposure pathways during the third year and the dose equivalent delivered during the third year from radionuclides internally deposited during the first and second years. For the third year, the annual dose is calculated by the expression:

$$
A_{3}=R_{3}^{*}+\left(R_{1,3}-R_{1,2}\right)+\left(R_{2,2}-R_{2,1}\right)
$$


where:

$A_{3}$ - the annual dose during the third year from all exposure pathways to the organ of reference, mrem

$R_{3}^{*}$ - the radiation dose equivalent in the third year to the organ of reference from all internal and external exposure pathways from intake and exposure in the third year of continuous exposure, mrem.

The terms $R_{1,3}, R_{1,2}, R_{2,2}$, and $R_{2,1}$ are of a similar form, each with two subscripts. The first subscript defines the year of intake or exposure after the start of continuous exposure, and the second defines the number of years used in calculating the committed dose equivalent.

The quantity in the first parenthesis in Equation C.20 is the dose equivalent to the organ of reference in the third year from radionuclides deposited in the first year of continuous exposure (i.e., the difference between the 3-year committed dose equivalent and the 2-year committed dose equivalent). The quantity in the second parenthesis is the dose equivalent in the third year to the organ of reference from radionuclides deposited in the second year of continuous exposure (i.e., the difference between the 2-year committed dose equivalent and the first-year committed dose equivalent).

The general expression for calculating the annual dose to an organ of reference during any year after the start of continuous exposure can be expressed as:

$$
A_{t}=R_{t}^{*}+\sum_{i=1}^{t-1} R_{i,(t-i+1)}-R_{i,(t-i)}
$$

where:

$A_{t}$ - the annual dose during the year $t$ from all exposure pathways to the organ of reference, mrem

$R_{t}^{*}$ - the radiation dose equivalent in year $t$ to the organ of reference from all internal and external exposure pathways from intake and exposure in the year $t$, mrem. 
The summation term in Equation 0.21 represents the dose equivaient delivered to the organ of reference in year $t$ from radionuclides deposited in the organ from intake in all previous years since the start of continuous exposure. This term is valid only for integer values of $t>l$. For $t$ equal to 1 , the summation term is set equal to zero, since the subscripts define a non-real case.

The annual dose, $A_{t}$, to the organ of reference is calculated for each value of $t$ from 1 to 50 for the 50-year exposure period of an individual who is assumed to live and work on the decommissioned site. The maximum annual dose is determined by inspection. For each year of exposure, the radionuclide inventories used in the calculations are adjusted for radioactive decay and daughter-product bui1dup.

\section{C.5 CALCULATED MAXIMUM ANNUAL RADIATION DOSES AT THE REFERENCE LLW BURIAL GROUNDS}

Maximum annual doses are calculated for two property release scenarios: conditional release of a decommissioned site 200 years after site closure, and unrestricted release of a decommissioned site 200 years after site closure. The scenarios are described in Section 8.5 of Volume 1 .

\section{C.5.1 Dose Calculations for the Western Site}

Calculated maximum annual doses to the maximum-exposed individual for various release conditions for the western site are presented in Tables $\mathrm{C.5-1}$ through C.5-3. Only those radionuclides that contribute $1 \%$ or more of the total dose to the organs of reference are shown.

Dose calculations are based on the radionuclide inventory of Table 8.4-1 and include contributions from radioactive daughters where appropriate. Dose contributions from radioactive daughters that grow into the inventory before deposition in the organ of reference are shown as separate entries in the tables. Dose contributions from radioactive daughters that grow into the inventory after deposition of the parent nuclide in the organ of reference are shown with the dose contribution from the parent. For example, $210 \mathrm{pb}$ is a radioactive daughter of ${ }^{226} \mathrm{Ra}$. The contribution to dose from ${ }^{210} \mathrm{~Pb}$ that grew into the inventory before deposition of the radioactivity in the organ 
of reference is shown as a dose contribution from $210 \mathrm{~Pb}+\mathrm{D}$. The contribution to dose from $210 \mathrm{~Pb}$ that grew into the inventory after $226 \mathrm{Ra}$ was deposited in the organ of reference is included as part of the dose from $226 \mathrm{Ra}+\mathrm{D}$.

Calculated maximum annual doses to the maximum-exposed individual for conditional release of the western site are presented in Table C.5-1. The doses are for the 50-year period immediately following release of the site. Farming that involves the cultivation of shallow-rooted crops is assumed to be permitted. However, it is assumed that the site resident does not excavate the area.

The nuclide which is the major contributor to both the total body and bone doses for the food ingestion pathway is $210 \mathrm{pb}$. Lead-210 is not present in the original burial ground inventory (Table 7.3-3), but is a radioactive daughter of ${ }^{226} \mathrm{Ra}$. The dose conversion factor is only slightly greater for $210 \mathrm{~Pb}$ than it is for ${ }^{226} \mathrm{Ra}$. However, the rate of plant-root uptake is more than an order of magnitude greater for $210 \mathrm{~Pb}$ than it is for ${ }^{226} \mathrm{Ra}$.

For comparison purposes, Table C.5-2 shows maximum annual doses that would result to the maximum-exposed individual during the 50-year period following site release if excavation were permitted. Doses presented in this table include inhalation and external exposure doses that would result if the resident worked at onsite construction, including excavation, for 2000 hours per year.

The doses in Table C.5-3 are also for comparison purposes and assume complete removal of the 3-m overburden as a result of wind erosion. Using the erosion rate of Section C.2.1, total erosion of the site overburden is calculated to occur approximately 450 years after site release. The dose data demonstrate the importance of erosion-prevention measures in connection with the conditional release of the site.

Calculated maximum annual organ doses to the maximum-exposed individual for unrestricted release of the western site with the inventory of Table 8.4-2 are presented in Table C.5-4. The revised inventory would permit unrestricted release of the site 200 years after burial ground closure. 
TABLE C.5-1. Maximum Annual Doses to Maximum-Exposed Individual from Conditiona1 Release of Western Site - Excavation Prohibited

\begin{tabular}{|c|c|c|c|c|}
\hline Organ of Reference & Radionuclide (a) & $\frac{\text { Maximum }}{\text { Ingestion }}$ & Annual Dose & $\begin{array}{l}\text { (mrem) via: } \\
\text { AlT Pathways }\end{array}$ \\
\hline \multirow[t]{10}{*}{ Total Body at 245 years $(b)$} & $5 \mathrm{Ni}$ & $1.4 E+0^{(C)}$ & 0.0 & $1.4 E+0$ \\
\hline & $249 \mathrm{U}+D^{(d)}$ & $5.7 \mathrm{E}-1$ & 0.0 & $5.1 E-1$ \\
\hline & $\because s r$ & $4.0 E-1$ & 0.0 & $4.0 E-7$ \\
\hline & $17 \mathrm{Cs}$ & $1.7 E-2$ & $8.1 E-9$ & $1.7 E-2$ \\
\hline & $\therefore \because T h+D$ & $6.6 \mathrm{E}-2$ & 0.0 & $6.6 \mathrm{E}-2$ \\
\hline & $2>\cdot R a+D$ & $1.7 \mathrm{E}-1$ & 0.0 & $1.7 E-1$ \\
\hline & $\therefore \therefore P D+D$ & $1.1 E+0$ & 0.0 & $1.1 E+0$ \\
\hline & $\therefore 3 R a+D$ & $1.0 E-1$ & 0.0 & $1.0 \mathrm{E}-1$ \\
\hline & $2: 5 y+0$ & $2.6 \mathrm{E}-2$ & 0.0 & 2.6E-? \\
\hline & Total & $3.8 E+0$ & 8. $1 E-9$ & $3.8 E+0$ \\
\hline \multirow[t]{10}{*}{ Bone at 234 Years } & $\mathrm{i}^{\mathrm{Ni}}$ & $4.5 E+1$ & 0.0 & $4.5 E+1$ \\
\hline & $\therefore \because \mathrm{U}+\mathrm{D}$ & $2.4 E+0$ & 0.0 & $2.4 E+0$ \\
\hline & $\because S r$ & $1.8 E+0$ & 0.0 & $1.8 \mathrm{E}+0$ \\
\hline & $\because 7 \mathrm{CS}$ & $2.4 \mathrm{E}-2$ & $1.2 E-8$ & $2,4 E-2$ \\
\hline & $23 \div T h+0$ & $1.8 E+0$ & 0.0 & $1.8 E+3$ \\
\hline & $\therefore \therefore a+0$ & $1.5 E+0$ & 0.0 & $1.5 E+0$ \\
\hline & $\angle \because P b+D$ & $2.8 E+1$ & 0.0 & $2.8 E+1$ \\
\hline & $\because \overline{R a+D}$ & $5.6 \mathrm{E}-1$ & 0.0 & $5.6 \mathrm{E}-1$ \\
\hline & $\therefore \mathrm{r} U * \mathrm{D}$ & $1.2 \mathrm{E}-\mathrm{i}$ & 0.0 & $1.2 E-1$ \\
\hline & Total & $8.1 E+1$ & $1.2 E-8$ & $8.1 E+1$ \\
\hline \multirow[t]{6}{*}{ Lungs at 202 Years } & ${ }^{79} \mathrm{~T}_{\mathrm{C}}$ & $6.9 E-6$ & 0.0 & $6.9 E-6$ \\
\hline & i $35 \mathrm{Cs}$ & $7.6 E-5$ & 0.0 & $7.6 E-5$ \\
\hline & $\because \because \mathrm{CS}_{5}$ & $7.9 E-3$ & $2.4 E-8$ & $7.9 E-3$ \\
\hline & $\because ? \mathrm{Pu}$ & $9.8 \mathrm{E}-6$ & 0.0 & $9.8 \mathrm{E}-6$ \\
\hline & $\therefore: \mathrm{Am}$ & 6. $2 \mathrm{E}-\underline{\mathrm{S}}$ & $\underline{0.0}$ & $6.2 \mathrm{E}-5$ \\
\hline & Total & $8.1 E-3$ & $2,4 E-8$ & $8.1 E-3$ \\
\hline \multirow[t]{3}{*}{ Thyroid at 207 Years } & 1291 & $5.3 E-2$ & $2.9 E-36$ & $5.3 E-2$ \\
\hline & $13 \mathrm{Cs}$ & $\underline{0.0}-$ & 2.1E-8 & $\underline{2.1 E-8}$ \\
\hline & Total & $5.3 E-2$ & $2.15-8$ & $5.3 \mathrm{E}-2$ \\
\hline \multirow[t]{9}{*}{ GI-LLI at 200 Years } & $=30+0$ & $1.0 \mathrm{E}-2$ & 0.0 & 1.0E-2 \\
\hline & $137 \mathrm{Cs}$ & 0.0 & $2.5 E-8$ & $2.5 E-8$ \\
\hline & $\therefore U+D$ & $6.8 \mathrm{E}-4$ & 0.0 & $6.8 E-4$ \\
\hline & $\because 31 T h+D$ & $8.9 E-4$ & 0.0 & $8.9 E-4$ \\
\hline & $\because \because p$ & $5.4 E-5$ & 0.0 & $5.4 E-5$ \\
\hline & $\therefore 39 \mathrm{Pu}$ & $3.4 E-5$ & 0.0 & $3,4 E-5$ \\
\hline & $2 \dot{\cos p}$ & $5.2 E-5$ & 0.0 & $5.2 E-5$ \\
\hline & $21+1 \mathrm{Am}$. & $3.4 E-4$ & 0.0 & $3.4 E-4$ \\
\hline & Total & $1.2 E-2$ & $2.5 E-8$ & $1.2 E-2$ \\
\hline
\end{tabular}

(a) Only radionuclides that contribute more than 1 s of the total dose for each pathway are 1 is ted.

(b) The time the annual dose peaks after site closure for the exposure period considered. (c) Notation: $1.4 \mathrm{E}+0$ is equivalent to $1.4 \times 10^{7}$.

(d) $+O$ indicates that after deposition in the organ of reference, the decay energy of the daughter is included with the parent. 


\section{TABLE C.5-2. Maximum Annual Doses to Maximum-Exposed Individual from Release of Western Site - Excavation Permitted}

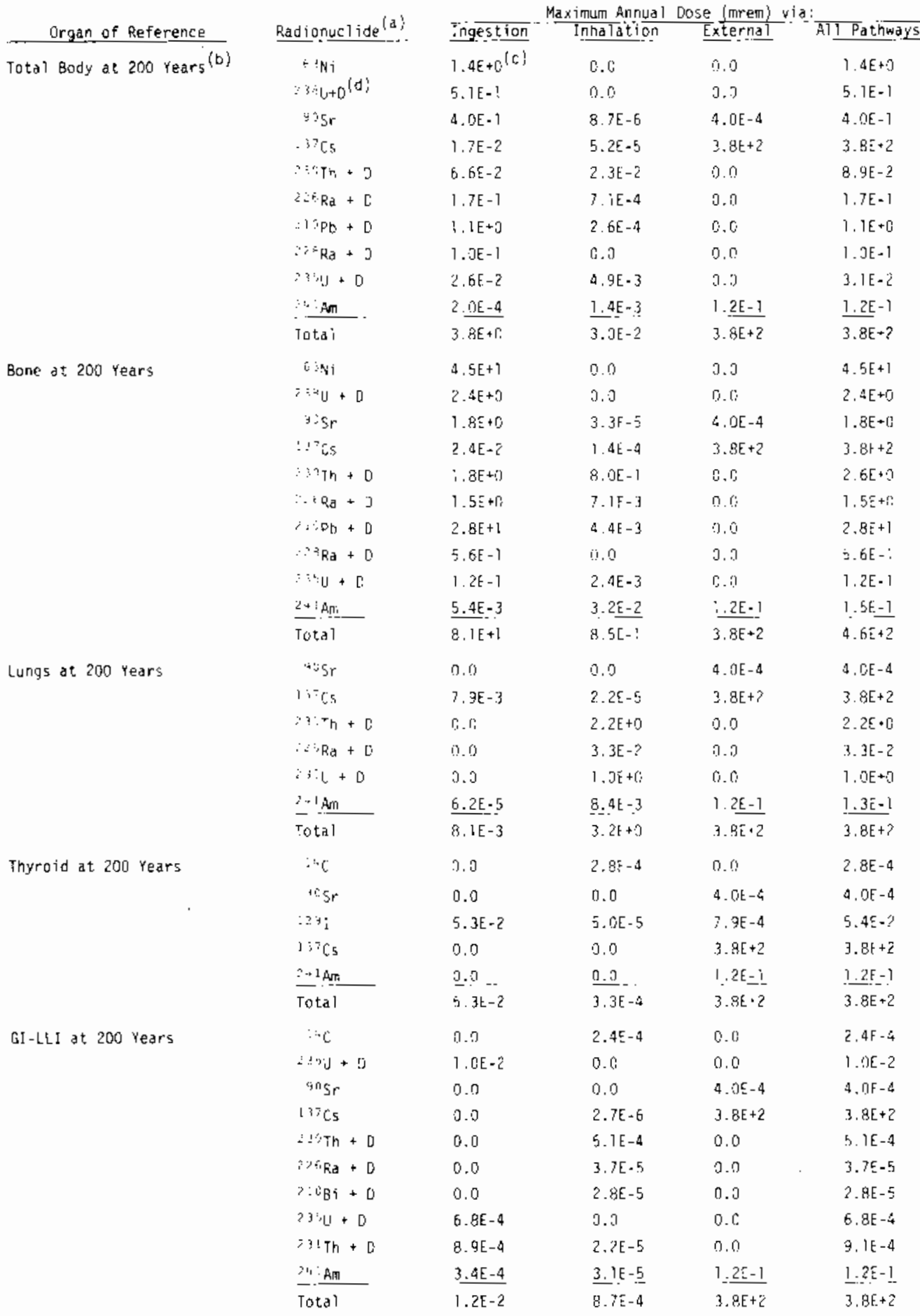

(ajonly radionuclides that contribute more than 1 \& of the total dose for each pathway are listed.

(b) The time the annual dose peaks after site closure for the exposure period considered.

(c) Notation: $1.4 \mathrm{E}+0$ is equivalent to $1.4 \times 10^{3}$.

$\{d\}+0$ indicates that after deposition in the organ of reference, the decay energy of the daughter is included with the parent. 
IABLE C.5-3. Maximum Annual Doses to Maximum-Exposed Individual from Release of Western Site - Overburden Removed by Erosion

\begin{tabular}{|c|c|c|c|c|c|}
\hline Grgan of Reference & Radronuclide!d! & Injestion & Maximum Annua: & $\frac{\text { Cose inrem }}{\text { Externd }}$ & via: \\
\hline \multirow[t]{12}{*}{ Total hody at 699 Years $\{b\}$} & $1:{ }^{3} \mathrm{I}$ & $5,5 E-i ; c)$ & $4,1 E-5$ & $1.8 \mathrm{f}-2$ & $5.7 \mathrm{~F} \cdot 1$ \\
\hline & $\therefore ? \mathrm{Cs}$ & $1.3 E-2$ & $2.65-6$ & $2.85-1$ & $2.9 E \cdot 1$ \\
\hline & $\therefore$ 圽 $+3(6)$ & $3 . B E \cdot 1$ & 0.0 & 0.0 & 3. $8 \mathrm{E}+1$ \\
\hline & $\therefore \because \mathrm{Th}+\mathrm{D}$ & $5.9 t+3$ & $2 . i \mathrm{it} z$ & 3.0 & $8.5 E+10$ \\
\hline & $\therefore \mathrm{Ro}+0$ & $1.7 t+2$ & $1.95-i$ & $(: .0$ & $\because I E+\ddot{2}$ \\
\hline & $\therefore \therefore \mathrm{Pt}+\mathrm{D}$ & $1.1 E+\widehat{3}$ & $\therefore .3 E-?$ & $? 0$ & $1.7 F \cdot 3$ \\
\hline & $\therefore \therefore 2 a+0$ & $7.5 E+0$ & 0.0 & $0 . ?$ & $\therefore .8 \mathrm{E}+\because \mathrm{G}$ \\
\hline & $\therefore \mathrm{Pd}+\mathrm{D}$ & $\hat{\imath} .1 \bar{c}-5$ & 1. $\mathrm{jE}-\hat{\mathrm{g}}$ & $1.75 \cdot 2$ & $1.7 E-2$ \\
\hline & $\therefore$ ipt & $1.0 \mathrm{E}-1$ & $7.2 \mathrm{E}-1$ & $1.0 E-3$ & A. $2 \mathrm{E}-1$ \\
\hline & : $" \mathrm{Fu}$ & $7.2 k-2$ & 5. $6 t-1$ & $7,4 E-4$ & $5.7 !-1$ \\
\hline & $\therefore$ ist & 9. $3 \mathrm{E}-1$ & 5. $5 \mathrm{E}+\mathrm{C}$ & $1.4 L+0$ & $7.8 \mathrm{E}+0$ \\
\hline & otal & $1.3 E+3$ & $9.6 \overline{+}+?$ & $1.7 E+5$ & $1.3 E+3$ \\
\hline \multirow[t]{12}{*}{ Bone at 649 'ears } & $\therefore "$ & $1.9[-1$ & $\vdots 9 L-7$ & $1.9 \mathrm{E}-2$ & $2.1 \mathrm{E}^{-}$ \\
\hline & $\because " c s$ & $\because .5 \tau-2$ & ?.0 -5 & $? .3 E-?$ & $3.65-1$ \\
\hline & $\cdot 11-2$ & $2.21+2$ & ח. ? & $\dot{0} . \ddot{z}$ & $2.2+\cdot 2$ \\
\hline & $\cdots+\pi+0$ & $\because 9 \mathrm{E}+?$ & $5.8 \mathrm{E}=1$ & $\therefore$ (1) & $\therefore 6=+\%$ \\
\hline & $\cdots \cdot R_{d} \cdot z$ & $1.7 \mathrm{E}+3$ & 1. $4 E+1 i$ & 0.3 & i., $\mathrm{EE}-\mathrm{I}$ \\
\hline & $\cdots \mathrm{Pb}+\mathrm{B}$ & $3.12+4$ & $1.3: 4$ & $\therefore 5$ & 3. $3+4$ \\
\hline & $\therefore-+D$ & $1.1 E=$ & $2.6 E \cdot 1$ & 0.9 & $\because 16+1$ \\
\hline & $\cdots P_{A} \cdot D$ & $1 . \mathrm{BE}-7$ & $5,95-9$ & $1.7 \vdots-2$ & $1.7 \mathrm{~F}-?$ \\
\hline & $\because \mathrm{Pu}$ & $2.3 \mathrm{E}+\mathrm{C}$ & 1. $6 \mathrm{E}^{*} \cdot$ & $\therefore$ of -3 & $\cdot 8 \mathrm{E}+1$ \\
\hline & $\cdot{ }^{\prime} \mathrm{Pu}$ & 1. $c_{L+0}$ & $1.11+1$ & $\therefore, \therefore E-4$ & $1.3[+1$ \\
\hline & $\cdots$ & $2 . \underline{1 E+1}$ & 1. $3 \hat{i}+2$ & $\underline{i .4 E} \cdot \hat{z}$ & 1. \\
\hline & lotal & $3.3 \mathrm{E}+4$ & $? .3 \mathrm{E}+2$ & $1.7:+9$ & $3.3 \mathrm{E} * 4$ \\
\hline \multirow[t]{12}{*}{ Lungs at 612 "ears } & iric & $5.6[-2$ & $0 . ?$ & 0.9 & $5.6[-2$ \\
\hline & $\therefore: c 5$ & $5.4 \bar{c}-?$ & $7, \hat{r}_{1}:-2$ & $2.9 i-3$ & $E .4 F-1$ \\
\hline & a'ss & $5.2 \mathrm{E}-3$ & $? .2 \mathrm{E}-6$ & $6.51-1$ & n. $7 \mathrm{E}-:$ \\
\hline & $\therefore \mathrm{Th}+\mathrm{D}$ & $\therefore . C$ & $1.7 i+1$ & 5.0 & 1. $3 \underline{+}+1$ \\
\hline & $\cdots \mathrm{ka}+\mathrm{g}$ & 0.0 & $4.2 f=?$ & 10.3 & 4. $2 \mathrm{E}+\mathrm{B}$ \\
\hline & $\Rightarrow P E+0$ & $\therefore, c$ & $5.45-1$ & $2.0:$ & $5.4 \mathrm{E} \cdot 1$ \\
\hline & $\cdots+0$ & $\because .0$ & $4 \cdot 3 \mathrm{E}+1)$ & 0.? & 4. $3 E+i:$ \\
\hline & $\cdot F_{1}$ & $3.55 \cdot 3$ & $4.85 \cdot 1$ & $4.3 i-5$ & $5.8 \mathrm{E}-1$ \\
\hline & $\sim r u$ & 3. $7 \mathrm{E}-2$ & $\therefore z+i$ & $\therefore \overline{E F} \cdot 3$ & 1. $2 E+i$ \\
\hline & ? ' " pu & $5.2 \mathrm{t}-2$ & $3.51+n$ & 2.55 .4 & $8.6 E+\pi$ \\
\hline & $\cdots$ 然I & $2.7 \mathrm{t}-1$ & $4: 4 \underline{4}+0$ & $1.41+0$ & $6.1 E+0$ \\
\hline & $0: a 1$ & $1.1 E+5$ & $4,74^{-}$ & ?. IE+ & $5.0 \bar{c}+1$ \\
\hline \multirow[t]{5}{*}{ 'Tyraid at 604 vears } & $\cdots \Gamma$ & r. u & 3. $2 E-4$ & ?.? & $5.2 \mathrm{E}-4$ \\
\hline & I & $3.95+2$ & $1.3-2$ & $? .8 \mathrm{E}-2$ & $3.8:+2$ \\
\hline & $\because c s+v$ & 5.0 & $\therefore 0$ & $8.9 \mathrm{~F}-1$ & ค. $0 \mathrm{E}-1$ \\
\hline & $\therefore \cdot A T \cdot-$ & 0.3 & $a . \hat{\sim}$. & $1.5 x+0$ & $1.5 E+0$ \\
\hline & $0: a 1$ & $3.8 \mathrm{E}+\hat{i}$ & $\because \mathrm{TE}-?$ & $2.3 t \cdot n$ & $3.8 \mathrm{E}-2$ \\
\hline \multirow[t]{11}{*}{ I-LLl at 600 Years } & $\because \because$ & 0.0 & 9. $9:-4$ & 9.9 & A. $3 E .4$ \\
\hline & $\cdot \cdots \cdot U \cdot 0$ & $7.4 \mathrm{f}-1$ & $\therefore 0$ & 0.9 & $? .9[-1$ \\
\hline & 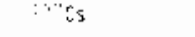 & 0.0 & $9.2 \mathrm{E}-\mathrm{s}$ & $3.7 \mathrm{E}-1$ & $3.7 \mathrm{t}-1$ \\
\hline & $\therefore T r_{1}+0$ & 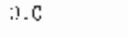 & $9.5 i-4$ & $\therefore 0$ & J. J. \\
\hline & $\cdot \operatorname{Ra}+5$ & $5 . / \mathrm{E}-2$ & $3.1 \mathrm{~F}-4$ & $0 . .9$ & $5.9 \mathrm{E}-2$ \\
\hline & $\cdots B i+D$ & 2.6 & Sof -4 & $\therefore n$ & b. Co $\bar{E}-6$ \\
\hline & $\cdots u+u$ & $4.9[-2$ & $1 . ?$ & 0.9 & 4. $\mathrm{gE}-?$ \\
\hline & 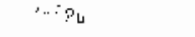 & $3.6 t-1$ & $4.25 \cdot 4$ & 1. Cé - ] & $x \cdot 65-1$ \\
\hline & $\therefore P u$ & $2.9 \mathrm{E}-1$ & $5.35-1$ & $7.5 \mathrm{E}-4$ & $? . Q E-i$ \\
\hline & $\cdots$, sin & $1.3 \mathrm{~L}+0$ & $3.2 \mathrm{~F}-\overline{3}$ & $1.5:+9$ & $\underline{2 .} \vec{E}+\underline{\underline{u}}$ \\
\hline & Total & $2.71+5$ & $7.2 \mathrm{E}-3$ & $2.4 E-C_{0}^{\circ}$ & $5.1 E+?$ \\
\hline \multicolumn{6}{|c|}{ 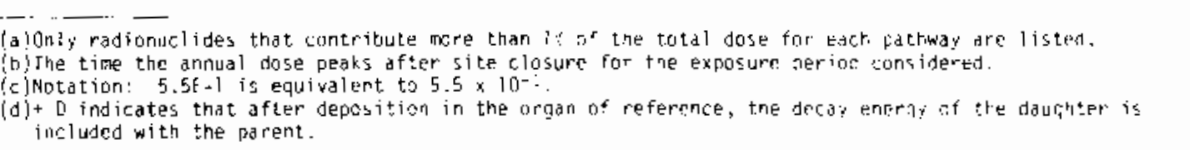 } \\
\hline
\end{tabular}


TABLE C.5-4. Maximum Annua 1 Doses to the Maximum-Exposed Individual from Unrestricted Release of the Western Site with the Radionuclide Inventory of Table 8.4-2.

Organ of Reference.

Tota 7 Body at 200 Years (b)

Bone at 200 Years

Lungs at 200 Years

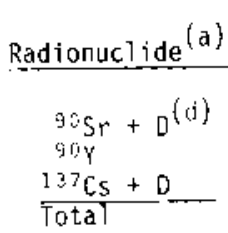

90 $\mathrm{S} r+D$
$13 \mathrm{Cs}+\mathrm{D}$
Total

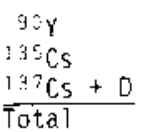

Maximum Annual Dose (mrem) via:

Ingestion Inhalation External All Pathways

$4.4 \mathrm{E}-1(\mathrm{C})$

1. $9 \mathrm{E}-10$

2. $4 \mathrm{E}-3$

4. $4 \mathrm{E}-1$

$1.8 \mathrm{E}+0$

$6.8 \mathrm{E}-9$

$2.6 \mathrm{E}-3$

$1.8 \mathrm{E}+0$

0.0

$2.9 \mathrm{E}-31$

$7.9 \mathrm{E}-4$
8.6E-6

7. $2 \mathrm{E}-10$

$5.1 \mathrm{E}-5$

$6.0 \mathrm{E}-5$

3. $2 E-5$

$2.7 \mathrm{E}-8$

1. $4 E-4$

$\frac{1.4 \mathrm{E}-4}{1.7 \mathrm{E}-4}$

1. $7 \mathrm{E}-\mathrm{B}$

3. $7 E-7$

2. $2 E-5$

$\frac{2.2 E-5}{2.2 E-5}$
4. OE-4

$2.6 \mathrm{E}-2$

$3.8 \mathrm{E}+1$

$3.8 \mathrm{E}+1$

4. OE -4

2. $6 \mathrm{E}-2$

$3.8 \mathrm{E}+1$

$\frac{3.8 \mathrm{E}+1}{3.8 \mathrm{E}+1}$

2. $6 \mathrm{E}-2$

1. $3 E-4$

$3.8 \mathrm{E}+1$

$\frac{3.8 E+1}{3.8 E+7}$
4. 4E-1

2. $6 \mathrm{E}-2$

$3 . \mathrm{BE}+1$

$3.8 E+1$

$1.8 \mathrm{E}+0$

$2.6 \mathrm{E}-2$

$3.8 \mathrm{E}+1$

$4.0 E+7$

$2.6 \mathrm{E}-2$

1. $3 E-4$

$\frac{3.8 \mathrm{E}+1}{3.8 \mathrm{E}+1}$

(a) Only radionuclides that contribute more than $1 \%$ of the total dose for each pathway are 1 isted.

b) The time the annual dose peaks after site closure for the exposure period considered.

(c) Notation: $4.4 \mathrm{E}-1$ is equivalent to $4.4 \times 10^{-1}$.

(d) $+D$ indicates that after deposition in the organ of reference, the decay energy of the daughter is included with the parent.

\section{C.5.2 Dose Calculations for the Eastern Site}

Contributions to the maximum annual dose to the maximum-exposed individual at the eastern site from water pathways are presented in Table C.5-5. Dose calculations are based on the radionuclide inventory of Table 8.4-1. Pathway contributions are shown for 1) ingestion of aquatic foods from the nearby river that is contaninated by radionuclide transport along the aquifer, 2) drinking water from a well drilled into the contaminated near-surface aquifer beneath the site, and 3) ingestion of aquatic and locally grown foods contaminated by overland flow. The large doses calculated for the well-water and overland flow pathways demonstrate the importance of restricting the use of well water at the conditionally released reference site and of maintaining site drainage features to prevent inundation of the site with water.

Calculated maximum annual organ doses to the maximum-exposed individual for unrestricted release of the eastern site with the inventory of Table 8.4-2 are presented in Table C.5-6. The revised inventory would permit unrestricted release of the site 200 years after burial ground closure. 


\section{TABLE C.5-5. Contributions to Maximum Annual Doses to Maximum-Exposed Individual from Water Pathways - Eastern Site}

\begin{tabular}{|c|c|c|c|c|c|c|}
\hline \multirow[b]{2}{*}{ Organ of Reference } & \multirow[b]{2}{*}{ Radionuclide $\{0\}$} & \multirow{2}{*}{$\begin{array}{l}\text { Ingestion of } \\
\text { Aquatic Fonds } \\
\text { Contamindted by } \\
\text { Radiondclide Franspart } \\
\text { - Along Aquifer }\end{array}$} & \multicolumn{3}{|c|}{ Maximur fnnual Bose imrem vid: } & $-\longrightarrow \cdots-$ \\
\hline & & & $\begin{array}{l}\text { Srinking of Water } \\
\text { from heil Jrilled } \\
\text { into Contarinated } \\
\text { Aquifer Beneath Site }\end{array}$ & \multicolumn{3}{|c|}{$\begin{array}{l}\text { Ingestion of roods Contaminated by } \\
\text { Overland Flow. }\end{array}$} \\
\hline \multirow[t]{17}{*}{ Total Body at 209 Years ${ }^{(b)}$} & $\therefore=\mathrm{C}$ & $1.9 E+1^{(c)}$ & $7.1 \mathrm{E}+2$ & 0.0 & $2.5 E-1$ & $2.5 E-1$ \\
\hline & (1) Мi & 0.0 & $6.4 E \cdot 2$ & $2.4 E+1$ & $2,1 E+2$ & $2.3 E+2$ \\
\hline & $\cdot u+C_{i}^{i d !}$ & $0 . \dot{0}$ & $1.0 E+\bar{z}$ & $9.5 E-2$ & $2.4 \mathrm{E}+0$ & $2.4 E \mapsto$ \\
\hline & $\because \mathrm{Sr}+\mathrm{C}$ & 0.0 & $1.2 E+5$ & $E .9 E+0$ & $E \cdot B E+0$ & $1.4 E+1$ \\
\hline & $\therefore T c$ & $5.9 \mathrm{E}-5$ & $3.6 \mathrm{E} \cdots 1$ & $4.0 \mathrm{E}-4$ & 0.0 & $4.0 E-4$ \\
\hline & 1. J J & $2.35-3$ & $1.0 E-1$ & $1.2 E-3$ & $2.6 \mathrm{E}-5$ & $1.2 \mathrm{E}-3$ \\
\hline & $: 1 c_{s+c}$ & $\therefore .0$ & $1.4 E+3$ & $2.8 E-1$ & $1,9 E+2$ & $1.9 E+2$ \\
\hline & $\therefore T h+D$ & 0.0 & $2.6 \mathrm{E}-1$ & $1.3 E+0$ & $2,9 E+0$ & $4.2 E+\square$ \\
\hline & $\therefore \cdot \mathrm{Fa} \cdot \mathrm{D}$ & 0.3 & $3.3 E+2$ & 4. 9E-1 & $3.6 \mathrm{E}+2$ & $3.6 E+2$ \\
\hline & $\therefore \because \because \mathrm{Pt}+\mathrm{J}$ & 3.0 & o. E. & $1,9 E+0$ & $1.0 E+1$ & $1,2 E+1$ \\
\hline & $\therefore \sum_{0}+D$ & 0.0 & 0.0 & $1.5 \mathrm{E}-1$ & $1.5 \mathrm{E}+1$ & $1.5 E+1$ \\
\hline & $\therefore b+j$ & 0.0 & $3,7 E+0$ & 3. IE-1 & $7.8 \mathrm{E}-2$ & $3.9 t-1$ \\
\hline & $\because " \mathrm{Pu}_{\mathrm{u}}$ & 0.0 & $3.9 E-1$ & $1,7 \mathrm{E}-4$ & $1.5 E-1$ & $1.5 E-1$ \\
\hline & נדקדמת & $0 . \hat{x}$ & $3.9[-]$ & $1.6 \mathrm{E}-4$ & $1.4 \mathrm{E}-1$ & $1.4 \mathrm{E}-1$ \\
\hline & $\therefore F_{L}$ & $=.0$. & $2.6 \mathrm{E}-1$ & $2.4 E-4$ & $2,1 E-1$ & $2.1 E-1$ \\
\hline & $\therefore 4$ \& & 0.0 & $2.8 t+0$ & 3. SE-3 & $4.0 E+1$ & $4.0 E+1$ \\
\hline & Tota: & 1. $9 E+1$ & 1.2545 & $3.5 E+1$ & 8. $0 \mathrm{E}+2$ & 8. $3 E+2$ \\
\hline \multirow[t]{17}{*}{ Bone at 249 Yeors } & ${ }^{1 \cdot 1} \mathrm{C}$ & $9.3 E+!$ & $3.5 E+3$ & 0.0 & $1.2 E+0$ & $1.2 E+0$ \\
\hline & $1 ? \mathrm{Mi}$ & 0.0 & 1. $9 E+4$ & $7.3 \mathrm{E}+2$ & $6.2 E+3$ & $6.9 E+3$ \\
\hline & $\therefore L^{\prime}+.$. & ¿.? & $5.8 E+2$ & $5.4 E-1$ & $1.3 E+1$ & $1,3 E+1$ \\
\hline & $\#=5 r+?$ & 0.0 & $4.9 E+5$ & 2. $9 \mathrm{E}+1$ & $2.9 E+1$ & 5. $\mathrm{a} E+1$ \\
\hline & " $\mathrm{TC}$ & $1.5 t-4$ & $9.0 E-1$ & $1.0 E-3$ & 0.0 & $1.0 \mathrm{E}-3$ \\
\hline & $1 \because 1$ & E. ?E-4 & $3.6 t-2$ & A. $3 E-4$ & 0.0 & $4.3 E-4$ \\
\hline & $\because ?^{\top} \mathrm{Cs}+\mathrm{C}$ & 0.0 & $1.4 E+3$ & $3.1 E-1$ & $2.1 E+2$ & $2.1 E+2$ \\
\hline & $\therefore \because[h+]$ & 0.0 & 8. $7 E+1 !$ & $4,3 E+1$ & $9.7 E+1$ & $1.4 E+2$ \\
\hline & $\therefore \cdot \operatorname{Ra} * D$ & 0.0 & $3.3 E \cdot 3$ & $4.4 E+0$ & $3.6 E+3$ & $3.6 \mathrm{E}+3$ \\
\hline & $.14 \mathrm{pb}+3$ & 3.0 & $0 . ᄃ$ & $5.4 E+1$ & 2. $9 E+2$ & 3. $4[+2$ \\
\hline & $\because \because\ulcorner R a+?$ & 0.0 & 0.0 & $2,1 E-1$ & $1.0 t+2$ & $1.0 E+2$ \\
\hline & $\therefore U \bullet 0$ & $0 . \hat{s}$ & $3.1 E+1$ & ใ. $6 \mathrm{E}-2$ & $6.55-1$ & $6.8 E=1$ \\
\hline & $2: A P \mathrm{Pu}$ & 0.0 & $8.0 E+E$ & $3.5 E-3$ & $3.0 \mathrm{E}+0$ & $3.0 \varepsilon+5$ \\
\hline & $\therefore 9 \mathrm{Pu}$ & 0.0 & $5.6 \mathrm{E}+0$ & $3.4 \mathrm{E}-3$ & $2.3 E+0$ & $2.9 E+0$ \\
\hline & ل & 0.0 & $8.3 E+0$ & $5.1 E-3$ & $4.4 E+0$ & $4.4 E+D$ \\
\hline & $-1 !$ & $3.0 \ldots$ & 6. $95+1$ & $\underline{9.9 E-2}$ & $\frac{1}{1}-\underline{a E+3}$ & $1,0 E+3$ \\
\hline & Totol & $9.3 \mathrm{E} \bullet 1$ & $5.2 E+5$ & $8.6 €+2$ & $1.2 \mathrm{E}+4$ & $1.2 E+4$ \\
\hline \multirow{7}{*}{ Lunçs at 203 Years. } & $\because " 1 T C$ & 1. AE-b & $1.1 E-1$ & $1.2 E-4$ & $2.06-7$ & $1.2 \mathrm{E}-\mathbf{4}$ \\
\hline & $: 77[s+]$ & 0.0 & $2.2 \hat{E}+2$ & $1,4 E \cdot]$ & 9. $5 \mathrm{E}+1$ & $9.5 \mathrm{E}+1$ \\
\hline & $\therefore \sin$ & 0.0 & 3. $4 E-1$ & $i .8 \mathrm{t}-4$ & $1.6 \mathrm{E}-1$ & $1.6 \mathrm{E}-\mathrm{t}$ \\
\hline & . inp. & 3.0 & 1. $9 E-1$ & $1.2 \hat{E}-4$ & $1,0 E-1$ & 1. $0 \mathrm{E}-1$ \\
\hline & $\therefore p_{L}$ & 0.0 & $2.9 E-1$ & $3.8 E-4$ & $1.5 E-1$ & $1.5 E-1$ \\
\hline & $2+1 \mathrm{Am}_{\mathrm{m}}$ & 0,0 & $7.7 \mathrm{E}-1$ & $\underline{1.15-3}$ & $\underline{1.2 E+1}$ & $\underline{1.2 E+1}$ \\
\hline & Total & 1. DE - 5 & $2.2 \mathrm{t}+2$ & $1.4 \mathrm{E}-1$ & $1.1 E+2$ & $1.1 E+2$ \\
\hline \multirow[t]{4}{*}{ Thyroid at 202 Years } & $i+c$ & 0.0 & 0.0 & 0.0 & 0.0 & 0.0 \\
\hline & $\therefore \stackrel{4}{1}$ & $1 . B E+0$ & $8.0 E+1$ & $9.4 \mathrm{E}-1$ & $2.0 E-2$ & $9.6 \mathrm{E}-1$ \\
\hline & ${ }^{17} \mathrm{cos} \cdot 0$ & $0.0 \ldots$ & $\underline{0.0}$ & 0.G & $\underline{0.0}-$ & $\underline{0.0} \ldots$ \\
\hline & otal & $i .8 \mathrm{E}+0$ & $8.0 \mathrm{OE}+1$ & $9.4 E-1$ & $2.0 \mathrm{E}-2$ & $9.6 \mathrm{E}-1$ \\
\hline \multirow[t]{8}{*}{ G]-LLI at 230 Years } & $\therefore \because 0+0$ & 0.6 & $2.0 E+0$ & 1. $9 E-3$ & $4.6 \mathrm{E}-2$ & 4. $8 \mathrm{E}-2$ \\
\hline & 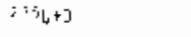 & 2.0 & $1.5 \mathrm{E}-1$ & $1,3 E-4$ & $3.0 E-3$ & $3.15-3$ \\
\hline & $231 T h+j$ & 0.0 & 0.0 & ] $.6 E-2$ & $1.7 E-6$ & $1.6 \mathrm{E}-2$ \\
\hline & $\operatorname{sip}$ & 0.0 & $1.6 \mathrm{t}+0$ & 9. $9 t-4$ & $8.6 \mathrm{E}-1$ & $8.6 \mathrm{E}-1$ \\
\hline & 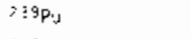 & $\pi .0$ & $1.0 E+0$ & $6.1 E-4$ & 5. $3 E-1$ & $5.3 E-1$ \\
\hline & $\therefore c \mathrm{pl}$ & 0.0 & $1.5\{=0$ & 9. $4 E-4$ & B.2E-1 & $8.2 E-3$ \\
\hline & " & 0.0 & Q. $2 E+0$ & $6.2 \mathrm{E}-3$ & $6 \cdot 3 E+1$ & $6.3 E+1$ \\
\hline & Total & 0.0 & $1.1 E+1$ & $2.75-2$ & $6.5 E+1$ & $6.5 E+1$ \\
\hline
\end{tabular}




\section{TABLE C.5-6. Maximum Annual Doses to the Maximum-Exposed Individual from Unrestricted Release of the Eastern Site with the Radionuclide Inventory of Table 8.4-2.}

Maximum Annual Dose (mrem) via:

\begin{tabular}{|c|c|c|c|c|c|c|c|}
\hline \multirow[b]{2}{*}{ Organ of Reference } & \multirow[b]{2}{*}{ Radionuclide ${ }^{(a)}$} & & \multirow[b]{2}{*}{$\begin{array}{c}\text { All } \\
\text { Pathways }\end{array}$} \\
\hline & & $\begin{array}{c}\text { Farm } \\
\text { Products }\end{array}$ & $\begin{array}{l}\text { igestion } \\
\text { Aquatic } \\
\text { Foods }\end{array}$ & $\begin{array}{l}\text { WeTा } \\
\text { Water }\end{array}$ & Inhalation & External & \\
\hline Total Body at 202 Years $(b)$ & $\begin{array}{l}95 \mathrm{Sr}+\mathrm{D}^{(\mathrm{C})} \\
3 \mathrm{~B}_{\mathrm{Cs}}+\mathrm{D} \\
\text { Total }\end{array}$ & $\begin{array}{l}1.7 \mathrm{E}-5^{(\mathrm{d})} \\
\frac{8.6 \mathrm{E}-3}{8.6 \mathrm{E}-3}\end{array}$ & $\begin{array}{l}1.6 \mathrm{E}-5 \\
\frac{5.5 \mathrm{E}+0}{5.5 \mathrm{E}+0}\end{array}$ & $\begin{array}{l}1.4 \mathrm{E}-1 \\
\frac{1.3 \mathrm{E}+7}{1.3 \mathrm{E}+7}\end{array}$ & $\begin{array}{l}2.2 \mathrm{E}-10 \\
\frac{2.1 \mathrm{E}-6}{2.1 \mathrm{E}-6}\end{array}$ & $\begin{array}{l}4.2 E-9 \\
4.0 E+0 \\
4.0 E+0\end{array}$ & $\begin{array}{l}\frac{1.4 E-1}{2.3 E+1} \\
\frac{2.3 E+1}{2.3 E+1}\end{array}$ \\
\hline Bone at 223 Years & $\begin{array}{r}90 S \gamma+D \\
{ }^{10} \mathrm{CS}+\mathrm{D} \\
\text { Total }\end{array}$ & $\begin{array}{l}3.2 \mathrm{E}-4 \\
6.0 \mathrm{E}-3 \\
6.3 \mathrm{E}-3\end{array}$ & $\begin{array}{l}3.0 \mathrm{E}-4 \\
\frac{3.8 \mathrm{E}+0}{3.8 \mathrm{E}+0}\end{array}$ & $\begin{array}{l}3.5 \mathrm{E}+0 \\
\frac{1.4 \mathrm{E}+1}{1.8 \mathrm{E}+1}\end{array}$ & $\begin{array}{l}3.7 \mathrm{E}-9 \\
\frac{3.3 \mathrm{E}-6}{3.3 \mathrm{E}-6}\end{array}$ & $\begin{array}{l}2.4 E-9 \\
2.4 E+0 \\
2.4 E+0\end{array}$ & $\begin{array}{l}3.5 E+0 \\
\frac{2.0 E+1}{2.4 E+1}\end{array}$ \\
\hline Lungs at 203 Years & $\cdot 3^{7} \mathrm{Cs}+\mathrm{D}$ & $1.5 E-3$ & $9.5 E-1$ & $2.2 E+D$ & $2.1 \mathrm{E}-6$ & $4.0 E+0$ & $7.2 E+0$ \\
\hline
\end{tabular}

(a) Only radionuclides that contribute more than $1 \%$ of the total dose for each pathway are 1 isted.

(b) The time the annual dose peaks after site closure for the exposure period considered.

(c) +0 indicates that after deposition in the organ of reference, the decay energy of the daughter is included with the parent.

(d) Notation: $1.7 \mathrm{E}-5$ is equivalent to $1.7 \times 10^{-5}$. 


\section{REFERENCES}

1. Task Group on Lung Dynamics for Committee 2 of the International Commission on Radiological Protection, "Deposition and Retention Models for Internal Dosimetry of the Human Respiratory Tract," Health Physics, Volume 12, pp. 173-207, February 1966.

2. G. G. Killough, D. E. Dunning, Jr., S. R. Bernard and J. C. Pleasant, Estimates of Internal Dose Equivalent to 22 Target Organs for Radionuclides Occurring in Routine Releases from Nuclear Fuel-Cycle Facilities, NUREG/CR-0150, report prepared for the Nuclear Regulatory Commission by Oak Ridge National Laboratory, Oak Ridge, TN, June 1978.*

3. Proposed Guidance on Dose Limits for Persons Exposed to Transuranium Elements in the General Environment, U.S. Environmental Protection Agency, EPA 520/4-77-076, September 1977.

4. W. H. Wischmeier and D. D. Smith, Predicting Rainfall-Erosion Losses from Cropland East of the Rocky Mountains. Agriculture Handbook No. 282,1965 .

5. B. A. Stewart, D. A. Woothiser, W. H. Wischmeier, J. H. Caro and M. H. Frere, Control of water Pollution from Cropland, Vol. I, U.S. Department of Agricuiture Report, ARS-H-5-1, November 1975.

6. J. H. Horton and E. L. Wilhite, Estimated Erosion Rate at the SRP Burial Ground, OP-1493, Savannah River Laboratory, Aiken, SC, Apri 1978.

7. E. L. Skidmore and N. P. Woodruff, Wind Erosion Forces in the United States and Their Use in Predicting Soil Loss, Agriculture Handbook No. 346, Agricultura 1 Research Service, USDA, Apri 1968.

8. N. P. Woodruff and F. H. Siddoway, "A Wind Erosion Equation," Soi] Science Society Proceedings, p. 605, 1965.

9. L. R. Anspaugh, J. H. Shinn, P. L. Phelps and N. C. Kennedy, "Resuspension and Redistribution of Plutonium in Soils," Health Physics, Vol. 29, pp. 571-582, October 1975.

10. L. R. Anspaugh, "Appendix A, Resuspension Element Status Report: The Use of NTS Data and Experience to Predict Air Concentrations of Plutonium Due to Resuspension on the Enewetak Atol1," Nevada Applied Ecology Group Procedures Handbook for Environmental Transuranics, NVO-166, Vol. 2, pp. 392-395, U.S. ERDA, Las Vegas, NV, October 7976.

11. K. Stewart, The Resuspension of Particulate Material from Surfaces, Surface Contamination Proceedings of a Symposium held at Gatiinburg, TN, June 1964. 
12. R. C. Miiham, J. F. Schubert, J. R. Watts and A. L. Boni, Measured Plutonium Resuspension and Resulting Dose from Agricultura Operations on an 0ld Field at the Savannah River plant in the Southeastern United States, IAEA-SM-199, Savannah River Laboratory, Aiken, SC, November 1975.

13. J. W. Healy, An Examination of the Pathways from Soil to Man for Plutonium, LA-6747-MS, Los Alamos Scientific Laboratory, Los ATamos, NM, Apri门 1977.

14. J. W. Healy and J. C. Rodgers, An Examination of Possible Limits for the Shallow Earth Burial of Transuranic Wastes, Draft report by Los Alamos Scientific Laboratory, Los ATamos, NM, JuTy T, 1977.

15. D. A. Baker, G. R. Hoenes and J. K. Soldat, "F00D - An Interactive Code to Calculate Internal Radiation Doses from Contaminated Food Products," in Environmental Modeling and Simulation, Proceedings of a conference heid in Cincinnati, 0H, ApriT 20-22, 1975, pp. 204-208, EPA, Washington, DC, 1976.

16. S. W. Ahistrom, H. P. Foote, R. C. Annett, C. R. Cole and R. J. Serne, Multicomponent Mass Transport Mode 1: Theory and Numerical Implementation Discrete-Parcel-Random-Walk Version, BNwL-2127, Battelle, Pacific Northwest Laboratories, Richiand, WA, May 1977.

17. J. R. Eliason and H. P. Foote, Long Beach Generating Station Thermal Transport Modeling Study, 212B01337 Report prepared for Southern California Edison Company by Battelle, Pacific Northwest Laboratory, Richland, WA November 1972 .

18. G. B. Staley, G. P. Turi, and D. L. Schreiber, "Radionuclide Migration from Low-Level Waste: A Generic Overview," Management of Low-Leve? Radioactive Waste, Vol. 2, pp. 1041-1072, Pergamon Press, New York, NY 1979 .

19. P. Colombo and R. M. Neilson, Critical Review of Properties of Solidified Radioactive Waste Packages Generated at Nuclear Power Stations, BNL-NUREG50591 , Brookhaven National Laboratory, Upton, NY, 1976.

20. Test Case Release Consequence Analysis for a Spent Fuel Geologic Repository, Draft report prepared for the Department of Energy's Office of Nuclear Waste Isolation by Battelle, Pacific Northwest Laboratory, Richland, WA, August 1978.

21. J. K. Soldat et a1., Models and Computer Codes for Evaluating Environmental Radiation Doses, USAEC Report BNWL-1754, Pacific Northwest Laboratory, Richland, WA, February 1974.

22. International Commission on Radiological Protection, Report of ICRP Committee II on Permissible Dose for Internal Radiation, ICRP Publication 2, Pergamon Press, NY, 1959. 
23. International Commission on Radiological Protection, The Assessment of Internal Contamination Resulting from Recurrent or Prolonged Uptakes, ICRP Publication 10A, Pergamon Press, New York, NY, 1969.

24. J. K. Soldat, Modeling of Environmental Pathways and Radiation Doses from Nuclear Facilities. USAEC Report BNWL-SA-3939, Battelle, Pacific Northwest Laboratory, Richland, WA, 1971.

25. G. R. Hoenes and J. K. Soldat, Age-Specific Radiation Ooses Commitment Factors for a one-Year Chronic Intake, NUREG-0172, a report for the U.S. Nuclear Regulatory Commission, prepared by Battelle, Pacific Northwest Laboratory, Richland, WA, November 1977.*ᄎ

26. J. R. Houston, 0. L. Strenge and E. C. Watson, DACRIN - A Computer Program for Calculating Organ Oose from Acute or Chronic Inhalation, BNWL-B-389, Battel]e, Pacific Northwest Laboratory, Richland, WA, December 1974.

27. R. L. Enge1, J. Greenborg and M. M. Hendrickson, ISOSHLD - A Computer Code for General Purpose Isotope Shielding Analysis, U.S. AEC Report, BNWL-236, Batte]le, Pacific Northwest Laboratory, Richland, WA, June 1966.

28. U.S. AEC, Final Environmental Statement Concerning Proposed Rule-Making Action: Numerical Guides for Design 0bjectives and Limiting Conditions for Radioactive Material in Light Water-Cooled Nuclear Power Reactor Effiuents, WASH-1258, Directorate of Regulatory Standards, Volume 1 of 3 , Tables $6 \mathrm{~B}-4$ and 6B-5, pp. 6B-34 and 6B-35, July 1973 .

29. D. A. Baker, User Guide for Computer Program Food, U.S. ERDA Report BNWL-2209, Battelle, Pacific Northwest Laboratory, Richland, WA February 1977.

30. F. W. Whicker, Biological Interactions and Reclamation of Uranium Mill Tailings, Symposium Proceedings on Uranium Mill Tailings Management held at Colorado State University, Fort Collins, Co, November 20-28, 1978.

31. Report of the Task Group on Reference Man, International Commission on Radiological Protection Report No. 23, Pergamon Press, Oxford, 1975.

\footnotetext{
ॠAvailable for purchase from the NRC/GPO Sales Program, U.S. Nuclear Regulatory Commission, Washington, D.C. 20555, and the National Technical Information Service, Springfield, Virginia 22161.

** Available for purchase from the National Technical Information Service, Springfie1d, Virginia 22161.
} 
APPENDIX D

ENVIRDNMENTAL SURVEILLANCE AND RECORDS MAINTENANCE DETAILS

This appendix provides details to support the description of environmental surveillance and records maintenance activities presented in Section 9 of Volume 1. Examples of environmental monitoring results from one of the commercial LLW burial sites are given in Section D.1. Generalized environmental sampling procedures, together with example data sheets, are given in Section D.2. An example Radioactive Shipment Record form is shown in Section D.3.

\section{D.1 TYPICAL ENVIRONMENTAL MONITORING RESULTS FROM}

A COMMERCIAL LLW SITE

The environmental monitoring programs postulated for the reference sites are discussed in Section 7.2.4 of Volume 1. These postulated programs are based on the existing programs at commercial LLW sites. Typical environmental monitoring results from one of the commercial sites, based on information in Reference 1 , are presented here to aid in the more complete understanding of environmental monitoring activities at existing sites.

Typical analytical results of routine environmental samples are presented in Table D.1-1. Results are shown for water, soil, and vegetation samples, and are reported for the same time period insofar as the reference data permits. The table is not a complete listing of all environmental results for the time period considered, but the results shown are selected to be typical of ali those reported.

Typical readings of direct radiation exposure, measured with thermoluminescent dosimeters (TLD), are presented in Table D.i-2. Results are given for five sample locations (including a cortrol) and for three time periods. 


\section{TABLE D.1-l. Typical Environmental Monitoring Results for a Commercial LLW Burial Ground}

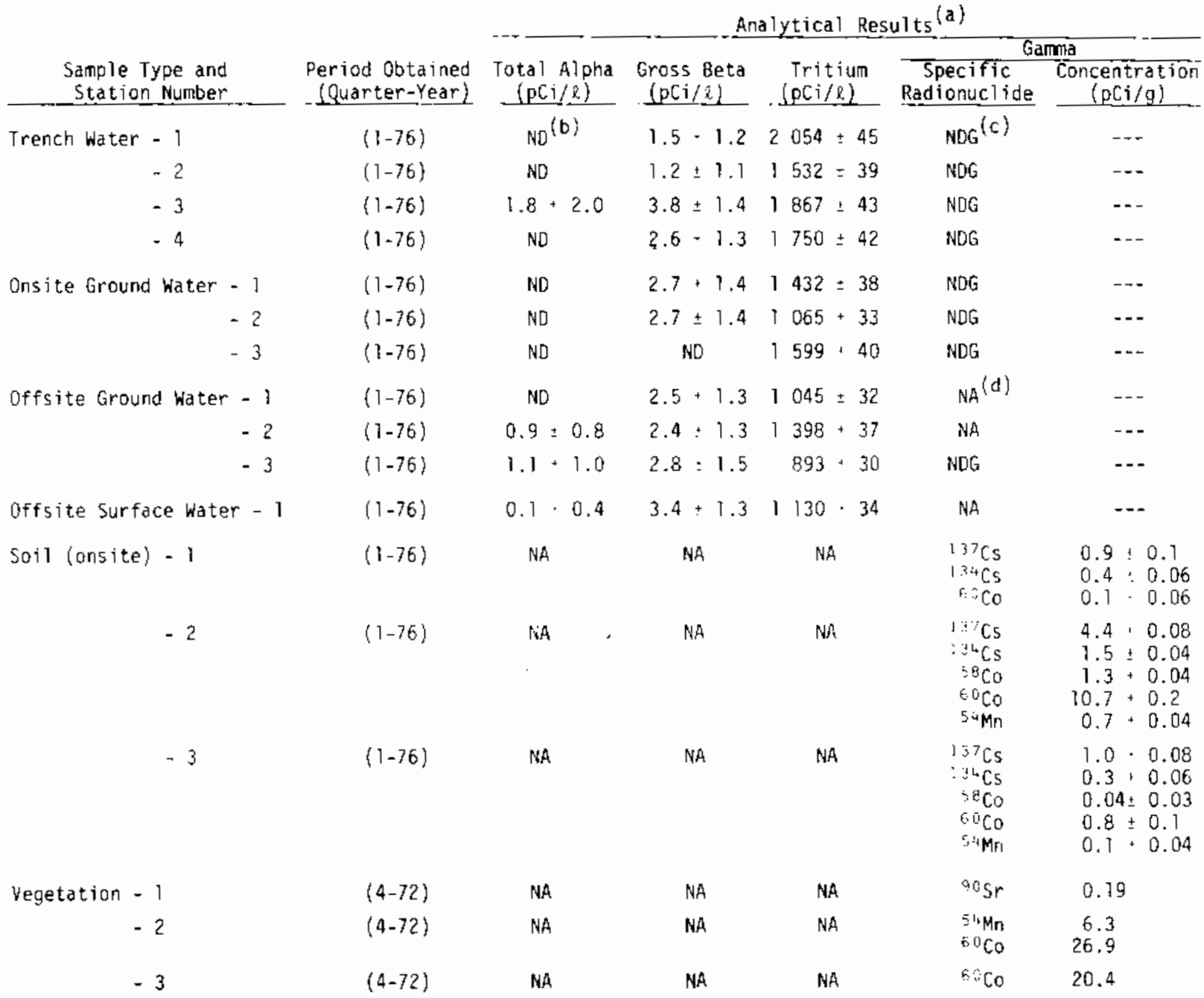

(a) Results include estimate of range ( \pm ) at the $95 \%$ confidence level, insofar as reference data pernits. (b) ND indicates radioactivity not detectable, below the sensitivity of the instrument used.

(c) NDG indicates no detectable ganma emitters.

(d) NA indicates no anaiys is performed. 
TABLE D.1-2. Typical Direct Radiation Exposure Readings for a Commercial LLW Burial Ground

\begin{tabular}{|c|c|c|c|c|}
\hline \multirow[b]{2}{*}{$\begin{array}{c}\text { Sample Station } \\
\text { Number }\end{array}$} & \multirow[b]{2}{*}{ Sample Period } & \multirow[b]{2}{*}{$\begin{array}{c}\text { Exposure } \\
\text { Time (days) }\end{array}$} & \multicolumn{2}{|c|}{ Exposure } \\
\hline & & & $\begin{array}{l}\text { Period Total } \\
\text { (mrem) } \\
\end{array}$ & $\begin{array}{l}\text { Period Average } \\
\text { (mrem/day) } \\
\end{array}$ \\
\hline \multirow[t]{3}{*}{1} & $3 / 18 / 76-6 / 14 / 76$ & 88 & 17 & 0.19 \\
\hline & $6 / 14 / 76-9 / 9 / 76$ & 87 & 69 & 0.79 \\
\hline & $9 / 9 / 76-12 / 10 / 76$ & 92 & 52 & 0.57 \\
\hline \multirow[t]{3}{*}{2} & $3 / 18 / 76-6 / 14 / 76$ & 88 & Yoid & -- \\
\hline & $6 / 14 / 76-9 / 9 / 76$ & 87 & וסו & 1.16 \\
\hline & $9 / 9 / 76-12 / 10 / 76$ & 92 & 135 & 1.47 \\
\hline \multirow[t]{3}{*}{3} & $3 / 18 / 76-6 / 14 / 76$ & 88 & Missing & -- \\
\hline & $6 / 14 / 76-9 / 9 / 76$ & 87 & 39 & 0.45 \\
\hline & $9 / 9 / 76-12 / 10 / 76$ & 92 & Missing & -- \\
\hline \multirow[t]{3}{*}{4} & $3 / 18 / 76-6 / 14 / 76$ & 88 & 12 & 0.14 \\
\hline & $6 / 14 / 76-9 / 9 / 76$ & 87 & 102 & 1.17 \\
\hline & $9 / 9 / 76-12 / 10 / 76$ & 92 & Yoid & -- \\
\hline \multirow[t]{3}{*}{ Control } & $3 / 2 / 76-6 / 9 / 76$ & 99 & 19 & 0.19 \\
\hline & $6 / 9 / 76-9 / 3 / 76$ & 87 & 25 & 0.29 \\
\hline & $9 / 3 / 76-12 / 8 / 76$ & 96 & Yoid & -- \\
\hline
\end{tabular}

\section{D.2 ENVIRONMENTAL SAMPLING PROCEDURES}

A general discussion of sampling methods and measurement techniques for environmental monitoring is contained in Reference 2. The reference also provides general guidance on the selection of sampling locations and the frequency of collection of sampies.

Generalized procedures for environmental sampling, together with examples of data sheets used to record sampling data, are presented here to provide additional detail concerning the methods used to obtain environmental data at an LLW burial site. These procedures are simplified somewhat to make them more readily understandable; the actual sampling procedures contain all information necessary to obtain the required samples at the specific LLW site. Procedures are given for all sample types required by the environmental surveilTance programs postulated for the reference LLW sites, as described in Section 7.2 .4 of Volume 1 . 


\subsubsection{Water Sampling}

Water samples are obtained using the following procedure, and are recorded on an Environmental Sampling Record form similar to the example shown in Figure $0.2-1$.

1. Assemble the sample containers (1-i plastic sample bottles) and other required equipment.

2. Check sample bottles for any flaws and discard damaged containers.

3. Rinse sample bottles with distilled water and attach self-adhesive iabels to bottles.

4. Remove well or sump cap, lower sampling bucket into wel1, withdraw filled bucket, and empty bucket into the sample bottle. Repeat until sample bottle is full, and then replace well cap.

5. Enter required data on the sample bottle label and on the Environmental Sampling Record form.

\section{D.2.2 Soil Sampling}

Soil samples are obtained using the following procedure:

1. Obtain a clean plastic bag and verify that it is unflawed. Discard any damaged bags.

2. Collect approximately $500 \mathrm{~g}$ of soil and seal it into the bag.

3. Enter required data on the Environmental Sampling Record form and on a self-adhesive label, and attach the label to the bag.

\section{D.2.3 Vegetation Sampling}

Vegetation samples are obtained using the following procedure:

1. Obtain a clean plastic bag and verify that it is unflawed. Discard any damaged bags.

2. Collect approximately $500 \mathrm{~g}$ of growing vegetation. If vegetation has died, select sample of latest growth. Put sample in bag and then seal the bag. 
ENVIRONMENTAL SAMPLING RECORD

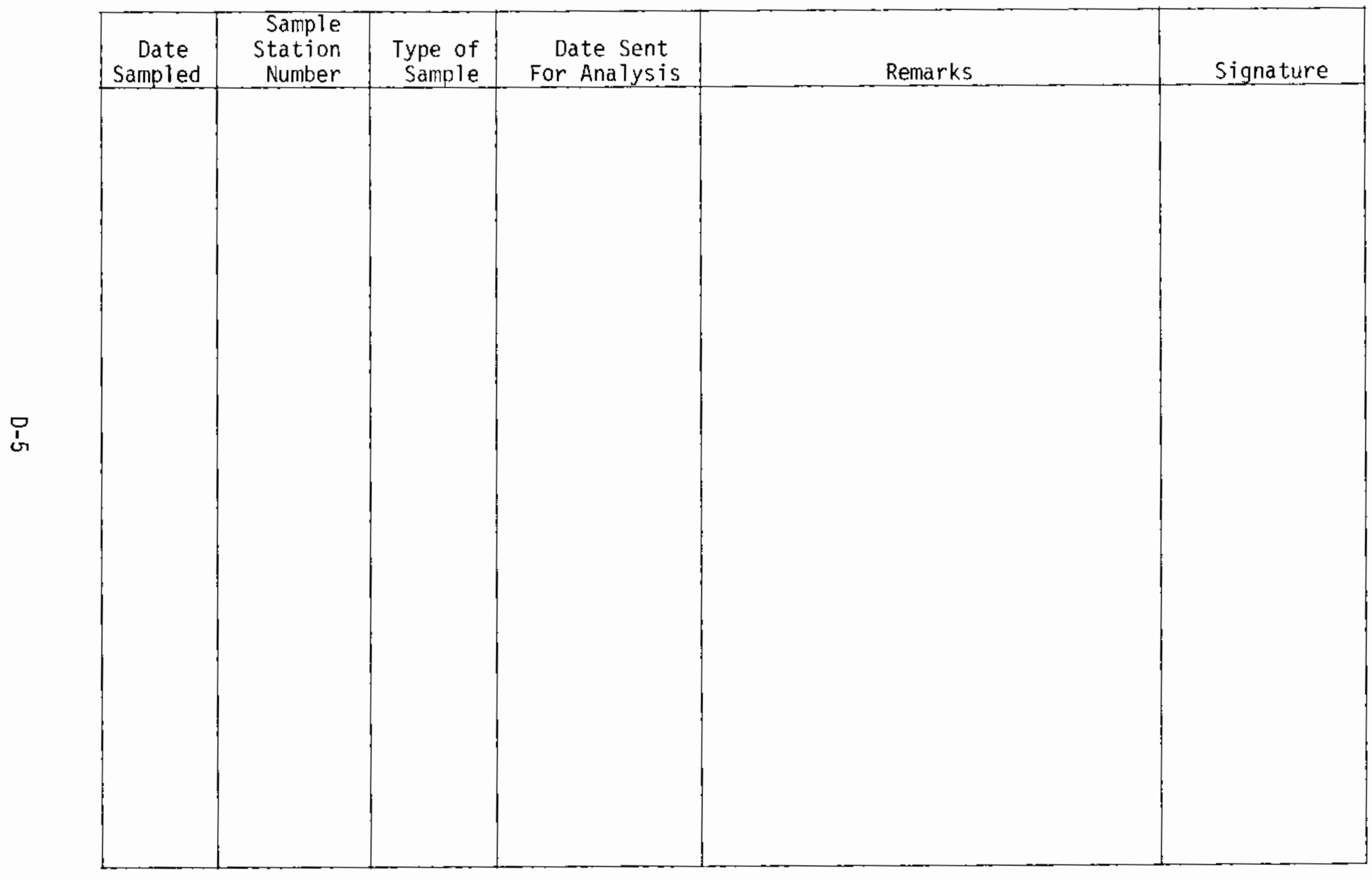

FIGURE D.2-1. Example Environmental Sampling Record Form 
3. Enter required data on the Environmental Sampling Record form and on a self-adhesive label, and attach the label to the bag.

\section{2 .4 Sma11 Mamma! Sampling}

Small mammal samples are obtained using the folfowing procedure:

1. Check trap to verify proper operation and then set it up in the area to be sampled.

2. Obtain sample box and verify its integrity, then attach self-adhesive label.

3. Check trap daily until sample is obtained.

4. Remove sample from trap and seal into sample box.

5. Enter required data on the sample box label and on the Environmental Sampling Record form.

\section{D.2.5 Air Sampling}

Air samples are obtained using the following procedure, and are recorded on an Air Sampling Record form similar to the example shown in Figure D.2-2.

1. Obtain a clean plastic bag and verify that it is unflawed. Discard any damaged bags.

2. Shut air sampler off.

3. Remove filter from sampler, insert it into bag, and then close and seal the bag. Replace fresh filter in sampler.

4. Remove strip-chart from sampler and retain, replace with fresh chart paper.

5. Restart air sampler and verify that it is operating properly.

6. Enter required data on the Air Sampling Record form and on a self-adhesive label, and attach the label to the bag. 
AIR SAMPLING RECORD

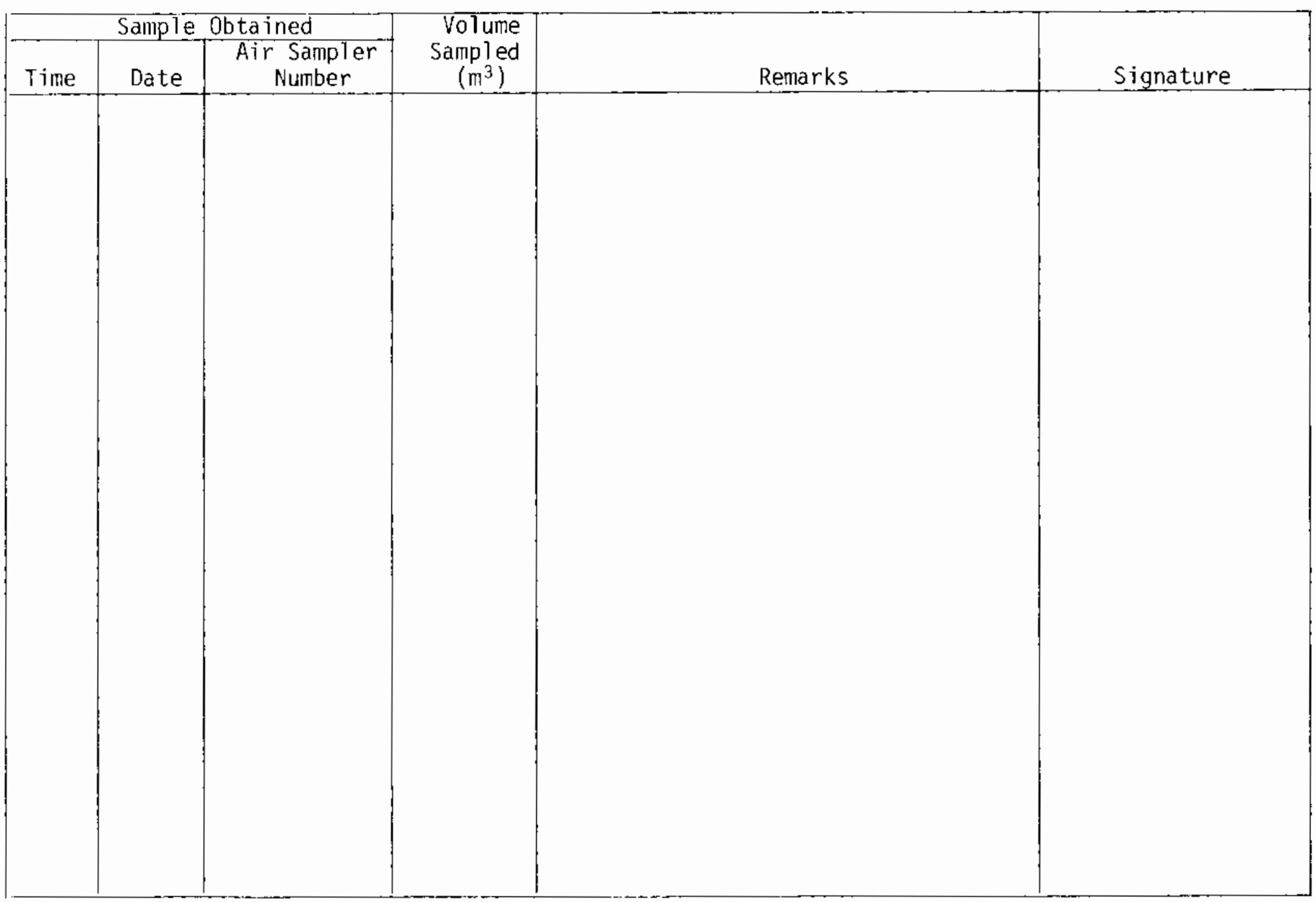

FIGURE D.2-2. Example Air Sampling Record Form 


\section{D.2.6 TLD Exposure Sampling}

TLD samples are obtained using the following procedures:

1. Obtain adequate supply of fresh (unexposed) TLDs.

2. Remove exposed TLD from holder, label properly, and replace with fresh TLD.

3. Enter required data on the Environmental Sampling Record form.

4. Package TLDs for shipment to analytical laboratory.

\section{D.3 RADIOACTIVE SHIPMENT RECORD FORM}

All shipments of radioactive material are accompanied by a Radioactive Shipment Record (RSR) form. An example of a form that is in current use is shown in Figure D.3-I. Shipments are made according to all applicable transportation regulations, as described in Appendix G, Section G.4.

The RSR transmits aIl applicable information concerning the wastes from the shipper to the burial ground operator (the receiver of the waste). For each waste package, the specific information required is contained in the main body of the form. Information concerning the entire shipment (e.g., shipper, receiver, number of items, and gross shipment weight) is shown at the top of the form. The form is basically self-explanatory; however, the following additional information is provided to clarify certain items.

Isotope(s) - Only the principal isotopes contained in the waste package are listed.

Form - The physical and chemical form of the waste is described in enough detail to provide the receiver with a complete picture of package contents. If the space provided is insufficient, additional information is supplied on a supplementary sheet attached to the RSR.

Transport Group - Radioactive materials are classified into one of seven transport groups according to their potential hazard if released to the environment, as described in Section G.4.1. 
RADIOACTIVE SHIPMENT RECORD

TO

FROM

CAFRIER

NUMBER OF ITEMS

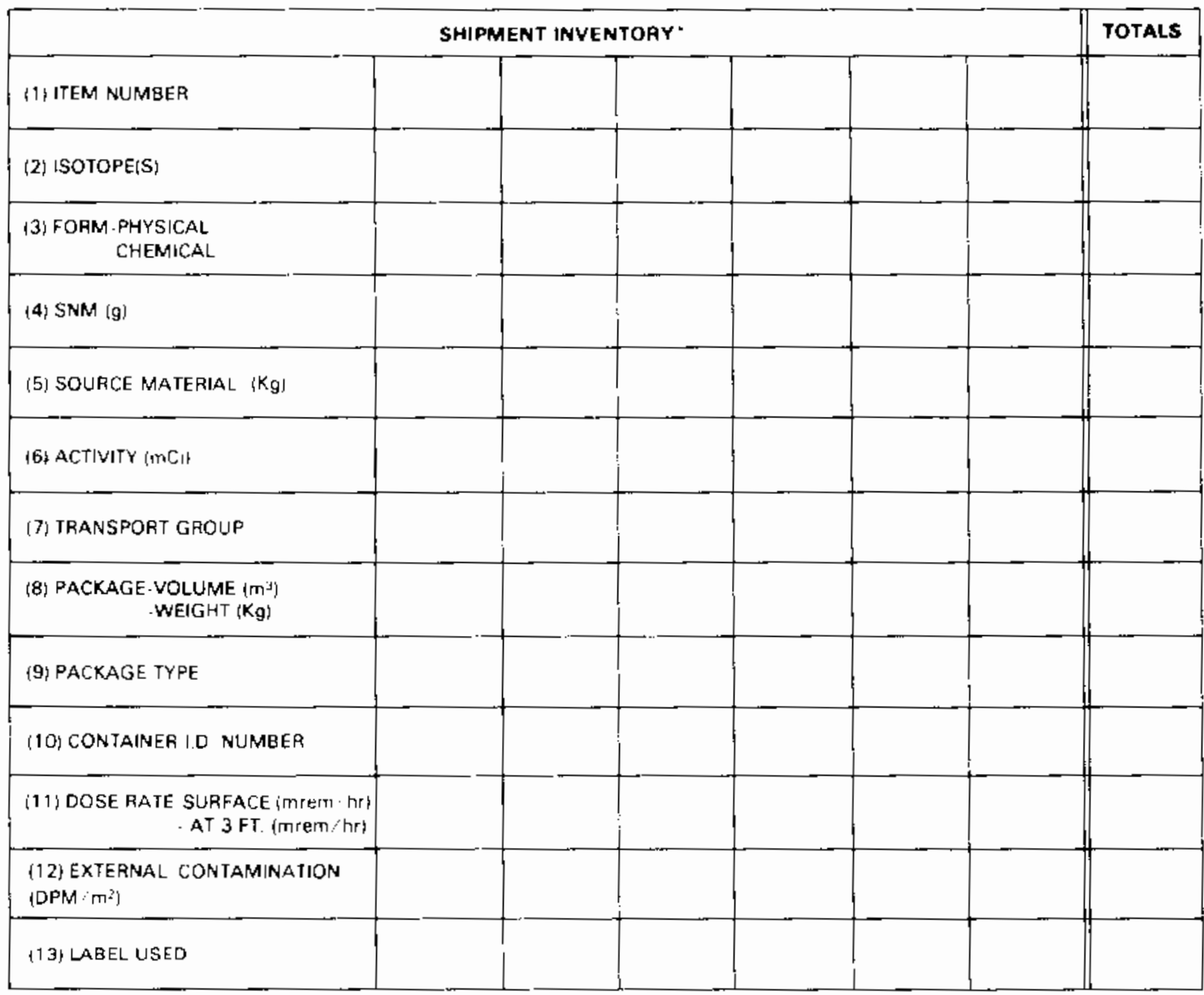

- SUPPLY ANY ADDITIONAL INFORMation ON AN ATTACHED SUPPLEMENTARY SHEET
DATE.

SURVEY NO

PAGE
GROSS SHIPMENT WEIGHT OF 
Package Type - This refers to Type A, Type B, or Type LSA packaging, as described in Section G.4.1.

Container ID Number - This is the identification number of the cask or overpack used, if applicable.

Label Used - Labeling requirements vary with the type and quantity of material shipped.

Copies of the RSR are retained by the shipper, the receiver, and the carrier. The RSR is used by the burial ground operator as part of the waste burial record. 


\section{REFERENCES}

1. Radiation Surveillance Data, Bureau of Radiological Health, South Carolina Department of Health and Environmental Control, Chem-Nuciear Systems, Inc., Barnwel1, SC, January 10, 1977.

2. J. P. Corley et al., A Guide for Environmental Radiological Surveillance at ERDA Installations, ERDA 77-24, U.S. Energy Research and Development Administration, Washington, DC, March 1977. 
APPENDIX E

\section{PAYMENTS NEEDED TO FINANCE DECOMMISSIONING}

The purpose of this appendix is to illustrate the payment schedules requirec to pay for site stabilization and long-term care of the reference burial ground under each of the three financing approaches discussed in Section 6 of Volume 1. The three basic financing approaches are:

1) Creation of a decommissioning and long-term care fund (i.e., a "sinking fund") during the operating life of the burial ground.

2) Prepayment of anticipated decommissioning and long-term care costs.

3) Payment of decommissioning costs when incurred (i.e., after closure of the burial ground).

\section{E.? BASES AND ASSUMPTIONS}

In the discussion that follows, the results are sensitive to the various costs of financing. It is, therefore, appropriate to define these various cost factors. This is done below.

Interest Rate

The rate of return on capital invested in normal securities (i.e., bonds, certificates of deposit, and similar financial instruments).

Inflation Rate

The rate of increase in cost of goods and services, on an annual basis, as determined from the nation's economic indicators by the Federal Department of Labor.

\section{Discount Rate}

The rate of return on capital that could have been realized in alternative investments, if the money were not comnitted to the plan being evaluated (i.e., the opportunity cost of alternative investments). This cost is equivalent to the weighted average cost of capital. 
Present Value of Money

When different business activities require disbursement of funds over different time frames, it is difficult for the sponsoring organization to compare the actual cost of each activity. One generally accepted method of placing these various disbursements on a common basis is to compute their value in terms of current dollars (i.e., the present value of money to be paid out or received at some time other than the present). For an investor, "the present value of a future payment or series of payments is the present investment necessary to secure the promise of that future payment or series of payments, with interest at a given rate.."(1)

Decommissioning cost estimates are made in Section 12 of Volume 1 . The costs of site stabilization and long-term care (for 200 years) are summarized in Table E.1-1. Payment schedules to cover these costs are estimated in this appendix.

TABLE E.1-1. Stabilization and Long-Term Care Costs (millions of 1978 doliars)

\begin{tabular}{|c|c|c|c|c|c|}
\hline \multirow[b]{2}{*}{ Stabilization Plan } & \multicolumn{5}{|c|}{$\operatorname{Costs}^{(a)}$} \\
\hline & $\begin{array}{c}\text { Site } \\
\text { Stabilization }\end{array}$ & $\begin{array}{r}\mathrm{Pe} \\
0-5 \frac{\mathrm{L}}{\mathrm{yr}}\end{array}$ & $\begin{array}{l}\text { riod Tota } \\
\text { ong-Term } \\
6-25 y r\end{array}$ & $\begin{array}{l}\text { Is for } \\
\text { Care } \\
26-200 \text { yr }\end{array}$ & $\begin{array}{l}\text { Total Costs } \\
\text { of Stabilization } \\
\text { plus Long-Term Care }\end{array}$ \\
\hline \multicolumn{6}{|l|}{ Western Site } \\
\hline Minima1 & 0.475 & 0.808 & 2.122 & 13.580 & 16.985 \\
\hline Modest & 2.576 & 0.808 & 2.122 & 13.580 & 19.086 \\
\hline Complex & 7.675 & 1.150 & 2.000 & 12.512 & 23.337 \\
\hline \multicolumn{6}{|l|}{ Eastern site } \\
\hline Minima] & 0.518 & 1.175 & 3.542 & 22.855 & 28.090 \\
\hline Modest & 3.866 & 1.175 & 3.542 & 22.855 & 31.438 \\
\hline Compiex & 5.466 & 7.815 & 3.642 & 23.730 & 34.653 \\
\hline
\end{tabular}

(a) Number of figures shown is for compucational accuracy only. 
For all computations in this appendix, the following assumptions are made:

1) decommissioning costs escalate $6 \%$ per year in nominal (current) dollars (i.e., the inflation rate is $6 \%$ )

2) the interest earned on invested funds is $8 \%$ per year (a)

3) interest is compounded annually.

To compute specific fund payments required for decommissioning, it is necessary to assume a hypothetical operating life for the burial ground. Because decommissioning cost estimates are made in 1978 dollars, it is convenient to assume an operating 1 ife that ends on December 31, 1977. A 30-year operating life is also assumed; therefore, the burial ground is assumed to start operations on January 1, 1948. Payments can be adjusted to reflect any other operating period if desired. For example, if sinking fund payments were desired for a 30-year operating 1ife beginning January 1, 1968, the 1948 sinking fund payment would be multiplied by 3.21 , the inflation factor for 20 years at $6 \%$ inflation.

\section{E.2 PAYMENT SCHEDULES FOR THE SINKING FUND OPTION}

Sinking funds are currently used to accumulate decommissioning funds at a 11 operating burial grounds. Sinking fund payments are made during the operating life of the burial ground. Sufficient funds must be collected during the operating 1 ife to pay for all decomissioning expenses after ciosure. As discussed in Section 6 of Volume 1, the magnitude of the payment might need to be adjusted regularly to account for changes in fund earnings, cost escalation, expected operating 1 ife, and changes in the estimated decommissioning expense caused by technology, regulations, or other factors. For this example, the simplifying assumptions are made that the fund earns a constant return, and that

(a)The yield on investments over and above infiation is the real return available to the investor. For the period 1967 to 1976, the average real return relative to the gross national product deflator on 3- to 5-year U.S. Government securities was $1.43 \% .(2)$ For the perjod 1963 to 1976 , the average real return on AAA corporate bonds was $1.95 \%$. (2) The average expected real return on 9- to 12-month Treasury issues, relatjye to expected inflation rates for the period 1953 to 1975 , was about $2.2 \%$. (3) Two percent thus appears to be a reasonable assumption for real rate of return. 
the only adjustment required in the sinking fund payment is for cost escalation (inflation). It is assumed that the sinking fund payment is made December 31 of each year of burial ground operation and that interest is compounded annualiy. Costs to administer the fund are not included.

For the various site stabilization options, the sinking fund must contain sufficient monies at site closure to stabilize the site and to provide for longterm care for the assumed 200-year period of administrative control. The required value of the sinking fund at the conclusion of burial ground operations (i.e., the terminal value of the sinking fund) is given in Table E.2-1 for each site stabilization option described in Section 10 of Volume 1 . The terminal value of the sinking fund is calculated from the equation:

$P=c+\sum_{n=1}^{5} \frac{L_{a}(1+j)^{n}}{(i+i)^{n}}+\sum_{n=6}^{25} \frac{L_{b}(1+j)^{n}}{(1+i)^{n}}+\sum_{n=26}^{200} \frac{L_{c}(1+j)^{n}}{(1+i)^{n}}$

where:

$P$ is the terminal value (or present value) of the sinking fund in 1978 dollars

$C$ is the cost of the site stabilization option chosen

$L_{a}$ is the annual cost of long-term care for the first 5 years of administrative control after the site is stabilized

$L_{b}$ is the annual cost of long-tern care for the 6 th through the 25 th year of administrative control after the site is stabilized

$L_{C}$ is the annual cost of long-term care for the 26 th through the 200 th year of administrative control after the site is stabilized

$j$ is the rate of inflation expressed as a decimal fraction

$i$ is the interest rate expressed as a decimal fraction.

The components of the terminal vaiue can be illustrated by considering modest stabilization of the western site. Of the $\$ 7.4$ million needed at the time of site closure, $\$ 2.6$ million is needed in 1978 to stabilize the site. An additional $\$ 0.77$ million is needed to provide long-term care (assumed to be 
TABLE E.2-1. Sinking Fund Terminal Varues

Required to Finance Site

Stabilization and Long-Term

Care (in 1978 dollars)

Stabilization Plan Terminal Value (\$ millions)

Western Site

Minimal Plan

Modest Pian

Complex Plan

Eastern Site

Minimal Plan

Modest Plan

Complex Plan
5.3

7.4

12.6

8.5

11.8

14.3

paid annually at year end) for the first 5 years after the site is stabilized. An additional $\$ 1.6$ million is needed to provide long-term care from year 6 through year 25 when annual costs have decreased to $\$ 106,000$ in 1978 dollars. Finally, $\$ 2.5$ million is needed to provide long-term care from year 26 through year 200 when annual costs have decreased to $\$ 78,000$ in 1978 doliars. This last figure would not be greatiy increased if long-term care were assumed to continue beyond 200 years after site closure.

\section{E.2.1 Sinking Fund Payments}

The required sinking fund payments in dollars of constant purchasing power are shown in Table E.2-2 for each of the postulated stabilization alternatives. The burial ground is assumed to operate for 30 years, and an inflation rate of $6 \%$ per year and an interest rate of $8 \%$ per year on invested funds are assumed. The payments are adjusted so that each year's payment is approximately equivalent in dollars of constant purchasing power (assuming decommissioning costs escalate at the same rate as other costs). The payments do not total the required terminal value of the fund because the interest earned by investing the fund monies is not shown.

To determine the annual payments shown in Table E.2-2, the following procedure is used. The initial payment at the end of the first year of burial 
TABLE E.2-2. Example Annual Sinking Fund Payments for site Stabilization and Long-Term Care

\begin{tabular}{|c|c|c|c|c|c|c|}
\hline \multirow[b]{3}{*}{$\begin{array}{l}\text { Payment Date } \\
\text { (December } 3 ! \text { ) }\end{array}$} & \multicolumn{6}{|c|}{ Annual Payment (\$ thousands) } \\
\hline & & Western site & & & Eastern site & \\
\hline & $\begin{array}{c}\text { Minima } \\
\text { Stabilization }\end{array}$ & $\begin{array}{c}\text { Modest } \\
\text { Stabilization }\end{array}$ & $\begin{array}{c}\text { Complex } \\
\text { Stabilization }\end{array}$ & $\begin{array}{l}\text { Minimal } \\
\text { Stabilization }\end{array}$ & $\begin{array}{c}\text { Modest } \\
\text { Stabilization }\end{array}$ & $\begin{array}{c}\text { Complex } \\
\text { Stabilization }\end{array}$ \\
\hline 1948 & 25 & 34 & 59 & 39 & 55 & 67 \\
\hline 1949 & 26 & 36 & 62 & 41 & 57 & 70 \\
\hline 1950 & 28 & 39 & 66 & 44 & 61 & 74 \\
\hline 1951 & 30 & 41 & 70 & 47 & 65 & 79 \\
\hline 1952 & 31 & 43 & 73 & 49 & 68 & 83 \\
\hline 1953 & 33 & 46 & 78 & 52 & 73 & 88 \\
\hline 1954 & 35 & 48 & 83 & 55 & 77 & 94 \\
\hline 1955 & 37 & 51 & 87 & 58 & 82 & 100 \\
\hline 1956 & 40 & 54 & 93 & 62 & 87 & 106 \\
\hline 1957 & 42 & 58 & 99 & 66 & 92 & 112 \\
\hline 1958 & 44 & 61 & 105 & 70 & 98 & 119 \\
\hline 1959 & 47 & 65 & 111 & 74 & 103 & 126 \\
\hline 1960 & 50 & 69 & 118 & 79 & 110 & 134 \\
\hline 1967 & 53 & 73 & 125 & 84 & 117 & 142 \\
\hline 1962 & 56 & 77 & 132 & 88 & 124 & 150 \\
\hline 1963 & 59 & 82 & 140 & 94 & 131 & 159 \\
\hline 1964 & 63 & 87 & 149 & 100 & 139 & 169 \\
\hline 1965 & 67 & 92 & 158 & 106 & 146 & 178 \\
\hline 1966 & 71 & 98 & 168 & 112 & 155 & 189 \\
\hline 1967 & 75 & 104 & 177 & 119 & 165 & 201 \\
\hline 1968 & 80 & 110 & 188 & 126 & 175 & 213 \\
\hline 1969 & 84 & 116 & 198 & 133 & 185 & 225 \\
\hline 1970 & 89 & 123 & 210 & 141 & 196 & 239 \\
\hline 1971 & 95 & 130 & 223 & 149 & 208 & 253 \\
\hline 1972 & 100 & 138 & 236 & 158 & 220 & 268 \\
\hline 1973 & 106 & 146 & 250 & 167 & 233 & 284 \\
\hline 1974 & 173 & 155 & 265 & 178 & 248 & 302 \\
\hline 1975 & 120 & 165 & 282 & 189 & 263 & 320 \\
\hline 1976 & 127 & 175 & 298 & 200 & 278 & 339 \\
\hline 1977 & 134 & 185 & 316 & 212 & 295 & 359 \\
\hline
\end{tabular}


ground operation is $R_{1}$. At the end of the second year of operation $R_{1}(1+j)$ is paid into the fund. During the second year ( $i$ ) $R_{T}$ interest is earned on the invested fund. Thus, at the end of the second year of operation, the fund has a total of $R_{1}(1+i)+R_{1}(1+j)$ dollars.

A closed-form expression for the amount of money in the fund can be derived by considering each year's payment as a separate sinking fund. Thus, the first-year payment will be worth $R_{1}(1+i)$ at the end of year two and will be worth $R_{1}(1+i)^{n-1}$, or $R_{1}(1+i)^{2 g}$ dollars, at the end of the 30 years of operation of the burial ground. The second-year payment, $R_{1}(1+j)$, will earn compound interest for 28 years and will ultimately total $R_{1}(1+j)(i+i)^{n-2}$, or $R_{1}(1+j)(1+i)^{28}$ dollars. The total value of the sinking fund at the end of year $n$ must equal $P$, the terminal value of the sinking fund. Thus,

$$
P=R_{1} \sum_{a=1}^{n}(1+j)^{a-1}(1+i)^{n-a}
$$

For this example, $n=30$ years of operation of the burial ground.

The initial payment is:

$$
R_{1}=\frac{P}{\left[\sum_{a=1}^{n}(1+j)^{a-1}(1+i)^{n-a}\right]}
$$

The bth annual payment is $R_{b}=R_{1}(1+j)^{b-1}$, or:

$$
R_{b}=\frac{P(1+j)^{b-1}}{\left[\sum_{a=1}^{n}(1+j)^{a-1}(1+i)^{n-a}\right]}
$$

where $P$ is given by Equation E.1. 


\section{E.2.2 Provision for Premature Site Closure}

An important concern regarding the sinking fund financing alternative is discussed in Section 6.3 of volume 1. The concern is that sufficient funds for site stabilization and long-term care may not be collected if the disposal site closes prematurely. Two basic alternatives are indicated to help alleviate this concern. The first is an extraordinary initial cash payment prior to startup. The second is to design the payment schedule so that payments in early years are higher in constant dollars than payments in later years. In practice, it may be desirable to utilize a combination of both alternatives.

For this example, uniform sinking fund payments (in current dollars) are assumed over the 30-year operating life. The payments are shown in Table E.2-3 for each of the postulated stabilization alternatives. Payments are designed so that the accumulated funds with interest will equal the sinking fund terminal values shown in Table E.2-1. Payments are derived from the equation:

$$
R=\frac{p}{\sum_{a=1}^{n}(1+i)^{n-a}}
$$

where $R$ is the annual payment and $n$ equals 30 .

A1 though the payments are constant in nominal or current dollars, they decrease in dollars of constant purchasing power. Assuming that the payments are passed on to the customers, early users of the site would pay a larger share of the decommissioning costs than would later users. Adoption of uniform payments would clearly increase the sinking fund faster during early years of operation than the payment schedules shown in Table E.2-2. This approach may be desirable for the added protection it provides.

\section{E.3 PREPAYMENT OF ANTICIPATED DECOMMISSIONING COSTS}

The second decommissioning financing option is prepayment of all anticipated decommissioning costs prior to startup (i.e., January 1, 1948). If the simplifying assumptions of constant interest returns, and no changes in expected 
TABLE E.2-3. Uniform Annual Sinking Fund Payments (1948 to 1977)

Decommissioning Option

Western Site

Minimal Stabilization

Modest Stabilization

Complex Stabilization

Eastern Site

Minimal Stabilization

Modest Stabilization

Complex Stabilization
Annual Payment

(\$ thousands)
47

65

111

75

104

126

decommissioning costs, escalation rates, and operating life are made, the required prepayment can be readily calculated. The required prepayment is the terminal value of the fund multiplied by the 30-year $8 \%$ present worth factor (0.0994). The required prepayments for the various decommissioning modes are shown in Table E.3-1.

TABLE E.3-1. Required One-Time Payments for Prepayment of Decommissioning costs

Decommissioning
Option

Payment (\$ millions)

Western Site

Minimal Stabilization

0.53

Modest Stabilization

0.74

Complex Stabilization

1.25

Eastern Site

Minimal Stabilization

0.84

Modest Stabilization

1.17

Complex Stabilization

1.42 


\section{E.4 PAYMENT OF DECOMMISSIONING COSTS WHEN INCURRED}

The third financing option is payment of decommissioning costs only when they are incurred. Under this approach, the site operator is obiigated to pay all decommissioning costs as they are incurred.

It is informative to compute and compare the present value cost to the burial ground operator of site stabilization and long-term care costs, assuming these costs are paid only when actually incurred.

The present value, $P$, of a sum of money, $S$, to be paid $n$ years later is given by

$$
P=\frac{s}{(1+j)^{n}}
$$

where $j$ and $k$ are the inflation rate and the discount rate, respectively. (These rates are assumed to be constant over the $n$-year time period.) If a $6 \%$ inflation rate and an $8 \%$ discount rate are assumed, then the present value of decommissioning costs computed as of January 1,1978 , is the same as the terminal value of these costs, which is shown in Table E.2-1. This is because the assumed discount rate is identical to the interest rate used for the teminal value calculation. For companies with significant requirements for capital to expand their operations or to make improvements in plant or equipment, the discount rate is usually higher than the interest rate on invested funds. For discount rates higher than $8 \%$, the present value of decommissioning costs would be lower than the terminal value of these costs, which is shown in Table E.2-1.

Payment of decomissioning costs when incurred would likely be the preferred procedure for the site operator. This is not permitted now, however, and is not likely to be permitted in the future. 


\section{REFERENCES}

1. E. L. Grant, W. G. Ireson and R. S. Leavenworth, Principles of Engineering Economy, 6ith Edition, The Ronald Press Co., New York, NY, 1976.

2. Statistical Abstract of the U.S., U.S. Government Printing Office, 1977.

3. J. A. Carison, "Short-Term Interest Rates as Predictors of Inflation: Comment," The American Economic Review, p. 471, June 1977. 
APPENDIX F

\section{SITE/WASTE STABILIZATION DECOMMISSIONING ACTIVITY DETAILS}

This appendix provides details to support the description of site/waste stabilization methods and procedures in Section 10 of volume 1 . The basic information needed to select and evaluate stabilization plans for the generic burial grounds considered in this study is included here. Detailed descriptions of radionuclide release mechanisms and of prospective site/waste stabilization techniques are given in Section F.7. Quality assurance details for stabilization activities are discussed in Section F.2.

\section{F.1 RADIONUCLIDE RELEASE MECHANISMS AND PROSPECTIVE SITE/WASTE STABILIZATION}

\section{TECHIIQUES}

To select stabilization plans for the generic burial ground sites considered in this study, radionuclide transport mechanisms capable of initiating a release of radioactivity from a burial site (i.e., release mechanisms) are identified and site/waste stabilization techniques that can be used to control these release mechanisms are evaluated. Release mechanisms and stabilization techniques are identified in Section 10.1 of Volume 1. Table 10.2-1 of Section 10.2 presents the results of an evaluation of the general effectiveness of the various stabilization techniques in controlling the individual release mechanisms. Table 10.2-2 presents approximate costs and related information for the stabilization techniques. The following descriptions of the release mechanisms and stabilization techniques are presented to clarify and expand on the information presented in Sections 10.1 and 10.2 .

\section{F.1.1 Radionuclide Release Mechanisms}

Radionuclides can migrate to the biosphere from a burial ground along a variety of pathways. These pathways consist of one or more radionuclide transport mechanisms, acting in series. In this study, the transport mechanism that acts to initiate the movement of radionuclides from a burial trench is referred to as a release mechanism. Release mechanisms considered in this study are described on the following pages. 


\section{F.1.1.1 Geomorphological Release Mechanisms}

Geomorphological release mechanisms are those in which the release of radionuclides is a direct result of the shaping or reshaping of the earth's surface by natural forces. Activities of man may have an influence on the geomorphological processes involved.

The rate of radionuclide movement as a result of individual geomorphological processes varies from site to site, depending on climate, topography, past burial practices, human activity in and around the site, and other variables. Exposure of buried waste materials as a result of the removal of overburden soil is the major concern for all geomorphological release mechanisms. The possibility of contaminated soit being transported away from the site is also a concern. This soil may be contaminated because of past burial practices (e.g., by the rupturing of waste containers during trench filling) or the prior action of other release mechanisms (e.g., hydrological displacement, plant uptake, etc.). The geomorphological release mechanisms considered in this study are water erosion, wind erosion, subsidence, frost action, and mass wasting.

Erosion (Water). Water erosion is the wearing away of the earth's surface by flowing water.

The rate of water erosion at a given sjte is related to climate, topography, soil properties, ground cover, and human activities prevalent at or near the site. Possible methods for control of water erosion include surface water control, modification of soil properties, adjustment of site topography, and maintenance of an erosion-resistant surface (either vegetation cover or erosion-resistant soil and/or rock cover).

Water erosion is mainiy of concern at the humid eastern site, where it can remove significant overburden in a relatively short period of time. (See Section C.l.1 for details.) The topography, soil permeability, and low annual precipitation at the arid western site make significant water erosion there extremely unlikely. (1) (Water erosion from flash floods at the reference western site is considered extremely unlikely based on the climate and topography of the site. However, it could occur at other western sites.) 
Erosion (Wind). Wind erosion is the wearing away of the earth's surface by moving air. Removal of overburden soil may occur as a direct result of wind action, or indirectly as a result of wind damage to vegetative ground cover.

The site variables relating to the rate of wind-erosion damage include climate, topography, soil properties, ground cover, and human activities at or near the site. Possible methods for control of wind erosion include local wind reduction (i.e., use of wind breaks), modification of soil properties, and maintenance of an erosion-resistant surface (either vegetation or gravel and/or rock cover).

The arid western site has a higher potential for wind-erosion damage than the humid eastern site, because of the relative sparsity and fragility of vegetation and the lack of soil cohesiveness at the western site. In dry areas where the surface has been disrupted, wind erosion may remove large amounts of overburden in a relatively short time (i.e., potholes up to $1 \mathrm{~m}$ in depth may form in only a few years). Wet areas such as the eastern site do not generally exhibit such marked wind erosion effects.

Subsidence. Subsidence refers to the sinking or collapse of the ground surface. This may occur generally, over a large area, or may take place in relatively snall areas, resulting in sink-holes. During a rapid subsidence event (surface collapse), waste materials or contaminated soil may be thrown into the air, causing local surface contamination and a temporary cloud of contaminated dust. This allows for further dispersion of contamination by other mechanisms, particularily wind or water. Subsidence can also alter the surface features in such a way that erosion and moisture infiltration rates are increased.

Subsidence in burial grounds is a function of burial practices, soil type, and waste packaging and compaction. Bulky, noncompacted wastes tend to settle in time under the weight of overburden, as does insufficientiy compacted fill. Waste package degradation can also lead to subsidence. The nature of the overburden materials, as well as methods of trench capping, can affect the degree of subsidence. Moisture flow through the waste trench 
matrix can redistribute material, resulting in subsurface cavities that subsequently collapse. Subsidence control measures include close placement of waste packages (to minimize voids), compaction of waste materials and overburden, reduction of moisture infiltration, and incorporation of structural bridging strength in the trench cover (i.e., use of a rigid structural trench cover that would bridge over subsiding areas).

The extent of subsidence damage at the two sites considered in this study is estimated to be similar, assuming similar burial practices. However, because of the slower rate of package degradation in dry areas, subsidence caused by degradation of waste materials in the trenches will likely occur over a longer period of time at the western site. It is estimated that, with present burial practices, as much as $30 \%$ of trench volume is void space. (3) This suggests the probability of significant subsidence probiems at any site.

Frost Action. Frost action, or heaving, is the result of water freezing in the soil profile. Expansion during freezing heaves up material above the frozen zone and creates bulges in the surface. Over periods of years, frost heaving can push material up through the soil profile to the surface. In a burial ground, this can result in wastes or other contaminated material being brought to a shallower level in the soil profile, where the radionuclides are more susceptible to movement by other transport mechanisms. Another result of frost action is disruption of the overburden, leading to increased erosion (both wind and water) and moisture percolation.

Frost action is a function of climate (temperature and precipitation), site drainage, soil properties (e.g., permeability and moisture retention), and depth in the soil profile (i.e., the effects are limited to the depth of frost penetration and are strongest at or near the ground surface). The extent of frost damage can be reduced by increasing the depth of waste burial, decreasing the permeability and moisture retention capacity of the soil, and increasing water drainage from the site.

Frost damage is of greater concern at the humid eastern site than the arid western site because of the colder and wetter winters at the eastern site. However, frost damage at either site is anticipated to be relatively minor. 
Mass Wasting. Mass wasting is defined as "the gravitative movement of rock debris (or sediment) downslope, without the aid of a flowing medium of transport such as air at ordinary pressure, water, or glacier ice." (4) The speed of mass wasting varies from sudden slides to very slow downslope movement called creep. (5)

Mass wasting is primarily controlled by topography, although other factors such as climate, seismicity, soil properties, and burial practices (e.g., compaction of filled trenches) can influence the rate of mass wasting at a given site. Possible techniques for control of mass wasting include reduction of moisture infiltration into sediments (saturation of sediments reduces internal friction, thus increasing potential for flow) and adjustment of site topography.

For the burial ground sites considered in this study, mass wasting is not anticipated to cause large-scale damage because the overall ground slopes are relatively mild. However, small areas with steep slopes may experience localized damage.

\section{F.1.1.2 Hydrological Release Mechanisms}

An important factor affecting the containment capability of a burial ground is the degree to which ground and surface water can contact the waste and subsequently cause migration of the confined radionuclides. Water is the principal mechanism that has been observed to cause radionuclide migration away from burial trenches at existing sites (see Section 3.2.1.). A hydrological assessment is currentiy required as a portion of the licensing procedure for each site. This assessment provides an estimate, prior to use of the burial ground, of: 1) the degree to which ground and surface water will contact the waste following burial, 2) the pathway of the water away from the burial site, 3) the ion-exchange or adsorptive capability of the materials aiong that path, and 4 ) the extent to which the radionuclide content of offsite ground and surface waters will be affected by the burial grounds.

The hydrological release mechanisms considered in this study are groundwater intrusion, moisture percolation, and overflow. 
Ground Water. Radionuclides may be transported by ground water (saturated flow) in several ways. In areas of high water table, ground water may occasionally or seasonally flow through buried waste, (7) thus providing a direct transport mechanism for radionuclide movement. More often, ground water will not come into direct contact with the waste but will receive radionuclides indirectly through the action of water percolating (unsaturated flow) through the wastes to the ground water (see Percolation below).

Variables relating to the degree of radionuclide migration via groundwater intrusion include climate, hydrology (e.g., groundwater depth and flow rate), soil and sediment properties (e.g., percolation rates, sorption and ionexchange characteristics), waste characteristics (e.g., physical and chemical form, and packaging), and topography. Surface soil cover and human activities at or around the site can also have an effect. Possible methods for control of radionuclide migration by groundwater intrusion include modification of groundwater flow (e.g., using curtain walls or trench dams to divert and/or reduce local groundwater flow) and modification of soil and/or waste properties to reduce the flow and/or leach rate of intruding ground water. Care in site selection is, of course, the preferred method for controlling groundwater intrusion.

In general, groundwater intrusion is of more concern at eastern sites than at western sites, because of the shallower leve? of the water table in the east. Groundwater intrusion is an important release mechanism at the humid eastern burial ground site ${ }^{(8)}$ but is considered to be extremely unlikely at the arid western site.

Percolation. Percolation of rain water and snow melt into and through burial ground sediments (unsaturated flow) provides a mechanism for radionuclide transport. Percolation may be in a downward, lateral, or upward direction, depending on a number of variables. In most areas, however, the general trend is for flow to be downward to the water table.

The rate of radionuclide migration as a result of percolation is a function of climate, topography, soil and sediment properties, waste characteristics, and ground surface cover. Human activities can also have a bearing on 
percolation rates (e.g., disruption or modification of surface cover, modification of soil and sediment properties, topography alteration, etc.). Possible percolation control methods include establishment of a relatively impermeable ground surface cover, reduction of soil and sediment permeability, and drainage of incident precipitation away from the site.

Percolation generally presents more potential for radionuclide movement at eastern sites than at western sites, because of the larger volume of incident precipitation at eastern sites.

Overflow. In some areas, impoundment (trapping) of infiltrating water in burial trenches produces a saturated condition that can result in eventual overflow of water from the trenches. This impoundment is the result of burial in relatively impermeable sediments. The more permeable overburden allows water infiltration (percolation) into the waste at a rate that exceeds drainage out of the trench bottom. The result is subsurface moisture migration, due to the hydrostatic head of the trapped water, and possible surface flow of overflow seepage. (9)

The rate of radionuclide release as a result of overflow is largely a function of climate (i.e., incident precipitation available for infiltration), topography (i.e., site drainage characteristics), and geology (i.e., permeability of sediments). Actions taken to control radionuclide release by overflow can include surface water control, surface sealing of trenches, and removal of trapped water from trenches (by pumping from collection sumps).

Overflow presents a greater potential for radionuclide movement at eastern sites than at western sites, due largely to the higher volume of incident precipitation and the lower permeability of the soil in the east. However, because of the variability of geological properties between and within sites, site-specific data must be carefully analyzed to determine the possible impact of overflow, and generatization is inadvisable.

\section{F.T.1.3 Biological Release Mechanisms}

Biological action can be a significant factor in the transport of radionuclides from a burial ground. The species involved and the relative rates 
of radionuclide movement vary from site to site, but the basic mechanisms can conveniently be described as either plant uptake or animal action.

Plant Uptake. Buried wastes can be infiltrated by the roots of plants growing in the burial site. Some plant species, such as corn or certain grasses, have shallow root systems; other plant species, such as alfalfa or sunflowers, have tap-root systems that can penetrate the soil to depths in excess of $1 \mathrm{~m}$. The plant roots absorb radionuclides, which are then transported throughout the plant. $(10,11)$ Thus, radionuclides can be brought to the surface by plants, becoming available for subsequent transport by a variety of mechanisms (e.g., wind transport of plant debris, ingestion of plant materials by animals, etc.). Plant roots are also instrumental in the mechanical breakdown of buried wastes and overburden materials. Wedging of plant roots into these materials tends to break them up, increasing erosion and water percolation rates. Most reports of biological interaction with wastes have involved piants. (11)

Variables relating to the rate of radionuclide migration by plant uptake include climate, plant species (shallow-rooted plants generally will not penetrate into buried wastes), soil and sediment properties, waste characteristics, and burial practices. Possible methods for controlling plant uptake include vegetation management practices, modification of soils and sediments, and introduction of barriers between plant roots and buried wastes.

For the burial sites considered in this study, the overall radionuclide movement caused by plant uptake is anticipated to be unimportant oniy if the overburden depth is maintained and the site vegetation is managed (i.e., problem species are controlled).

Animal Action. Digging and burrowing animals can penetrate the overburden into burjed wastes. (2) The wastes can then be ingested or otherwise scattered, (12) increasing the rate of radionuclide transport by other mechanisms. In addition, disruption of the surface cover and overburden by animal action increases erosion and moisture percolation rates.

The rate of radionuclide migration resulting from animal action varies from site to site, depending on the animal species present, soil and sediment 
properties, ground cover, waste characteristics, and burial depth. Some possible control strategies are elimination of troublesome species, use of overburden materials that inhibit burrowing activities, or deeper burial to place waste below the range of burrowing.

For the burial ground sites considered in this study, the overall radionuclide migration caused by animal action is anticipated to be unimportant in comparison to migration caused by other release mechanisms. However, small localized "hot spots" can result from animal action.

\section{F.1.1.4 Human Activity Release Mechanisms}

Future human activities at burial ground sites may cause inadvertent radionuclide migration. These activities might be undertaken for a variety of reasons. For this study, human activities that can disturb buried waste are classified into two major groups: excavation (including digging, drilling, grading, and blasting) and agriculture.

Excavation. Excavation into radioactive waste burial grounds can release significant quantities of radionuclides. Inadvertent excavation can occur in cases where a lack of knowledge of the buried wastes exists, or where information concerning the location of the wastes is inaccurate.

The extent of radionuclide movement resulting from excavation depends on the depth and extent of the excavation, waste characteristics, and the time elapsed since waste placement (i.e., the radionuclide decay of the waste). Both administrative and physical measures can be used to reduce the potential for radionuclide movement due to excavation. Possible administrative measures include controlled use of the site, use of permanent trench-location markers, or fencing of the site to provide exclusive access. Physical measures are mainly centered on modification of the soil profile to increase the difficulty of any excavation near the buried wastes (e.g., use of subsurface hard or rock layers to deter excavation efforts).

Human excavation is judged to be an important release mechanism for any decomrissioned burial ground, including the two sites considered in this study. 
Agriculture. Agricultural activities in a burial ground can cause radionuclide migration in several ways. Field preparation and tillage can bring contaminated soil to the surface, providing for subsequent transport by erosion. The growing of crops in areas with subsurface contamination can result in radionuclide uptake by plant roots, thus introducing radionuclides into the food chain and also returning radionuclides to the ground surface in crop residues. Irrigation of crops and surface tillage at burial sites increases the percolation of moisture through the soil profile, thus hastening radionuclide migration. Processing of contaminated agricultural products leads to dispersion of radionuclides in liquid and gaseous effluents.

Control of radionuclide migration caused by agricultural activities can be administrative or physical. Administrative controls can ban agricultural activities at the site, or limit them to those with the lowest potential for disruption of the buried waste. Possible physical controls include increasing burial depth to reduce the potential for plant-root intrusion, placing barriers in the soil profile to exclude plant roots and limit percolation of water, and modifying the ground surface to limit or eliminate the agricultural potential of the site.

The potential for radionuclide movement caused by agricultural activities is judged to be significant, depending on the degree and type of agriculture practiced in the burial ground areas. It is considered likely that administrative controls will be applied to decommissioned burial grounds to reduce this potential to an acceptable level.

\section{F.1.1.5 0ther Considerations}

It is possible to postulate other considerations that could be of concern at specific sites, depending on projected land use. For example, if Tand use plans include regular human presence in the area, or human presence for extended periods of time, cumulative radiation doses from buried waste might become significant. In this case, measures to reduce radiation exposure to these individuals would undoubtedly be instituted. In the case of unrestricted land use, additional measures may be required to reduce the effects of inadvertent damage caused by onsite human activities. Detajled evaluation 
of these other considerations is beyond the scope of this study, however, and they are not considered further.

\section{F.1.2 Prospective Site/Waste Stabilization Techniques}

Various stabilization techniques can be used to reduce the potential for radionuclide migration from LLW burial grounds. Each stabilization technique is useful in providing control over certain release mechanisms, as shown in Table 10.1-1 of Volune 1. Combinations of several stabilization techniques can be used to provide various degrees of control over all potentially significant release mechanisms for a given site. Several stabilization techniques in combination can also be used to provide protection against an individual release mechanism that has a high potential for initiating radionuclide migration from a site.

Interactions between stabilization techniques used in combinations can change the effectiveness of an individual technique, either in a positive or a negative way. These interactions must be taken into account when combinations of techniques are used.

Each of the stabilization techniques considered in this study is summarized in Section 10.1 of Volume 1 and is discussed here, in detail, to further clarify what each technique involves (in terms of methods, materials and costs[a]), how each one works, and how each one might be applied to a given site. The individual stabilization techniques are identified by code letters that also appear in Tables 10.1-1, 10.2-1, and 10.2-2. These code 1etters are used in Section 10 to identify combinations of techniques that go together to form stabilization plans.

A. Subsurface Rock Layer. A subsurface rock layer is a thick blanket of rock or cobblestone that is placed in the soil profile over the buried wastes. It is topped with a material to prevent soil from sifting down into the void spaces between the rocks. The area is then backfilled with topsoil to cover the rock 3 ayer and to provide a base for surface stabilization.

[a]Costs include material, equipment and labor, and are adjusted for 1978 dollars. Unless otherwise noted, costs are based on stabilization of an average burial trench, as described in Section 7 of Volume 1. Stabilization of larger areas will result in reduction of per-unit costs. 
The layer is composed of 40-mm or larger diameter rock or cobbles placed to a thickness of 0.3 to $1.0 \mathrm{~m}$. Plastic or other composite sheeting, layers of progressively smaller gravel or rock chips, or a polymeric or asphaltic sealer can be used to prevent topsoil from sifting down between the rocks. At sites where the waste is covered by a minimum soil depth, the rock layer can be taid directly on the surface with a minimum of preparation (leveling and removal of vegetation and debris), and then covered with backfill hauled to the site. At sites with thicker soil cover over the wastes, some of the soil cover can be removed before placement of the barrier. This removed soil is then available for use as backfill over the emplaced layer.

The rock layer provides a barrier to digging and burrowing animals, (11) as well as a deterrent to human excavation, by creating a layer in the soil profile that is much more difficult to penetrate than the surrounding earth. The layer is effective in preventing damage from agricultural tiliage and is not damaged by ordinary agricultural activities when buried below the maximum tillage depth. The barrier protects against penetration by plant roots, because of the hostile environment presented to the roots by the rocks in the layer and the void spaces between them. The rock layer also provides a lower limit to erosive action by presenting a relatively erosion-resistant surface if uncovered, and thus can be used as a secondary erosion control. Increasing the thickness of the layer generally increases its effectiveness against all of these release agents.

The initial cost per trench is estimated to be $\$ 13,000$ to $\$ 37,000$, depending on the thicknesses of the rock layer and the backfill, and based on adjusted costs of $\$ 9.95 / \mathrm{m}^{3}$ for graded stone $f i 11$ hauled $8 \mathrm{~km}$ and $\$ 3.57 / \mathrm{m}^{3}$ for backfill hauled an average of $3.2 \mathrm{~km}$. (13) No maintenance of the layer is assumed. It is anticipated that the layer will remain at least $75 \%$ effective for a period of 80 to 200 years and will not need to be replaced during the long-term care period following stabilization.

B. Subsurface Hard Layer. A layer of hard material can be placed in the soil profile over the buried wastes, (14) similar to the subsurface rock layer. 
The area is then backfilled with topsoil to cover the layer and to provide a base for surface stabilization. (The hard layer may also be placed on top of a rock layer to fortil a combination barrier.)

The layer is composed of any of a variety of materials, including concrete, (15) asphalt, asphait-soil, soil cement, bentonite or other clays, (16) and other mineral or chemical materials. The thickness of the layer is dependent on the material or materials used, but is generally in the range of 20 to 200 im. Soil can be removed from the surface of the burial ground before the layer is emplaced or the layer can be laid directly on the prepared surface. Care must be taken to compact the area to provide adequate support for the hard layer, to prevent subsequent deterioration by settling and cracking.

The hard layer provides a physical barrier to digging and burrowing animals, human excavation, and plant-root penetration by presenting a relatively impenetrable layer in the soil profile. In addition, it can provide protection against subsidence, depending on the materials and methods used, because of the structural strength of the emplaced barrier. A hard layer also provides protection against hydrological release mechanisms, depending on its placement with respect to the various water movements in and around the wastes. Finally, the subsurface hard layer provides a lower limit to erosive action, similar to the rock layer.

The initial cost per trench for a hard layer is estimated to be $\$ 8,600$ to $\$ 35,000$. This is based on the estimated cost for similar layers on the surface, with backfill added as described in item $A$ above. The range of costs represents a range of materials from soil cement or asphalt-soil to 0.1-mthick concrete, and the reference costs ${ }^{(17)}$ are adjusted for trench size. As with the subsurface rock layer, no maintenance is assumed, and the layer will not need to be replaced during long-term care because of the anticipated useful tife of 80 to 200 years. A subsurface hard layer is more difficult to construct than a subsurface rock layer, because of the tighter specifications - and standards required.

C. Subsurface Membrane. A thin membrane can be placed in the soil profile over the buried wastes. The membrane can be placed on earth fill 
similar to the subsurface layers discussed previously or, if desired, it can be placed directiy on top of and around waste containers. It is then covered with topsoil to protect it and to provide a base for surface stabilization.

The layer can be composed of plastic, (18) rubber or other composite sheeting, or can be a thinly applied coating or injected layer of asphaitic, polymeric, or other chemical material. (14) Layers composed of sheeting are emplaced in the same manner as the subsurface layers discussed previously. Coatings are applied by spraying them directly onto the soil, where they set up to form the membrane. For an injected membrane, the material is pumped into the soil profile at the level desired, where it sets up to form the layer.

Depending on the materials used, the membrane presents a barrier to animal burrowing and plant-root penetration and provides a lower limit to erosive action, similar to the layers discussed previously. If the membrane is of adequate strength, it reduces the incidence of "pothole" subsidence by supporting the earth cover over small void areas and also by restricting the flow of moisture that, in some cases, tends to increase subsidence. The restriction of moisture flow provides protection against the hydrological release agents by reducing moisture infiltration into the wastes.

Using costs estimated for a variety of synthetic polymer membranes, (19) and adjusting for trench size and for a minimum soil cover of $0.5 \mathrm{~m}$, the initial cost of a subsurface membrane is estimated at $\$ 4,800$ to $\$ 14,000$ per trench. No maintenance of the membrane is assumed, and its useful iife is estimated to be 10 to 40 years, depending on the material used. Therefore, it is anticipated that membrane replacement will be required during the longterm care period.

D. Surface Rock Cover. A rock layer can be placed on the surface of a burial site as a ground cover. The layer is composed of rocks or large gravel. It is placed directly on the surface to a depth of 0.15 to $0.4 \mathrm{~m}(20)$ after a minimum of ground surface preparation (leveling and removal of vegetation and debris). The surface of the rock is leveled to obtain a layer of uniform specified depth. 
The rock layer provides protection against erosive action by presenting a relatively erosion-resistant surface. (21) Aninal burrowing is restricted by the difficulty of digging through the layer, ${ }^{(22)}$ and inadvertent human excavation is also deterred. Agriculture is essentialiy eliminated by the rock cover.

The initial cost per trench is estimated to be $\$ 3,000$ to $\$ 8,100$, depending on the thickness of the cover. This is based on an adjusted cost of $\$ 7.40 / \mathrm{m}^{3}$ for gravel hauled $8 \mathrm{~km}$ to the site. (13) Maintenance costs are estimated to be $\$ 90$ to $\$ 470$ per trench per year, or 3 to $5 \%$ of the initial cost, which is equivalent to a useful 1 ife of 20 to 35 years with no maintenance. It is anticipated that, with proper maintenance, the useful life of the cover will be greater than 200 years and the cover will not be replaced during the long-term care period.

E. Surface Hard Cover. A layer composed of a hard material can be placed on the surface of a burial ground, similar to the surface rock cover, to form a surface hard cover. (21) It can be constructed of asphalt, concrete, paving blocks, or other suitable material. The thickness of the cover is anticipated to be in the range 20 to $200 \mathrm{~mm}$, depending on the material used, the degree of structural strength desired, and other variables. The hard surface cover is placed directly on the surface of the burial ground after site preparation (clearing and leveling of the area and compaction to provide adequate support for the layer). Provision is made for arainage of rain water and snow melt from the surface. Conventional techniques for placement of materials are used.

The hard surface cover provides protection against erosive action by presenting a relatively erosion-resistant surface. If the construction is of sufficient structural strength, voids created by subsidence are bridged by the cover, reducing the impact of subsidence. The surface is unsuited to plant growth, thus eliminating plant-root penetration and agricultural concerns. The hard surface is aiso a deterrent to animal burrowing and to human excavation. Infiltration of percolating water into the wastes is restricted by the cover; this also reduces the potential for overflow seepage of trench water. Groundwater infiltration into the wastes is oniy reduced where the 
increased drainage due to the surface cover is sufficient to lower the local water table; thus, control of groundwater intrusion is not attributed to this stabilization technique.

To maintain the effectiveness of a surface hard layer, a certain amount of upkeep is necessary. Cracks and other damage to the layer must be repaired. Without this upkeep, the effectiveness of the layer is severely reduced, particularly in preventing water percolation.

Using cost estimates for a range of materials from soil cement or asphaltsoil to $0.1-m$-thick concrete ${ }^{(17)}$ and adjusting for trench size, the initial cost per trench is estimated to be $\$ 3,700$ to $\$ 25,000$. Maintenance costs are estimated to be $\$ 180$ to $\$ 2,000$ per trench per year ( 5 to $8 \%$ of initial cost), equivalent to a useful 1 ife of 12 to 20 years with no maintenance. It is anticipated that the useful life of the cover will be 40 to 100 years with proper maintenance, after which the cover is assumed to be replaced.

F. Capping Soil Properties Modification. The incorporation of various soil amendments into the capping soil in an LLW burial ground can modify the properties of the capping soil. The type and amount of soil amendment used varies with the existing soil properties, the properties of the amendment, and the results desired.

Various soil amendments can be used to modify capping soil properties, including clays, sand, gravel, chemicals, and organic materials. Soil tests are made to determine the type and amount of the amendment needed to obtain the desired capping soil properties. The area is prepared by leveling, removing vegetation and debris, and tilling as necessary. Soil amendments are spread over the area in the specified amounts and incorporated into the soil by tilling. After the amendments are sufficiently mixed into the soil the surface is graded, compacted, and contoured as desired. A surface cover (vegetative or other) is then applied.

Modification of capping soil properties can be used to increase the erosion resistance of the surface, increase water runoff from the site, and reduce percolation and moisture retention in the soil. Erosion potential can be decreased in several ways, including increasing cohesion between surface 
soil particles and increasing soil-particle size. Since soil moisture plays an important role in both frost heaving and mass wasting, the rate and extent of damage caused by both is decreased by reducing moisture retention in the soil. Reduction of water percolation and resulting overflow in the burial ground is accomplished by reducing soil permeability and increasing drainage, thus making less moisture available for these mechanisms. Modification of soil properties is, in some cases, also effective in limiting or controlling plant growth, reducing the extent of plant-root intrusion into buried wastes.

The initial cost for modifying capping soil properties is estimated to be $\$ 3,400$ to $\$ 13,000$ per trench. This is based on the addition of a $0.1-m-$ thick equivalent layer of soil conditioning material at 1 to 5 times the cost of washed sand delivered $8 \mathrm{~km}$ at $\$ 9.10 / \mathrm{m}^{3}$. (13) Material costs will vary depending on the transport distances involved. Tilling costs are estimated to be equivalent to fine grading of a site, with three passes with a motor grader, at $\$ .35 / \mathrm{m}^{2}$. (23) Maintenance costs are anticipated to be low but are not estimated, as maintenance is anticipated to be performed only when site surveillance indicates that it is necessary. The useful life of this treatment, with necessary maintenance, is expected to be greater than 200 years and, thus, replacement is not required during long-term care. The application of this technique is anticipated to be very straightforward and, consequentiy, quite easy.

G. Backfill and Compaction. Backfill can be added to the surface of a burial ground and then compacted. The backfill used is generally selected to provide a suitable base for subsequent surface stabilization. The fill is spread on the area to the desired depth and is then compacted either by packing the area using heavy rolling equipment (e.g., a sheepsfoot roller, [a] wobbly-wheel rolier, ${ }^{[b]}$ or road roller), or by vibrating the earth with vibrating baseplate compactor to effectively shake the soil particles and waste materials into a more compact configuration. Both compaction methods can be used in combination. In addition, other measures can be taken to aid in compaction, the most common being the use of water sprays to wet the soil to be

[a]A cylindrical steel drum to which knob-headed spikes are fastened. [b]A roller with freely suspended pneumatic tires. 
compacted. Littie or no surface preparation is needed prior to compaction and backfilling of an area, although removal of vegetation and debris is desirable. Care must be taken during backfilling and compaction to avoid disruption of waste materials that can result from the operation of heavy equipment in unstable areas (i.e., areas where the weight of the equipment may initiate further subsidence), but this technique is generally easy to use. Reference 24 provides a detailed treatment of fill compaction.

Backfilling and compaction can be used as a control measure against subsidence. Compaction reduces the extent of subsidence caused by future settling, and backfill returns the surface to its original level and contour. Compaction probably also has some effects on plant growth and moisture percolation, but these are likely to be temporary and are not considered here.

The initial cost for backfill and compaction is calculated to be $\$ 7,200$ to $\$ 12,000$ per trench, based on the following assumptions: 1) common borrow is hauled 3 to $8 \mathrm{~km}$ to the site, 2) an average $0.5-\mathrm{m}$ thickness of $\mathrm{fill}$ is added, and 3) the fill is compacted with a sheepsfoot or wobbly-whee] roller. The cost of obtaining and hauling the backfill is $\$ 3.57$ to $\$ 5.27 / \mathrm{m}^{3}$ and the cost of compaction, allowing for one to two times the normal compaction effort, is $\$ 1.67$ to $\$ 3.33 / \mathrm{m}^{3}$. Maintenance costs during long-term care are not estimated because maintenance will be performed only when necessary, as site surveillance indicates. Assuming that necessary maintenance is performed, the useful life of this treatment is expected to be greater than 200 years.

H. Site Topography Adjustment. Site topography adjustment is the grading, scraping, or other movement of surface soils to alter site contours.

Burial ground topography is adjusted using standard earthmoving and surface contouring techniques. The only difference between contouring activities in a burial ground and standard contouring procedures is that extra care must be exercised in burial ground sites to avoid disturbance of buried wastes, which can result in the inadvertent release of radionuclide contamination. After completion of a contouring operation, the surface is stabilized as desired, using one of the surface stabilization techniques described in this section. 
Adjustment of site topography can be very effective in reducing radionuclide migration. Topography is a factor in both wind and water erosion, and adjustment therefore provides a method of reducing erosion damage. Topography adjustment is a means of controliing runoff from rainfall and snow melt, (25) and therefore is useful in adjusting the hydrological parameters of a site. Reduction of percolation also reduces frost heaving by reducing moisture retention in the soil. Mass wasting is a function of soil moisture and surface slope, and therefore can be controlled by topography adjustment.

Assuming that an average of $0.5 \mathrm{~m}^{3}$ of soil is moved per square meter of surface area, the initial cost per trench is estimated at $\$ 1,800$ to $\$ 3,800$, depending on the equipment used. This is based on an adjusted cost of $\$ 1.33$ to $\$ 2.77 / \mathrm{m}^{3}$ for site grading. (23) Annual maintenance costs during longterm care are anticipated to be 3 to $5 \%$ of the original cost, or $\$ 50$ to $\$ 190$ per trench. With proper maintenance, the useful life of this treatment is anticipated to be greater than 200 years.

I. Increased Capping Thickness. This technique simply involves adding soil to the surface of a burial ground to increase the depth of the buried wastes in the soil profile.

To increase capping thickness, additional backfjll is applied to the surface of a burial ground with little or no surface preparation. (The surface may be cleared of vegetation and debris, depending on circumstances at the site.) The backfill is hauled in, dumped, and graded to form a layer of uniform specified depth. Standard earthmoving techniques are used. Compaction of the added fill may be accomplished using the techniques described above for Backfill and Compaction. The new surface can be graded to preserve the original site contours, or new contours can be established. After the operation is completed, the surface is revegetated or otherwise stabilized.

Increasing the capping thickness over buried wastes can be used to reduce radionuclide migration due to biological (plant and animal) action, subsidence, frost heaving, and human activities. The extent of significant surface effects resulting from subsidence is reduced by increasing the depth of fill. Subsurface voids may still collapse, but the increased volume of overburden provides 
more material to fill the voids. This reduces the incidence of surface ruptures, or breaches, that expose contamination or increase percolation and erosion rates. Frost heaving in the waste is reduced as the depth of overburden increases, because the insulating effect of the backfilt prevents freezing below a certain depth. (This depth varies with minimum surface temperature but is generally less than $1 \mathrm{~m}$ in the 48 contiguous United States.) Penetration of the wastes by biological action (animal burrowing or plantroot penetration) is reduced as the depth to the wastes increases. The chance for inadvertent human disturbance of the wastes also decreases as the depth increases.

The initial cost per trench for increasing capping thickness is estimated to be $\$ 4,900$ to $\$ 7,200$, based on common borrow hauled 3 to $8 \mathrm{krm}$ to the site and spread to an average thickness of $0.5 \mathrm{~m}$, with no compaction. (13) The treatment is assumed to be maintained as needed during long-term care, as indicated by site surveillance, and so maintenance costs are not estimated. A useful life of over 200 years is anticipated for this treatment.

J. Improved Capping Drainage. Capping drainage improvement refers to the construction of an engineered drainage system in the capping soi $i$ of the burial ground. This system routes runoff from incident precipitation away from the burial trenches.

After a civil survey of the site and an analysis of the drainage requirements, a drainage system is designed and installed. Runoff from rain water and snow melt is channeled away from the burial ground by a system of pipes and/or trenches. Surface waters are drained, if desired, in the same manner. Pipes and trenches can be sealed, where necessary, to prevent leakage that can percolate into the soil. Installation of the drainage system is accomplished using standard construction techniques.

Improvement of capping drainage reduces moisture percolation and any subsequent buildup of soil moisture in the burial ground. 26,27$)$ The hydrological parameters of a site are altered by drainage: percolation of surface runoff is reduced, the potential for overflow seepage is decreased, and the local level of the water table can be reduced in areas where percolation significantly 
influences the groundwater flow. Reduction of soil moisture also reduces frost heaving and mass wasting, as previously discussed.

Costs for capping drainage vary with the type and extent of the system used, and range from $\$ 10 / \mathrm{m}$ for berms or small drainage ditches to $\$ 100 / \mathrm{m}$ for narrow gravel-filled diversion trenches. (26) Assuming that one ditch is constructed along the side of each buriat trench and another is located at one end of the trench, the initial cost for such a system is estimated to be $\$ 1,700$ to $\$ 17,000$ for an average-size trench. Required annual maintenance is anticipated to average about $5 \%$ of the initial cost, or $\$ 90$ to $\$ 850$ per trench per year. The useful 1 ife of the system is anticipated to be over 200 years, assuming regular maintenance.

K. Peripheral Drainage and Diversion. Peripheral drainage and diversion is the interception and diversion of surface and/or ground waters either at the site boundaries or outside of the site. Ditches for drainage of surface waters can be iined to prevent leakage if desired, but ditches used to intercept ground water are not lined to allow the water to seep into the ditch.

As with improving capping drainage, a civil survey and subsequent analysis are made to determine requirements. The resulting design is then constructed using standard earthmoving techniques. The ditch banks are stabilized using one of the surface stabilization techniques discussed in this section.

This technique alters periphera? water flows to reduce their effects in the burial ground. (28) Surface runoff is intercepted at the site boundaries, reducing moisture percolation and resulting overfiow. Ground water can also be intercepted, reducing groundwater intrusion into the buried wastes.

The initial cost of a peripheral drainage system is estimated to be one to five times that for the narrow gravel-filled diversion trenches as mentioned in $J$ above. Thus, the system is estimated to cost $\$ 700$ to $\$ 500 / \mathrm{m}$, depending on the depth and width of the ditches required and upon the methods used to stabilize the ditch banks. The cost is not calculated on a per trench basis, as this is dependent on the layout of the burial ground in question. The annual maintenance cost is estimated to be $5 \%$ of the initial cost, or $\$ 5$ to $\$ 25 / \mathrm{m}$ of ditch length. With regular maintenance, the useful iife is 
anticipated to be more than 200 years. This treatment is slightiy more difficult than improving capping drainage, primarily because of the larger volume of earth to be moved and the increased need to stabilize ditch banks to prevent serious erosion problems.

L. Sump Pumping with Treatment. Sump pumping with treatment is a method of collecting contaminated trench water and removing the radionuclides from it. $(29,30)$ Trench waters are collected in sumps located below the burial trenches. The water is periodically pumped from the sumps into holding tanks and is then treated (i.e., by evaporation, ion-exchange, filtration, etc.) to remove dissolved or entrained radionuclides. After treatment, the water is released. The collected radionuclides are solidified, packaged, and buried.

Sumps for trench water collection, along with associated French drains and standpipes, are described in Section 7.2.2 of Volume 1 . If removal of trench water is desired, submersible pumps are lowered into the standpipes and connected to a piping system. Trench water is then pumped through the piping system to the holding tanks. From the holding tanks, the water is routed to the treatment plant for radionuclide recovery. The resultant wastes are solidified and are either buried onsite or shipped to another facility for disposal.

Pumping and treatment of trench water reduces the potential for radionuclide migration via water pathways. Intruding ground water is removed from the burial ground, as is percolation trapped by impermeable sediments. Retention time for trench water is reduced, thus reducing radionuclide leaching. Trench water is not allowed to accumulate to the amount necessary for overflow.

Based on assessment of perpetual care and maintenance of the Maxey Flats site, (32) the initial cost per trench for this technique is estimated to be $\$ 550$ to $\$ 7,700$. (a) (This cost estimate assumes that sumps aiready exist in the burial trenches and includes only the costs of water removal and treatnent.) Annual maintenance costs and operating expenses are estimated at $\$ 110$ to $\$ 230^{(a)}$ per trench per year. These costs assume onsite burial of the resultant (a) A factor of 1.1 is used to adjust the reported costs to 1978 leve1s. 
solidified wastes; transportation of wastes to another site for burial would result in increased operating expenses. The useful life of the system is anticipated to be 30 years; thus the system requires replacement during the long-term care period.

M. Curtain Wall. A curtain wall is a vertical wall, or trench dam, (33) constructed in the soil profile. The wall is constructed using any of a variety of materials and is impervious to moisture flow.

Several methods are available for the construction of curtain walis. One method consists of the injection of grouting material into the earth to form an impervious wall. (34) Possible grouting materials include cement, clays, asphalts, bitumens, silicates, lignochromes, lignosulfates, epoxy resins, acrylamide, polyester resins, polyphenolics, resorcinolformaldehyde, and other chemical polymers. (35) Another possible method is slurry-wall construction, in which the wall material is slurried and introduced into a trench where it settles out to form the wall. clays are commonly used for this type of wal1. A third method involves the use of rigid prefabricated wall sections (sheet pilings), which are driven into position by a pile-driver. The sections are constructed with mating edges to ensure a seal between adjacent sections of the completed wall.

A curtain wall at the edge of a burial ground can be used to prevent horizontal infiltration of water into the site, either by percolation or by groundwater flow. (35) It diverts water that would ordinarily infiltrate the burial ground and thus reduces radionuclide release from the burial ground.

The initial cost for a grouted curtain wall is reported to be about $\$ 400 / \mathrm{m}^{3}$ installed, (35) or up to $\$ 110,000$ per trench for a complete curtain around al1 four sides of an average trench. However, if applied to encompass a complete burial ground, the cost per trench would be significantly less, because each trench would not be completely surrounded by the curtain. No maintenance of the curtain wal1 is assumed, and the useful life is estimated to be 25 to 100 years, after which time it is assumed to be replaced.

N. Waste Permeability Reduction. Waste permeability reduction refers to the injection of suitable materials into the buried wastes to reduce the 
permeability of the waste-soil matrix. (This technique could be used similarly to reduce the permeability of the trench cap.)

Waste permeability is reduced by injecting grout materials into the waste and surrounding soil. Candidate materials are similar to those for the grouted curtain wall, discussed previously. These materiais are injected by pumping through distribution pipes driven through the overburden into the buried wastes. Injection technique details are described in Reference 34.

By reducing the permeability of the wastes, moisture infiltration is minimized, resulting in a decrease in the leaching of radionuclides from the waste. During the injection process, the pressurized materials also tend to fill voids and compress or compact soft areas in the wastes, increasing the strength of the waste-soil matrix and limiting future subsidence damage. (34,36)

Assuming $30 \%$ void space in the trench ${ }^{(3)}$ and an installed cost of $\$ 70$ to $\$ 350 / \mathrm{m}^{3},(36)$ the initial cost for the technique is estimated to be $\$ 300,000$ to $\$ 1.5$ million per trench. A useful life of 25 to 100 years is anticipated, assuming no regular maintenance. Therefore, replacement is anticipated to be required during the long-term care period.

0 . Waste Leachability Reduction. Waste leachability reduction involves the injection of suitable materials into the buried wastes to chemically and/or physically bond the radionuclides into a relatively stable mass, thus reducing leaching. This technique is quite similar to waste permeability reduction, discussed previously, and both leachability and permeability can be reduced in one operation, depending on the materials used.

Various chemical substances are commercially available to bond wastes into a stable chemical-physical matrix. These materials could be injected into the wastes, as described previously for waste permeability reduction, to reduce waste leachability.

By reducing waste leachability, radionuclide releases caused by hydrological action are reduced by limiting or eliminating dissolution of the radionuclides. 
The costs and useful life for this technique are estimated to be the same as those for waste permeability reduction, described previously.

Ideally, the leachability of wastes should be reduced prior to burial. However, in some cases, the need for remedial action may justify the high cost of in-situ leachability reduction.

P. Retention Media Injection. This technique involves the injection of suitable material into the soil surrounding the buried wastes to filter out, adsorb, bond to, or otherwise retain radionuclides migrating through the soil.

Candidate materials for this technique include any of a variety of substances that will retain or hold-up migrating radionuclides, including ionexchange materials, adsorption media, clays, etc. Methods of injection are similar to those used for grouting, except that the material is injected into the soil surrounding the wastes, rather than into the wastes themselves. The long-term effectiveness of this technique is questionable because of the channeling, bypassing, and material breakdown that are likely to occur with time.

Retention media injection reduces radionuclide movement caused by hydrological action by recapturing migrating radionuclides and retaining them in the soil surrounding the wastes.

To calculate costs for this technique, it is assumed that the burial trench is surrounded on all four sides and below with a layer of soil $2 \mathrm{~m}$ thick, with $20 \%$ void space filled with the injected retention media. Assuming an installed cost $\$ 140$ to $\$ 710 / \mathrm{m}^{3}$, or about twice that for waste permeability reduction, the initial cost is estimated to be $\$ 220,000$ to $\$ 1.1$ million per trench. Assuming a useful life of 10 to 40 years, based on no regular maintenance, the technique is anticipated to require replacement during long-term care.

Q. Revegetation. Revegetation is the reestablishment of a vegetative ground cover on a site whose surface has been disturbed. A variety of vegetation types and species can be used, depending on soil and climate conditions 
and also on the results desired. Shallow-rooted plants are preferred for LLW burial ground revegetation to limit plant-root penetration into the wastes.

Before revegetation begins, soil tests are made at the site to determine the plant species to be used and the nutrient balance in the soil. Then, after the surface to be revegetated is graded or leveled as desired and cleared of debris, the area is planted with selected vegetation species. Use of fertilizers and soil amendments to improve soil texture and nutrient balance is common, as is the use of mulches and/or chemical stabilizers to protect the area until the vegetation becomes established. Mulches and, in some cases, chemical stabilizers ${ }^{(37)}$ also conserve moisture for plant growth at dry western sites.

Several methods can be used to seed an area. A drill-type seeder of the kind used to plant grain crops can be employed if the surface is relatively smooth and slopes are gentle enough to allow safe equipment operation. Hydroseeding can be used with a variety of surface conditions. For this method, the seed and other materials to be applied are mixed in a water-based siurry and sprayed on the surface. All the materials used can be applied in one pass or, as is more common, several passes can be made.

Revegetation can be used to control wind and water erosion of the ground surface. $(38-40)$ It also affects the site moisture balance by reducing runoff and increasing moisture return to the atmosphere through evapotranspiration. Revegetation may, in some cases, reduce mass wasting by anchoring the soil. One possible disadvantage of revegetation is that plant roots can disrupt overburden or stabilization materials, as described in Section F.1.1.3.

The erosion protection afforded a site by a vegetation cover increases as the plant community becomes more established. This results in a gradual improvement of the site over several years, untit the plant community reaches maturity.

For hydroseeding of large areas (larger than 40 hectares), costs (updated to 1978) are reported to be $\$ 740$ to $\$ 1,670 /$ hectare. (42) This is equivalent to $\$ 200$ to $\$ 460$ per trench, if a reasonable number of trenches are revegetated at the same time. Piecemeal revegetation of individual trenches woutd 
probably be two to three times as expensive. Maintenance costs for a revegetated area are considered to be part of Vegetation Management (see below). If properly maintained, the useful life of this treatment is anticipated to be greater than 200 years.

R. Vegetation Management. Vegetation management is the maintenance of a revegetated surface to ensure the continued viability of the vegetative community and to provide remedial measures for incidentat problems.

Vegetation management includes a number of elements that can be used separately or in various combinations, depending on the particular needs at the site. A vegetation management program can also be altered with time to correspond with changing needs.

A vegetation management program can include, but is not 7 imited to, the following elements: herbicides, acting at the surface and/or subsurface to control undesirable plant growth and to limit plant-root penetration; use of competing plant species to control growth of undesirable species; periodic clearing of undesirable vegetation from the site; use of bacterial and/or insect controls to limit the growth of undesirable species; and replanting of areas damaged by erosion, pests, or human activities. Application of surface controls is by established methods. Herbicides acting below the surface can be applied at the same time as subsurface stabilization techniques are performed or, in some cases, can be applied at the surface.

A vegetation management program can be used to reduce radionuclide releases caused by plant-root penetration into buried wastes. It is also useful in reducing erosion and mass wasting by ensuring the continued effectiveness of site vegetation.

No initiai cost is assumed for vegetation management. These annual activities are anticipated to cost approximately 10 of the initial cost of revegetating an area, or $\$ 20$ to $\$ 50$ per trench per year.

5. Wind Breaks. Wind breaks (shelterbelts) are barriers that reduce wind speed in the area of concern. They can take the form of vegetation (e.g., trees, shrubs, or strip plantings) or can be physical barriers (e.g., 
fences, walls, or soj] ridges). They are an established soil-conservation tool and can be used in combination with other stabilization techniques. (43)

wind breaks are planted or instailed using standard techniques. They are generaily placed at right angles to the prevailing winds.

Wind breaks reduce site erosion by reducing the wind speed, thus reducing the scouring action of the wind. (44) However, vegetative barriers can result in the penetration of plant or tree roots into the buried waste.

In establishing a shelterbelt, three paraliel rows of trees are recommended, with a different species in each row. Assuming a spacing of 2.5 to $4.0 \mathrm{~m}$ in the rows and an installed cost of $\$ .36$ per seedling, the initiat cost of a shelterbelt is estimated to be $\$ 300$ to $\$ 440 / \mathrm{km}$. If irrigation is required, as at the arid western site, the installed cost of the sheiterbelt (including the irrigation system) would be one to two orders of magnitude greater. The annual maintenance cost, without irrigation, is estimated to be $5 \%$ of the initial cost, or $\$ 15$ to $\$ 22 / \mathrm{km}$. The usefu? life of the sheiterbelt is estimated to be 50 to 100 years, after which is anticipated to require replacenent or revitalization. Physical barriers are generally more expensive than shelterbelts; maintenance costs and useful life depend on the type of construction.

\section{F.2 QUALITY ASSURANCE}

Planning for quality assurance (QA) is required from the earliest stages of the decommissioning effort to assure that the $Q A$ regulations imposed on the project are met. As each detajled procedure is developed during the planning and preparation phase of site/waste stabilization, the QA portions are included. Current regulations and guides applicable to the QA requirements and procedures for decommissioning are given in Section 5 of Volume $\mathrm{T}$.

In this study, a $Q A$ engineer is assumed to handle all QA matters. He is organizationally independent of the project staff, up to the highest possible lever of the decomissioning organization. 


\section{F.2.1 Methods Review}

Whenever a new procedure is written, a documented peer review of the procedure is held. The review ensures that the planning includes suitable controls for application to physics, radiation, safety, accident, security, $Q A / Q C$, and environmentai analyses. The controis may inciude other checks, tests, and formal design reviews as necessary. Other aspects of the planning that are reviewed are reilability criteria, the choice of test methods, and the choice of methods or materials. The conservatism in margins of safety for procedures, equipment, or structures aiso receives documented review.

\section{F.2.2 Procurement Document Control}

The project's suppliers, inciuding fixed-price contractors, are selected from a $Q A$ list of Qualified Suppliers. QA inspections of the vendor's plant are performed as needed to place new firms on the qualified list.

Procurement Document Control is a $Q A$ procedure to verify that any $Q A$ requirements for specified hardware, materials, or services are clearly and accurately identified in procurement documents or purchase orders. This includes references to applicable drawings, specifications, standards, codes, regulations, required records, test data, certifications, and qualifications of personnel or procedures. Special handing, shipping, or packaging requirements are also communicated to vendors. This control is applied to any supplier of the specific devices and equipment vital to the project, such as environmental monitoring equipment, safety and shielding devices, radiation detection equipment, chemicals, and other materials.

\section{F.2.3 Work Instructions, Procedures, and Drawings}

Formal documentation of work instructions, procedures, and drawings and of the sequence of action for preparation, review, approval, and control of information is required. The people responsible for the sequence are clearly identified. These procedures verify the proper completion of activities or steps in the decomissioning process to ensure that vital services remain intact and that the proper sequence of events is maintained. The latest revisions of drawings, plans, and work instructions are required to be at the work place. Aiso included are work instructions for vendors to review 
hardware for quantitative (dimensions, tolerances, or 7 imits) and for qualitative (finish, workmanship) acceptability criteria. Changes in planning receive the same levels of review and approval as original planning.

\section{F.2.4 Document Control}

Document control verifies that all essential documentation receives the proper review, approval, release, change and distribution control. A procedure is used to purge the system of obsolete or erroneous information.

\section{F.2.5 Identification and Control of Procured I tems}

A program of suppiier surveillance or source inspection for vendors of critical items is established. (Also see Section F.2.7.) Records, such as certification of conformance, are required from vendors to show they meet the $Q A$ requirements. Inspection of purchased materials or itens is performed upon recejpt of the items. Items must be sufficiently identifjed to allow proper seiection for use, completion of processing, or segregation of nonconforming items. The life and required storage and use conditions of chemicals must be clearly stated.

\section{F.2.6 Special Procedures}

Decommissioning may involve several tasks requiring new or unusual work procedures. Special provisions are made to identify and control any unusua? procedures, using reviews, written procedures, and audits.

\section{F.2.7 Inspection and Testing}

A17 items produced for the project must be properiy inspected or verified. Inspections in the vendor's plant may be necessary for some items. Adequate inspection instructions are prepared, and inspection records are prepared and retained.

Verification procedures ensure inspection of each essential operation, as well.

\section{F.2.8 Caibration}

A1l measurements require the use of properiy calibrated equipment. Therefore, a system of calibration control is used to ensure the validity of 
instrument readings. The accuracy requirements and tolerances for the project measurements are identified. Examples of equipment with calibration requirements include radiation monitoring devices, portable radiation detection equipment, and environmental monitoring systems.

\section{F.2.9 Shipping and Receiving}

Special instructions are prepared for the handling, packaging, shipping, receiving, storing, and marking of components and materials for the project. Any radioactive shipments require written $Q A$ procedures for each package type, specifying all steps in the package inspection, preparation, loading, and closing. Signed checklists are used to record all shipments in or out, and records are retained.

\section{F.2.10 Operating Status}

Sufficient identification procedures are used to prevent the inadvertent operation of systems temporarily or permanentiy removed from service. Restricted use niay be necessary for some systems (e.g., environmental monitoring systems) during modifications.

\section{F.2.11 Nonconformance and Corrective Action}

AT) nonconformances and resulting corrective actions are documented, and the reports are retained as part of the project records.

\section{F.2.12 Special Quality Records}

An index of records and their required retention periods is maintained. These records include operating logs, results of reviews, inspections, training and qualifications of personnel, procedures, drawings, specifications, criteria documents, procurement documents, shipping records, nonconformance and corrective action reports, and audit reports. Complete records of dose rate surveys are also maintained.

\section{F.2.13 Quality Auditing}

Regular audits are performed to verify that each of the $Q A$ procedures is being followed. Examples include witnessing shipments, calibration audits, 
verification that the correct procedures are at all work locations, vendor inspection, receiving and storage inspections, and audits for complete $Q A$ procedures and record retention. 


\section{REFERENCES}

1. R. E. Isaacson and D. J. Brown, Environmental Assessment Related to Hanford Radioactive Waste Burial. RHO-SA-36, Rockwel1 Hanford Operations, p. 25, Richland, WA, February 1978.

2. Ibid., p. 35 .

3. Study of Engineering and Water Management Practices that will Minimize the Infiltration of Precipitation into Trenches Containing Radioactive Waste, ORP LV-78-5, U.S. EPA by SCS Engineers, P. 18, 30, Long Beach, $\overline{\mathrm{CA}}$, June 1978 .

4. C. R. Longwe 11, R. F. FTint and J. E. Sanders, Physical Geology, John Wiley and Sons, Inc., P. 654, New York, NY, 1969.

5. P. T. Flawn, Environmental Geology, Harper and Row, Publishers, Inc., p. 19, New York, NY, 1970.

6. Alternatives for Managing Wastes from Reactors and Post-Fission Operations in the LWR Fuel Cycle, ERDA 76-43, U.S. Energy Research and Development Administration, p. 24.13, May 1976.

7. Fieference 3, pp. 10-11.

8. J. S. Means, D. A. Crerar and J. 0. Duguid, Chemical Mechanisms of $60 \mathrm{Co}$ Transport in Ground Water from Intermediate-Level Liquid Waste Trench 7: Progress Report for Period Ending June 30, 1975. ORNL/TM-5348, Oak Ridge National Laboratory, Oak Ridge, TN, November 1976.

9. Reference 6, p. 24.28.

10. Reference 1, p. 33, 36 .

11. J. F. Cline, et a1., Experimental Design for Demonstration of Bio-barriers Placed in a Simulated Burial Trench. BNWL -2035 , Batteile, Pacific Northwest Laboratories, Rich]and, WA, May 1976.

12. T. P. O'Farrell and R. 0. Gilbert, "Transport of Radioactive Materials by Jackrabbits on the Hanford Reservation," Hea]th Physics 29:9-15, 1975.

13. R. S. Godfrey, ed., Building Construction Cost Data 1975, R. S. Means Co., Inc., p. 17, Duxbury, MA, 7975.

14. Reference 3, pp. 33-51.

15. The Shallow Land Burial of Low-Level Radioactively Contaminated Solid Waste. National Research Council, Washington, DC, 1976 . 
16. R. H. Hawkins and J. H. Horton, "Bentonite as a Protective Cover for Buried Radioactive Waste." Heaith Physics 13:287-292, 1967.

17. Reference 3, pp. 36-45.

18. J. 0. Duguid, Annual Progress Report of Burial Ground 5tudies at Oak Ridge National Laboratory: Period Ending September 30, 1975, ORNL-5141 Oak Ridge National Laboratory, pp. 39-41, Oak Ridge, TN 37830, October 1976 .

19. Reference 3, pp. 39-40, 46-49.

20. Itid., p. 52,54 .

21. R. P. Donovan, R. M. Felder and H. H. Rogers, Vegetative Stabilization of Minera? Waste Heaps, EPA-600/2-76-087, U.S. EPA by Research TriangTe Institute, p. 45, Research Triangle Park, NC 27711, April 1976.

22. Reference 1, p. 33.

23. Reference 13, p. 20.

24. R. L. Soderberg and R. A. Busch, Design Guide for Metal and Nonmetal Tailings Disposal, IC-8755, U.S. Department of the Interior, Bureau of Mines, pp. 60-63, 1977.

25. Reference 3, pp. 25-28.

26. Ibid., pp. 56-57, 60 .

27. Reference 6, p. 24.34.

28. Reference 18, pp. 37-39.

29. Reference 3, pp. 7,70-71.

30. Reference 6, p. $24.6,24.28$.

31. S. A. Johnston, J. L. Warren and L. Lynch, Financial Analysis of Perpetual Care and Maintenance for the Maxey Flats Low Leve? Nuclear Waste DisposaI Site, RF 23U-1492, for Kentucky Legisiative Research Commission, pp. T-2, Frankfort, KT, September 1977.

32. Ibid., pp. 10-16.

33. Reference 18, pp. 39-42.

34. R. Bowen, Grouting in Engineering Practice, Applied Sciences Publishers Ltd., London, England, 7975 . 
35. Reference 3, pp. 63-65.

36. Ibid., pp. 66-67.

37. 3. F. Cline and G. M. Holter, "The Effect of Soil Affixants on Germination, Emergence, and Growth of Cheatgrass and Russian Thistle, "Health Physics 35:409-417, 1978.

38. K. C. Dean, R. Havens and M. W. Glantz, Methods and Costs of Stabilizing Fine-Sized Mineral Wastes, RI-7896, pp. 7-13, U.S. Department of the Interior, Bureau of Mines, 1974.

39. Reference 21.

40. Reference 3, p. 71.

41. Ibid., pp. 27-29.

42. Reference 38, p. 12 .

43. Reference 21 , pp. 57-58.

44. Reference 4, p. 312. 

APPENDIX G

WASTE RELOCATION DECOMMISSIONING ACTIVITY DETAILS

This appendix provides details to support the description of waste relocation methods and procedures in Section 11 of volume $i$.

Al ternative procedures for exhumation of highly activated reactor components from a slit trench are described in Section G.1. Enclosure requirements and special equipment for the exhumation of transuranic-contaminated (TRU) waste are described in Section G.2. Exhumation of the waste remaining in a burial trench after seiective removal of high-dose-rate and TRU waste is described in Section G.3. Some requirements for packaging and shipping radioactive wastes are summarized in Section G.4.

\section{G.1 DETAILS OF SLIT TRENCH EXCAVATION ALTERNATIVES}

Section 11.2 of Volume 1 describes alternative methods for excavation of a slit trench and exhumation of canisters containing highly activated non-fuel-bearing LWR core internals. Because of the high radiation dose rates associated with the packages being retrieved from the trench, all of the excavation alternatives involve remote operations and assume installation of sheet piling to limit excavation width and prevent trench wall cave-in. Details of these excavation alternatives are given in this section. To assess the impact of the use of sheet piling on decommissioning schedules and costs, a non-piled exhumation is also examined in connection with one excavation option (the polar crane option).

The section begins with a brief description of core drilling and sampling procedures. Core drilling is used in connection with burial ground records to precisely define the limits of a proposed excavation and to characterize the nature and condition of the wastes to be exhumed.

\section{G.1.1 Core Drilling and Sampling Procedures}

A light drilling rig is used to drill 0.1-m-diameter cores. A drilling rate of about 20 linear meters per day is assumed. (1) Information needed 
to plan for an excavation is obtained from core drilling in two ways: 1) core drilling provides a hole for insertion of a monitoring instrument probe to measure radioactivity levels, and 2) selected core samples are analyzed for radioactive contamination to determine the condition of the waste packages and to ascertain the degree of radionuclide migration into the soil. To protect against a release of radioactivity to the environment when a core is brought up, the drill is encircled with a donut of accordioned plastic sleeve. The plastic is enclosed around a core as it is removed from the earth; the plastic is then sealed at both ends.

\section{G.1.2 Hydraulic Excavation}

Hydraulic excavation is an established method of materials transport.

In the mining industry it is used to excavate overburden from an ore face. In dredging operations, the water/earth slurry is sucked up through hoses to settiement basins or tanks. There, the heavier earth settles out and liquid is drawn off for reuse.

The use of hydraulic methods for excavation of a slit trench is illustrated in Figure G.1-1. After overburden removal and sheet piling installation, a high-velocity stream of water is used to sluice out soil from the burial trench. The loosened soil is removed from the work area in the form of a mud or slurry. The sluicing head is specially designed for remote operation. It consists of sluicing nozzles and a slurry-pickup pipe as shown in the figure. The sluicing head is moved and positioned over the desired location, using a crane. A television camera is used to visually monitor the siuicing operation. Flexible hoses (0.1-m-diameter) supply the nozzles with the sluice stream and retrieve the resultant slurry.

A 2300-l/min pump, capable of developing about 14 atm pressure, delivers approximately $1500 \mathrm{\ell} / \mathrm{min}$ to the sluice nozzles. An automatic valve controlied by a level-detecting conductivity probe is used to control the sluice and slurry streams. A water-jet ejector is supplied with the remaining $800 \mathrm{l} / \mathrm{min}$, which serves as the motive fluid to eject the slurry stream. Assuming the average slurry solids concentration to be $8 \%$, the slurry fiow rate is approximately $1650 \mathrm{l} / \mathrm{min}$ and the excavation rate is approximately $5 \mathrm{~m}^{3} / \mathrm{hr}$. Solidsseparation and clarification equipment is used to recover as much of the 


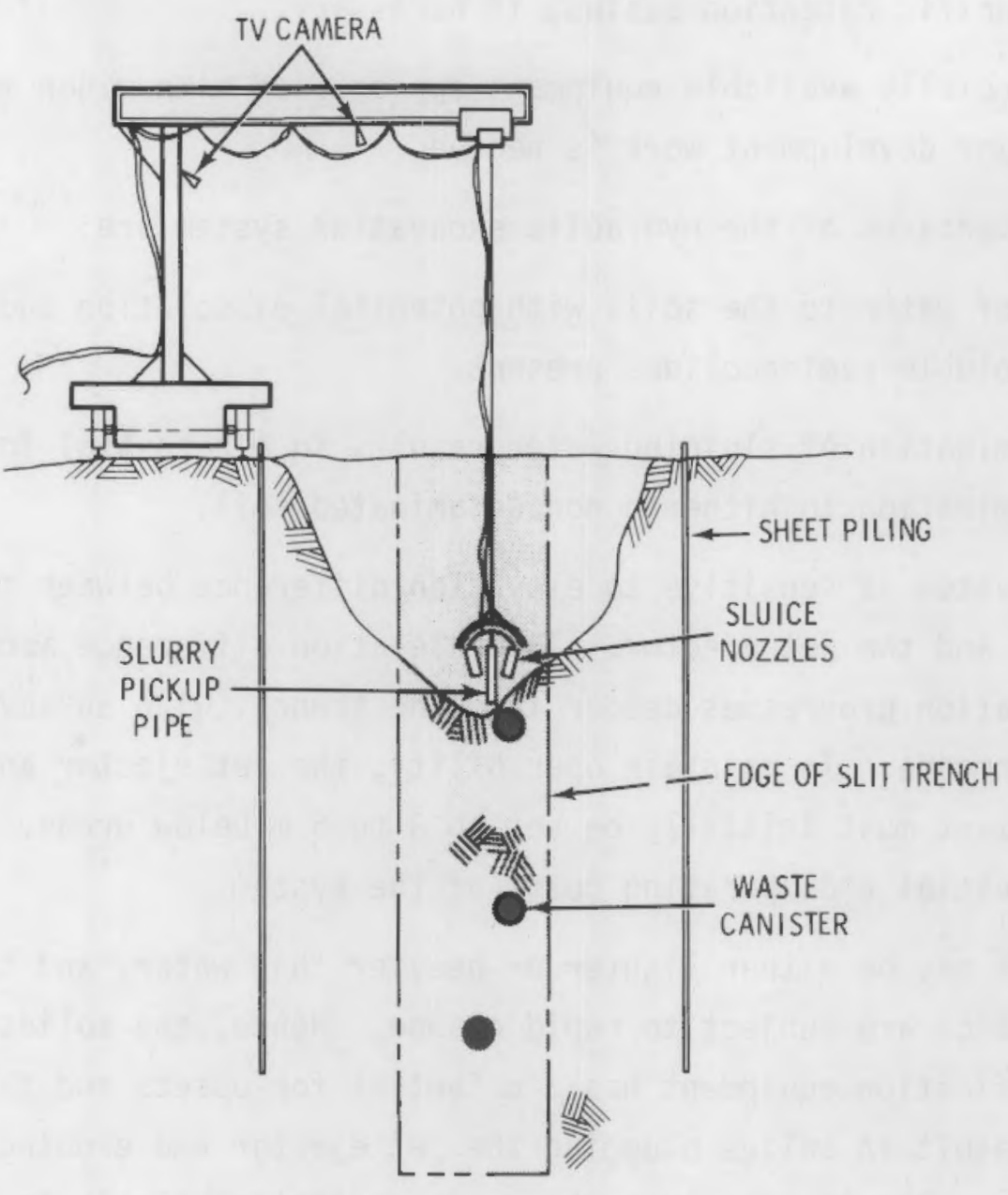

FIGURE G.1-1. Hydraulic Excavation of S1it Trench

sluicing water as possible for recycle. Makeup water is added as required. The wet solids are monitored for contamination and dewatered. Contaminated solids are packaged in 208- $\ell$ drums for shipment to offsite disposal. Noncontaminated solids are used as backfill. Any air ejected with the slurry is drawn through high-efficiency particulate air (HEPA) filters and exhausted by a small blower.

Advantages of the hydraulic excavation system are:

1) The long boom crane can spend a major portion of the time actually digging and excavating instead of transporting soil. 
2) Soil slurry can be monitored for radioactive contamination and diverted to specific retention basins, if necessary.

3) Commercially available equipment can be used with minor modifications. No major development work is needed.

Disadvantages of the hydraulic excavation system are:

1) Loss of water to the soil, with potential dissolution and migration of any soluble radionuclides present.

2) Contamination of sluicing water results in a potential for spreading contamination to hitherto noncontaminated soil.

3) The system is sensitive to elevation difference between the slurry pickup point and the jet ejector. This elevation difference increases as the excavation progresses deeper into the trench, with an adverse effect on performance. To maintain operability, the jet ejector and attendant equipment must initially be set up 3 to $5 \mathrm{~m}$ below grade. This increases the initial and operating costs of the system.

4) Solids may be either lighter or heavier than water, and the solids characteristics are subject to rapid change. Hence, the solids-separation and clarification equipment has a potential for upsets and failures. These can result in solids plugging the jet ejector and eroding the bearings and impeller of the sluice pump, necessitating costly equipment replacements.

5) There is substantially more weather dependence of this system over other systems. Cold weather can freeze operating parts of the system, seriously slowing production.

6) The system has substantial water requirements, in spite of equipment designed to facilitate water reuse.

This system has the highest unit cost and the linest excavation rate of any of the excavation systems considered in this study. 


\section{G.1.3 Pneumatic Excavation}

This excavation concept involves mechanical digging of trench soil, with pneumatic transport of the soil out of the trench. As shown schematically in Figure G.1-2, soil is dug remotely, using an excavation device (such as a spud fork) suspended from a crane. A fluidizing stream of air is used to transport the freshly dug soil from the burial trench. At a point downstream, the fluidized soil stream can be transported along two alternate paths, one for

- contaminated soil and the other for noncontaminated soil.

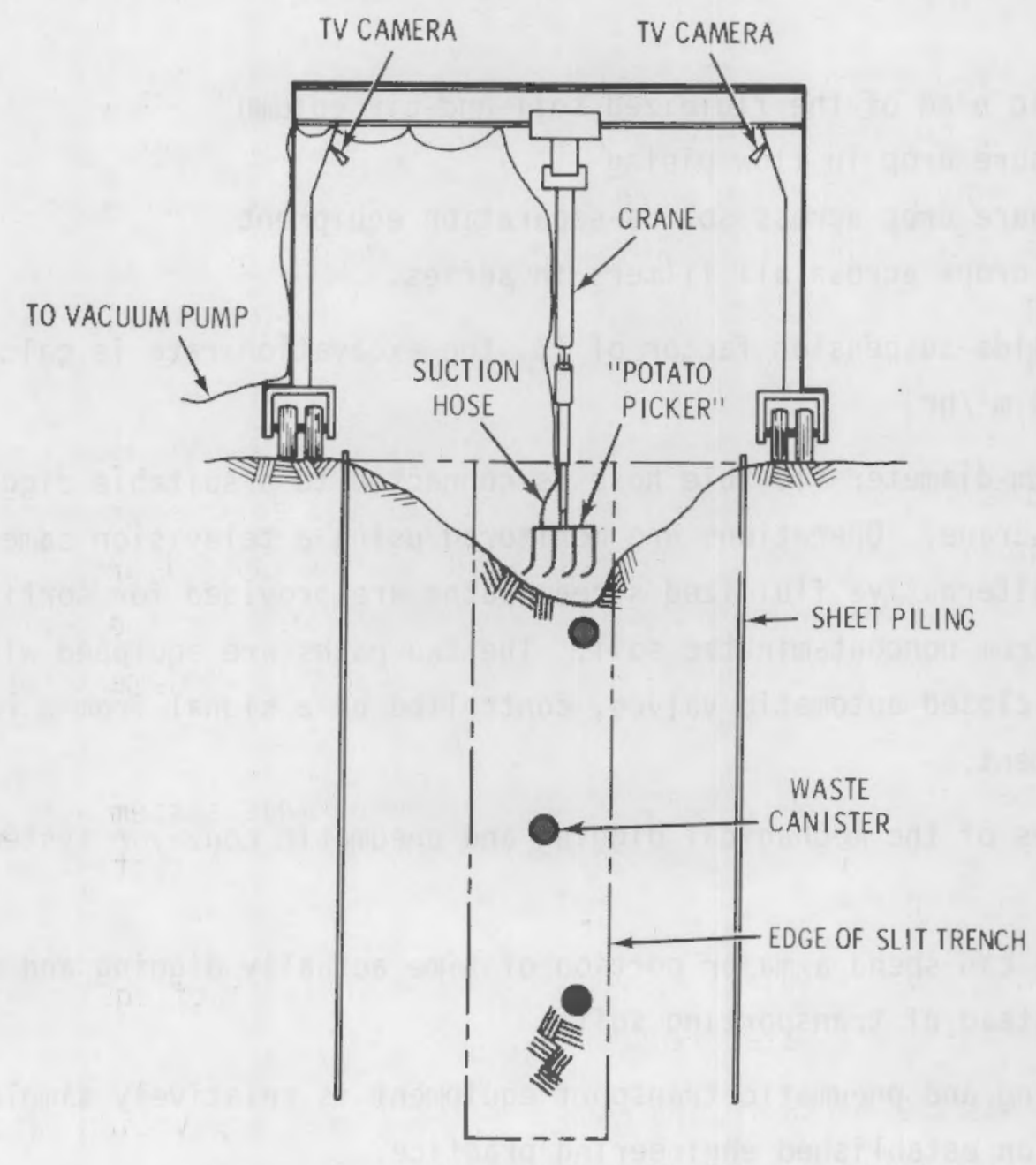

FIGURE G.1-2. Pneumatic Excavation of S1it Trench 
Pneumatic transfer is described at length in the engineering literature. Examples of its use in industry include transfer of zirconium sand between process steps, crushed sintered ore transfer, transfer of pellet-size excavated ore from mine depths to the surface, and crushed coal transfer. Interior abrasion of pipe surfaces is a concern, but resilient liners have been developed to minimize this problem.

The system for pneumatic excavation of a slit trench utilizes a $95-\mathrm{kW}$ vacuum pump rated at $40 \mathrm{~m}^{3} / \mathrm{min}$ at $430-\mathrm{mm} \mathrm{Hg}$ vacuum to generate the fluidizing stream of air. The $430-\mathrm{mm} \mathrm{Hg}$ pressure differential is balanced by a combination of:

- the static head of the fluidized soil-and-air column

- the pressure drop in flow piping

- the pressure drop across solids-separation equipment

- pressure drops across all filters in series.

Assuming a solids-suspension factor of $1 \%$, the excavation rate is calculated to be about $10 \mathrm{~m}^{3} / \mathrm{hr}$.

The 0.1-mm-diameter flexible hose is connected to a suitable digger suspended from a crane. Operations are monitored using a television camera. If desired, two alternative fluidized stream paths are provided for sorting contaminated from noncontaminated soil. The two paths are equipped with fully open or fully closed automatic valves, controlled by a signal from a radiation detection element.

Advantages of the mechanical digging and pneumatic conveyor system are:

1) The crane can spend a major portion of time actually digging and excavating, instead of transporting soil.

2) The digging and pneumatic transport equipment is relatively simple and is based on established engineering practice.

3) The system can be designed for automatic sorting of contaminated from noncontaminated soil. 
4) With minor modifications, commercially available equipment can be used. Disadvantages of the system are:

1) The system may not work well in a humid climate, because wet soil can plug pneumatic lines and equipment.

2) If solids-separating equipment does not operate efficiently, excessive dust loading on the filters occurs, requiring their frequent replacement.

3) There is a potential for spread of contamination to the environment during excavation from dust, pressurized line breaks, etc.

4) Winter weather can severely impact the operation of the system.

\section{G.1.4 Polar Crane}

For this excavation option, a remotely operated clamshell-type digger is suspended from the arm of an approximately 2-metric-ton capacity jib crane. Figure G.1-3 is a schematic representation of this option. Use of the jib (polar) crane allows digging to proceed with or without sheet piling.

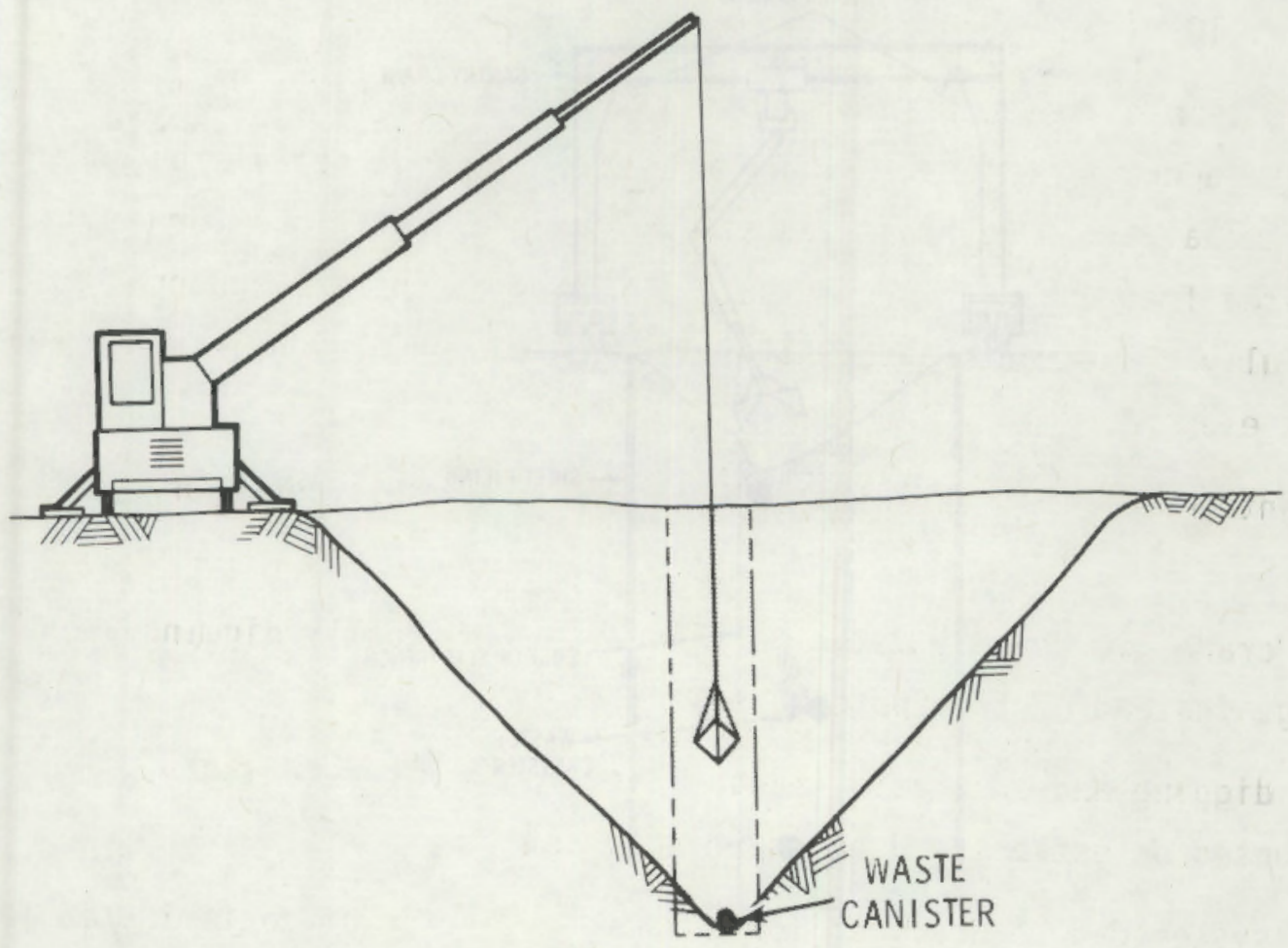

FIGURE G.1-3. Excavation of Slit Trench Using Polar Crane 
The crane is motorized for travel and has a shielded cab for the operator. A television camera is used to monitor the digging operations. The jibcrane arm can travel in a horizontal plane on an arc, and the carriage can travel radialiy along the arm.

This excavation method utilizes established digging techniques. It is simple, low in cost, and has a high production rate. The digging rate is estimated at $30 \mathrm{~m}^{3} / \mathrm{hr}$ for an excavation without sheet piling and $20 \mathrm{~m}^{3} / \mathrm{hr}$ for an excavation with sheet piling. A disadvantage of the system is that it contains no provision for the automatic sorting of contaminated soil.

\section{G.1.5 Mobile Gantry Crane}

For this excavation option, a remotely operated clamshell-type digger is suspended from the articulated arm of a gantry crane. Figure G.1-4 is a schematic representation of this option. Digging operations are performed remotely and are monitored with the aid of a television camera.

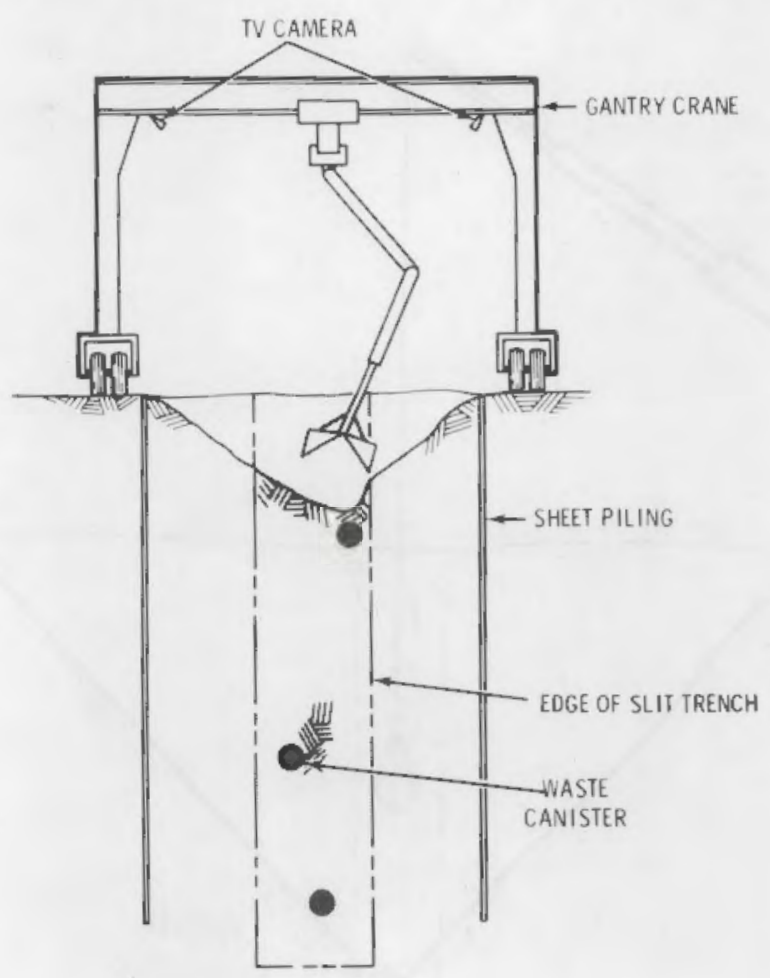

FIGURE G.1-4. Excavation of Slit Trench Using Gantry Crane 
The gantry crane articulated-arm clamshell is more convenient to move and operate than the clamshell attached to the arm of a jib crane. However, the capital cost of the equipment is somewhat higher. Excavation rates are comparable for the two options. The gantry crane moves on wheels that ride on tracks laid along either side of the trench. Thus, this option probably requires the use of sheet piling.

\section{G.1.6 Mobile Gantry Crane in Enclosed Structure}

For this excavation option, the gantry crane is enclosed in a lightweight sheet-metal building that provides both weather protection and, if necessary, some confinement of contamination. Figure G.1-5 is a schematic representation of the option.

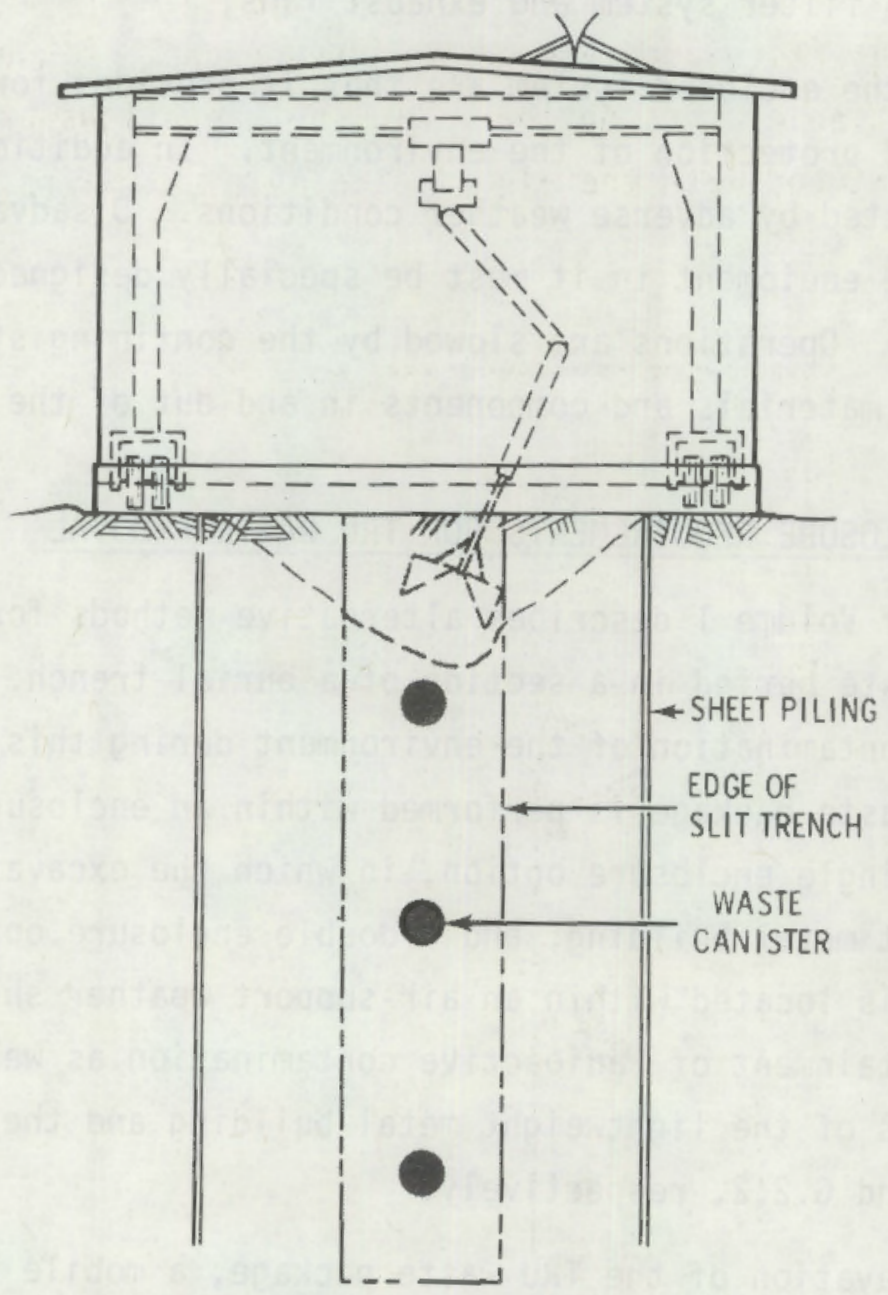

FIGURE G.1-5. Excavation of S1it Trench Using Gantry Crane in Enclosed Structure 
A 7.5-m-wide by 15-m-long chassis, mounted on wheeled carriages at the four corners, is equipped with the framework for a 5-metric-ton capacity bridge crane and the associated building. The building has lightweight sheetmetal walls and roof to minimize its weight. The bridge crane is equipped with a clamshell-type digging device and is remotely operated. The building is provided with lighting, remote television cameras, water-spraying capability, and radiation-detection instrumentation. The wheels on which the building chassis are mounted ride on tracks on either side of the trench. A trap door in the roof permits the movement of casks and drums into and out of the enclosure. The lower edges of the building are sealed at grade level with metal and rubber strips or with inflatable rubber bumpers. The building is equipped with a HEPA filter system and exhaust fans.

Advantages of the enclosed system are that it provides for confinement of contamination and protection of the environment. In addition, operations are not unduly affected by adverse weather conditions. Disadvantages are that the building and the equipment in it must be specially designed and built, increasing the cost. Operations are slowed by the confining structure, particularly movement of materials and components in and out of the trench.

\section{G.2 DETAILS OF ENCLOSURE REQUIREMENTS FOR TRU WASTE REMOVAL}

Section 11.3 of Volume 1 describes aiternative methods for removal of a package of TRU waste buried in a section of a burial trench. Because of the potential for contamination of the environment during this operation, the excavation of the waste package is performed within an enclosure. Two options are evaluated: a single enclosure option, in which the excavation is performed inside a lightweight metal building; and a double enclosure option, in which the metal building is located within an air-support weather shield (ASWS) that provides double containment of radioactive contamination as well as all-weather protection. Details of the lightweight metal building and the ASWS are given in Sections G.2.1 and G.2.2, respectively.

For remote excavation of the TRU waste package, a mobile remotely controlled manipulator is postulated to provide mechanical assistance to the gantry crane. This manipulator (robot) is described in Section G.2.3. 


\section{G.2.1 Lightweight Metal Building}

The primary confinement structure for TRU waste retrieval operations, shown in the plan view in Figure G.2-1, is similar to the building used in the Early Waste Retrieval Program at the Idaho National Engineering Laboratory (INEL). ${ }^{(5,6)}$ It is a lightweight metal building approximately $12 \mathrm{~m}$ by $18 \mathrm{~m}$ by $6 \mathrm{~m}$ high. The building is constructed of lightweight metal panels reinforced with steel beams and diagonal struts. It can be divided into two 6 -m-wide bays for ease of relocation from one site to another. Experience at INEL indicates that relocation requires about 2 weeks to complete.

The inside of the building is maintained at slightly lower air pressure than outside, so that the flow of air is always into the building. Exhaust air is filtered through one stage of roughing and two stages of HEPA filters. All interior surfaces of the building are painted with a strippable coating that can be removed to strip off contamination if necessary.

Personnel enter the building through a three-compartment personnel access hatch. One set of coveralls, shoe covers, and gloves are required to be worn

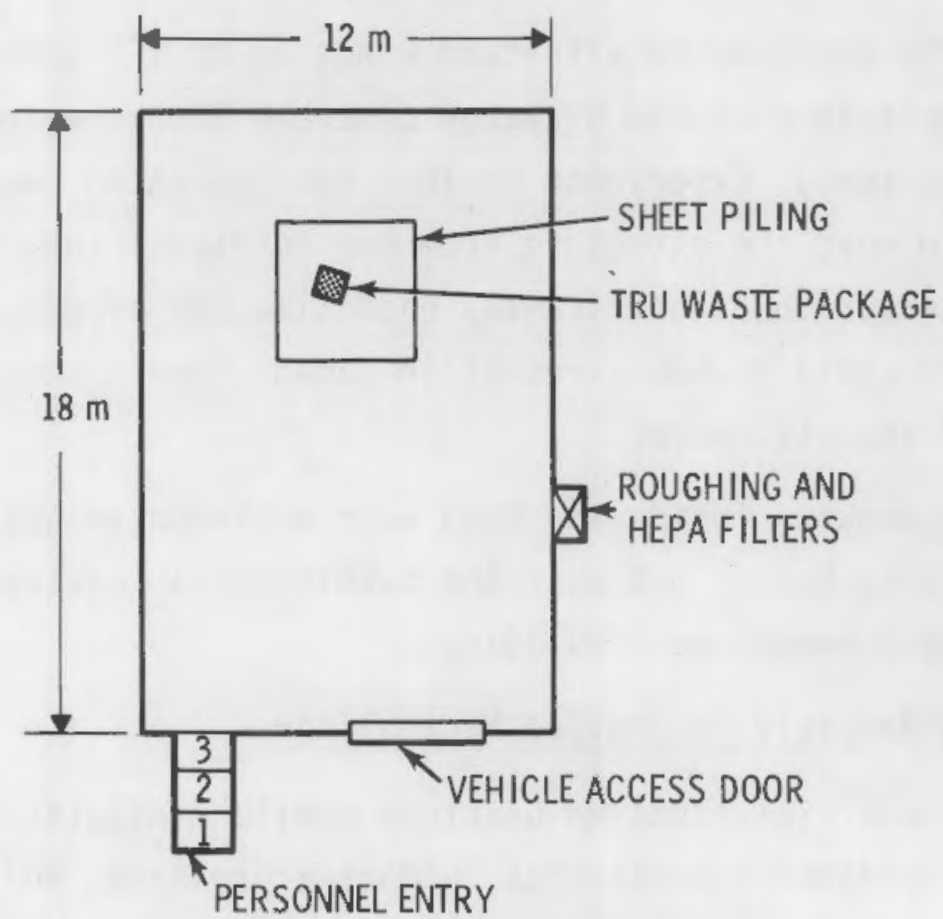

FIGURE G.2-1. Plan of Lightweight Metal Enclosure for TRU Waste Exhumation 
under the fresh-air-supplied bubble suit, and additional shoe covers and gloves are worn on the exterior of the bubble suit. Personnel are carefully surveyed prior to leaving the building. Outer shoe covers and gloves are always removed in Compartment 3. If the bubble suit is found to be contaminated, it is also removed in Compartment 3 . When entry is made into the outermost compartment, Compartment 1 , the individual should be free from contamination. If contamination is detected, inner garments can be removed in Compartment $\mathrm{I}$ and appropriate measures taken to control the contamination.

A sma11 backhoe is used for excavation in the pit area within the building.

\section{G.2.2 Air Support Weather Shield (ASWS)}

Figure G.2-2 shows a plan view of the lightweight metal enclosure located inside the ASWS. The ASWS is a reinforced fabric structure similar to that used in the Early Waste Retrieval program at INEL. $(5,6)$ The structure is $20 \mathrm{~m}$ by $40 \mathrm{~m}$ by $12 \mathrm{~m}$ high, and is supported by air pressure from inside. It provides effective weather protection for the lightweight steel confinement building and associated equipment, and also provides a second level of confinement for radioactivity dispersed in the air.

The ASWS is designed to withstand winds up to $160 \mathrm{~km} / \mathrm{hr}$ and snow loading to $140 \mathrm{~kg} / \mathrm{m}^{2}$. It is anchored by large concrete blocks weighing a total of about 40 metric tons. Experience at INEL has indicated that about 2 months are required to move the structure from one retrieval location to another. The fabric deteriorates significantly each time the structure is moved; and two relocations would probably result in damage severe enough to necessitate replacement of the structure.

Personnel working inside the ASWS wear anti-contamination clothing and carry respirators, but do not wear the bubble suits required for work inside the steel primary containment building.

\section{G.2.3 Mobile, Remotely Controlled Manipulator}

Several commercial firms manufacture mobile manipulators (robots) for use in nuclear plants, laboratories, undersea projects, and industrial applications. Commercially available robots present a broad choice of electrical, 


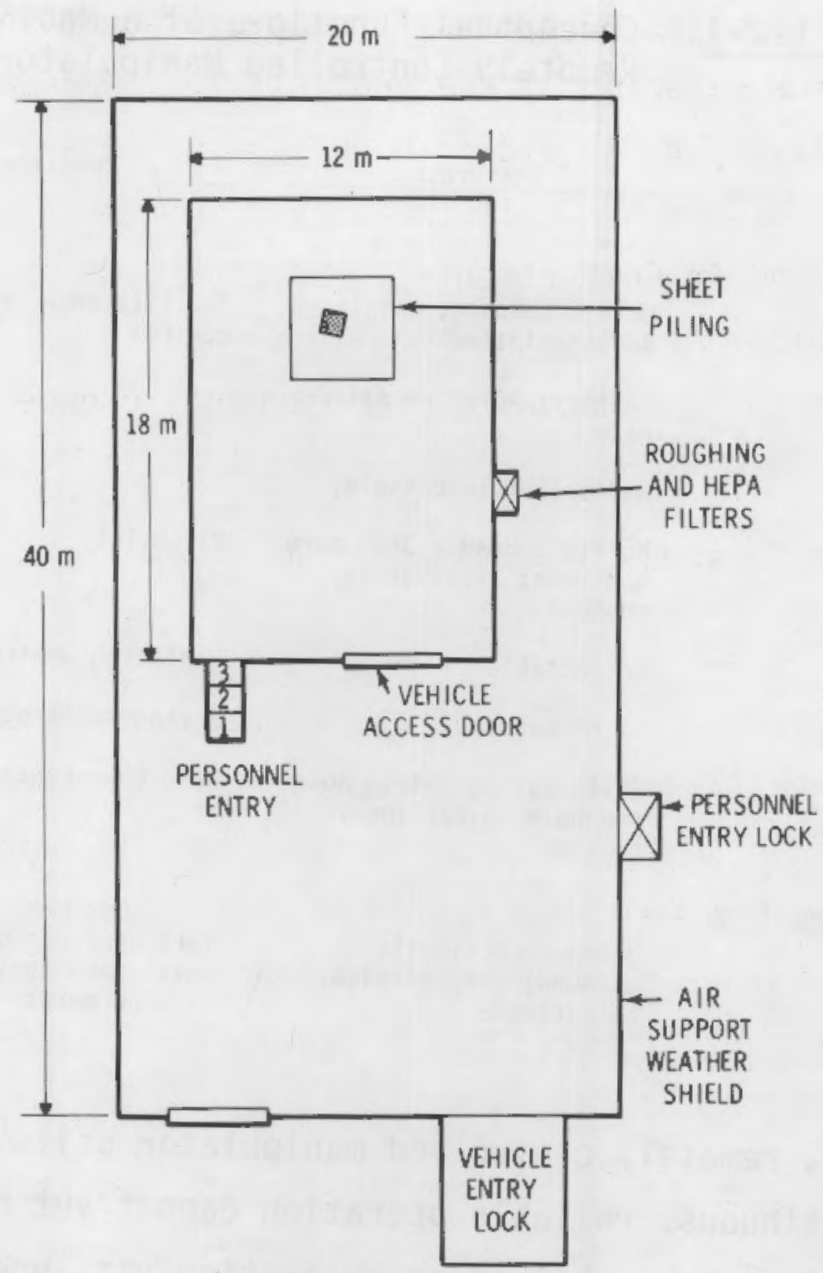

FIGURE G.2-2. Plan of Air-Support Weather Shield and Lightweight Metal Enclosure for TRU Waste Exhumation

hydraulic, pneumatic, and mechanical operation in reaches and strengths to suit many applications. A wide variety of tools, such as wrenches, screwdrivers, tongs, tong fingers and custom fittings, adapt the manipulators to many types of material and equipment.

For this study, the postulated manipulator is capable of using a small shovel to assist in package exhumation or cleanup of contaminated soil, and is able to perform package closure functions. The unit is track-mounted for mobility. Conceptual functions of the unit are listed in Table G.2-1. 


\section{TABLE G.2-1. Conceptual Functions of a Mobile, Remotely Controlled Manipulator}

$\frac{\text { Component }}{\text { Basic Unit }}$
Structure
Power
Control
IV Capability
Extendable Mast
Fork-Lift Hoist
Water/Air Supply

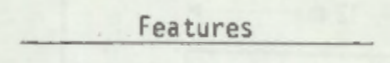

Metal, compact, easily decontaminated

Battery; $A C$ as an alternate

Radio (Remote console)

Multiple heads; $360^{\circ}$ turn and tilt; receiver at console

Retractable

2) MT capacity

Self-reeling hoses; hose channels; directional nozzle

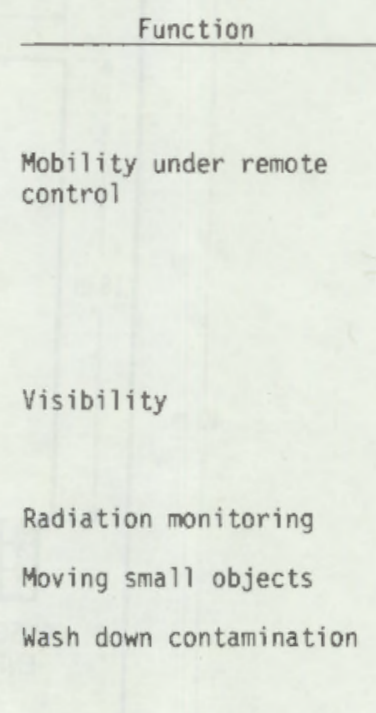

Various functions using small hand tools; secure lids on boxes

Although mobile, remotely controlled manipulator units are commercially available, their continuous, reliable operation cannot yet be guaranteed. Reliable operation of such a robot in an excavation pit, under conditions of severe dusting and on an uneven ground surface, is certainly open to question.

\section{G.3 DETAILS OF BURIAL TRENCH EXCAVATION ALTERNATIVES}

Section 11.4 of Volume 1 describes procedures for the complete exhumation and relocation of the waste remaining in a burial trench, after selective removal of high-dose-rate and TRU waste. The remaining waste is exhumed by bulk excavation of the trench, using conventional commercially available equipment. Two excavation options are considered. In one option, the excavation is carried out from above the trench, and most members of the operating crew are relatively remote from the exposed waste. In the other option, the excavation is performed by personnel operating within the excavation pit. Details of these two options are given in this section. 


\section{G.3.1 Excavation from Above the Trench}

Placement of equipment for this option is shown in Figure G.3-1. The bulk of the excavation is performed by a large backhoe $\left(2-m^{3}\right.$-capacity) operating from above the trench. The backhoe is provided with a shielded,

- ventilated cab for operator protection.
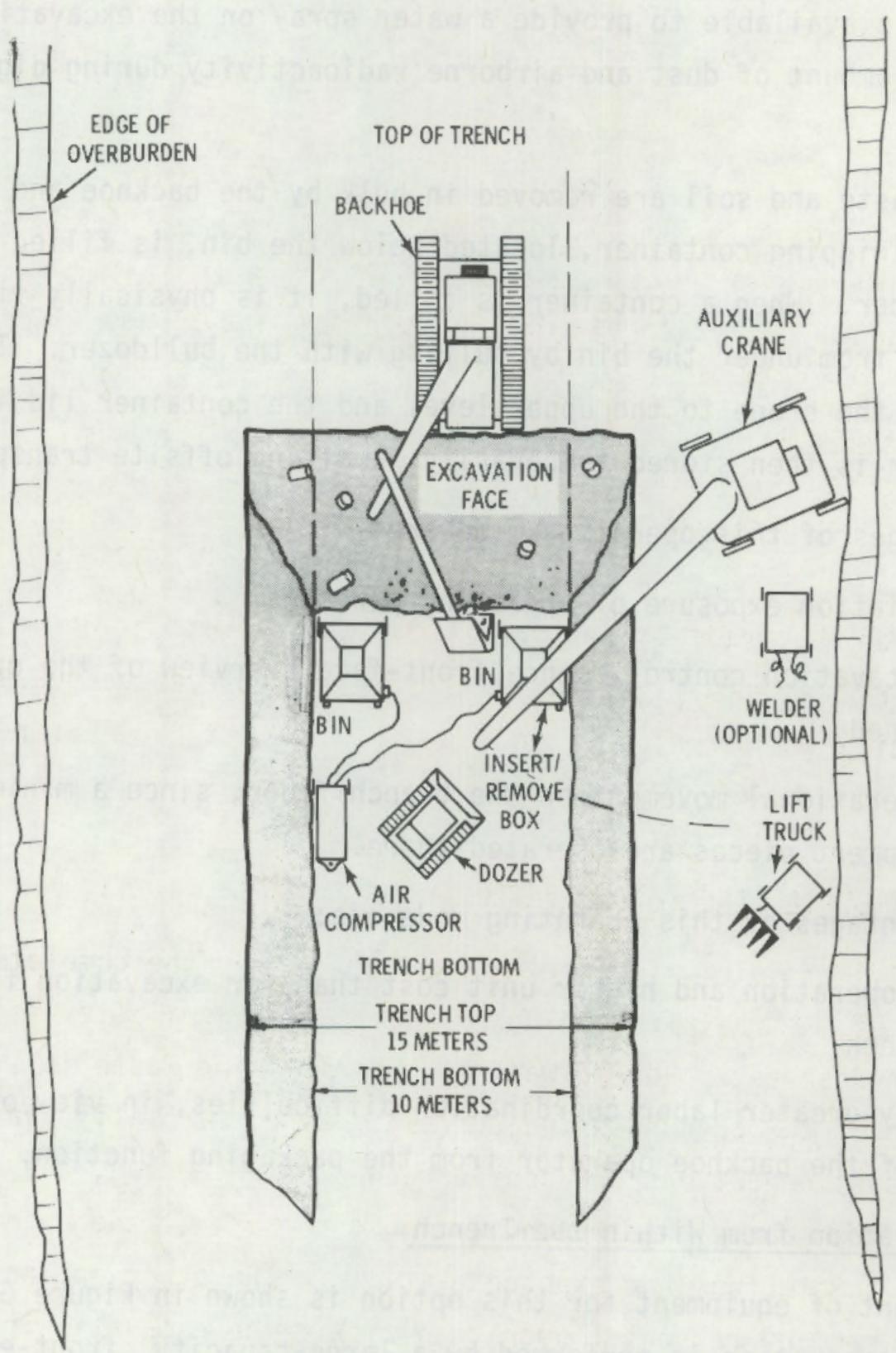

FIGURE G.3-1. Waste Relocation from a Conventional Burial Trench by Excavation from Above the Trench 
In addition to the backhoe, an auxiliary crane with hook, a lift truck, and a welder are positioned above the open face of the trench. A bulldozer and two loading bins are located in the trench. A compressor with appropriate leads can either be in or above the trench as space permits. The backhoe and crane are full-time operations. Other equipment is operated as required. One equipment operator and one laborer are stationed in the pit area. A water truck is available to provide a water spray on the excavation face, to minimize the amount of dust and airborne radioactivity during digging operations.

Loose waste and soil are removed in bulk by the backhoe and dropped into a bin. The shipping container, located below the bin, is filled from a vibrated hopper. When a container is filled, it is physically vibrated and then removed from under the bin by pulling with the bulldozer. The container is lifted by the crane to the upper level and the container lid is attached. The container is then stored temporarily, awaiting offsite transport.

Advantages of this operating mode are:

- low radiation exposure of operating personnel

- good excavation control, since front-face overview of the operation is maintained

- good operational movement on the trench floor, since a minimum number of equipment pieces are operated there.

Disadvantages of this operating mode are:

- slower operation and higher unit cost than for excavation from within the trench

- possibly greater labor coordination difficulties, in view of the distance of the backhoe operator from the packaging function.

\section{G.3.2 Excavation from Within the Trench}

Placement of equipment for this option is shown in Figure G.3-2. The bulk of the excavation is performed by a large-capacity, front-end loader $\left(2-m^{3}\right.$-capacity) operated from the trench floor, against the face of the 

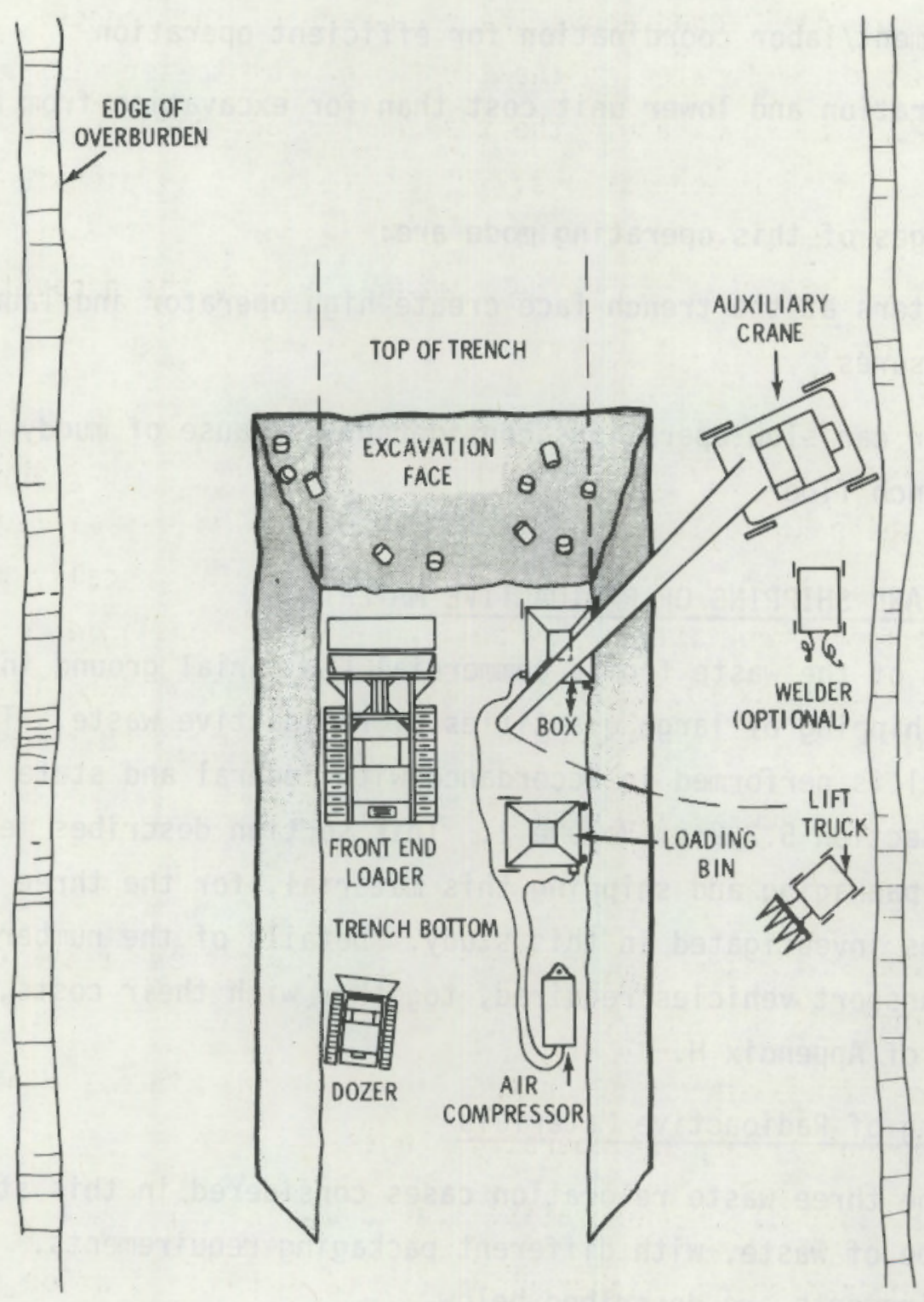

FIGURE G.3-2. Waste Relocation from a Conventional Burial Trench by Excavation from Within the Trench

excavation. Laborers provide manual assistance in dislodging waste forms and in grappling onto waste packages. Water sprays are used to minimize airborne dust levels.

Procedures for filling shipping containers are the same as those described previously in Section G.3.1. 
Advantages of this operating mode are:

- good equipment/labor coordination for efficient operation

- faster operation and lower unit cost than for excavation from above the trench.

Disadvantages of this operating mode are:

- close quarters at the trench face create high operator and laborer radiation exposures

- bad weather can slow operations considerably because of muddy conditions on the trench floor.

\section{G.4 PACKAGING AND SHIPPING OF RADIOACTIVE MATERIALS}

Relocation of the waste from a commercial LLW burial ground involves the packaging and shipping of large quantities of radioactive waste. Transport of this material is performed in accordance with federal and state regulations summarized in Section 5.2.2 of Volume 1. This section describes methods and procedures for packaging and shipping this material, for the three waste relocation cases investigated in this study. Details of the number of containers and transport vehicles required, together with their costs, are given in Section H.4 of Appendix H.

\section{G.4.1 Packaging of Radioactive Materials}

Each of the three waste relocation cases considered in this study involves a different type of waste, with different packaging requirements. These packaging requirements are described below.

\section{G.4.1.1 Packaging of Waste Exhumed from a Slit Trench}

Waste exhumed from a slit trench is assumed to consist of non-fuel-bearing reactor components having high levels of beta-gamma radioactivity and which are packaged in steel canisters $0.76 \mathrm{~m}$ in diameter by $3.6 \mathrm{~m}$ long. Because of the high surface dose rates associated with these canisters, they are placed in massive lead and steel casks, for protection of the public and of transport 
workers during shipment to another disposal site. One canister is placed in each cask for transport by truck. A cask weighs about 20 metric tons.

\section{G.4.1.2 Packaging of Transuranic-Contaminated Waste}

The Nuclear Regulatory Commission (NRC) has proposed adoption of a rule requiring all wastes contaminated with more than $10 \mathrm{nCi}$ of transuranic elements per gram of waste to be classified as TRU wastes ${ }^{(7)}$ and shipped to a federal repository.

TRU-contaminated wastes are assumed to be shipped in containers that conform to current techniques for the packaging of these wastes. For this study, the containers are DOT-specification $7 \mathrm{~A}$ steel boxes, ${ }^{(8)}$ with outer dimensions of $1.2 \mathrm{~m}$ by $1.2 \mathrm{~m}$ by $1.8 \mathrm{~m}$. The boxes are assumed to require a rigid polyethylene liner to satisfy a retrievability requirement at the federal repository.

Because individual packages of TRU waste will probably exceed the 0.001 Ci limitation for Group I radionuclides, ${ }^{(9)}$ all of these shipments are presumed to be made in overpacks that meet Type B package standards $(10)$ or their equivalent. To determine transportation costs, in this study it is assumed that the steel boxes are transported in a Super Tiger. (11) Figure G.4-1 is a schematic of the Super Tiger container. The Super Tiger is a double-walled steel box with a fire-resistant polyurethane foam filler for shock and thermal insulation. Interior dimensions are $1.93 \mathrm{~m}$ by 1.93 by $4.36 \mathrm{~m}$. The empty weight is $6,800 \mathrm{~kg}$, and the maximum payload is $13,600 \mathrm{~kg}$. Total usable volume in the Super Tiger is $16.3 \mathrm{~m}^{3}$.

\section{G.4.1.3 Packaging of Waste Exhumed from a Burial Trench}

The waste exhumed from a burial trench after the TRU waste is removed can be classified into two broad categories:

- large intact containers (cement caissons and steel liners used as packaging for demineralizer resins and solidified liquids, and large plywood boxes used for failed or obsolete equipment)

- smaller drums and packages in various stages of preservation, loose waste, and soil. 


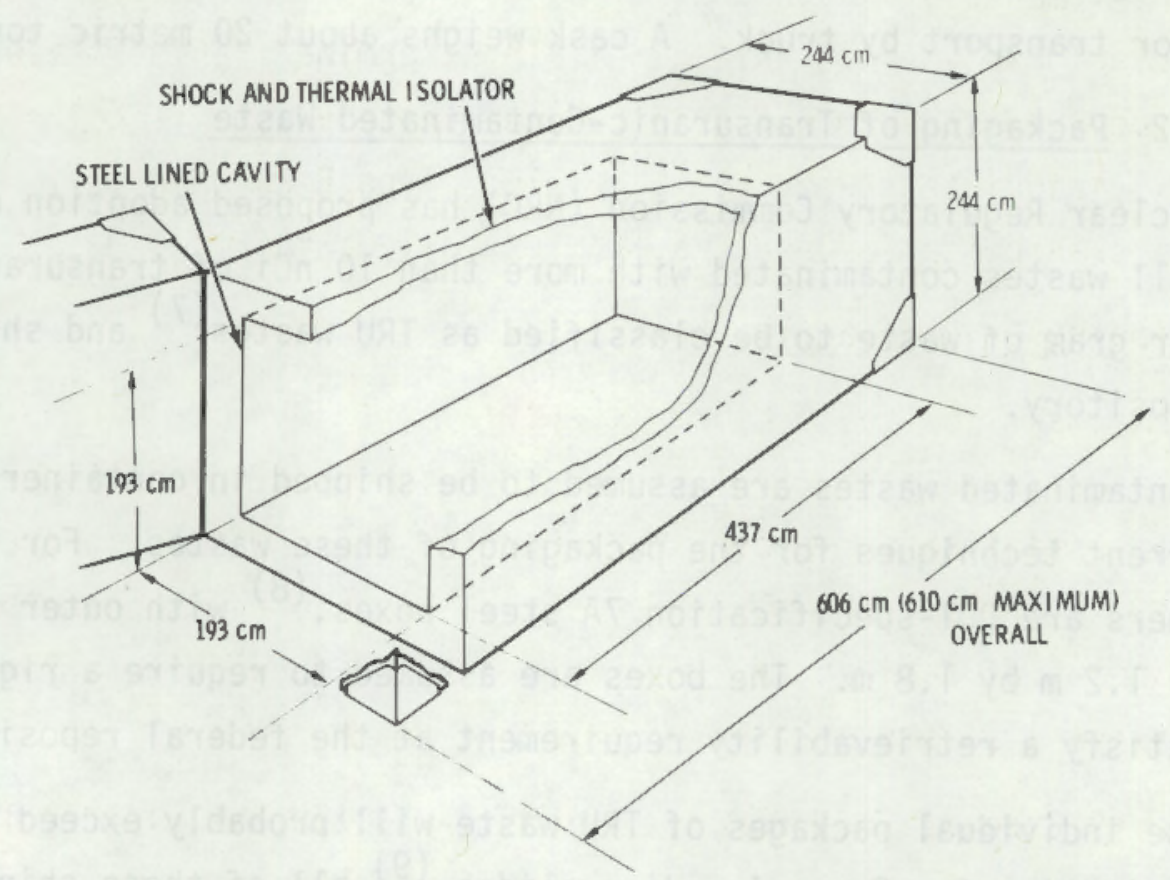

FIGURE G.4-1. Characteristics of a Super Tiger Overpack

For transport to an offsite repository, the large containers are presumed to be shipped intact on flat-bed trailers, after being covered with plastic to prevent the spread of surface contamination. The smaller packages and the loose waste and soil are packaged in $1.2-\mathrm{m}$ by $1.2-\mathrm{m}$ by $1.8-\mathrm{m}$ steel or plywood boxes and transported in exclusive-use vans. Steel boxes are used for shipments to deep geologic disposal. Plywood boxes are used for shipments to other shallow-land disposal sites.

To determine transportation costs (Section 12 of Volume 1) all of the waste and soil removed from the burial trench is assumed to be packaged in $1.2-\mathrm{m}$ by $1.2-\mathrm{m}$ by $1.8 \mathrm{-m}$ boxes. This results in a conservative estimate of transportation costs. 
Most shipments of waste qualify as low-specific-activity (LSA) material (a) and can be shipped without shielding. To determine transportation costs, in this study it is assumed that $2 \%$ of the waste volume (see Table 7.3-2 of Volume 1) requires transport in shielded Type B containers to protect the public and transportation workers from excessive radiation doses.

\section{G.4.2 Shipping of Radioactive Materials}

Al1 shipments of radioactive materials must be made in compliance with federal, state, and local regulations. DOT and NRC federal transportation regulations establish container requirements, dose rate limits, and handing procedures that ensure the safety of the public and transportation workers during shipment of radioactive materials. (12) Federal regulations applicable to the transport of radioactive materials are:

- Title 49 Code of Federal Regulations Parts 170-199 (49 CFR 170-199)-DOT regulations governing the transport of hazardous materials.

- 10 CFR 71--NRC regulations governing the packaging and shipment of radioactive materials.

In addition, for highway transport, state agencies regulate vehicle sizes and weights and, in some cases, transportation routes and times of travel.

Dose rates, for shipments in exclusive-use, closed transport vehicles, must not exceed the following values (DOT, 49 CFR 173.393):

(a) Radioactive materials are classified for transportation purposes into one of seven transport groups according to their potential hazard if released to the environment. Transport Group I is the most restrictive. Plutonium and other transuranic elements are in this transport group. Transport Group VII is the least restrictive. Shipments that pose a negligible risk to the public health may be classified as LSA material [10 CFR 71.4(g)]. If the radioactivity is essentially distributed uniformly, with a concentration of not more than $0.1 \mu \mathrm{Ci} / \mathrm{g}$ of Group I material, or $5 \mu \mathrm{Ci} / \mathrm{g}$ of Group II material, or $300 \mu \mathrm{Ci} / 9$ of Group III or IV material, the waste qualifies as LSA material. Externally contaminated nonradioactive material may be considered as low specific activity provided that the radioactive contamination averaged over $1 \mathrm{~m}^{2}$ does not exceed $0.1 \mu \mathrm{Ci} / \mathrm{cm}^{2}$ for Group I radionuclides or $1.0 \mu \mathrm{Ci} / \mathrm{cm}^{2}$ for others. Basically, only strong, tight packaging that will not leak in normal transport is required for the shipment of LSA material. 
1) 1000 mrem per hour at $0.91 \mathrm{~m}$ from the external surface of the package;

2) 200 mrem per hour at any point on the external surface of the vehicle;

3) $10 \mathrm{mrem}$ per hour at $2 \mathrm{~m}$ from the external surface of the vehicle; and

4) 2 mrem per hour at any normally occupied position in the transport vehicle.

These dose rate limits are illustrated in Figure G.4-2 for truck transport. (13) All of these criteria must be met on a given shipment, with a properly placarded exclusive-use vehicle.

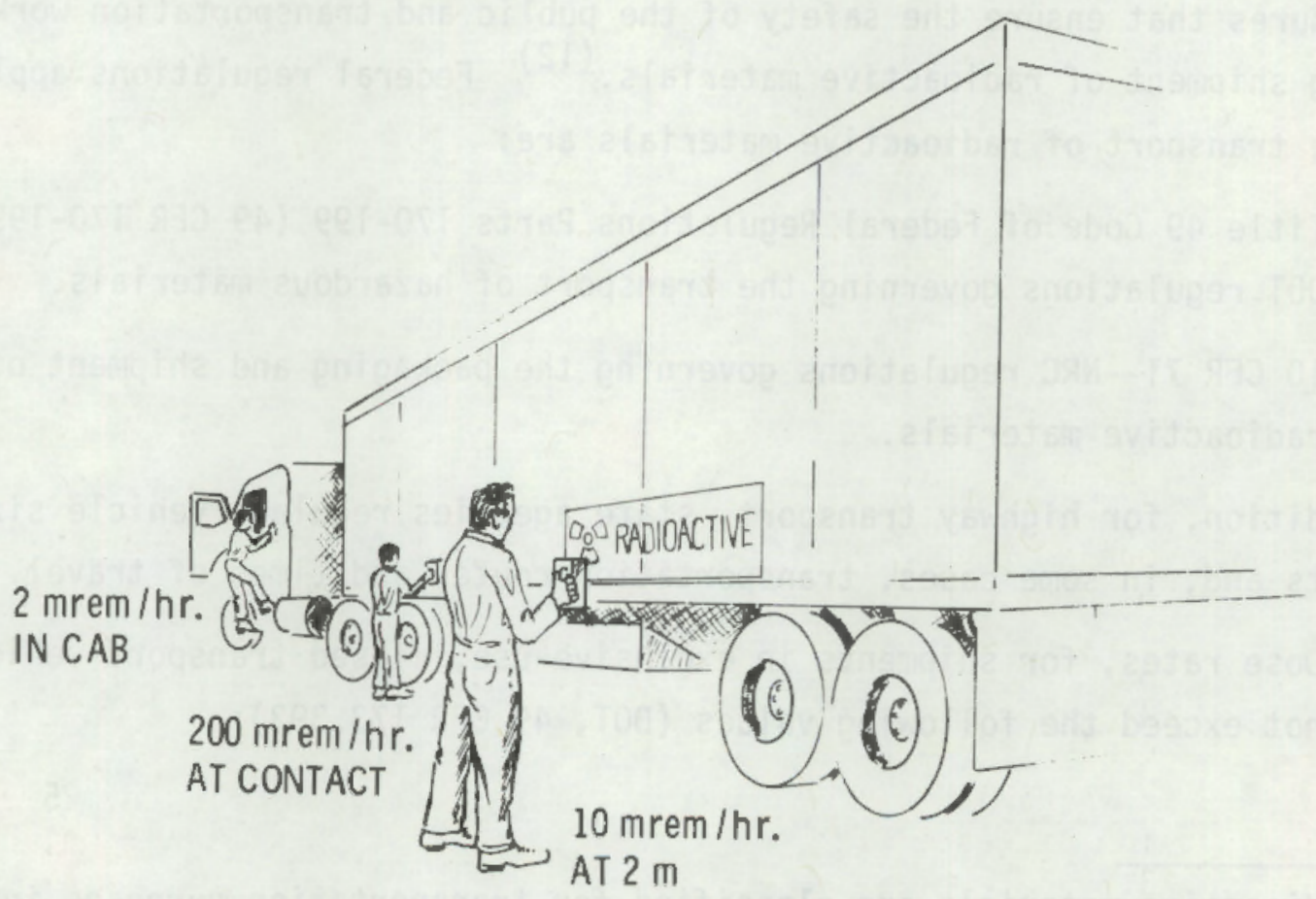

FIGURE G.4-2. Radiation Dose Rate Limits for Exclusive-Use Vehicles 


\section{REFERENCES}

1. Building Construction Cost Data - 1977, Robert S. Means Co., Inc., Duxbury, MA, $197 \overline{7}$.

2. Robert Peele, Mining Engineering Handbook, 3rd Edition, Merriam-Wiggins Co., 1966.

3. Leonard Urguhard, Civil Engineering Handbook, 4th Edition, McGraw-Hill Book Co., New York, NY, 1959.

4. Materials Handiing Handbook, Rona1d Press, 1958.

5. D. H. Card, Early Waste Retrieval Interim Report, TREE-1047, EG and G Idaho, Inc., Idaho Fal1s, ID, February 1977.

6. K. B. McKinley and J. D. Mckinney, Early Waste Retrieval Interim Report, TREE-1265, EG and G Idaho, Inc., Idaho Fa115, ID, May $1 \overline{9} 78$.

7. "Proposed Rulemaking on Transuranic Waste Disposal," Published in Federal Register, Volume 39, No. 32922, September 12, 1974.

8. D. A. Edling and J. F. Griffin, Certification of ERDA Contractors Packaging with Respect to Compliance With DOT Specification $7 \mathrm{~A}$ Performance Requirements, MLM 2228, Monsanto Research Corporation, Mound Laboratory, Miamísburg, $\mathrm{OH}$, June 1975.

9. Title 10, Code of Federal Regulations, Part 71.4, Government Printing office, washington, DC, issued annualiy.

10. Title 10, Code of Federal Regulations, Part 71.36, Government Printing office, Washington, DC, issued annualiy.

11. Directory of Packagings for Radioactive Material, WASH-1279, p. 251, USAEC Division of Waste Management and Transportation, Washington, DC, October 1973.

12. F. B. Conlon and G. L. Pettigrew, Summary of Federal Regulations for Packaging and Transportation of Radioactive Materials, BRH/DMRE-71-i, U.S. Department of Health, Education and Welfare, Public Health Service, Bureau of Radiological Health, Rockville, MD, February 1971.

13. Radioactive Materials Transportation Manual, Nuclear Transport Division, Tri-State Motor Transit Co., Joplin, Mo, 1974. 
APPENDIX H

\section{COST ASSESSMENT DETAILS}

This appendix provides details for the decommissioning cost assessments in Section 12 of Volume 1. Section H.l gives the basic data used for making cost estimates. Cost details for site/waste stabilization, 1ong-term care, and waste relocation are presented in Sections H.2, H.3, and H.4, respectively.

\section{H. 1 COMPILATION OF UNIT COST FACTORS}

For ease in applying the information developed during this study to other decommissioning situations, the basic data used for making the decomissioning cost estimates are presented in this section. Categories for which basic cost data are given include saiaries, waste managenent costs, and costs of equipment, materials, and services. All data are late 1977 or early 1978 costs.

\section{H. 1.1 Unit Manpower Costs}

Salary data for typical decommissioning staff positions are given in Table H.1-1. The original 1975 data base has been adjusted by a factor of 1.29 to account for cost escalation between 1975 and 1978 , based on the Handy-Whitman Index. (1)

\section{H. I.2 Unit Waste Management Costs}

Waste management costs include the costs of shipping containers, transportation costs, and waste disposal charges.

\section{H.1.2.1 Unit Shipping Container Costs}

The cost of containers for packaging radioactive materials for disposal is a major cost item for waste relocation. The containers assumed to be used in this study, together with their unit costs, are 1isted in Table H.l-2. Containers of TRU waste destined for deep geologic disposal are assumed to be overpacked in a DOT-approved Type B container (e.g., a Super Tiger). To protect transport workers and the pub]ic from radiation exposure during shipment of 


\section{TABLE H.1-1. Unit Salaries for Decommissioning Staff}

\begin{tabular}{|c|c|c|c|c|}
\hline Source & Position & Base Pay $/ Y_{r}(\$)$ & Overhead Rate (:) & $\cos t / \operatorname{Mr}(\$)$ \\
\hline a & Project Engineer & 37400 & 70 & 63600 \\
\hline d & Health and Safety Supervisor & 28000 & 70 & 47600 \\
\hline c & Health Physics Technician & 16800 & 50 & 25200 \\
\hline d & Security Force Supervisor & 20000 & 70 & 34000 \\
\hline$b$ & Security Patrolman & 14200 & 50 & 21300 \\
\hline$d$ & Contracts and Accounting Specialist & 19000 & 70 & 32300 \\
\hline d & Q.A. Engineer & 25800 & 70 & 43800 \\
\hline$a$ & Planning Engineer & 25800 & 70 & 43800 \\
\hline$a$ & Operations Supervisor & 25800 & 70 & 43800 \\
\hline$c$ & Foreman & 21900 & 50 & 32900 \\
\hline$d$ & Secretary & 13500 & 50 & 20200 \\
\hline$b$ & Laborer & 17300 & 50 & 25900 \\
\hline d & Equipment Operator & 21900 & 50 & 32900 \\
\hline d & Truck Driver & 17300 & 50 & 25900 \\
\hline$d$ & Dribling Foreman & 24800 & 70 & 42700 \\
\hline
\end{tabular}

a U.S. Department of Labor, Bureau of Labor Statistics, Bulletin, March 1975.

b R. S. Means Company, Building Construction Cost Data - 1975.

c. Hanford Atomic Metal Trades Council Pay Scales.

d Author's estimate.

NOTE: Base salary data has been adjusted to January 1978 using the Handy-whitman Index of Public Utility Construction Costs, Pacific Region.

TABLE H.1-2. Unit Costs for Shipping Containers Used in this Study

Shipping Container

Plywood box

$1.2-m \times 1.2-m \times 1.8-m$ Stee 1 Box

Super Tiger Rental

Cask rental for high beta-gamma activity waste

Cask rental for intermediate beta-gamma activity waste
Estimated Unit Cost (\$)

$50 / \mathrm{m}^{3}$

1000 each

200 per day

750 per day

350 per day 
waste packages with high surface dose rates, all of the waste exhumed from a slit trench and $2 \%$ of the waste exhumed from a burial trench is assumed to be transported in massive steel and lead casks. Daily rental charges for the Super Tiger and for shipping casks are included in Table H.1-2.

\section{H.1.2.2 Unit Transportation Costs}

Transport of radioactive waste materials from the decommissioned LLW burial ground to another shallow-land burial ground or a deep geologic disposal site is assumed to be by truck. The distance from the decomissioned burial ground to an alternate disposal site is assumed to be $2400 \mathrm{~km}$. A rate schedule for truck shipments of legal size and weight is shown in Table H.1-3. This table forms the basis for transportation costs used in this study. The table is reproduced from the pubitished rates ${ }^{(2)}$ of a carrier 1 icensed to transport radioactive materials.

The gross vehicle weight (GVW) for normal shipments by truck is assumed to be less than 20.41 MT. The maximum allowed GVW varies from state to state, ranging from $30.21 \mathrm{MT}$ to $45.36 \mathrm{MT}$, with the majority of states having 1 imits in the vicinity of 33.11 MT. Overweight charges by states also vary widely. For this study, the maximum allowed GVW and the overweight charges for the state of washington are assumed to apply. These overweight charges are shown in Table H.1-4. An additional surcharge of $\$ 0.126$ per $\mathrm{km}$ is imposed by the carrier for shipments with GVW greater than 20.41 MT. Shipments in excess of $33.11 \mathrm{MT}$ GVW require special equipment and special permission. Carrier charges for these cases would have to be determined on a case-by-case basis.

For this study, the GWW of an unloaded exciusive-use van or tractortraiter is assumed to be 12.70 MT. Therefore, the payload per shipment in an exclusive-use van is 7.7 MT legal weight and 20.41 MT overweight. The empty weight of a Super Tiger is 6.8 MT. Therefore, the payload per shipment for wastes overpacked in a Super Tiger is 0.9 MT legal weight and 13.6 MT overweight.

To assure rapid turnaround on waste shipments requiring use of a Super Tiger or cask, a second truck driver is assumed to be required, at an additional cost of $\$ 0.09$ per kilometer. 
TABLE H.1-3. Transportation Rates for Legal-Size and -Weight Shipments (effective April 1, 1978)

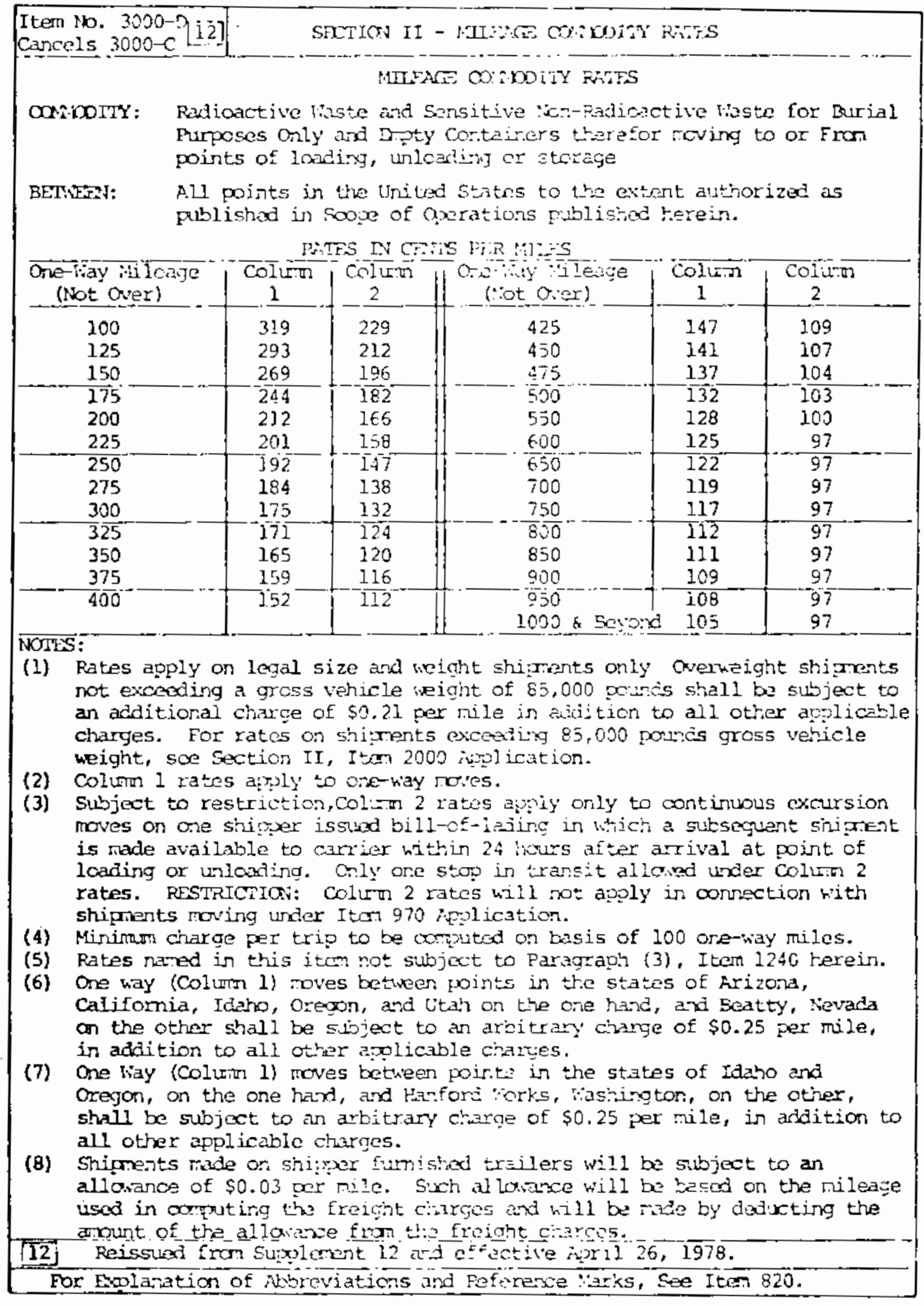


TABLE H.1-4. Additional Charges when Gross Shipment

Weight Exceeds 20.47 MT, Based on Rates

for the State of Washington $(a, b)$

\begin{tabular}{ccc} 
Weight (MT) & Charge $(\$ / \mathrm{km})$ \\
\hline 20.47 to 23.13 & 0.047 \\
23.14 to 25.85 & 0.093 \\
25.86 to 28.57 & 0.140 \\
28.58 to 31.29 & 0.233 \\
31.30 to 34.01 & 0.326 \\
34.02 to 36.73 & 0.420 \\
36.74 and over & 0.513
\end{tabular}

(a) A flat charge of $\$ 5.00$ is levied in addition to the charges shown in the table.

(b) From Reference 2.

\section{H.1.2.3 Unit Waste Disposal Costs}

Radioactive wastes generated during waste relocation operations at an LLW burial ground will be disposed of by interment at a deep geologic disposal site or another shatlow-land burial ground.

Since a facility for deep geologic disposal does not presently exist, burial costs at such a facility can only be speculative. Based on deep geologic disposal costs in Reference 3 , unit costs of $\$ 2,100 / \mathrm{m}^{3}$ for burial of low-level waste (waste that does not require shielding for transport or handling), and $\$ 7,100 / \mathrm{m}^{3}$ for intermediate-level waste (waste that arrives in a shielded container) are assumed for this study.

A basic cost of $\$ 168 / \mathrm{m}^{3}$ is assumed for disposal at a shaliow-land burial ground, based on a representative 1978 burial cost of $\$ 4.75 / \mathrm{ft}^{3}$ at a commercial burial ground. (4) Charges for handling casks and high surface-dose-rate packages are added to this basic charge, as applicable. These additional charges are shown in Table H.1-5. 
TABLE H.1-5. Schedule of Disposal Charges

for Shallow-Land Burial(a)

I - Disposal Charges for Non-TRU Material in Steel Drums, Wood Boxes, or Liners

R/hr at Container Surface Charge $\left(\$ / \mathrm{m}^{3}\right)$

$0.00-0.20 \quad 168$

$0.201-1.00 \quad 184$

$1.01-2.00205$

$2.01-5.00 \quad 25 i$

$5.01-10.00 \quad 297$

$10.01-20.00 \quad 383$

$20.01-40.00 \quad 489$

$40.01-60.00 \quad 727$

$60.01-80.00 \quad 877$

$80.01-100.00 \quad 964$

II - Disposal Charges for Non-Tru Material in Disposable Liners Removed from Shield

R/hr at Container Surface Surcharge per Liner (\$) Disposal Charge $\left(\$ / \mathrm{m}^{3}\right)$

$\begin{array}{cccc}0.00-0.20 & \text { No Charge } & 168 \\ 0.201-1.00 & 65 & 168 \\ 1.01-2.00 & 160 & 168 \\ 2.01-5.00 & 225 & 168 \\ 5.01-10.00 & 325 & 168 \\ 10.01-20.00 & 415 & 168 \\ 20.01-40.00 & 515 & 168 \\ 40.01-60.00 & 610 & 168 \\ 60.01-80.00 & 705 & 168 \\ 80.01-100.00 & 800 & 168\end{array}$

III - Cask Handling Fee: $\$ 250$ each

(a) From Reference 4 . 


\section{H.1.3 Unit Costs of Equipment, Materials, and Supplies}

The various types of equipment, materials, and suppiies used in decommissioning an LLW burial ground are described in Sections 10 and 11 of Volume 1. Estimated unit costs for these items are given here.

Decommissioning is assumed to be performed by a contractor hired by the site operator. Unit charges for equipment owned by the decommissioning contractor are shown in Table H.1-6. The monthly charges shown in the table are calculated on the basis of $6 \%$ of the capital cost of the equipment and include al lowances for equipment depreciation, maintenance and operating expenses (e.g., fuel, lubrication, etc.), the cost of decontamination following use, and return on investment. These costs do not include the operator's wage. Weekly charges are calculated to be approximately one-third of the monthiy charges.

Unit costs for materials and expendable equipment required for decommissjoning are shown in Table H.T-7.

\section{H.1.4 Unit Costs of Environmental Services}

An environmental monitoring program is required during waste relocation, stabilization, or long-term care of an LLW burial ground, as described in Section 9 of Volume 1. Estimated unit costs for the various environmental analyses required are given in Table H.1-8. These costs are based on prices currently charged for such analyses by a typical testing laboratory, and are adjusted for the size of the sampling program (i.e., the number of samples submitted per period).

\section{H.2 COST ASSESSMENT DETAILS FOR STABILIZATION}

The six stabilization plans considered in this study are described in Sections 10.3 and 10.4 of volume 7 . This section provides amplifying details on manpower and equipment requirements and costs for site stabilization.

\section{H.2.1 Stabilization Activity Details and Assumptions}

Details and assumptions for the various stabilization activities that are incorporated into the six stabilization plans are presented below. These 
TABLE H. I-6. Unit Charges for Contractor Equipment ${ }^{(a)}$

Item

Tractor, farm-type

Tractor, dozer

Scraper, self-propelled, $20 \mathrm{~m}^{3}$ capacity

Grader, self-propelled

Front-loader, $2 \mathrm{~m}^{3}$ capacity

Roller, sheepsfoot, self-propelled

Roller, tandem-drum, self-propelled

Soil stabilizer, self-propelled, horizontal drum

Truck, $10 \mathrm{~m}^{3}$ capacity dump

Truck, tanker

Truck, tanker-sprayer

Hydroseeder, self-propelled

Truck, off-highway, $20 \mathrm{~m}^{3}$ capacity dump

Brush-hog chopper, tractor-drawn

Sprayer, tractor-drawn

Disc-harrow, tractor-drawn

Seeder, tractor-drawn

Mower, tractor-drawn

Compactor, vibratory, hand-operated

Backhoe, $2 \mathrm{~m}^{3}$ capacity

Backhoe, $1 / 2 \mathrm{~m}^{3}$ capacity

Lift-truck, 10 MT capacity

Crane, boom-type, 10 MT capacity

Crane, boom-type, 50 MT capacity

Crane, gantry with clamshell

PiTe hammer

Pile extractor

Pile driver leads

Welder, 250 amp

Air compressor, $3 \mathrm{~m}^{3} / \mathrm{min}$

Air compressor, $10 \mathrm{~m}^{3} / \mathrm{min}$

Electric Generator, $25 \mathrm{kw}$

Center Sections-Guides

Make-Up Tank

Contaminated Earth Bin

TV Monitor

Mobile Robot

\begin{tabular}{rr} 
Estimated & Estimated \\
Cost per & Cost per \\
Week (\$) & Month (\$) \\
\hline
\end{tabular}

1225

3200

5000

1850

2750

3000

1050

12000

1600

3750

4500

6000

3750

540

330

450

600

600

240

5800

3000

1000

3000

4500

6000

3300

1200

450

200

250

600

800

225

300

1000

600

9000

(a) Includes equipment depreciation, operating expenses (fuel, lubrication, etc.), decontamination following use and return on investment. Does not include operator's wage. 
TABLE H.T-7. Unit Costs for Materials and Expendable Equipment

\section{Item}

Herbicide, per ha coverage

Backfill (topsoil) per $1000 \mathrm{~m}^{3}(\mathrm{a})$

Backfill (common borrow), per $1000 \mathrm{~m}^{3}(\mathrm{a})$

Seed, per metric ton

Fertilizer, per metric ton

Straw, per 1000 bales

Chemical soil stabilizer, per 1000 liters

PVC pipe, $0.15 \mathrm{~m}$ dia, per $1000 \mathrm{~m}$

PVC pipe connectors, $0.15 \mathrm{~m}$ dia, per 1000

Stone, graded, per $? 000 \mathrm{~m}^{3}(\mathrm{a})$

Gravel, graded, per $1000 \mathrm{~m}^{3}(\mathrm{a})$

Clay, per I $000 \mathrm{~m}^{3}$

Asphalt emulsion, per 1000 liters

Plastic bubble suit

Anti-contamination clothing (per person per week)

Scott air pack

Steel pallet

HVAC/HEPA air filtration unit

Bin, for contaminated earth

Steel building with facilities $(12 \times 18 \times 6 \mathrm{~m})$

Air support weather shield

Robot with TV

Clamshell and hooks

Sheet piling, per $1000 \mathrm{~m}^{2}$

Wales/Cross-supports, per metric ton

Pump

Dredge/suction eauipment

Make-up tank

Storage shed $(3 \times 5 \times 2.5 \mathrm{~m})$

Chain-link fencing, $7.8 \mathrm{~m}$ wide, per $100 \mathrm{~m}$

(a) Cost given does not include delivery to site.
Estimated

Unit Cost

(\$ thousands)

0.25

2.00

1.25

4.40

0.22

1.50

0.26

6.56

4.00

3.00

3.50

10.00

0.18

0.05

0.05

0.84

0.20

25.00

75.00

200.00

325.00

150.00

2.00

80.00

1.00

20.00

25.00

5.00

2.00

2.00 
TABLE H.1-8. Postulated Unit Costs of Environmental Sample Analyses

\begin{tabular}{|c|c|c|c|c|c|}
\hline Sample Type & Type of Analysis & $\begin{array}{r}\text { Estir } \\
\text { Detecti }\end{array}$ & $\begin{array}{l}\text { mated } \\
\text { on Limits }\end{array}$ & $\begin{array}{l}\text { Required } \\
\text { Sample Size }\end{array}$ & $\begin{array}{c}\text { Cost/Analysis } \\
(\$)\end{array}$ \\
\hline Water & $\begin{array}{l}\text { Tritium } \\
\text { Total Alpha } \\
\text { Total Beta } \\
\text { Gamma Spectrum: (a) } \\
60 \mathrm{Co} \\
134 \mathrm{Cs} \\
137 \mathrm{Cs}\end{array}$ & $\begin{array}{c}500 \\
1.0 \\
2.1 \\
10 \\
15 \\
8\end{array}$ & $\begin{array}{l}\mathrm{pCi} / \ell \\
\mathrm{pCi} / \ell \\
\mathrm{pCi} i / \ell \\
\mathrm{pCi} \\
\mathrm{pCi} / \ell \\
\mathrm{pCi} / \ell\end{array}$ & $\begin{array}{rl}500 & \mathrm{ml} \\
250 & \mathrm{ml} \\
500 & \mathrm{ml} \\
& \\
1 & \ell \\
1 & \ell \\
1 & \ell\end{array}$ & $\begin{array}{l}60 \\
30 \\
20 \\
35\end{array}$ \\
\hline Soil & $\begin{array}{l}\text { Total Alpha } \\
\text { Total Beta } \\
\text { Gamma Spectrum: (b) } \\
{ }^{60} \mathrm{Co} \\
13^{4} \mathrm{Cs} \\
13^{7} \mathrm{Cs}\end{array}$ & $\begin{array}{l}2.3 \\
1.0 \\
0.22 \\
0.21 \\
0.22\end{array}$ & $\begin{array}{l}\mathrm{pCi} / \mathrm{g} \\
\mathrm{pCi} / \mathrm{g} \\
\mathrm{pCi} / \mathrm{g} \\
\mathrm{pCi} / \mathrm{g} \\
\mathrm{pCi} / \mathrm{g}\end{array}$ & 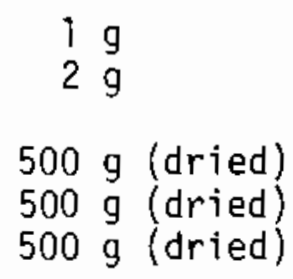 & $\begin{array}{l}30 \\
20 \\
65\end{array}$ \\
\hline Vegetation & $\begin{array}{l}\text { Total Alpha } \\
\text { Total Beta } \\
\text { Gamma Spectrum: (a) } \\
60 \mathrm{Co} \\
134 \mathrm{Cs} \\
137 \mathrm{Cs}\end{array}$ & $\begin{array}{l}2.3 \\
1.0 \\
0.56 \\
0.53 \\
0.54\end{array}$ & $\begin{array}{l}\mathrm{pCi} / \mathrm{g} \\
\mathrm{pCi} / \mathrm{g} \\
\mathrm{pCi} i \mathrm{~g} \\
\mathrm{pCi} / \mathrm{g} \\
\mathrm{pC} i / g\end{array}$ & $\begin{array}{r}1 \mathrm{~g} \text { (dried) } \\
2 \mathrm{~g} \text { (dried) } \\
200 \mathrm{~g} \text { (dried) } \\
200 \mathrm{~g} \text { (dried) } \\
200 \mathrm{~g} \text { (dried) }\end{array}$ & $\begin{array}{l}30 \\
20 \\
35\end{array}$ \\
\hline Small Mammal & $\begin{array}{l}\text { Gamma Spectrum: } \\
{ }_{60} \mathrm{Co} \\
134 \mathrm{Cs} \\
137 \mathrm{Cs}\end{array}$ & $\begin{array}{l}0.18 \\
0.29 \\
0.14\end{array}$ & $\begin{array}{l}\mathrm{pCi} / \mathrm{g} \\
\mathrm{pCi} / \mathrm{g} \\
\mathrm{pCi} / \mathrm{g}\end{array}$ & $\begin{array}{ll}50 & 9 \\
50 & 9 \\
50 & 9\end{array}$ & 35 \\
\hline Air Samples & $\begin{array}{l}\text { Total Alpha } \\
\text { Total Beta } \\
\text { Gamma Spectrum: (a) } \\
60 \mathrm{Co} \\
134 \mathrm{Cs} \\
137 \mathrm{Cs}\end{array}$ & $\begin{array}{l}0.001 \\
0.050 \\
0.035 \\
0.050 \\
0.030\end{array}$ & $\begin{array}{l}\mathrm{pCi} / \mathrm{m}^{3} \\
\mathrm{pCi} / \mathrm{m}^{3} \\
\mathrm{pCi} / \mathrm{m}^{3} \\
\mathrm{pCi} / \mathrm{m}^{3} \\
\mathrm{pCi} / \mathrm{m}^{3}\end{array}$ & $\begin{array}{l}300 \mathrm{~m}^{3} \\
300 \mathrm{~m}^{3} \\
300 \mathrm{~m}^{3} \\
300 \mathrm{~m}^{3} \\
300 \mathrm{~m}^{3}\end{array}$ & $\begin{array}{l}30 \\
20 \\
35\end{array}$ \\
\hline $\begin{array}{l}\text { Direct Radi- } \\
\text { ation Dosi- } \\
\text { meter }\end{array}$ & External Dose & - & & -- & 10 \\
\hline
\end{tabular}

\footnotetext{
(a) Gamma scan using sodium iodide (NaI) crystal detector.

(b) Gamma scan using lithium-drifted germanium diode (GeLi) detector.
} 
details form the bases for the manpower cost estimates presented in Section H.2.2 and the equipment and material cost estimates presented in Section H.2.3.

\section{Repair of Damaged Areas}

This activity is part of the minimal plans for the western and eastern sites.

Areas damaged by subsidence or erosion are backfilied and compacted. At the western site it is assumed that about $5 \%$ of the actual surface area of the burial trenches, or 2 ha, requires an average of $0.3 \mathrm{~m}$ of added fill. At the eastern site the damaged area is assumed to be $25 \%$ greater than it is at the western site. Dump trucks $\left(10-m^{3}\right.$-capacity) are used to haul the backfill to the site, with each truck delivering about $160 \mathrm{~m}^{3}$ per day. The fili is spread by bulldozers at a rate of $720 \mathrm{~m}^{3}$ per day, and is then compacted by laborers with vibratory compactors. The work is supervised by a foreman and requires 4 weeks to complete ( 5 weeks at the eastern site).

An additional activity at the eastern site is the cleaning of site drainage systems. These systems are assumed to be cleaned manually by laborers, with assistance from a front-end loader. A foreman, an equipment operator, and four laborers are allowed for this work, which is assumed to require 2 weeks to complete.

\section{Site Preparation}

This activity is part of the modest and compiex plans at both the western and eastern sites.

Site vegetation is chopped with a brush-hog, after which the site is sprayed with herbicide to kill the roots. The total area to be covered is $51.8 \mathrm{ha}$. (This includes the area of a 71 of the trenches plus 3-m-wide borders between and around the trenches.) The brush-hog covers 5.3 ha per day, requiring 2 weeks to cover the entire area, and the sprayer covers 19.6 ha per day, requiring 1 week. Tractors (farm-type) are required to pult the equipment, and a laborer is required to assist the equipment operator during the week of spraying. A foreman supervises the work, which requires 3 weeks to complete. 
Soft areas that may subside under equipment traffic are backfilled and compacted. It is assumed that about $5 \%$ of the actual surface area of the burial trenches, or $2 \mathrm{ha}$, requires an average of $0.3 \mathrm{~m}$ of added fill. Dump trucks (10-m ${ }^{3}$-capacity) are used to haul the backfill to the site, with each truck delivering about $150 \mathrm{~m}^{3}$ per day. The fill is spread by bulldozers at a rate of $720 \mathrm{~m}^{3}$ per day, and is then compacted by laborers with vibratory compactors at a rate of $57.5 \mathrm{~m}^{3}$ per day per laborer. The work is supervised by a foreman and requires 4 weeks to complete.

A civil survey of the 51.8 ha area is performed by three-man crews (one foreman and two laborers). Each crew can survey 0.8 ha per day.

The wells on the site are extended to allow for the capping thickness increase. For the modest plan at the western site, each well is assumed to require $0.75 \mathrm{~m}$ of PVC pipe and one connector. For the other stabilization plans, $1.5 \mathrm{~m}$ of PVC pipe is required because of the greater increase in capping thickness (soil plus rock- or hard-layer) for these plans. Two laborers, working together, complete one well in one-half hour. A foreman supervises four laborers, and the work is completed in 4 weeks.

For the complex plan at the eastern site the civil survey must include the peripheral drainage/diversion ditches. Thus, 60.3 ha require survey, resulting in an increase in the cost of this activity.

In addition, for the complex plan at the eastern site, the site surface must be contoured to provide a base for the hard layer. Bulldozers are used for this. An average of $0.1 \mathrm{~m}$ of soil over the surface of the trench area $(51.8 \mathrm{ha})$ is assumed to be moved, totalling $51,800 \mathrm{~m}^{3}$. Each bulldozer moves an estimated $300 \mathrm{~m}^{3}$ per day. A foreman is required to supervise the work, and a laborer is provided to assist the equipment operators.

\section{Capping Thickness Increase}

This activity is part of all of the plans for both the western and eastern sites. For the minimal plans, an increase in capping thickness is required for the nine trenches filled during the final 18 months of site operation. For the modest and complex plans, an increase in capping thickness is required for the entire burial grounds. The description that follows pertains to this latter case. 
The 51.8 ha area is covered with an average thickness of $0.6 \mathrm{~m}$ of $\mathrm{fil1}$, requiring a total of $311,000 \mathrm{~m}^{3}$. Self-propelled scrapers $\left(20-\mathrm{m}^{3}\right.$-capacity) are used to haul the material to the site, with each scraper delivering about $300 \mathrm{~m}^{3}$ per day. One laborer is provided to assist every four equipment operators.

After the backfill is in place, it is graded to the specified contours with three passes of a grader. Each grader covers 1,340 $\mathrm{m}^{2}$ per day. One laborer is provided to assist every two equipment operators. A foreman supervises the hauling and grading work, which is completed in 21 weeks.

Three-man survey crews check the completed work at a rate of 4 ha per day.

A portion of the fill $\left(173,000 \mathrm{~m}^{3}\right)$ required for the complex plan at the eastern site is provided by digging the peripheral drainage/diversion ditches required for that plan.

\section{Rock Layer Emplacement}

This activity is part of the complex plan for the western site.

The 51.8 ha area is covered with an average $0.6-\mathrm{m}$ thickness of rock, requiring a total of $311,00 \mathrm{~m}^{3}$. Front-end loaders (2-m ${ }^{3}$-capacity) load about $600 \mathrm{~m}^{3}$ per day each into off-highway dump trucks (20-m $\mathrm{m}^{3}$-capacity). Each truck delivers about $300 \mathrm{~m}^{3}$ of rock to the site each day. Four laborers are provided to assist the loading and dumping, which requires 20 weeks to complete.

The rocks are leveied by grading with bulldozers. Each bulldozer is assumed to cover about 0.3 ha per day. A foreman supervises the rock layer emplacement, which requires 21 weeks to complete.

After the layer is in place, survey crews check the completed work at a rate of 4 ha per day.

\section{Rock Layer Hard-Topping}

This activity is part of the complex plan for the western site.

The rock layer is covered with a gravel layer $0.1 \mathrm{~m}$ thick, requiring a total of $51,800 \mathrm{~m}^{3}$. Front-end loaders are used to load the gravel into dump trucks $\left(10-m^{3}\right.$-capacity). Each truck delivers about $160 \mathrm{~m}^{3}$ to the site per day. One laborer is provided to assist in the loading. 
The gravel is leveled with two passes of a grader. Each grader covers 2,000 $\pi^{2}$ per day. A laborer is provided to assist with the dumping and grading at the site. A foreman supervises the placement of the gravel, which requires 21 weeks to complete.

The gravel is sprayed with asphalt emulsion at an assumed rate of $20 \mathrm{l} / \mathrm{m}^{2}$ to form a hard layer. A tanker truck equipped with spray-bars is used and is assumed to cover 5.2 ha per day. Three laborers are provided to assist with loading and mixing the asphalt, and a foreman supervises the operation.

Capping Drainage Improvement

This activity is part of the modest plan for the eastern site.

Drainage ditches are dug and the surface recontoured where necessary to improve capping drainage. Bulldozers are used to move about $51,800 \mathrm{~m}^{3}$ of soil (an average of $0.1-m$ soil depth over the entire surface). Each bulidozer moves an estimated $300 \mathrm{~m}^{3}$ per day. One laborer is provided to assist the two equipment operators. A foreman is required for 20 weeks to supervise the work.

Three-man survey crews check the completed work at a rate of 4 ha per day. Capping Soil Properties Modification

This activity is part of the modest plan for the eastern site.

A layer of clay assumed to be $0.1 \mathrm{~m}$ thick is spread on the surface of the backfill and mixed with the soil. Dump trucks $\left(10-m^{3}-c a p a c i t y\right)$ are used to haul the clay to the site. Each truck delivers about $160 \mathrm{~m}^{3}$ per day. The clay is spread by a bulldozer at the rate of $650 \mathrm{~m}^{3}$ per day. The clay is mixed into the soil with a disc-harrow, which covers about 6 ha/day. A laborer is provided to assist in the work.

The soil is compacted with self-propelled sheepsfoot rollers, each of which covers $1,200 \mathrm{~m}^{2}$ per day. Two laborers are provided to assist the equipment operators, and a foreman supervises the work. A total of 20 weeks is required for spreading and mixing the clay and compacting the soil.

The area is then fine graded and the work checked by survey crews. 
Hard Layer Emplacement

This activity is part of the complex plan for the eastern site.

To provide a stable base for emplacement of the hard layer, the surface is compacted using road rollers. Each roller covers $1,340 \mathrm{~m}^{2}$ per day. Two laborers are provided to assist the equipment operators.

An asphalt-soil layer is then laid on the surface. A self-propelled soil stabilizer, covering 0.55 ha per day, is used. The asphalt is applied at an assumed rate of $20 \mathrm{l} / \mathrm{m}^{2}$, and is supplied from a tanker truck. Two laborers assist in the work.

After the laver is laid down, the area is again compacted as described above. A foreman supervises the emplacement of the layer, which requires 22 weeks to complete.

\section{Peripheral Drainage/Diversion}

This activity is part of the complex plan for the eastern site.

Drainage/diversion ditches $(20 \mathrm{~m}$ wide at the top, $5 \mathrm{~m}$ wide at the bottom, and $7.5 \mathrm{~m}$ deep) are dug around the site perimeter. Self-propelled scrapers (20- $\mathrm{m}^{3}$-capacity) are used, with each scraper removing about $475 \mathrm{~m}^{3}$ per day. The top $3 \mathrm{~m}$ of soil, or $173,000 \mathrm{~m}^{3}$, are assumed to be topsoil and are spread on the hard layer as part of the capping thickness increase for the eastern site. The remaining $145,000 \mathrm{~m}^{3}$ of subsoil are removed from the site. One laborer is provided to assist every three equipment operators, and a foreman supervises the work, which requires 20 weeks. Three-man survey crews check the work. The ditches are then revegetated. One week is required for revegetation.

\section{Preparations for Sump Pumping}

This activity is part of the complex plan for the eastern site.

To prepare for possible pumping of trench water during long-term care, the wells on the site are checked to ensure that they are in a useable condition. It is assumed that $5 \%$ of the wells will require repairs or redrilling. A light-duty dri11 rig is used for this activity, which also requires $270 \mathrm{~m}$ of 0.15-m-diameter PVC pipe. Four laborers, under the direction of a foreman, are required for this work. 
The water treatment system is also serviced to ensure that it will perform satisfactorily when and if needed. Servicing this system is estimated to require $\$ 2,500$ in miscellaneous equipment and $\$ 500$ in materials.

Preparations for sump pumping and water treatment are estimated to require 8 weeks for completion.

\section{Revegetation}

This activity is part of all of the plans at both the western and eastern sites.

The area to be revegetated is hydroseeded at a rate of 3.25 ha per day. A foreman, an equipment operator, two truck drivers, and two laborers are required. Equipment required includes the hydroseeder and two trucks (one dump truck and one tanker). Materials are applied at the following rates: 1) seed - $22.5 \mathrm{~kg} / \mathrm{ha}, 2)$ fertilizer - $90 \mathrm{~kg} / \mathrm{ha}, 3)$ straw - $150 \mathrm{bales} / \mathrm{ha}$, and 4) chemical soil stabilizer $-3,740 \mathrm{\ell} / \mathrm{ha}$. This activity is assumed to take 3.5 weeks to complete.

\section{Vegetation Management}

This activity is part of all the plans at both the western and eastern sites.

Vegetation management is limited to repair of areas disturbed during other site stabilization activities. One-half week is assumed for this activity, using the same procedures and assumptions as for revegetation.

\section{H.2.2 Manpower Details for Stabilization}

Manpower requirements for site stabilization are summarized in Section 12.1.1 of Volume 1 , and the organizational chart for the decommissioning work force is presented in Figure 12.1-1. For this study, the decommissioning staff is categorized into two broad groups: 1) support staff, and 2) decommissioning workers. The requirements for these two manpower groups are discussed below. 


\section{H.2.2.I Support Staff Manpower Requirements}

Summaries of the functions performed by key individuals in the decommissioning support staff are presented in Section 12.1.1. Additional descriptive information about the staff-member functions is presented here.

Project Engineer. This person is responsible for planning, coordinating, and carrying out the stabilization activities in a safe and expeditious manner. He provides engineering services and detailed procedures necessary to implement the decomissioning plan. He is responsible for the preparation of all routine and special reports, and he compiles a chronological history of the entire site stabilization project. He provides necessary liaison with the site operator, with appropriate government regulatory agencies, and with the agency responsible for long-term care of the site.

Hea]th and Safety Supervisor. This person is responsible for recommending policy in matters of radiological and industrial safety and for enforcing these policies when they are approved. He establishes and implements radiological safety, industrial safety, and emergency preparedness programs.

Security Force Supervisor. This person is responsible for all site security matters. He supervises the decommissioning security force in protecting the facility and equipment against unauthorized entry or use.

Contracts and Accounting Specialist. This person prepares and expedites procurement orders and purchase requisitions for special tools, equipment, and materials required for stabilization. He maintains a complete record of all costs incurred during the project. He disburses funds with the approval of the project engineer and the site manager.

Quality Assurance Engineer. This person prepares the stabilization quality assurance plan and works with the project engineer to implement the quality assurance program. He reports directly to the site manager in quality assurance matters. He monitors the performance of stabilization crews and equipment and material suppliers and provides other QA functions as outlined in Section F.2. 
Planning Engineer. This person provides planning and scheduling services to the project engineer. He monitors the performance of stabilization activities to ensure adherence to schedule and, where necessary, recommends schedule changes to hasten work completion or to allow for unforeseen work difficulties.

Operations Supervisor. This person develops detailed working procedures and supervises the performance of all stabilization activities. He writes specifications for special equipment and tools that must be procured or fabricated to carry out the stabilization project, and he prepares routine and special reports as requested by the project engineer.

The support staff manpower requirements for each of the six stabilization plans considered in this study, together with the associated costs, are shown in Table H.2-1. These manpower requirements include those during the planning and preparation phase as well as those during the actual site stabilization periods.

\section{H.2.2.2 Decommissioning Worker Manpower Requirements}

Estimates of the number of decommissioning worker man-weeks required to perform the burial ground stabilization, together with the associated manpower costs, are shown in Table H.2-2 for each of the six stabilization plans considered in this study. This table is based on stabilization activity descriptions in Sections 10.3, 10.4, and H.2.1, and on salary data from Table H.1-1.

\section{H.2.3 Equipment and Material Details for Stabilization}

Table H.2-3 gives details of equipment and material requirements and costs for the three stabilization plans for the western site. Table H.2-4 gives details of equipment and material requirements and costs for the three stabilization plans for the eastern site. The data in these tables are based on stabilization activity descriptions in Sections 10.3, 10.4 and H.2.1, and on unit cost data from Tables H.1-6 and H.1-7.

\section{H. 3 COST DETAILS FOR LONG-TERM CARE}

This section provides ampiifying details on manpower requirements for long-term care, and on long-term care maintenance requirements. 


\section{TABLE H.2-l. Estimated Support Staff Manpower Requirements for Burial Ground Stabilization}

\begin{tabular}{|c|c|c|c|c|c|c|c|c|}
\hline Title or Function & $\begin{array}{l}\text { PTanning and } \\
\text { Preparation } \\
\text { Phase }\end{array}$ & $\begin{array}{l}\text { Arid Wes } \\
\text {-Years } \\
\text { Stabil- } \\
\text { ization } \\
\text { Phase. }\end{array}$ & $\begin{array}{l}\text { tern site } \\
\text { Tota! } \$\end{array}$ & $\begin{array}{c}\cos t \\
\text { thousands] }\end{array}$ & $\begin{array}{l}\text { PTanning and } \\
\text { Preparation } \\
\text { Phase }\end{array}$ & $\begin{array}{l}\text { Humid Eas } \\
\text {-Years } \\
\text { Stabit- } \\
\text { ization } \\
\text { Phase }\end{array}$ & Total is & $\begin{array}{c}\text { Cost } \\
\text { thousands }\{a, b\}\end{array}$ \\
\hline \multicolumn{9}{|l|}{ Mimimol Stabilization plans } \\
\hline Project Engineer & 1.00 & 0.19 & 1.19 & 75.7 & 1.00 & 0.21 & 1.21 & 77.0 \\
\hline Heal th and Safety Supervisor & -- & 0.19 & 0.19 & 9.0 & - & 0.21 & 0.21 & 10.0 \\
\hline Health Physics Technician & -- & 0.38 & 0.38 & 9.6 & -- & 0.42 & 0.42 & 10.6 \\
\hline Security Force Supervisor & - & 0.19 & 0.19 & 6.5 & $\cdots$ & 0.21 & 0.21 & 7.1 \\
\hline Security Force Patrolman & -- & 0.76 & 0.76 & 16.2 & -- & 0.84 & 0.84 & 17.9 \\
\hline Contracts and Accounting Specialist & $-\cdots$ & 0.19 & 0.19 & 6.1 & -- & 0.21 & $0.2 !$ & 6.8 \\
\hline Q. A. Engineer & 0.50 & 0.19 & 0.69 & 30.2 & 0.50 & 0.21 & 0.71 & 31,1 \\
\hline Planning Engineer & 1.00 & 0.19 & 1.19 & 52.1 & 1,00 & 0.21 & 1.21 & 53.0 \\
\hline Operations Supervisor & - & 0.19 & 0.19 & 8.3 & - & 0.21 & 0.21 & 9.2 \\
\hline secretary & 1.00 & 0.19 & $\underline{1.19}$. & 24.0 & 1.00 & 0.21 & 1.21 & 24.4 \\
\hline Totals & & & 6.16 & 237.7 & & & 6.44 & 247.1 \\
\hline \multicolumn{9}{|l|}{ Modest Stabilization Plans } \\
\hline Project Engineer & 1.50 & 0.56 & 2.06 & 137.0 & 7.50 & 0.65 & 2.15 & 136.7 \\
\hline Health and Safety Supervisor & 0.50 & 0.56 & 1.06 & 50.5 & 10. 50 & 0.65 & 1.15 & 54.7 \\
\hline Mealth Physics Technician & -- & 1.12 & 1.12 & 28.2 & -- & 1.30 & 1.30 & 32.8 \\
\hline Security Force Supervisor & -+ & 0.56 & 0.56 & 19.0 & -- & 0.65 & 0.65 & 22.1 \\
\hline Security Force Patrolman & -. & 2.24 & 2.24 & 47.7 & -- & 2.60 & 2.60 & 55.4 \\
\hline Contracts and Accounting Specialist & 0.50 & 0.56 & 1.06 & 34.2 & 0.50 & 0.65 & 1.15 & 37.2 \\
\hline Q. A. Engineer & 1.00 & 0.56 & 1.56 & 68.3 & 1.00 & 0.65 & 1.65 & 72.3 \\
\hline Planning Engineer & 1.50 & 0.56 & 2.06 & 90.2 & 1.50 & 0.65 & 2.15 & 94.2 \\
\hline Operations Supervisor & 0.50 & 0.56 & 1.06 & 46.4 & 0.50 & 0.65 & 1.15 & 50.4 \\
\hline Secretary & 1.50 & 0.84 & 2.34 & 47.3 & 1,50 & 0.98 & 2.48 & 50.1 \\
\hline Totais & & & 75.12 & 562.8 & & & 16.43 & 605.9 \\
\hline \multicolumn{9}{|l|}{ Complex Stabilization Plans } \\
\hline Project Engineer & 1.50 & 0.67 & 2.17 & 138.0 & 1.50 & 0.69 & 2.19 & 139.3 \\
\hline Heal th and Sofety Supervisor & 0.50 & 0.67 & 7.17 & 55.7 & 0.50 & 0.69 & 1.19 & 56.6 \\
\hline Health Physics Technician & -- & 1.35 & 1.35 & 34.0 & $\cdots$ & 1.38 & 1.38 & 34.8 \\
\hline Security Force Superyisor & -- & 0.67 & 0.67 & 22.8 & -- & 0.69 & 0.69 & 23.5 \\
\hline Security Force Patrolman & -- & 2.70 & 2.70 & 57.5 & -- & 2,76 & 2.76 & 58.8 \\
\hline Contracts and Accounting Specialist & 0.50 & 0.67 & 1.17 & 37.8 & 0.50 & 0.69 & 1.19 & 38.4 \\
\hline Q. A. Engineer & 1.00 & 0.67 & 1.67 & 73.2 & 1.00 & 0.69 & 1.69 & 74.0 \\
\hline Planning Engineer & 1.50 & 0.67 & 2.17 & 95.0 & 1.50 & 0.69 & 2.19 & 95.9 \\
\hline Doerations Supervisor & 0.50 & 0.67 & 1.17 & 51.2 & 0.50 & 0.69 & 1.19 & 52.1 \\
\hline Secretary & 1.50 & 1.01 & 2.51 & 50.7 & 1.50 & 1.04 & 2.54 & 51.3 \\
\hline Totals & & & 16.75 & 615.9 & & & 37.01 & 624.7 \\
\hline
\end{tabular}

(a) Number of figures shown is for computational accuracy and does not imply precision to the nearest hundred doltars. (b) Contingency of $25 \%$ is not inciuded with these costs. 


\section{TABLE H.2-2. Estimated Decommissioning Worker Manpower Requirements for Burial Ground Stabilization}

Stabilization Activity

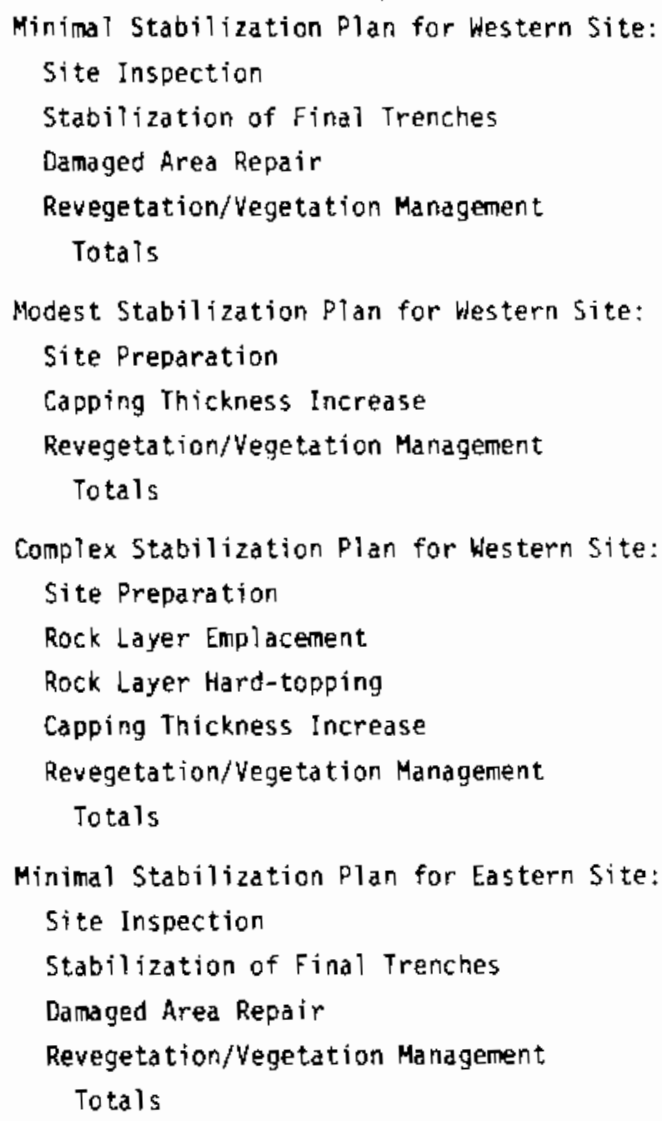

(a) Number of Figures shown is for computational accuracy only. lo) Contingency of $25 \%$ is not included with these costs.
Estimated Man+Heeks (a)

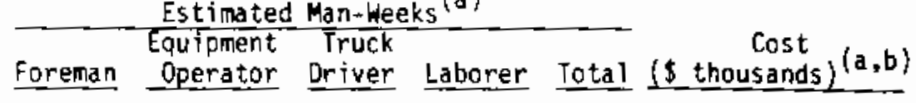

$\begin{array}{rrrrrr}0.5 & \cdots & \cdots & 0.5 & 1 & 0.6 \\ 4 & 16 & \cdots & 4 & 24 & 14.6 \\ 4 & 4 & 8 & 32 & 48 & 25.0 \\ 1 & 1 & 2 & 2 & \frac{6}{79} & \frac{3.3}{43.5}\end{array}$

$\begin{array}{rrrrrr}19 & 7 & 8 & 65 & 99 & 52.8 \\ 24 & 273 & --- & 69 & 366 & 222.3 \\ 4 & 4 & 8 & 8 & \underline{24} & \frac{13.0}{288.1}\end{array}$

$\begin{array}{rrrrrr}19 & 7 & 8 & 65 & 99 & 52.8 \\ 24 & 142 & 200 & 86 & 452 & 247.5 \\ 23 & 145 & 42 & 48 & 258 & 151.1 \\ 24 & 273 & -2 & 69 & 366 & 222.3 \\ 4 & 4 & 8 & 8 & \frac{24}{1199} & \frac{13.0}{686.7}\end{array}$

$\begin{array}{rrrrrr}0.5 & -. & \ldots & 0.5 & 1 & 0.6 \\ 4 & 16 & -.- & 4 & 24 & 14.6 \\ 7 & 7 & 10 & 48 & 72 & 37.8 \\ 1 & 1 & 2 & 2 & \frac{6}{103} & \frac{3.3}{56.3}\end{array}$

$\begin{array}{rrrrrr}20 & 10 & 10 & 81 & 121 & 64.3 \\ 24 & 273 & \ldots- & 69 & 366 & 222.3 \\ 21 & 40 & -- & 22 & 83 & 49.6 \\ 31 & 128 & 64 & 54 & 277 & 159.4 \\ 4 & 4 & 8 & 8 & -\frac{24}{871} & \frac{13.0}{508.6}\end{array}$

$\begin{array}{rrrrrr}26 & 46 & 10 & 87 & 169 & 93.9 \\ 22 & 180 & 20 & 88 & 310 & 181.6 \\ 21 & 161 & 2 & 62 & 246 & 147.0 \\ 24 & 163 & -- & 69 & 256 & 152.7 \\ 8 & \cdots- & --- & 32 & 40 & 21.0 \\ 4 & 4 & 8 & 8 & \underline{24} & \frac{13.0}{609.2}\end{array}$




\section{TABLE H.2-3. Equipment and Material Requirements and Costs for Stabilization of the Western Site}

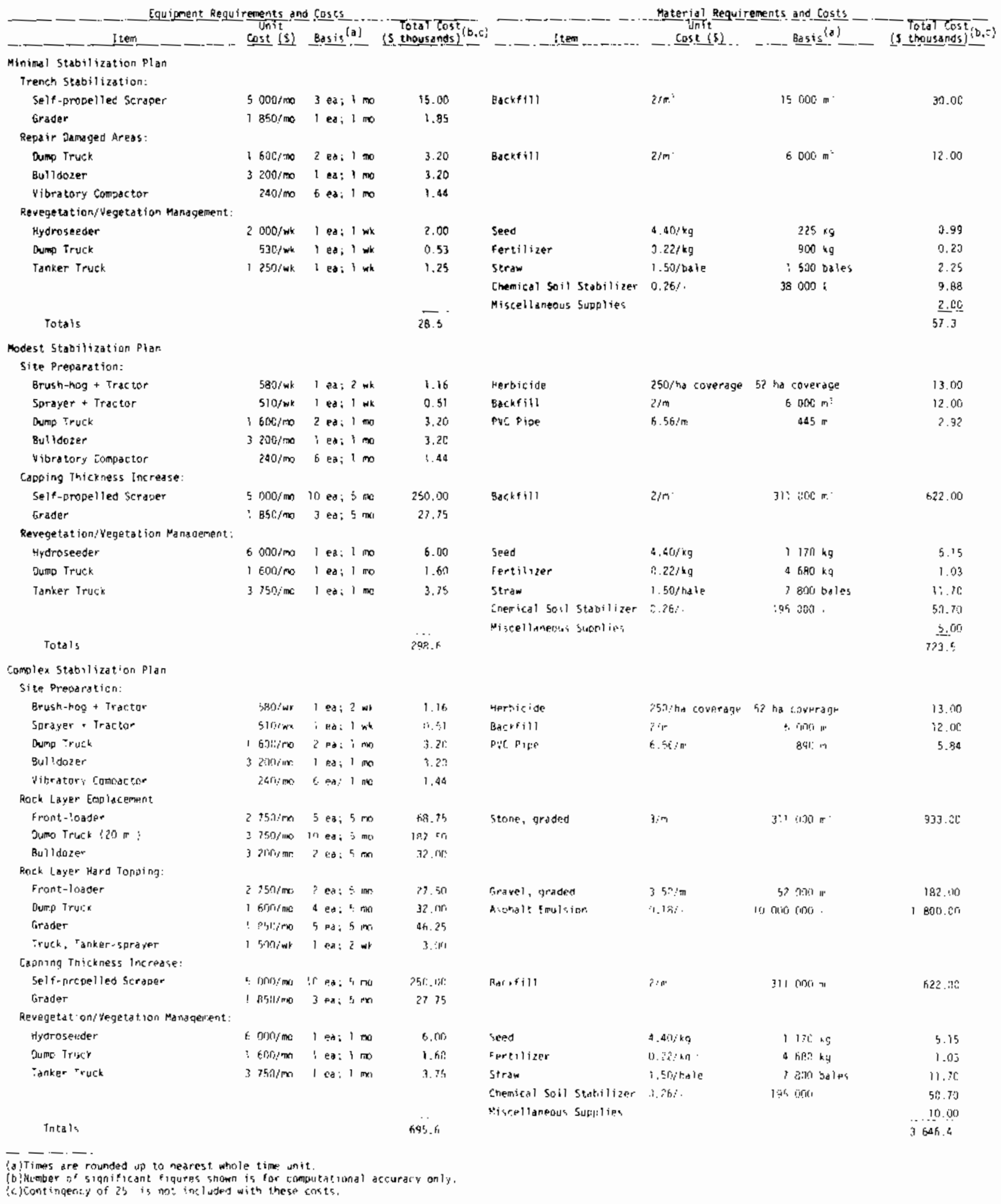




\section{TABLE H.2-4. Equipment and Material Requirements and Costs for Stabitization of the Eastern Site}

\begin{tabular}{|c|c|c|c|c|c|c|c|}
\hline \multicolumn{4}{|c|}{ Equipent Aequirements and costs. } & \multicolumn{4}{|c|}{ Material Requirements and Costs } \\
\hline lte. & $\begin{array}{l}\text { thit } \\
\text { cost }(5)\end{array}$ & Bas $(5)$ & (5 Thousands] $(0,0)$ & - item & $\begin{array}{l}\text { Untit } \\
\text { cost }[5 y \\
\end{array}$ & Basis (a) & 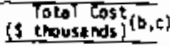 \\
\hline \multicolumn{8}{|l|}{ Minimal stabllitation Plan } \\
\hline \multicolumn{8}{|l|}{ Trench Stabllization: } \\
\hline Self-propelled Scraper & $5000 / n 0$ & 3 ed: 1 mo & $15 . \infty$ & \multirow[t]{2}{*}{ Aackfill } & $2 / m^{1}$ & \multirow[t]{2}{*}{$15200 m^{3}$} & \multirow[t]{2}{*}{30.00} \\
\hline Grzder & $1850 / m$ & $1 \mathrm{ed} ; 1 \mathrm{mo}$ & 1.85 & & & & \\
\hline \multicolumn{8}{|l|}{ Repoir Ounaged Areds: } \\
\hline then Truek & $1600 / 0$ & 2 ea; 1 mo $+1 m k$ & 4. 26 & Bockfrl1 & $2 / m^{4}$ & $7500 \mathrm{~m}^{3}$ & 35.00 \\
\hline Bulldozer & $3200 / \mathrm{mo}$ & : ed: $1 \mathrm{~m}+1 \mathrm{mk}$ & 4. 36 & & & & \\
\hline Hibrutory Compac tor & $240 / m 0$ & Eet 1 mo +1 wk & 1.92 & & & & \\
\hline Front-poder & $500 / \mathrm{wk}$ & $1 \Leftrightarrow, 2 \cdots$ & 1.80 & & & & \\
\hline Revegetsat ian/Vege Lation Manageme & & & & & & & \\
\hline Hydroseeder & $2000 / \mathrm{wk}$ & 1 ed : 1 ik & $2.0 \mathrm{C}$ & Seed & $4.40 / \mathrm{kg}$ & $225 \mathrm{~kg}$ & 0.99 \\
\hline Tou Truck & $530 / \omega h$ & 1 ed ; 1 mk & 0.53 & Dertilizer & $0.22 / \mathrm{kg}$ & $900 \mathrm{~kg}$ & 0.20 \\
\hline Tanker irues: & $1250 / \mathrm{nk}$ & $1 \mathrm{ed}, 1 \mathrm{wk}$ & 1.25 & Strow & $1.50 / \mathrm{bal} 1 \mathrm{e}$ & 1500 doles & 2.25 \\
\hline & & & & themical soil stabilizer & $0.26 / 8$ & 380008 & 9.88 \\
\hline & & & - - & Misceilaneous Supdies & & & 3.00 \\
\hline Totals & & & 32.9 & & & & 61.3 \\
\hline Motest Stubilization Plan & & & & & & & \\
\hline Site Preparation: & & & & & & & \\
\hline Brush-rog + Tractor & $580 / 4 k$ & 1 et: $2 \mathrm{mk}$ & 1.16 & & & & \\
\hline Sprayer + Tractor & $5) 0 /=k$ & 1 ed: 1 wh & 0.53 & Herbicude & $250 / n d$ coverage & 52 hid coverape & 3.00 \\
\hline an iruck & $1600 / \mathrm{mo}$ & 2 ed; 1 mo $+1 \mathrm{mk}$ & 4.26 & $\operatorname{Asc} x+111$ & $2 / m^{3}$ & $7500 \mathrm{~m}^{3}$ & 15.00 \\
\hline Bulloozer & $3200 / 00$ & ied; $1 m+1 m$ & 4.90 & puc pipe & $6.56 / \mathrm{m}$ & $890 \mathrm{~m}$ & 5.64 \\
\hline Vibratory Eomactor & $240 / m$ & $6 \mathrm{ed} ; 1 \mathrm{mo}+1 \mathrm{mk}$ & 1.92 & & & & \\
\hline Front-loader & $990 / \mathrm{mk}$ & 1 ed. 2 wh & $1.8 c$ & & & & \\
\hline Copping Thickness increase. & & & & & & & \\
\hline Self-propelled scraper & S $000 / \mathrm{mo}$ & 10 ed: $5 \mathrm{mo}$ & 250.00 & & & & \\
\hline bracer & $1850 / 100$ & 3 ed: 5 mo & 27.75 & Eachentil & $2 / \mathrm{m}$ & $311000 \mathrm{~m}^{3}$ & 522.00 \\
\hline Cupping Orsinage Improvement. & & & & & & & \\
\hline Qulldozet & $3200 / \mathrm{mo}$ & $200: 5 n$ & $32 . \infty$ & & & & \\
\hline Copping soil properties modifice & & & & & & & \\
\hline man Truck & $16000 / \mathrm{mo}$ & 8 es: $2 \mathrm{mo}$ & 25.60 & & & & \\
\hline enlldozer & $3200 / m 0$ & $2 \mathrm{ed} ; 2 \mathrm{mo}$ & 12.80 & & & & \\
\hline Disc-Aarrox + Tractor & $1675 / \mathrm{mo}$ & 1 ed: $2 \mathrm{me}$ & 335 & Clay & $1 \mathrm{C} / \mathrm{m}^{\prime}$ & $52000 \mathrm{~m}^{3}$ & $520, \infty$ \\
\hline Sinepsfoot noller & $3000 / \pi 0$ & $5=8 ; 5 \pi$ & $35 . \mathbf{C}$ & & & & \\
\hline Grader & $185 \mathrm{C} / \mathrm{mo}$ & 1 ea, $1 \mathrm{mc}$ & 1.85 & & & & \\
\hline Revegetation/regetation magyemer & & & & & & & \\
\hline Mydroseceder & $6000 / \mathrm{mo}$ & 1 से 1 m & 6.60 & seed & $4.40 / \mathrm{kg}$ & $1170 \mathrm{~kg}$ & 5.15 \\
\hline $\operatorname{mos}$ iruck & $1600 / \mathrm{mo}$ & 1 ed; $1 \mathrm{mo}$ & $1 . \mathrm{bc}$ & Fertilizer & c. $z 2 / \mathrm{kg}$ & $4680 \mathrm{~kg}$ & 1.03 \\
\hline Tanker Truck & $3750 / \mathrm{mo}$ & 1 es; 1 mo & 3.75 & Straw & $1.50 / \mathrm{te}$ & 3800 bales & 11.70 \\
\hline & & & & Chemical soil stabllizer & $0.26 i$ & $195000 ;$ & 50.70 \\
\hline & & & -- & Miscellapgous Supdies & & & 6.00 \\
\hline Totais & & & 4538 & & & & 1250.4 \\
\hline cosplen Subjilization Plan & & & & & & & \\
\hline Site Preparstion: & & & & & & & \\
\hline Brush-nog + Tractor & $\mathbf{s 8 0 / \pi k}$ & $1 \mathrm{ed}: 2 \mathrm{wh}$ & 1.16 & Herbucide & $250 /$ ha coverage & 52 ha coverape & 19.00 \\
\hline Sprayer + Tractor & $510 / \mathrm{k}$ & 1 et i 1 ak & 0.51 & Backfill & $2 / m$ & $7500 \pi ?$ & 15.00 \\
\hline an Truck & $1600 / \pi 0$ & 2 ed; $1 m+1$ & s. 26 & Py: Pipe & e. $56 / \pi$ & $890 \mathrm{~m}$ & 5.84 \\
\hline dullozer & $3700 / m$ & 7 eat 2 m & 44.80 & & & & \\
\hline Wibratory comactor & $240 / \mathrm{mm}$ & b er: $2 \mathrm{mo}$ & 2.88 & & & & \\
\hline front-louder & $900 / \times k$ & $1 e d ; z \omega$ & 1.80 & & & & \\
\hline Hard Layer Eplacement: & & & & & & & \\
\hline Roller, Tanders Drum & $1050 / 00$ & $10 \mathrm{et} ; 4 \mathrm{mo}$ & 92.00 & Asponde Emalsion & $0.18 \%$ & $10000000 \mathrm{e}$ & 1800.00 \\
\hline Self-propelied soil Stabilizer & $12000 / m 0$ & 1 ed i $5 \mathrm{mo}$ & 60.00 & & & & \\
\hline Truck, Tanker-spruyer & $4500 / \pi 0$ & 1 tes: 5 mo & 22.50 & & & & \\
\hline Peripheral Dralnage/Diversion: & & & & & & & \\
\hline Self-propelled scraper & $5000 / \mathrm{mo}$ & 8 ea: 5 mo & 200.00 & 5eed & $4.45 / \mathrm{kg}$ & $225 \mathrm{~kg}$ & 0.99 \\
\hline Hydrusecder & $2000 / \pi \mathrm{k}$ & 1 ea: 1 at & 2.00 & Fertrilizer & $0.22 / \mathrm{kg}$ & $900 \mathrm{~kg}$ & 4.20 \\
\hline men Iruck & $530 / w k$ & 1 ed, 1 . & 0.53 & straw & $1.50 / 0$ ale & 1500 bales & 2.25 \\
\hline Tanker Iruck & $1250 / \pi k$ & 1 ed : 1 mk & 1.25 & Chemiral soil Stabllizer & $0.26 / i$ & 280008 & 9.88 \\
\hline Copping inickness increase: & & & & & & & \\
\hline Selt-propelied Scraper & $50000 / m_{0}$ & $10 \mathrm{ed} ; 2 \mathrm{mo}+2 \mathrm{mk}$ & 134.90 & Backfill & $2 / m$ & $138000 \mathrm{~m}^{?}$ & 276.00 \\
\hline Grader & $1850 / \mathrm{moc}$ & 3 ea; 5 mo & 27.75 & & & & \\
\hline Preperations for Sulw Pumping: & & & & & & & \\
\hline Light-duty artil Rig & $500 / d a y$ & & 1 ea : 10 day & & 5.00 & PU: Pipe & 1.97 \\
\hline Revege tut ion/Yege ta cion Marlageme & & & & & & & \\
\hline Hidrosender & $6000 / \mathrm{mo}$ & Ied: $1 \mathrm{mo}$ & 6.00 & seed & $4.40 / \mathrm{kg}$ & $1170 \mathrm{~kg}$ & 5.15 \\
\hline Don Truck & $1600 / m 0$ & $1 \mathrm{ex}: 1 \mathrm{mo}$ & 1.60 & Fertilizer & $0.227 \mathrm{hg}$ & $4680 \mathrm{~kg}$ & 1.03 \\
\hline Tanker Truck & $3750 / \mathrm{mo}$ & 1 ea: $1 \mathrm{mo}$ & 3.75 & straw & 1.5c/oale & 7 a0o bales & 11.70 \\
\hline & & & & Chemical solil Statilizer & $0.26 i:$ & $195300 \mathrm{R}$ & 50.70 \\
\hline & & & - - & Miscellaneous Supplies & & & 12.00 \\
\hline Touls & & & 561.8 & & & & 2205.7 \\
\hline
\end{tabular}

(a) Times are rounded up wo neterst whole $t$ late unft. 


\section{H.3.1 Manpower Details for Long-Term Care}

Manpower requirements for long-term care are sumnarized in Section 12.2.1 of Volume 1. For this study, it is assumed that the responsible government agency provides the manpower for long-term care either directly (by using agency staff members to perform long-term care tasks) or indirectly (by contracting for labor as needed).

The project engineer is responsible for the long-term care of the site. He is assumed to be a staff member of the responsible agency and is engaged in the management of the site on a part-time basis. He is responsible for inspecting the site and for planning, coordinating, and carrying out the longterm care tasks in a safe and cost-effective manner. He provides the necessary engineering services and detailed procedures and is responsible for the preparation of reports.

The manpower requirements and costs for long-term care of the stabilized burial ground are shown in Tables H.3-l through H.3-4. The requirements and costs are broken down by tasks and are shown for three time periods (corresponding to different levels of effort) during long-term care.

\section{H.3.2 Long-Term Care Details and Assumptions}

The long-term care of a stabilized burial ground site is discussed in Section 10.6 of volume 1 . Further details and assumptions used to calculate costs are presented here. Cost summaries for long-term care are presented in Section 12.2 .

\section{H.3.2.1 Environmental Monitoring Details}

Environmental sampling requirements during long-term care are summarized in Table 9.2-1 of Volume 1. For the first 25 years after site stabilization, the sampling frequency and the number of sample locations are assumed to be maintained at the level required during the operational period of the site. After the initial 25 years of the long-term care period, the environmental sampiing requirements are assumed to be reduced, on an overall basis, to about one-quarter of the operational support level. It is assumed that personnel from the responsible government agency obtain the environmental samples and that a non-agency contractor provides analytical laboratory services and 
TABLE H.3-1. Annual Manpower Requirements for Long-Term Care of the Arid Western Site Following Site Stabilization by the Minimal or Modest Plan

\begin{tabular}{|c|c|c|c|c|c|c|c|c|c|c|c|c|c|c|c|c|c|c|}
\hline & & & $\begin{array}{l}5 \text { Yedrs A } \\
\text { Equibivent }\end{array}$ & & 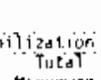 & & & & 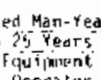 & ftets $s_{0}$ & oitizatior & & Project & -26 & 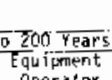 & & Tobiti & 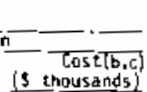 \\
\hline Long-1erm Care Task (d) & Inqineer & & & & & is thurusonds! & Englaner & & & & & [E thoustands! & & & & Laborer & & \\
\hline te Inspection and Plaming & 0.20 & 0.20 & -. & -. & 0.40 & 19.3 & 0.14 & a.1; & - & -- & ए:. 30 & 14.5 & ii. 15 & 0.15 & -. & -. & 0.30 & 14.5 \\
\hline ostion Repsits & .. & 0.06 & 18. 13 & $0.0 \mathrm{~b}$ & 0.34 & 5.2 & .. & 0.116 & 0.06 & 0.06 & 0.18 & 5.5 & $\cdots$ & 0.96 & 0.06 & 0.06 & 0.18 & 5.5 \\
\hline sidencer Repsir ir & -. & 0.20 & 0.20 & 1. 20 & 0.60 & 19.3 & -. & -. & -. & -- & -. & -. & -- & -- & . & -- & -- & -- \\
\hline te Access Controt suintenance & -. & 0.02 & -. & 0 , the & 18.06 & 1.1 & -. & 0.92 & -- & 0.194 & 3.06 & 1.7 & .. & 0.02 & -- & 0.04 & 0.06 & 1.7 \\
\hline jetation magement & -. & 0.92 & -- & $\mathrm{Dr}, 0 \mathrm{~d}$ & 0.116 & 1.7 & .. & (1.1) 2 & -- & 19.04 & 0.06 & 1.7 & -- & 0.02 & -- & 0.04 & 0.06 & 1.7 \\
\hline riramental sogling & $\therefore$ &. & 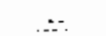 & 0.40 & 13.40 & 10.4 & -- & . & $\because$ & $0,4 \mathrm{D}$ & 0.40 & 1114.4 & $\therefore$ & $\because$ &.$=-$ & 0.20 & 0.20 & 5.2 \\
\hline tals & 0.20 & 0.50 & 0.26 & 0.74 & 1.70 & 56.9 & $0.1 \%$ & 4.25 & 0.00 & $0.9 \mathrm{~A}$ & 1.00 & 33.3 & a. 15 & 0.25 & 0.06 & 0.34 & 0.80 & 28.6 \\
\hline
\end{tabular}

(1) The long-term care tasks are describes in Section 10.6 of yolume

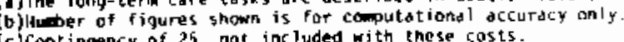

TABLE H.3-2. Annual Manpower Requirements for Long-Term Care of the Arid Western Site Following Site Stabilization by the Complex Plan

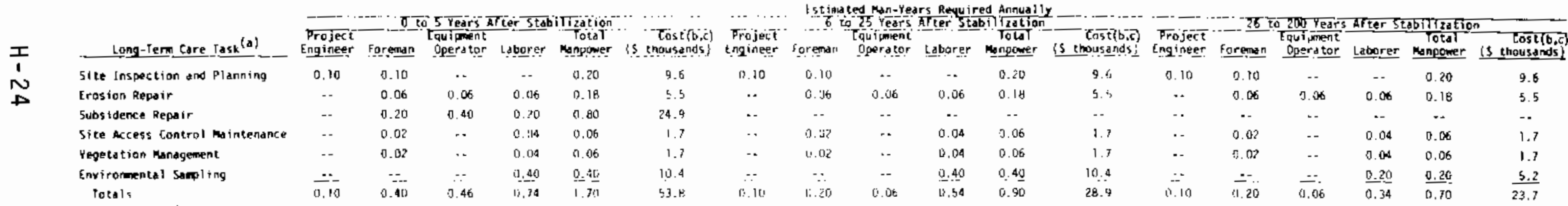

a) The lang-term care tasks are described in Section 10.6 of volune 1 .

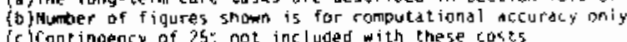


TABLE H.3-3. Annual Manpower Requirements for Long-Term Care of the Humid Eastern Site Following Site Stabilization by the Minimal or Modest Plan

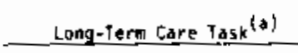

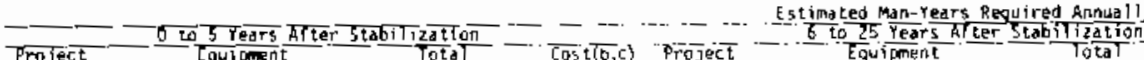

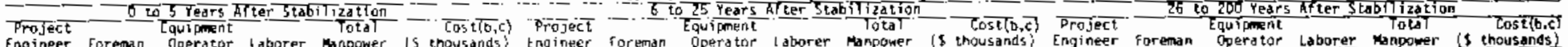

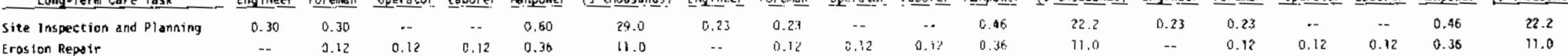
Erasion Repotr

Subsidence Repsir

Access Control and Orainage

Access Control
Ma intenance

Vegetstion Management

Envtronmental Samplitig

Totals

$\begin{array}{ccccc}- & 0.04 & 0.02 & 0.08 & 0.14 \\ -- & 0.08 & \cdots & 0.15 & 0.23 \\ --- & -\because .74 & \underline{-} & \frac{0.60}{1.15} & \frac{0.60}{2.53}\end{array}$

29.0
11.0
18.3
4.0
6.5
15.5
10.3

(a) The long-term care tasks are described in Section $10.60^{\circ}$ volume 1.

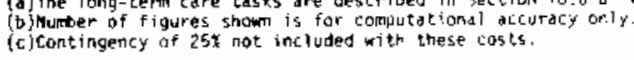

TABLE H.3-4. Annual Manpower Requirements for Long-Term Care of the Humid Eastern Site Following Site Stabilization by the Complex Plan

\begin{tabular}{|c|c|c|c|c|c|c|c|c|c|c|c|c|c|c|c|c|c|c|}
\hline __Long-Term Care Task (A) & $\begin{array}{l}\text { Project } \\
\text { Enginer }\end{array}$ & E- & 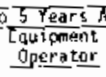 & $\begin{array}{l}\text { Teat stats } \\
\text { Labarer. }\end{array}$ & 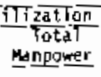 & 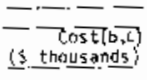 & 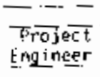 & Foreman & 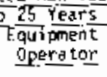 & Laborer & 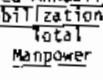 & $\begin{array}{r}\operatorname{Tost}(0, c) \\
\text { \{s thousands) }\end{array}$ & $\begin{array}{l}\text { Project } \\
\text { Engineser }\end{array}$ & forenan. & 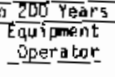 & Laborer & rotat & $\begin{array}{l}\text { Costitb,a) } \\
\text { (s) thousandsi }\end{array}$ \\
\hline Site inspection and planning & 0.30 & c. 30 & .. & -- & 0.60 & 29.0 & 0.23 & 0.23 & $\cdots$ & -- & 0.46 & 22,2 & 0.23 & 0.23 & -. & -- & 0.46 & 22.2 \\
\hline Erosion Repair & .- & 0.12 & (1. 12 & 0.12 & 0.36 & 11.0 &.- & 0.12 & 0.12 & 0.12 & 0.36 & 11.0 & -- & 0.12 & 0.12 & 0.12 & 0. 36 & 11,0 \\
\hline Subsidence Repair & -. & 0.30 & 0.60 & 0,30 & 1.20 & 37.4 & -. & -- & -. & $-\cdot$ & -. & $\cdot$ & -. & -- & $\cdots$ & $\cdots$ & $\cdots$ & $-\bullet$ \\
\hline $\begin{array}{l}\text { Access Contral and Dratnage } \\
\text { Moincenance }\end{array}$ & -- & 0.06 & 0.04 & 0.12 & 0.27 & 6.4 & -- & 0.06 & 0.04 & 0.12 & 0.22 & 6.4 & -. & 0.06 & 0.94 & 0.12 & 0.72 & 6.4 \\
\hline Vegetation Munagement & -- & 0.08 & -. & 0.15 & $0.2 \hat{3}$ & ह. & -. & $0 . \mathrm{cH}$ & -- & 0.75 & 0.23 & 6.5 & -- & 0.08 & -. & 0.75 & 0.23 & 6.5 \\
\hline Envitronmentel sampling & $=$ & $\ddot{-}$ & $=-$ & 0.69 & 0.66 & $15 \div$ & $\because$ & $\because$ &.. & v. 60 & 0.60 & 15.5 & $\ddot{z}$ & $\therefore-$ & 二- & 0.30 & $\underline{0.30}$ & $\underline{7.8}$ \\
\hline & 0.30 & 0.86 & 0.76 & 1.29 & 3.21 & 105.8 & $0.2: 1$ & 0.94 & 6.36 & 0.99 & 1.37 & 64.6 & 0.23 & 0.49 & 0.16 & 0.69 & 3.57 & 53.9 \\
\hline
\end{tabular}

(a) The Tong-term care tasks are described in Section 10,6 of volunie

cicontingency of $25 \%$ not included with these costs. 
data-reporting support. Due to differences in the physical site characteristics, sampling and analytical requirements for the eastern site are somewhat greater than those for the western site.

\section{H.3.2.2 Site Maintenance Details}

Site maintenance tasks during long-term care are based on the requirements for maintaining the confinement measures provided by each of the stabilization plans described in Section 10. Site maintenance tasks are assumed to be accomplished with personnel, materials, and equipment similar to those employed during the initial site stabilization activities. Cost parameters (such as salaries, work capacities, unit costs, and equivalent material requirements) are assumed to be identical to those used for estimating the initial site stabilization costs given in Section H.2.

A major maintenance task anticjpated at the reference sites is the repair of areas of trench subsidence after the stabilization work is completed. For these cost estimates, it is assumed that during the first 5 years after site stabilization, an average of $2 \%$ per year of the completed trench area will subside; after the initial 5-year subsidence period, little or no additional subsidence is expected. Accordingly, the site maintenance cost estimates are highest during the first 5 years after site stabilization.

A second major maintenance task expected at the sites is repair of trench caps that have been damaged by surface erosion. It is estimated that, at the reference western site, approximately 1\% of the trench cap area will require repair each year; at the reference eastern site, $2 \%$ per year of the trench cap area will require repair. Some minor degree of trench cap damage from surface erosion is expected to be a "chronic" condition for the entire long-term care period. Vegetation management and site access control maintenance (i.e., maintenance of fences, trench markers, etc.) are also continued for the entire 200-year period.

\section{H.4 COST ASSESSMENT DETAILS FOR WASTE RELOCATION}

This section provides amplifying details for the cost estimates for waste relocation given in Section 12.3 of Volume 1 . 


\section{H.4.1 Manpower Requirements and Costs for Waste Relocation}

Details of manpower requirements and costs for waste relocation activities are presented in Tables H.4-T through H.4-6. Tables H.4-l and H.4-2 show manpower requirements and costs for relocation of high beta-gamma radioactivity waste from a slit trench for the reference western and eastern sites, respectively. Tables H.4-3 and H.4-4 show manpower requirements and costs for exhumation of a TRU waste package from a burial trench. Tables H.4-5 and H.4-6 show manpower requirements and costs for relocation of all of the waste from a burial trench. Manpower and cost details are shown in the tables for each of the excavation options considered for the three cases studied.

Decomissioning manpower requirements are calculated on the bases of time requirements and operating crews postulated for the performance of the various decomissioning operations described in Section 11 of Volume 1 . Time requirements and operating crews for waste relocation from a slit trench are shown in Tables 11.2-2 and 11.2-3. Time requirements and operating crews for exhumation of a TRU waste package are shown in Tables 11.3-2 and 11.3-3. Time requirements and operating crews for relocation of all the waste from a single burial trench are shown in Tabies 11.4-1 and 11.4-2. Labor costs are based on unit salary data shown in Table H. 1-l of Section H.l.

\section{H.4.2 Material and Equipment Cost Details for Waste Relocation}

Details of material and equipment costs for waste relocation activities are presented in Tables H.4-7 through H.4-12. Tables H.4-7 and H.4-8 show contractor's equipment costs and costs of expendable equipment and supplies for relocation of high beta-gamma radioactivity waste from a slit trench. Tables H.4-9 and H.4-10 show material and equipment cost details for exhumation of a TRU waste package from a section of a burial trench. Tables H.4-11 and H.4-12 show material and equipment cost details for relocation of all the waste from a single burial trench.

Material and equipment requirements are based on waste relocation methods and procedures described in Section 11 and Appendix $G$. Costs are based on unit cost data shown in Tables H.1-6 and H.1-7 of this appendix and on time requirements for waste relocation activities sumarized in Tables 11.2-2, $17.3-2$, and 11.4-1 of Section 11 . 
TABLE H.4-1. Manpower Requirements and Costs for Slit Trench Exhumation - Western Site

\begin{tabular}{|c|c|c|c|c|c|c|c|}
\hline \multirow[b]{2}{*}{ Operation } & \multicolumn{5}{|c|}{ Mn-Heeks } & \multicolumn{2}{|c|}{ Iotal Labor } \\
\hline & Foreman & $\begin{array}{l}\text { Equipment } \\
\text { Operator }\end{array}$ & Laborer & $\begin{array}{r}\text { Truck } \\
\text { Driver } \\
\end{array}$ & $\begin{array}{c}\text { Health } \\
\text { Physics } \\
\text { Technician }\end{array}$ & Man-Weeks & $(\$ \text { thousands })^{(\mathrm{a}, \mathrm{b})}$ \\
\hline \multicolumn{8}{|l|}{ Common Activities } \\
\hline Core Orilling & 4.0 & -- & 8.0 & -- & 4.0 & 16.0 & 8.45 \\
\hline Remove Overburden & -- & 0.6 & -- & -- & 0.6 & 1.2 & 0.67 \\
\hline Install sheet Piring & 5.4 & 10.8 & 5.4 & - & 5.4 & 27.0 & 15.56 \\
\hline Remove Sheet Piling & 7.6 & 15.2 & 7.6 & -- & 7.6 & 38.0 & 21.89 \\
\hline Backfill irench & - & 1.6 & $\cdots$ & 0.8 & 0.8 & 3.2 & 1.80 \\
\hline \multicolumn{8}{|l|}{ Hydraulic Excavation } \\
\hline Common Activities & 17.0 & 28.2 & 21.0 & 0.8 & 18.4 & 85.4 & 48.4 \\
\hline Exhume Waste & 30.8 & $6\}, 6$ & 61.6 & $=$ & $30 . \underline{8}$ & 184.8 & 104.1 \\
\hline Totals & 47.8 & 89.9 & 82.6 & 0.8 & 49.2 & 270.2 & 152.5 \\
\hline \multicolumn{8}{|l|}{ Pneumatic Excavation } \\
\hline Common Activities & 17.0 & 28.2 & 21.0 & 0.8 & 18.4 & 85.4 & 48.4 \\
\hline Exhume Haste & 19.2 & 38.4 & $\underline{38.4}$ & $\approx$ & 19.2 & 115.2 & 64.9 \\
\hline Totals & 36.2 & 66.6 & 59.4 & 0.8 & 37.6 & 200.6 & 113.3 \\
\hline \multicolumn{8}{|c|}{ Polar Crane $w /$ Sheet Piling } \\
\hline Common Activities & 17.0 & 28.2 & 21.0 & 0.8 & 18.4 & 85.4 & 48.4 \\
\hline Exhume Haste & $\underline{11} . \underline{8}$ & $\underline{23.6}$ & $\underline{23.6}$ & $=$ & $\underline{11.8}$ & 70.8 & 39.9 \\
\hline Totals & 28.8 & 51.8 & 44.6 & 0.8 & 30.2 & 156.2 & 88.3 \\
\hline \multicolumn{8}{|c|}{ Polar Crane $w / 0$ Sheet Piling } \\
\hline Common Activities & 4.0 & 2.2 & 8.0 & 0.8 & 5.4 & 20.4 & 10.9 \\
\hline Exhume Waste & 13.6 & 27.2 & $\underline{27.2}$ & $\because$ & 13.6 & 81.6 & 46. .0 \\
\hline Totals & 17.6 & 29.4 & 35.2 & 0.8 & 19.0 & 102.0 & 56.9 \\
\hline \multicolumn{8}{|l|}{ Gantry Crane } \\
\hline Common Activities & 17.0 & 28.2 & 21.0 & 0.8 & 18.4 & 85.4 & 48.4 \\
\hline Exhume Waste & 14.4 & 28.8 & 28.8 & $\approx$ & 14.4 & 86.4 & 48.7 \\
\hline Totals & 31.4 & 57.0 & 49.8 & 0.8 & 32.8 & 171.8 & 97.1 \\
\hline \multicolumn{8}{|l|}{ Gantry Crane Enclosed } \\
\hline Common Activities & 17.0 & 28.2 & 21.0 & 0.8 & 18.4 & 85.4 & 48.4 \\
\hline Exhume Waste & $\underline{21} . \underline{6}$ & 43.2 & 43.2 & $=$ & 21.6 & 129.6 & 73.0 \\
\hline Totals & 38.6 & 71.4 & 64.2 & 0.8 & 40.0 & 215.0 & 121.4 \\
\hline
\end{tabular}

(a) Number of figures shown is for computationa? accuracy only.

(b) Contingency of $25 \%$ not included with these costs. 


\section{TABLE H.4-2. Manpower Requirements and Costs for slit Trench Exhumation - Eastern Site}

\begin{tabular}{|c|c|c|c|c|c|c|}
\hline \multicolumn{5}{|c|}{ Man-Heeks } & \multicolumn{2}{|c|}{ Total Labor } \\
\hline oreman & $\begin{array}{r}\text { Equipment } \\
\text { Operator }\end{array}$ & Laborer & $\begin{array}{l}\text { Truck } \\
\text { Driver }\end{array}$ & $\begin{array}{l}\text { Physics } \\
\text { Technician }\end{array}$ & Man-Week 5 & $\begin{array}{c}\text { Cost } \\
(\$ \text { thousands })\end{array}$ \\
\hline
\end{tabular}

\begin{tabular}{|c|c|c|c|c|c|c|c|}
\hline \multicolumn{8}{|l|}{ Common Activities } \\
\hline Core Drilling & 4.8 & $-\mu$ & 9.2 & $\cdots$ & 4.8 & 18.8 & 9.94 \\
\hline Remove Overburden & $\cdots$ & 0.6 & -- & -- & 0.6 & 1.2 & 0.70 \\
\hline Install sheet Piling & 6.6 & 13.2 & 6.6 & -- & 6.6 & 33.0 & 19.01 \\
\hline Remove Sheet Piling & 9.0 & 18.0 & 9.0 & -- & 9.0 & 45.0 & 25.93 \\
\hline Backfill Trench & $-\cdot$ & 2.0 & + & 1.0 & 1.0 & 4.0 & 2.34 \\
\hline \multicolumn{8}{|l|}{ Kydraulic Excavation } \\
\hline Common Activities & 20.4 & 33.8 & 24.8 & 1.0 & 22.0 & 102.0 & 57.9 \\
\hline Exhume waste & 37.0 & 74.0 & $\underline{74.0}$ & $\approx$ & 37.0 & $\underline{222.0}$ & 125.0 \\
\hline Totals & 57.4 & 107.8 & 98.8 & 1.0 & 59.0 & 324.0 & 182.9 \\
\hline \multicolumn{8}{|l|}{ Pneumatic Excavation } \\
\hline Conmon Activities & 20.4 & 33.8 & 24.8 & 1.0 & 22.0 & 102.0 & 57.9 \\
\hline Exhume waste & 23.0 & 46.0 & 46.0 & $\because$ & 23.0 & 138.0 & 77.7 \\
\hline Totais & 43.4 & 79.8 & 70.8 & 1.0 & 45.0 & 240.0 & 135.6 \\
\hline \multicolumn{8}{|c|}{ Polar Crane w/Sheet Piling } \\
\hline Comon Activities & 20.4 & 33.8 & 24.8 & 1.0 & 22.0 & 102.0 & 57.9 \\
\hline Exhume Waste & 14.2 & $\underline{28.4}$ & 28.4 & $\approx$ & 14.2 & 85.2 & 48.0 \\
\hline Totals & 34.6 & 62.2 & 53.2 & 1.0 & 36.2 & 187.2 & 105.9 \\
\hline \multicolumn{8}{|c|}{ Polar Crane w/o Sheet Piling } \\
\hline Comon Activities & 4.8 & 2.6 & 9.2 & 1.0 & 6.4 & 24.0 & 13.0 \\
\hline Exhyme Waste & 16.2 & $\underline{32.4}$ & 32.4 & $\because$ & 16.2 & 97.2 & 54.7 \\
\hline Totals & 21.0 & 35.0 & $4 ! .6$ & 1.0 & 22.6 & 121.2 & 67.7 \\
\hline \multicolumn{8}{|l|}{ Gantry Crane } \\
\hline Comon Activities & 20.4 & 33.8 & 24.8 & 1.0 & 22.0 & 102.0 & 57.9 \\
\hline Exhume Waste & 17.4 & 34.8 & 34.8 & $\cong$ & 17.4 & 104.4 & 58.8 \\
\hline Totals & 37.8 & 68.6 & 59.6 & 1.0 & 39.4 & 206.4 & 116.7 \\
\hline \multicolumn{8}{|l|}{ Gantry Crane Enclosed } \\
\hline Common Activities & 20.4 & 33.8 & 24.8 & 1.0 & 22.0 & 102.0 & 57.9 \\
\hline Exhune Waste & 26.0 & 52.0 & 52.0 & $=$ & 25.0 & $\underline{156.0}$ & 87.8 \\
\hline Totals & 46.4 & 85.8 & 76.8 & 1.0 & 48.0 & 258.0 & 145.7 \\
\hline
\end{tabular}

(a) Number of figures showf is for computational accuracy only.

(b) Contingency of 25: not inciuded with these casts. 


\section{TABLE H.4-3. Manpower Requirements and Costs for TRU Waste Exhumation - Western Site}

\begin{tabular}{|c|c|c|c|c|c|c|c|}
\hline \multirow{2}{*}{ Copration } & \multicolumn{5}{|c|}{ Man-Weeks } & \multicolumn{2}{|c|}{ Total Labor } \\
\hline & Foreman & $\begin{array}{l}\text { Equipment } \\
\text { Operator }\end{array}$ & Laborer & $\begin{array}{c}\text { Truck } \\
\text { Oriver }\end{array}$ & $\begin{array}{r}\text { Health } \\
\text { Physics } \\
\text { Technician }\end{array}$ & Man-keeks & (s thousan \\
\hline \multicolumn{8}{|l|}{ Common Activities } \\
\hline Core Drilling & 2.6 & - & 5.2 & -- & 2.6 & 10.4 & 5.50 \\
\hline Remove Overburden & $\cdots$ & 0.2 & -- & - & 0.2 & 0.4 & 0.23 \\
\hline Install sheet piling & 1.2 & 2.4 & 1.2 & -- & 1.2 & 6.0 & 3.46 \\
\hline Remove Sheet Piling & 1.6 & 3.2 & 1.6 & -- & 1.6 & 8.0 & 4.61 \\
\hline Backfill Trench & $\cdots$ & 0.8 & -- & - & 0.4 & 1.2 & 0.70 \\
\hline \multicolumn{8}{|c|}{ Single Enclosure with Manual Excavation } \\
\hline Conmon Activities & 5.4 & 6.6 & 8.0 & - & 6.0 & 26.0 & 14.5 \\
\hline Install \& Remove Enclosure & 2.0 & 4.0 & 4.0 & -- & 2.0 & 12.0 & 6.8 \\
\hline Exhume Waste & 2.0 & 14.0 & 14.0 & $=$ & 7.0 & $42 . \underline{\underline{1}}$ & 23.6 \\
\hline Totais & 14.4 & 24.6 & 26.0 & -- & 15.0 & 80.0 & 44.9 \\
\hline \multicolumn{8}{|c|}{ Single Enclosure with Remote Excavation } \\
\hline Cormon Activities & 5.4 & 6.6 & 8.0 & -- & 6.0 & 26.0 & 14.5 \\
\hline install \& Remove Enctosure & 2.0 & 4.0 & 4.0 & -. & 2.0 & 12.0 & 6.8 \\
\hline Exhume Waste & $\underline{5.0}$ & 20.0 & 10.0 & $=$ & $\underline{5.0}$ & 30.0 & 16.9 \\
\hline Totals & 12.4 & 20.6 & 22.0 & -- & 13.0 & 68.0 & 38.2 \\
\hline \multicolumn{8}{|c|}{ Double Enclosure with Manual Excavation } \\
\hline Comman Activities & 5.4 & 6.6 & 8.0 & - & 6.0 & 26.0 & 14.5 \\
\hline Install \& Remove Enclosure & 7.0 & 14.0 & 14.0 & -- & 7.0 & 42.0 & 23.6 \\
\hline Exhume Waste & 7.0 & 14.0 & 14.0 & $\approx$ & 2.0 & 42.0 & $\underline{23.6}$ \\
\hline Totals & 19.4 & 34.6 & 36.0 & -- & 20.0 & 110.0 & 67.7 \\
\hline \multicolumn{8}{|c|}{ Double Enclosure with Remote Excavation } \\
\hline Comon Activities & 5.4 & 6.6 & 8.0 & - & 6.0 & 26.0 & 14.5 \\
\hline Insta11 \& Remove Enclosure & 7.0 & 14.0 & 14.0 & -- & 7.0 & 42.0 & 23.6 \\
\hline Exhume Waste & 5.0 & $\underline{10.0}$ & 10.0 & $\approx$ & 5.0 & 30.0 & 16.9 \\
\hline Totais & $\sqrt{17.4}$ & $\overline{30.6}$ & $\overline{32.0}$ & $=$ & 18.0 & 98.0 & $\overline{55.0}$ \\
\hline
\end{tabular}

a) Number of figures shown is for computational accuracy only.

(b) Contingency of $25 \%$ not included with these costs. 


\section{TABLE H.4-4. Manpower Requirements and costs for TRU Waste Exhumation - Eastern Site}

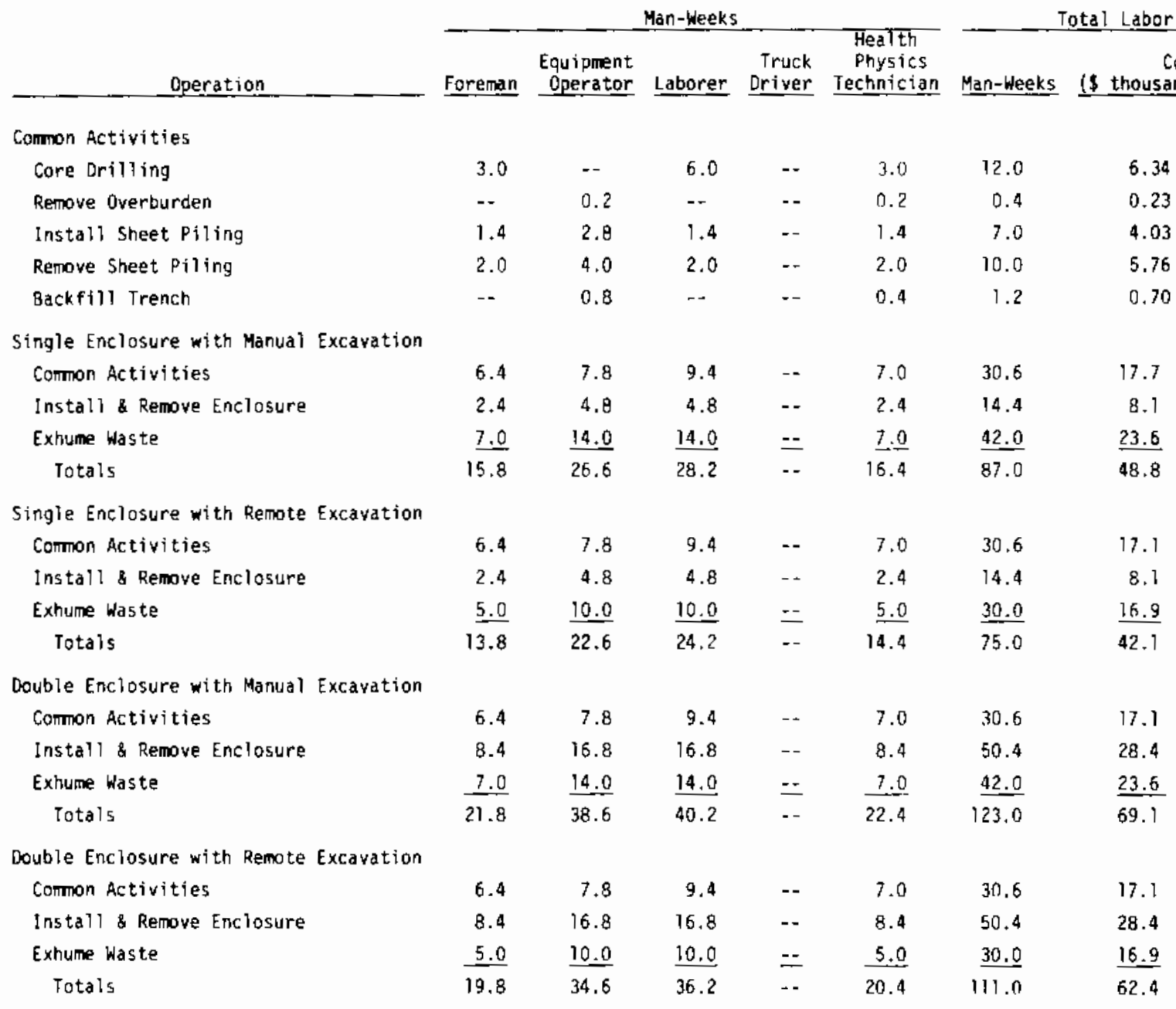

(a) Number of figures shown is for computational accuracy only. (b) Contingency of $25 \%$ not included with these costs. 


\section{TABLE H.4-5. Manpower Requirements and Costs for Relocation of the Waste from One Trench - Western Site}

\begin{tabular}{|c|c|c|c|c|c|c|c|}
\hline \multirow[b]{2}{*}{ Operation } & \multicolumn{5}{|c|}{ Mn-Weeks } & \multicolumn{2}{|c|}{ Tota? Labor } \\
\hline & Foreman & $\begin{array}{l}\text { Equi pment } \\
\text { Operator }\end{array}$ & Laborer & $\begin{array}{r}\text { Truck } \\
\text { Driver }\end{array}$ & $\begin{array}{c}\text { Health } \\
\text { Ohysics } \\
\text { Technician } \\
\end{array}$ & Mon-Heeks. & $\begin{array}{c}\text { Cost } \\
\text { (s thousands) }\end{array}$ \\
\hline \multicolumn{8}{|c|}{ Excavation from Above the Trench } \\
\hline Core Orilling & 12.4 & -- & 24.8 & $\cdots$ & 12.4 & 49.6 & 26.2 \\
\hline Remove Overburden & -- & 1.2 & $\cdots$ & $\cdots$ & 0.6 & 1.8 & 1.0 \\
\hline Exhume Haste & 24.8 & 99.2 & 99.2 & 24.8 & 24.8 & 272.8 & 152.2 \\
\hline Backfill Trench & $\underline{2.4}$ & $-\underline{9.6}$ & 4.8 & $\underline{9.6}$ & 2.4 & $28, B$ & 15.9 \\
\hline Totals & 39.6 & 110.0 & 128.8 & 34.4 & 40.2 & 353.0 & 195.3 \\
\hline \multicolumn{8}{|c|}{ Excavation from within the Trench } \\
\hline Core Drilling & 12.4 & -- & 24.8 & $-\cdot$ & 12.4 & 49.5 & 26.2 \\
\hline Remove Overburden & -- & 1.2 & $\sim$ & $\cdots$ & 0.6 & 1.8 & 1.0 \\
\hline Exhume Waste & 18.8 & 75.2 & 75.2 & 18.8 & 18.8 & 206.8 & 115.4 \\
\hline Backfill Trench & 2.4 & $\underline{9.6}$ & 4.8 & 9.6 & $\underline{2.4}$ & 28.9 & 15.9 \\
\hline Totals & 33.6 & 86.0 & 104.8 & 28.4 & 34.2 & 287.0 & 158.5 \\
\hline
\end{tabular}

\section{TABLE H.4-6. Manpower Requirements and Costs for Relocation of the Waste from One Trench - Eastern Site}

\begin{tabular}{|c|c|c|c|c|c|c|c|}
\hline \multirow[b]{2}{*}{ Dperation } & \multicolumn{5}{|c|}{ Man-Heeks } & \multicolumn{2}{|c|}{ Total Labor } \\
\hline & Foreman & $\begin{array}{l}\text { Equipment } \\
\text { Operator }\end{array}$ & Laborer & $\begin{array}{r}\text { Truck } \\
\text { Driver }\end{array}$ & $\begin{array}{c}\text { Hedith } \\
\text { Physics } \\
\text { Technician }\end{array}$ & Man-Weeks & $\begin{array}{c}\text { Cost } \\
\text { (5) thousands) }(a, b)\end{array}$ \\
\hline \multicolumn{8}{|c|}{ Excavation from above the Trench } \\
\hline Core Drilling & 14.8 & 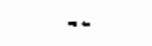 & 29.6 & - & 14.8 & 59.2 & 31.3 \\
\hline Remove Overburden & - & 1.6 & $-\cdot$ & $\cdots$ & 0.8 & 2.4 & 1.4 \\
\hline Exhume Waste & 30.0 & 120.0 & 120.0 & 30.0 & 30.0 & 330.0 & 184.2 \\
\hline Backfill Trench & 2.8 & 11.2 & 5.6 & 11.2 & 2.8 & 33.6 & 18.6 \\
\hline Totais & 47.6 & 132.8 & 155.2 & 41.2 & 48.4 & 425.2 & 235.5 \\
\hline \multicolumn{8}{|c|}{ Excayation from within the Trench } \\
\hline Core Orilling & 14.8 & $\cdots$ & 29.6 & - & 14.8 & 59.2 & 31.3 \\
\hline Remove Overburden & $\ldots$ & 1.6 & $\cdots$ & -- & 0.8 & 2.4 & 1.4 \\
\hline Exhume Waste & 22.4 & 89.6 & 89.6 & 22.4 & 22.4 & 246.4 & 137.5 \\
\hline Backfill Trench & 2.8 & 11.2 & 5.6 & 11.2 & 2.8 & 33.6 & 38.6 \\
\hline Totals & 40.0 & 102.4 & 124.8 & 33.6 & 40.8 & 341.6 & 188.8 \\
\hline
\end{tabular}




\section{TABLE H.4-7. Contractor's Equipment Costs for Excavation of a Slit Trench}

\begin{tabular}{|c|c|c|c|c|c|c|c|}
\hline \multirow{2}{*}{ _.......... } & \multirow[b]{2}{*}{$\begin{array}{l}\text { Unit } \\
\text { Cost }(5)\end{array}$} & \multicolumn{2}{|c|}{ Western site } & \multicolumn{4}{|c|}{ Eastern sice } \\
\hline & & Basis (a) & $\begin{array}{l}\text { Yotal cost }(b, c) \\
(3 \text { thousands) }\end{array}$ & & Basis (a) & & (s thousands) \\
\hline $\begin{array}{l}\text { Core Drilling } \\
\text { Light Duty Drilling Rig } \\
\text { Probe }\end{array}$ & $\begin{array}{l}500 / d a y \\
100 / d a y\end{array}$ & $\begin{array}{l}20 \text { days } \\
20 \text { days }\end{array}$ & $\begin{array}{r}10.00 \\
2.00\end{array}$ & & $\begin{array}{l}\text { days } \\
\text { days }\end{array}$ & & $\begin{array}{r}12.00 \\
2.40\end{array}$ \\
\hline $\begin{array}{l}\text { Overburden Removal } \\
\text { Bottom Loading Scraper }\end{array}$ & $1625 / w k$ & I wk & 1.62 & 1 & wk & & 1.62 \\
\hline $\begin{array}{l}\text { Sheet Piling Installation } \\
\text { Truck } \\
\text { lo M Crane } \\
\text { Pile Hammer } \\
\text { Pile Oriver Leads } \\
\text { Center Sections - Guides } \\
\text { Air Compressor }\end{array}$ & $\begin{array}{l}1600 \mathrm{mo} \\
3000 / \mathrm{mc} \\
3 \quad 300 / \mathrm{mo} \\
450 / \mathrm{mo} \\
225 / \mathrm{mo} \\
600 / \mathrm{mo}\end{array}$ & $\begin{array}{l}1 m+2 w k \\
1 m+2 w k \\
1 m+2 w k \\
1 m o+2 w k \\
1 m o+2 w k \\
1 m o+2 w k\end{array}$ & $\begin{array}{l}2.66 \\
5.00 \\
5.50 \\
0.75 \\
0.38 \\
1.00\end{array}$ & $\begin{array}{l}1 \\
1 \\
1 \\
1 \\
1 \\
1\end{array}$ & $\begin{array}{l}m+3 \\
m 0+3 \\
m 0+3 \\
m 0+3 \\
m 0+3 w \\
m 0+3 w\end{array}$ & $\begin{array}{l}w k \\
w k \\
w k \\
w k \\
w k \\
w k\end{array}$ & $\begin{array}{l}3.20 \\
6.00 \\
6.60 \\
0.90 \\
0.45 \\
1.20\end{array}$ \\
\hline $\begin{array}{l}\text { Sheet Piling Removal } \\
\text { Truck } \\
10 \text { MT Crane } \\
\text { Extractor } \\
\text { Air Compressor } \\
\text { Pile Extractor Leads }\end{array}$ & $\begin{array}{l}1600 / \mathrm{mo} \\
3000 / \mathrm{mo} \\
1200 / \mathrm{mo} \\
600 / \mathrm{mo} \\
450 / \mathrm{mo}\end{array}$ & $\begin{array}{ll}2 & \mathrm{mo} \\
2 & \mathrm{mo} \\
2 & \mathrm{mo} \\
2 & \mathrm{mo} \\
2 & \mathrm{mo}\end{array}$ & $\begin{array}{l}3.20 \\
6.00 \\
2.40 \\
1.20 \\
0.90\end{array}$ & $\begin{array}{l}2 \\
2 \\
2 \\
2 \\
2\end{array}$ & $\begin{array}{l}m+1 w \\
m 0+1 w \\
m+1 \\
m o+1\end{array}$ & $\begin{array}{l}w k \\
w k \\
w k \\
w k \\
w k\end{array}$ & $\begin{array}{l}3.73 \\
7.00 \\
2.80 \\
1.40 \\
1.05\end{array}$ \\
\hline $\begin{array}{l}\text { Trench Backfilling } \\
\text { Truck } \\
\text { Iractor-Dozer } \\
\text { Roller, Tanden Drum }\end{array}$ & $\begin{array}{l}1600 / \mathrm{mo} \\
3200 / \mathrm{mo} \\
1 \text { 050/mo }\end{array}$ & $\left\{\begin{array}{l}1 \mathrm{wk} \\
j \mathrm{wk} \\
l \mathrm{wk}\end{array}\right.$ & $\begin{array}{l}0.53 \\
1.10 \\
0.35\end{array}$ & $\begin{array}{l}1 \\
1 \\
1\end{array}$ & $\begin{array}{l}\text { wk } \\
w k \\
w k\end{array}$ & & $\begin{array}{l}0.53 \\
1.10 \\
0.35\end{array}$ \\
\hline $\begin{array}{l}\text { Hydraulic Excavation } \\
\text { Gantry Crane } \\
\text { Make-Up Tank } \\
\text { Contaminated Earth Bins } \\
\text { Ty Monitors } \\
\text { Crame, Boom Type, 50 Mt } \\
\text { Truck } \\
\text { Tractor-Dozer }\end{array}$ & $\begin{array}{l}6000 / \mathrm{mo} \\
300 / \mathrm{mo} \\
1000 / \mathrm{mo} \\
1200 / \mathrm{mp} \\
4500 / \mathrm{mo} \\
1600 / \mathrm{mo} \\
3200 / \mathrm{mo}\end{array}$ & $\begin{array}{l}7 \\
7 \\
7 \\
7 \\
7 \\
7 \\
7 \\
7 \\
7 \\
7 \\
7 \\
7 \\
700\end{array}$ & $\begin{array}{r}42.00 \\
2.10 \\
7.00 \\
8.40 \\
31.50 \\
11.20 \\
22.40\end{array}$ & $\begin{array}{l}9 \\
9 \\
9 \\
9 \\
9 \\
9 \\
9\end{array}$ & 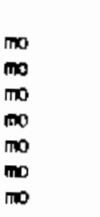 & & $\begin{array}{r}54.00 \\
2.70 \\
9.00 \\
10.80 \\
40.50 \\
14.40 \\
28.80\end{array}$ \\
\hline $\begin{array}{l}\text { Pneumatic Excavation } \\
\text { Gantry Crane. } \\
\text { Contaminated Earth Bins } \\
\text { IW Honitors } \\
\text { Crane, Boom Type, } 50 \text { MT } \\
\text { Truck } \\
\text { Tractor-Dozer }\end{array}$ & $\begin{array}{ll}6 & 000 / \mathrm{mo} \\
1 & 000 / \mathrm{mo} \\
1 & 200 / \mathrm{mo} \\
4 & 500 / \mathrm{mo} \\
1 & 600 / \mathrm{mo} \\
3 & 200 / \mathrm{mo}\end{array}$ & $\begin{array}{l}4 m+2 w k \\
4 m+2 w k \\
4 m o+2 w k \\
4 m+2 w k \\
4 m o+2 w k \\
4 m o+2 w k\end{array}$ & $\begin{array}{r}26.00 \\
4.70 \\
5.60 \\
21.00 \\
7.46 \\
15.00\end{array}$ & $\begin{array}{l}5 \\
5 \\
5 \\
5 \\
5 \\
5\end{array}$ & $\begin{array}{l}\mathbf{m}+2 \\
\mathbf{m}+2 \\
\mathbf{m}+2 \\
\mathbf{m}+2 \\
\mathbf{m}+2 \\
\mathbf{m}+2\end{array}$ & $\begin{array}{l}w k \\
w k \\
w k \\
w k \\
w k \\
w k \\
w k\end{array}$ & $\begin{array}{r}34.00 \\
5.65 \\
6.80 \\
25.50 \\
9.10 \\
18.20\end{array}$ \\
\hline $\begin{array}{l}\text { Polar Crane w/Sheet Piling } \\
\text { Crane, Boom Type, } 10 \mathrm{MT} \\
\text { TV Honitors } \\
\text { Crane, Bcom Type, } 50 \mathrm{MT} \\
\text { Truck } \\
\text { Tractor-Dozer }\end{array}$ & $\begin{array}{ll}3 & 000 / \mathrm{mo} \\
1 & 200 / \mathrm{mo} \\
4 & 500 / \mathrm{mo} \\
1 & 600 \mathrm{mo} \\
3 & 200 / \mathrm{mo}\end{array}$ & $\begin{array}{ll}3 & \mathrm{mo} \\
3 & \mathrm{no} \\
3 & \mathrm{mo} \\
3 & \mathrm{mo} \\
3 & \mathrm{mo}\end{array}$ & $\begin{array}{r}9.00 \\
3.60 \\
13.50 \\
4.80 \\
9.60\end{array}$ & $\begin{array}{l}3 \\
3 \\
3\end{array}$ & $\begin{array}{l}\mathrm{mo}+2 \\
\mathrm{mo}+2 \\
\mathrm{mo}+2 \\
\mathrm{mo}+2\end{array}$ & $\begin{array}{l}w k \\
w k \\
w k \\
w k \\
w k\end{array}$ & $\begin{array}{r}11.00 \\
4.40 \\
16.50 \\
5.90 \\
11.80\end{array}$ \\
\hline $\begin{array}{l}\text { Polar Crane w/o Sheet Piling } \\
\text { Crane, Boom Type, } 10 \mathrm{MT} \\
\text { TV Monitors } \\
\text { Crane, Boom Type, } 50 \mathrm{MT} \\
\text { Iruck } \\
\text { Tractor-Dozer }\end{array}$ & $\begin{array}{ll}3 & 000 / \pi 0 \\
1 & 200 / \mathrm{mo} \\
4 & 500 / \mathrm{mo} \\
1 & 600 / \mathrm{mo} \\
3 & 200 / \mathrm{mo}\end{array}$ & $\begin{array}{l}3 m o+1 w k \\
3 m o+1 w k \\
3 m o+1 w k \\
3 m_{0}+1 w k \\
3 m o+1 w k\end{array}$ & $\begin{array}{r}10.00 \\
4.00 \\
15.00 \\
5.40 \\
10.70\end{array}$ & $\begin{array}{l}4 \\
4 \\
4 \\
4 \\
4\end{array}$ & $\begin{array}{l}n \infty \\
m 0 \\
n 0 \\
m 0\end{array}$ & & $\begin{array}{r}12.00 \\
4.80 \\
18.00 \\
6.40 \\
12.80\end{array}$ \\
\hline $\begin{array}{l}\text { Gantry Crane } \\
\text { Gantry Crane } \\
\text { TW Honitors } \\
\text { Crane, Boom Type, so hr } \\
\text { Truck } \\
\text { Tractor-Dozer }\end{array}$ & $\begin{array}{ll}6 & 000 / \mathrm{mo} \\
1 & 200 / \mathrm{mo} \\
4 & 500 / \mathrm{mo} \\
1 & 600 / \mathrm{mo} \\
3 & 200 / \mathrm{mo}\end{array}$ & $\begin{array}{l}3 m+2 w k \\
3 m+2 w k \\
3 m+2 w k \\
3 m+2 w k \\
3 m o+2 w k\end{array}$ & $\begin{array}{r}22.00 \\
4.40 \\
16.50 \\
5.86 \\
11.80\end{array}$ & $\begin{array}{l}4 \\
4 \\
4 \\
4\end{array}$ & $\begin{array}{l}m+1 \\
m 0+1 \\
m 0+1 \\
m 0+1\end{array}$ & $\begin{array}{l}w k \\
w k \\
w k \\
w k \\
w k\end{array}$ & $\begin{array}{r}26.00 \\
5.20 \\
19.50 \\
7.00 \\
13.90\end{array}$ \\
\hline $\begin{array}{l}\text { Gantry Crane Enclosed } \\
\text { Gantry Crane } \\
\text { TV Monitors } \\
\text { Crane, Boom Type, } 50 \text { HT } \\
\text { Truck } \\
\text { Tractor-Dozer }\end{array}$ & $\begin{array}{ll}6 & 000 / \mathrm{mo} \\
1 & 200 / \mathrm{m0} \\
4 & 500 / \mathrm{mo} \\
1 & 600 / \mathrm{mo} \\
3 & 200 / \mathrm{mo}\end{array}$ & $\begin{array}{ll}5 & \mathrm{mo} \\
5 & \mathrm{mo} \\
5 & \mathrm{nto} \\
5 & \mathrm{mo} \\
5 & \mathrm{mo}\end{array}$ & $\begin{array}{r}30.00 \\
6.00 \\
22.50 \\
8.00 \\
16.00\end{array}$ & 6 & $\begin{array}{l}m+1 \\
m+1 \\
m o+1 \\
m o+1 \\
m+1\end{array}$ & $\begin{array}{l}w k \\
w k \\
w k \\
w k \\
w k\end{array}$ & $\begin{array}{r}38.00 \\
7.60 \\
28.50 \\
10.20 \\
20.30\end{array}$ \\
\hline
\end{tabular}

(a) Times are rounded up to nearest whole time unit.

(b) Wumber of significant figures show is for computational accuracy only.
(c) Contingency of $25 \%$ not included with these costs. 
TABLE H.4-8 Costs of Expendable Equipment and Supplies for Excavation of a Slit Trench

\begin{tabular}{|c|c|c|c|c|c|}
\hline \multirow{2}{*}{ _.___._. Item } & \multirow[b]{2}{*}{$\begin{array}{l}\text { Unit } \\
\text { Cost (\$) }\end{array}$} & \multicolumn{2}{|c|}{ Western Site } & \multicolumn{2}{|c|}{ Eastern Site } \\
\hline & & Bas is & $\begin{array}{l}\text { Total Cost }(a, b) \\
\text { (s thousands) }\end{array}$ & Basis & $\begin{array}{l}\text { Total Cost }(a, b) \\
\text { thousands) }\end{array}$ \\
\hline $\begin{array}{l}\text { Core Orilling } \\
\text { Core Sampling } \\
\text { Anti-contanination Clothing }\end{array}$ & $\begin{array}{l}100 / \text { sample } \\
50 / \text { man-week }\end{array}$ & $\begin{array}{l}50 \text { samples } \\
16 \text { man-weeks }\end{array}$ & $\begin{array}{l}5.00 \\
0.80\end{array}$ & $\begin{array}{l}50 \text { samples } \\
20 \text { man-weeks }\end{array}$ & $\begin{array}{l}5.00 \\
1.00\end{array}$ \\
\hline $\begin{array}{l}\text { Sheet Piling Installation } \\
\text { Sheet Pfling } \\
\text { Cross Supports } \\
\text { Expendable Supplies } \\
\text { Anti-contamination Clothing }\end{array}$ & $\begin{array}{l}2 B / m^{2}(C) \\
1000 / M T \\
100 / \text { day } \\
50 / \text { man-week }\end{array}$ & $\begin{array}{l}2200 \mathrm{~m}^{2} \\
10 \mathrm{kT} \\
27 \text { days } \\
30 \text { man-weeks }\end{array}$ & $\begin{array}{r}61.60 \\
10.00 \\
2.70 \\
1.50\end{array}$ & $\begin{array}{l}2200 \mathrm{~m}^{2} \\
10 \mathrm{RT} \\
33 \text { days } \\
35 \text { man-weeks }\end{array}$ & $\begin{array}{r}61.60 \\
10.00 \\
3.30 \\
1.75\end{array}$ \\
\hline $\begin{array}{l}\text { Sheet Pfling Removal } \\
\text { Expendable Supplies } \\
\text { Anti-contamination clothing }\end{array}$ & $\begin{array}{l}\text { 100/day } \\
50 / \text { man-week }\end{array}$ & $\begin{array}{l}38 \text { days } \\
40 \text { man-weeks }\end{array}$ & $\begin{array}{l}3.80 \\
2.00\end{array}$ & $\begin{array}{l}45 \text { days } \\
45 \text { man-weeks }\end{array}$ & $\begin{array}{l}4.50 \\
2.25\end{array}$ \\
\hline $\begin{array}{l}\text { Hydraulic Excavation } \\
\text { Pump } \\
\text { Dredge/Suction Equipment } \\
\text { Hoses \& Misc. Suppries } \\
\text { Anti-contamination Clothing }\end{array}$ & $\begin{array}{l}20000 \\
25000 \\
10000 \\
50 / \text { man-week }\end{array}$ & $\begin{array}{l}\text { each } \\
\text { each } \\
\text { each } \\
186 \text { man-weeks }\end{array}$ & $\begin{array}{r}20.00 \\
25.00 \\
10.00 \\
9.30\end{array}$ & $\begin{array}{l}\text { each } \\
\text { each } \\
\text { each } \\
222 \text { man-weeks }\end{array}$ & $\begin{array}{l}20.00 \\
25.00 \\
10.00 \\
11.10\end{array}$ \\
\hline $\begin{array}{l}\text { Pneumatic Excavation } \\
\text { Oredge/Suction Equipment } \\
\text { Hoses \& Misc. Supplies } \\
\text { Anti-contamination Clothing }\end{array}$ & $\begin{array}{l}30000 \\
10000 \\
50 / \text { man-week }\end{array}$ & $\begin{array}{l}\text { each } \\
\text { each } \\
120 \text { man-weeks }\end{array}$ & $\begin{array}{r}30.00 \\
10.00 \\
6.00\end{array}$ & $\begin{array}{l}\text { each } \\
\text { each } \\
138 \text { man-weeks }\end{array}$ & $\begin{array}{r}30.00 \\
10.00 \\
6.90\end{array}$ \\
\hline $\begin{array}{l}\text { Polar Crane w/Sheet Piling } \\
\text { Clamshell } \\
\text { Miscellaneous Supplies } \\
\text { Anti-contamination Clothing }\end{array}$ & $\begin{array}{l}2000 \\
2000 \\
50 / \text { man-week }\end{array}$ & $\begin{array}{l}\text { each } \\
\text { each } \\
72 \text { man-weeks }\end{array}$ & $\begin{array}{l}2.00 \\
2.00 \\
3.60\end{array}$ & $\begin{array}{l}\text { each } \\
\text { each } \\
90 \text { man-weeks }\end{array}$ & $\begin{array}{l}2.00 \\
2.00 \\
4.50\end{array}$ \\
\hline $\begin{array}{l}\text { Polar Crane w/o Sheet Piling } \\
\text { Clanshell } \\
\text { Miscellaneous Supplies } \\
\text { Anti-contamination Clothing }\end{array}$ & $\begin{array}{l}2000 \\
2000 \\
50 / \text { man-week }\end{array}$ & $\begin{array}{l}\text { each } \\
\text { each } \\
84 \text { man-weeks }\end{array}$ & $\begin{array}{l}2.00 \\
2.00 \\
4.20\end{array}$ & $\begin{array}{l}\text { each } \\
\text { each } \\
102 \text { man-weeks }\end{array}$ & $\begin{array}{l}2.00 \\
2.00 \\
5.10\end{array}$ \\
\hline $\begin{array}{l}\text { Gantry Crane } \\
\text { Clamsheil } \\
\text { Miscellaneous Suppiies } \\
\text { Anti-contamination Clothing }\end{array}$ & $\begin{array}{l}2000 \\
5000 \\
50 / \text { man-week }\end{array}$ & $\begin{array}{l}\text { each } \\
\text { each } \\
90 \mathrm{man} / \text { weeks }\end{array}$ & $\begin{array}{l}2.00 \\
5.00 \\
4.50\end{array}$ & $\begin{array}{l}\text { each } \\
\text { each } \\
108 \text { man-weeks }\end{array}$ & $\begin{array}{l}2.00 \\
5.00 \\
5.40\end{array}$ \\
\hline $\begin{array}{l}\text { Gantry Crane Enclosed } \\
\text { Clamsheli } \\
\text { Miscellaneous Supplies } \\
\text { Anti-contamination Clothing } \\
\text { Enciosure }\end{array}$ & $\begin{array}{l}2000 \\
5000 \\
50 / \text { man-week } \\
125000\end{array}$ & $\begin{array}{l}\text { each } \\
\text { each } \\
132 \text { man-weeks } \\
\text { each }\end{array}$ & $\begin{array}{r}2.00 \\
5.00 \\
6.60 \\
125.00\end{array}$ & $\begin{array}{l}\text { each } \\
\text { each } \\
156 \text { man-weeks } \\
\text { each }\end{array}$ & $\begin{array}{r}2.00 \\
5.00 \\
7.80 \\
125.00\end{array}$ \\
\hline
\end{tabular}


TABLE H.4-9. Contractor's Equipment Costs for Exhumation of TRU Waste

\begin{tabular}{|c|c|c|c|c|c|}
\hline \multirow{2}{*}{ _. Iteni } & \multirow[b]{2}{*}{$\begin{array}{c}\text { Unit } \\
\text { Cost }(\$)\end{array}$} & \multicolumn{2}{|c|}{ Western Site } & \multicolumn{2}{|c|}{ Eastern Site } \\
\hline & & Basis (a) & $(1$ thousands) $(b, c)$ & Basis (a) & $\begin{array}{l}\text { Total cost } \\
\text { (s thousands) }(b, c)\end{array}$ \\
\hline $\begin{array}{l}\text { Core Drilling } \\
\text { Light Duty Drill Ris } \\
\text { Probe }\end{array}$ & $\begin{array}{l}500 / \text { day } \\
100 / \text { day }\end{array}$ & $\begin{array}{l}13 \text { days } \\
13 \text { days }\end{array}$ & $\begin{array}{l}6.50 \\
1.30\end{array}$ & $\begin{array}{l}\text { i5 days } \\
15 \text { days }\end{array}$ & $\begin{array}{l}7.50 \\
1.50\end{array}$ \\
\hline $\begin{array}{l}\text { Overburden Renova? } \\
\text { Bottom Loading Scraper }\end{array}$ & i $625 / \% k$ & l wk & 1.62 & $1 \mathrm{mk}$ & 1.62 \\
\hline $\begin{array}{l}\text { Sheet Piling Installation } \\
\text { Truck } \\
\text { 10 MT Crane } \\
\text { Pile Hanmer } \\
\text { Pile Oriver Leads } \\
\text { Center Sections - Guides } \\
\text { Air Compressor }\end{array}$ & $\begin{array}{l}1600 / m 0 \\
3000 / m 0 \\
3300 / m 0 \\
450 / m 0 \\
225 / m 0 \\
600 / m 0\end{array}$ & $\begin{array}{l}2 w k \\
2 w k \\
2 w k \\
2 \\
2 w k \\
2 \\
2 \\
2 w k\end{array}$ & $\begin{array}{l}1.06 \\
2.00 \\
2.20 \\
0.30 \\
0.15 \\
0.40\end{array}$ & 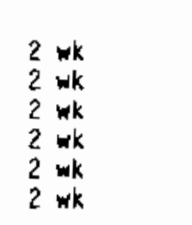 & $\begin{array}{l}1.06 \\
2.00 \\
2.20 \\
0.30 \\
0.15 \\
0.40\end{array}$ \\
\hline $\begin{array}{l}\text { Sheet Piiing Removal } \\
\text { Truck } \\
10 \text { H Crane } \\
\text { Extractor } \\
\text { Air Compressor } \\
\text { Pile Extractor Leads }\end{array}$ & $\begin{array}{l}1600 / m 0 \\
3000 / \pi \mathrm{co} \\
1200 / \mathrm{mo} \\
600 / m 0 \\
450 / m 0\end{array}$ & 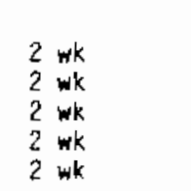 & $\begin{array}{l}1.06 \\
2.00 \\
0.80 \\
0.40 \\
0.30\end{array}$ & $\begin{array}{l}2 w k \\
2 w k \\
2 \\
2 w k \\
2 w k \\
2 w k\end{array}$ & $\begin{array}{l}1.06 \\
2.00 \\
0.80 \\
0.40 \\
0.30\end{array}$ \\
\hline $\begin{array}{l}\text { Trench Backfilling } \\
\text { Truck } \\
\text { Tractor-Dozer } \\
\text { Roller. Tandem Drum }\end{array}$ & $\begin{array}{ll}1 & 600 / \mathrm{mo} \\
3 & 200 / \mathrm{mo} \\
1 & 050 / \mathrm{mo}\end{array}$ & $\begin{array}{l}1 \text { wk } \\
1 \\
1 \\
1\end{array}$ & $\begin{array}{l}0.53 \\
1.10 \\
0.35\end{array}$ & $\begin{array}{l}l w k \\
1 \\
1 \\
1 \\
w k\end{array}$ & $\begin{array}{l}0.53 \\
1.10 \\
0.35\end{array}$ \\
\hline $\begin{array}{l}\text { Manual Excavation - Single Enciosure } \\
\text { Backloe, } 1 / 2 \mathrm{~m}^{3} \text { Capacity } \\
\text { TV Monitor } \\
\text { Crane, Boom Type, } 10 \mathrm{nT}\end{array}$ & $\begin{array}{r}3000 / m o \\
600 / m o \\
3000 / m o\end{array}$ & $\begin{array}{l}2 m 0 \\
2 m o \\
2 m o+1 w k\end{array}$ & $\begin{array}{l}6.00 \\
1.20 \\
7.00\end{array}$ & $\begin{array}{l}2 m 0 \\
2 m o \\
2 m o+l w k\end{array}$ & $\begin{array}{l}6.00 \\
1.20 \\
7.00\end{array}$ \\
\hline $\begin{array}{l}\text { Remote Excavation - Single Enclosure } \\
\text { Backhoe, } 1 / 2 \mathrm{~m}^{3} \text { Capacity } \\
\text { TV Monitors } \\
\text { Crane, Boom Type, } 10 \mathrm{MT} \\
\text { Mobile Robot }\end{array}$ & 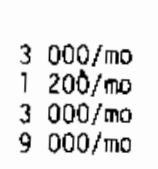 & $\begin{array}{l}1 \mathrm{mo}+1 w k \\
1 \mathrm{mo}+1 w k \\
2 m o \\
1 \mathrm{mo}+1 w k\end{array}$ & $\begin{array}{r}4.00 \\
1.60 \\
6.00 \\
12.00\end{array}$ & $\begin{array}{l}1 m 0+1 w k \\
1 m o+1 w k \\
2 m o \\
1 m o+1 w k\end{array}$ & $\begin{array}{r}4.00 \\
1.60 \\
6.00 \\
12.00\end{array}$ \\
\hline $\begin{array}{l}\text { Manual Excavation - Double Enclosure } \\
\text { Backhoe, } 1 / 2 \mathrm{~m}^{3} \text { Capacity } \\
\text { Ty Monitor } \\
\text { Crane, Boom Type, } 10, m\end{array}$ & $\begin{array}{r}3000 / m 0 \\
600 / m 0 \\
3000 / m 0\end{array}$ & $\begin{array}{l}2 m o \\
2 m o \\
3 m o+1 w k\end{array}$ & $\begin{array}{r}6.00 \\
1.20 \\
10.00\end{array}$ & $\begin{array}{l}2 \mathrm{mo} \\
2 \mathrm{mo} \\
4 \mathrm{mo}\end{array}$ & $\begin{array}{r}6.00 \\
1.20 \\
12.00\end{array}$ \\
\hline $\begin{array}{l}\text { Remote Excavation - Double Enciosure } \\
\text { Backhoe, } 1 / 2 \mathrm{~m}^{3} \text { Capacity } \\
\text { TV Monitors } \\
\text { Crane, Boom Type, } 10 \mathrm{~m} \\
\text { Mobile Robot }\end{array}$ & $\begin{array}{ll}3 & 000 / m 0 \\
1 & 200 / \mathrm{mo} \\
3 & 000 / \mathrm{mo} \\
9 & 000 / \mathrm{mo}\end{array}$ & $\begin{array}{l}1 m o+1 w k \\
1 m o+1 \omega k \\
3 m o \\
1 m o+i w k\end{array}$ & $\begin{array}{r}4.00 \\
1.60 \\
9.00 \\
12.00\end{array}$ & $\begin{array}{l}1 m o+1 w k \\
1 m o+1 w k \\
3 m o+1 w k \\
1 m o+1 w k\end{array}$ & $\begin{array}{r}4.00 \\
1.60 \\
10.00 \\
12.00\end{array}$ \\
\hline
\end{tabular}

(a) Times are rounded up to nearest whole time unit.

(b) Number of significant figures shown is for computational accuracy only.

(c) Contingency of $25 \%$ not included with these costs. 


\section{TABLE H.4-10, Costs of Expendable Equipment and Supplies for Exhumation of TRU Waste}

\begin{tabular}{|c|c|c|c|c|c|}
\hline \multirow{2}{*}{ I tem } & \multirow[b]{2}{*}{$\begin{array}{c}\text { Undt } \\
\text { Cost }(5)\end{array}$} & \multicolumn{2}{|c|}{ Western Site } & \multicolumn{2}{|c|}{ Eastern Site } \\
\hline & & Basis & $\begin{array}{l}\text { Total Cost }(a, b) \\
\text { (s thousands })^{(a, b)}\end{array}$ & Basis & (s thousands) $(a, 0)$ \\
\hline $\begin{array}{l}\text { Core Orilling } \\
\text { Core Sample } \\
\text { Anti-contamination clothing } \\
\text { Plastic }\end{array}$ & $\begin{array}{l}100 / \text { sample } \\
50 / \text { man-week } \\
1000\end{array}$ & $\begin{array}{l}40 \text { samples } \\
12 \text { man-weeks } \\
\text { each }\end{array}$ & $\begin{array}{l}4.00 \\
0.60 \\
1.00\end{array}$ & $\begin{array}{l}40 \text { samples } \\
12 \text { man-weeks } \\
\text { each }\end{array}$ & $\begin{array}{l}4.00 \\
0.60 \\
1.00\end{array}$ \\
\hline $\begin{array}{l}\text { Sheet Piling Instailation } \\
\text { Sheet Piling } \\
\text { Cross Supports } \\
\text { Expendable Supplies } \\
\text { Ant } \hat{i} \text {-Contanination flothing }\end{array}$ & $\begin{array}{l}28 / m^{2}(c) \\
1000 / m i \\
100 / d a y \\
50 / \text { man-meek }\end{array}$ & $\begin{array}{l}350 \mathrm{~m}^{2} \\
5 \mathrm{MT} \\
6 \text { days } \\
10 \text { man-weeks }\end{array}$ & $\begin{array}{l}9.80 \\
5.00 \\
0.60 \\
0.50\end{array}$ & $\begin{array}{l}350 \mathrm{~m}^{2} \\
5 \mathrm{MT} \\
7 \text { days } \\
10 \text { man-weeks }\end{array}$ & $\begin{array}{l}9.80 \\
5.00 \\
0.70 \\
0.50\end{array}$ \\
\hline $\begin{array}{l}\text { Sheet Piling Removal } \\
\text { Expendable Supplies } \\
\text { Ant - contanindtion Clothing }\end{array}$ & $\begin{array}{l}100 / d a y \\
50 / \text { man-week }\end{array}$ & $\begin{array}{l}8 \text { days } \\
10 \text { man-weeks }\end{array}$ & $\begin{array}{l}0.80 \\
0.50\end{array}$ & $\begin{array}{l}10 \text { days } \\
10 \text { man-weeks }\end{array}$ & $\begin{array}{l}1.00 \\
0.50\end{array}$ \\
\hline $\begin{array}{l}\text { Hanual Excavation - Single Enclosure } \\
\text { Plastic Bubble Suits } \\
\text { Scott Air Pack } \\
\text { Anti-contamination Clothing } \\
\text { Clamsheli } \\
\text { Miscel?aneous Suppities }\end{array}$ & $\begin{array}{l}\text { 50/ea; } 2 \text { man-days/suit } \\
835 / \text { each } \\
50 / \text { man-week } \\
2000 \\
2000\end{array}$ & $\begin{array}{l}100 \text { sujts } \\
24 \text { each } \\
54 \text { mon-weeks } \\
\text { each } \\
\text { each }\end{array}$ & $\begin{array}{r}5.00 \\
20.04 \\
2.70 \\
2.00 \\
2.00\end{array}$ & $\begin{array}{l}100 \text { suits } \\
24 \text { each } \\
60 \text { man-weeks } \\
\text { each } \\
\text { each }\end{array}$ & $\begin{array}{r}5.00 \\
20.04 \\
3.00 \\
2.00 \\
2.00\end{array}$ \\
\hline $\begin{array}{l}\text { Remote Excavation - Single Enclosure } \\
\text { Plastic Bubble Suits } \\
\text { Scott Air Pack } \\
\text { Anti-contamination clothing } \\
\text { Clamshell } \\
\text { Miscellaneous Supplies }\end{array}$ & $\begin{array}{l}\text { 50/ea; } 2 \text { man-days/suit } \\
835 / \text { each } \\
50 / \text { man-mek } \\
2000 \\
3000\end{array}$ & $\begin{array}{l}8 \text { suits } \\
8 \text { each } \\
42 \text { man-weeks } \\
\text { each } \\
\text { each }\end{array}$ & $\begin{array}{l}0.40 \\
6.68 \\
2.10 \\
2.00 \\
3.00\end{array}$ & $\begin{array}{l}8 \text { suits } \\
8 \text { each } \\
48 \text { man-weeks } \\
\text { each } \\
\text { each }\end{array}$ & $\begin{array}{l}0.40 \\
6.68 \\
2.40 \\
2.00 \\
3.00\end{array}$ \\
\hline $\begin{array}{l}\text { Manual Excavation - Double EncTosure } \\
\text { Plastic Bubble Suits } \\
\text { Scott Atr Pack } \\
\text { Anti-contarination Clothing } \\
\text { Clanshell } \\
\text { Miscellaneous Supplies }\end{array}$ & $\begin{array}{l}50 \text { ea; } 2 \text { man-oays/suit } \\
835 / \text { each } \\
50 / \text { man-week } \\
2000 \\
4000\end{array}$ & $\begin{array}{l}100 \text { suits } \\
24 \text { each } \\
84 \text { man-meeks } \\
\text { each } \\
\text { each }\end{array}$ & $\begin{array}{r}5.00 \\
20.04 \\
4.20 \\
2.00 \\
4.00\end{array}$ & $\begin{array}{l}100 \text { suits } \\
24 \text { each } \\
96 \text { man-weeks } \\
\text { each } \\
\text { each }\end{array}$ & $\begin{array}{r}5.00 \\
20.04 \\
4.80 \\
2.00 \\
4.00\end{array}$ \\
\hline $\begin{array}{l}\text { Remote Excayation - Double Enclosure } \\
\text { Flastic Bubble Suits } \\
\text { Scott Air Pack } \\
\text { Anti-contamination Clothing } \\
\text { Clamshell } \\
\text { Miscellaneous Supplies }\end{array}$ & $\begin{array}{l}50 \text { ea; } 2 \text { man-days/suit } \\
835 / \text { each } \\
50 / \text { man-week } \\
2000 \\
6000\end{array}$ & $\begin{array}{l}8 \text { swits } \\
8 \text { each } \\
72 \text { man-weeks } \\
\text { each } \\
\text { each }\end{array}$ & $\begin{array}{l}0.40 \\
6.68 \\
3.60 \\
2.00 \\
6.00\end{array}$ & $\begin{array}{l}8 \text { suits } \\
8 \text { each } \\
84 \text { man-meks } \\
\text { each } \\
\text { each }\end{array}$ & $\begin{array}{l}0.40 \\
6.68 \\
4.20 \\
2.00 \\
6.00\end{array}$ \\
\hline
\end{tabular}

(a) Number of significant figures shown is for computational accuracy only.

(b) Contingency of $25 \%$ not included with these costs.

(c) Wnit cost computed on the basis that the actual cost is $\$ 80 / \mathrm{m}^{2}$, but that 65 t of the cost can be recovered when the sheet piling is sold after being decontaminated. 
TABLE H.4-17. Contractor's Equipment Costs for Relocation of Waste from One Burial Trench

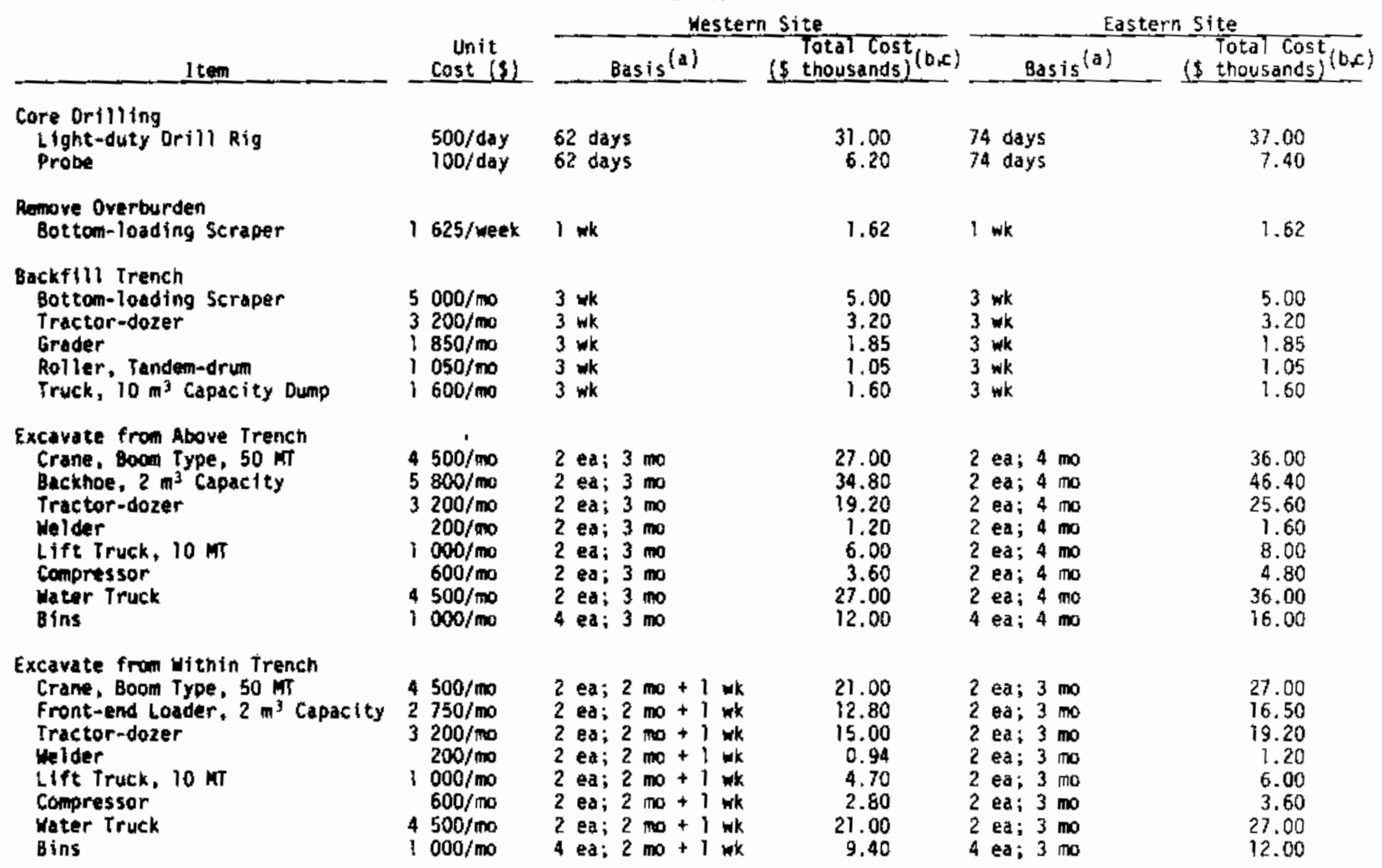

(a)Thes ore rounded up to nearest whole time untt.

(b) Nwiter of significant figures shown is for computational accuracy only.

(c) Contingancy of 255 not included with these costs.

TABLE H.4-12. Costs of Expendable Equipment and Supplies for Relocation of waste from One Burial Trench

\begin{tabular}{|c|c|c|c|c|c|}
\hline \multirow{2}{*}{ _teem } & \multirow[b]{2}{*}{$\begin{array}{c}\text { Unit } \\
\text { cost }(\$) \\
\end{array}$} & \multicolumn{2}{|c|}{ Western Site } & \multicolumn{2}{|c|}{ Eastern site } \\
\hline & & Basis. & (s thousands) & Basis & $\begin{array}{l}\text { Total Cost }(a, b) \\
\text { thousands }\end{array}$ \\
\hline $\begin{array}{l}\text { Core Drilling } \\
\text { Core Sample } \\
\text { Anti-contantination Clothing }\end{array}$ & $\begin{array}{l}\text { 100/sample } \\
50 / \text { mon-week }\end{array}$ & $\begin{array}{l}115 \text { samples } \\
52 \text { man-weeks }\end{array}$ & $\begin{array}{r}11.50 \\
2.60\end{array}$ & $\begin{array}{l}115 \text { samples } \\
60 \text { man-weeks }\end{array}$ & $\begin{array}{r}11.50 \\
3.00\end{array}$ \\
\hline $\begin{array}{l}\text { Backfill Trench } \\
\text { Common Borrow }\end{array}$ & $1.25 / \mathrm{m}^{3}$ & $12000 \mathrm{~m}^{3}$ & 15.00 & $12000 \mathrm{~m}^{3}$ & 15.00 \\
\hline $\begin{array}{l}\text { Excavate from Above Trench } \\
\text { clanshell } \\
\text { Miscellaneous Suppl tes } \\
\text { Anti-contamination Clothing }\end{array}$ & $\begin{array}{l}2000 \\
22000 / \text { mo } \\
50 / m s n-\text { week }\end{array}$ & $\begin{array}{l}2 \text { each } \\
3 \text { mo } \\
286 \text { man-meeks }\end{array}$ & $\begin{array}{r}4.00 \\
6.00 \\
14.30\end{array}$ & $\begin{array}{l}2 \text { each } \\
3.5 \text { mo } \\
330 \text { man-weeks }\end{array}$ & $\begin{array}{r}4.00 \\
7.00 \\
16.50\end{array}$ \\
\hline $\begin{array}{l}\text { Excavate from Within Trench } \\
\text { Loader Blade } \\
\text { Miscellaneous Supplies } \\
\text { Anti-contamination Clothing }\end{array}$ & $\begin{array}{l}11000 \\
2000 / \text { mo } \\
50 / \text { man-week }\end{array}$ & $\begin{array}{l}2 \text { each } \\
2.2 \text { mo } \\
220 \text { man-weeks }\end{array}$ & $\begin{array}{r}2.00 \\
4.40 \\
11.00\end{array}$ & $\begin{array}{l}2 \text { each } \\
3.0 \mathrm{mo} \\
264 \text { man-weeks }\end{array}$ & $\begin{array}{r}2.00 \\
6.00 \\
13.20\end{array}$ \\
\hline
\end{tabular}

(a) Mumber of significant figures shown is for computational accuracy only. (b) Contingency of $25 \%$ not included with these costs. 
To calculate contractor's equipment costs, it is assumed that a contractor does not supply an item of equipment for less than 1 week (i.e., if an item is only used for 2 or 3 days, the charge for 1 full week applies.) Furthermore, use of an item for a full time period plus a fraction of the time period results in an additional week or month of use being charged. For example, use of an item for 12 working days results in a charge for 3 weeks of use. However, use of an item for 17 working days results in a charge for 1 month of use rather than for 4 weeks of use. This is because the charge for 1 month is less than 4 times the charge for 1 week.

\section{H.4.3 Waste Management Cost Details for Waste Relocation}

Waste management inciudes packaging, shipment, and reburial at another repository of the waste and contaminated soil exhumed from a decommissioned LLW burial ground.

Details of waste management requirements and costs for waste relocation are given in Tables H.4-13 through H.4-15. Table H.4-13 gives waste management requirements and costs for relocation of high beta-gamma radioactivity waste from a slit trench. Table H.4-14 gives waste management requirements and costs for exhumation of a TRU waste package from a section of a burial trench. Table H.4-75 gives waste management requirements and costs for relocation of all the waste from a single burial trench. Waste management requirements are based on waste relocation methods and procedures described in Section 11 of Volume 1.

Transportation is assumed to be performed by a private contractor experienced in the shipment of radioactive waste. Transportation costs include labor costs for this activity. These costs (including overweight charges) are based on unit cost information in Section H.1.2. The distance from the decomissioned LLW burial ground to a deep geologic disposal or other shallow-land burial site is assumed to be $2,400 \mathrm{~km}$. To reduce transit times and minimize rental charges for casks and Type B overpacks, all shipments of high betagamma radioactivity or TRU waste are assumed to require the services of a second driver.

High beta-gamma radioactivity waste is assumed to be shipped to deep geologic disposal or to another site for shallow-land burial. TRU waste is assumed to 
TABLE H.4-13. Waste Management Requirements and Costs for Exhumation of a slit Trench

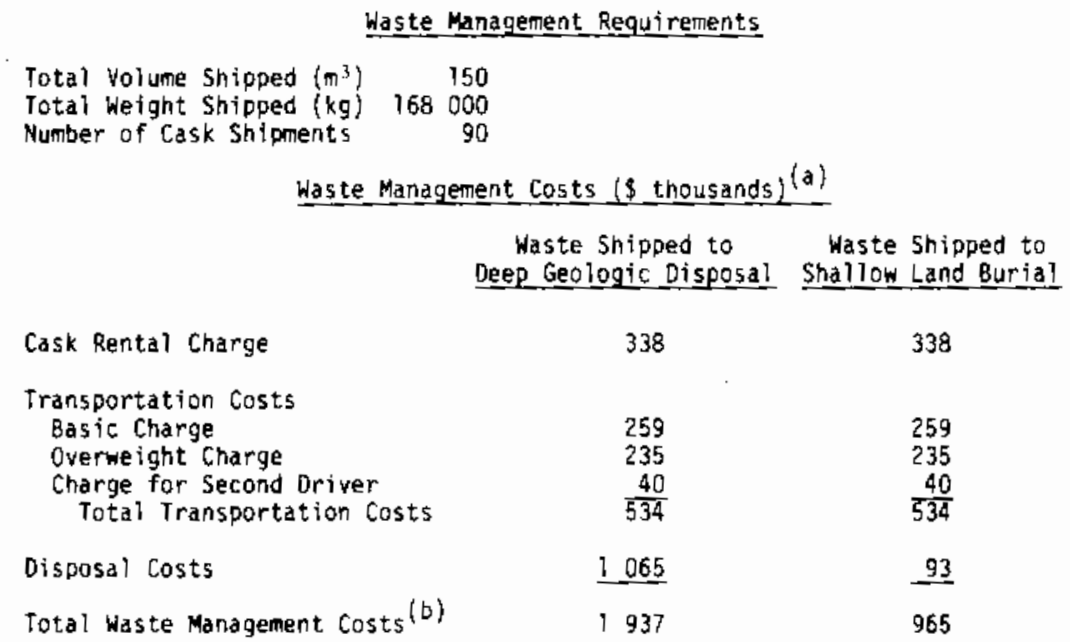

(a) Number of figures shown is for computational accuracy only.

(b) 25: contingency not included.

TABLE H.4-14. Waste Management Requirements and Costs for Exhumation of TRU Waste

Waste Managenent Requirements

\begin{tabular}{|c|c|}
\hline Total Waste volume shipped $\left(\pi^{3}\right)$ & 5.2 \\
\hline Total Weight of Waste Shipped $(\mathrm{kg})$ & 8300 \\
\hline Container Type & $1.2 \times 1.2 \times 1.8-m$ Steel Box \\
\hline Number of Containers & 2 \\
\hline Number of Shipments & $i$ \\
\hline \multicolumn{2}{|c|}{ Waste Management Costs (s thousands) $(a)$} \\
\hline \multicolumn{2}{|l|}{ Packaging costs } \\
\hline Container cost & 2.0 \\
\hline Super Tiger Rental Charge & $\underline{1.0}$ \\
\hline Total Packaģing Costs & 3.0 \\
\hline \multicolumn{2}{|l|}{ Transportation costs } \\
\hline Basic Charge & 2.9 \\
\hline Overweight Charge & 3.3 \\
\hline Charge for Second Driver & $\underline{0.4}$ \\
\hline Total Transportation Costs & 4,6 \\
\hline Disposal Costs & 10.9 \\
\hline Total Waste Management $\operatorname{Cos} t_{5}(\mathrm{~b})$ & 78.5 \\
\hline
\end{tabular}

(a) Number of figures shown is for computational accuracy only. (b) 25\% contingency not included. 
IABLE H.4-15. Waste Management Requirements and Costs for Relocation of the Waste from an Entire Burial Trench

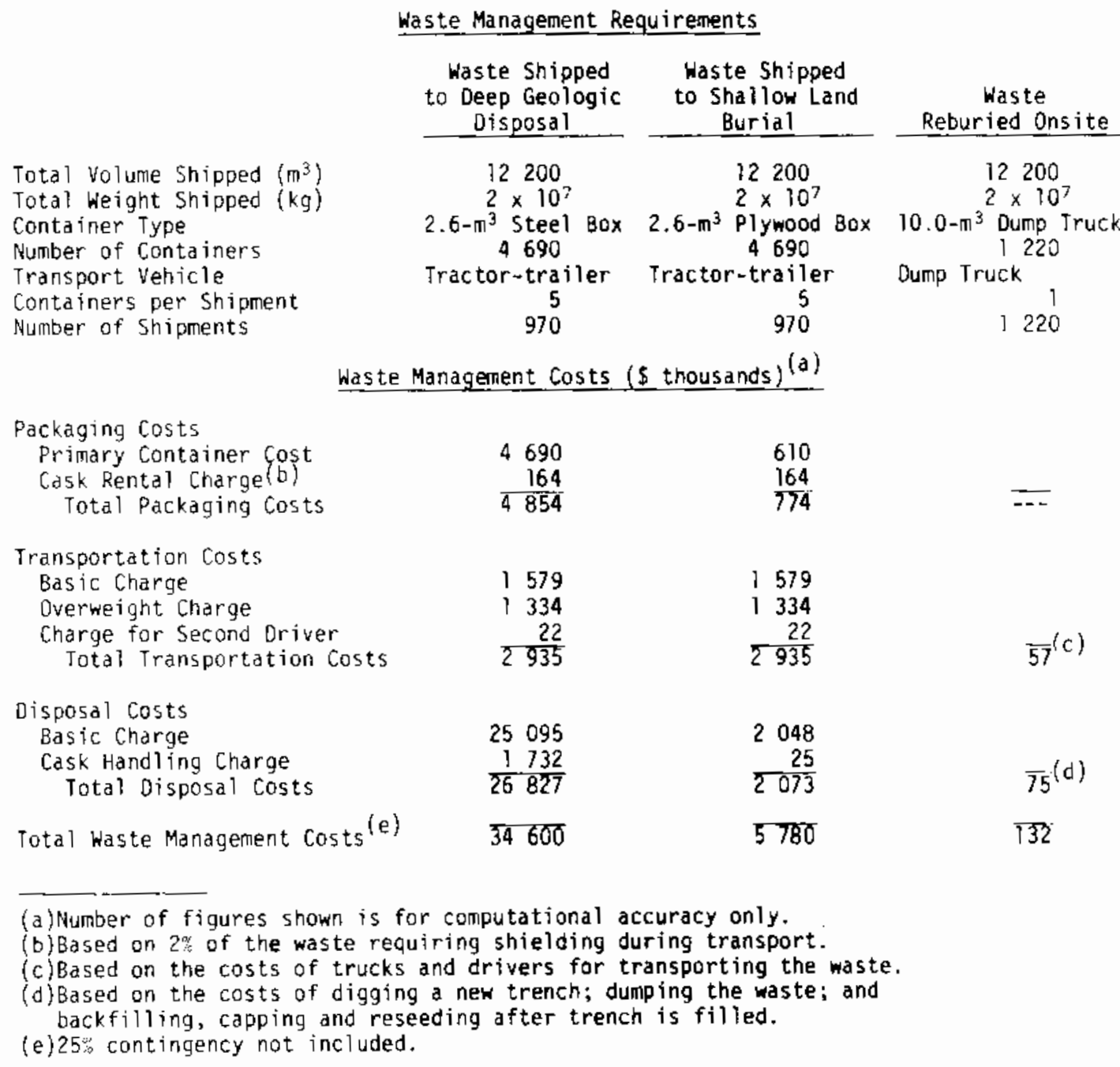

be shipped to deep geologic disposal. The waste and soil from relocation of an entire burial trench is assumed to be shipped to deep geologic disposal, or to another site for shallow-land burial, or to be reburied in another trench at the reference burial site. Costs of deep geological disposal or shallow-land burial are based on unit cost information in Section H.1.2.

Waste that is reburied in another trench at the same burial site is transported in 10-m dump trucks 1 ined with plastic, as described in Section 11.4.3. Transportation costs include the costs of trucks and truck drivers. Disposal costs include the cost of digging the new trench, the cost of equipment and personnel to assist in burial of the waste, and the cost of capping the trench and seeding the area when the new trench is filled with waste. 


\section{REFERENCES}

1. Handy-Whitman Index of Public Utility Construction Costs, Bulietin No. 105, Section B-6, Amended January 1, 1978.

2. MF-I.C.C. No. 195, Local Commodity Tariff No. 1045-E, Tri-State Motor Transit Co., Jopl in, MO, May 1977.

3. K. J. Schneider and C. E. Jenkins, Technology, Safety and Costs of Decommissioning a Reference Nuclear Fuel Reprocessing P7ant, NUREG-0278, Prepared by Pacific Northwest Laboratory for U.S. Nuclear Regulatory Cormission, Volume 1, p. 7-129, October 1977. *

4. Nuclear Engineering Company Schedule of Charges for Radioactive Waste Disposal at the Richland, Washington, Site, June 1, 1978.

Available for purchase from the National Technical Information Service, 5pringfield, Virginia 22161. 


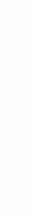




\section{APPENDIX I}

\section{RADIOLOGICAL SAFETY DETAILS}

Assurance of public and occupational safety is a major consideration in decommissioning any nuclear facility. This appendix presents the details necessary to quantify the public and occupational safety impacts of decommissioning a low-level waste (LLW) burial ground. As in previous decommissioning studies in this series, $(1-3)$ it is beyond the scope of this study to present a detailed probabilistic analysis and comparison of specific routine or accidental industrial situations (and associated efforts to minimize their impacts). An attempt is made, however, to realistically quantify the parameters relating to important safety considerations for decommissioning the reference LLW burial ground.

The details of calculations to determine doses to the public from airborne releases of radioactivity during routine decommissioning operations and decommissioning accidents are presented in Section I. 1 . Details of occupational dose calculations are presented in Section I.2. Estimated radiation doses to the public and to transportation workers from the relocation of radioactive waste are presented in Section I.3. The radioactive waste inventories on which dose calculations are based are listed in Section 1.4. These waste inventories are based on information about the reference site that is found in Section 7 of Volume 1 .

The bases and assumptions used for the radiation safety analyses are as follows:

1. State-of-the-art methodology and data bases are used, with realistically maximized parameters, in the radiological safety assessment calculations. Airborne radionuclide releases are calculated using models and data found in the 1 iterature, together with the reference radionuclide inventories derived from information in Section 7 of Volume 1. 
2. The reference waste exhumation technologies analyzed are: gantry crane exhumation for the slit trench, a single enclosure building with manual operations for TRU waste exhumation, and excavation from within the trench for complete trench exhumation.

3. The reference trench is characterized by the average radionuclide content, based on the total burial ground inventory at the time of site closure.

4. Airborne radionuclide concentrations from trench exhumation operations are calculated using mechanical and wind resuspension rates. $(4,5)$

5. Water sprays, where used, are assumed to reduce the airborne dust concentrations by a factor of $10 .(6,7)$

6. Airborne dust concentrations inside the single enclosure building used for TRU waste exhumation are assumed to reach $10 \mathrm{mg} / \mathrm{m}^{3}{ }^{(8)}$ (Water sprays reduce this concentration to $1 \mathrm{mg} / \mathrm{m}^{3}$.)

7. The HEPA filter system for the single enclosure building has a transmission factor of $1 \times 10^{-6} .(9)$

8. No credit is taken for waste package integrity and the waste is assumed to be uniformly mixed with the soil. Only 10\% of each waste/soil mixture is assumed to be of a correct physical form and particle size to permit airborne transport. $(6,10,11)$

9. All offsite waste shipments are assumed to be made in exclusive-use trucks meeting DOT and NRC reguTations. Surface dose rates are assumed to be the maximum allowed by these regulations.

1D. For offsite waste relocation shipments (to either deep geologic or shallowland burial facilities) a constant transportation distance of $2,400 \mathrm{~km}$ oneway is assumed.

11. Environmental parameters (including population, land use, and growing season), are generaliy the same for both the western and eastern sites. The only differences are in the wind resuspension rates and the population densities along transportation routes. 
Additional assumptions needed for the radiological safety calculations are presented as appropriate in the following text.

\section{I.I RADIOLOGICAL PUBLIC SAFETY}

Details of airborne release calculations that provide source terms for dose calculations are presented in this section. Doses to the public from airborne releases during routine decommissioning operations and decommissioning accidents are summarized in Section I.1.4.

As stated in Section 13 of Volume 1, airborne radioactivity is a function of several complex site and waste parameters. It is beyond the scope of this study to quantify all of these parameters for each site. Therefore, several simplifying assumptions are made to obtain estimates of the airborne releases. For this study, airborne releases from routine decommissioning operations or postulated accidents that occur in the open environment (i.e., outside of containment structures) are generally found using the concept of resuspension rates. Basically, the total resuspended radioactivity is assumed to be the sum of two resuspension terms that account for mechanical and wind forces.

Mechanical resuspension calculations are made using a constant resuspension rate of $1 \times 10^{-7} \mathrm{sec}^{-1}$ for both western and eastern sites. (4) This mechanical resuspension rate is used because it is a representative value within the range of values reported for farming activities at Savannah River. (4) (The actual mechanical-mixing resuspension rate for a site is directly related to several complex parameters.) The airborne radioactivity resulting from mechanical resuspension is calculated by determining the product of the mechanical resuspension rate $\left(\mathrm{sec}^{-1}\right)$, the volume of waste disturbed $\left(\mathrm{m}^{3}\right)$, the total disturbance time (sec), and the specific activity of the radionuclide mixture $\left(\mathrm{Ci} / \mathrm{m}^{3}\right)$.

Wind resuspension factors for the western and eastern sites are calculated using the wind-speed-dependent resuspension rate relationship shown as a power function in Equation 1.1 : $^{(5)}$

$$
R_{r}=10^{-13}(\bar{\mu})^{3}
$$


where:
$R_{r} \bullet$ wind resuspension rate $\left(\sec ^{-1}\right)$,
TI - site-averaged annual ground-level windspeed $(\mathrm{m} / \mathrm{sec})$, and
10-13 - an empirical correction factor derived from experimental data $\left(\sec ^{2} / \mathrm{m}^{3}\right)$.

This basic equation does not contain a correction for surface friction effects. For ground-level average annual windspeeds of 5 and $2 \mathrm{~m} / \mathrm{sec}$ for the western and eastern sites, respectively, the wind resuspension rates are $1 \times 10^{-11}$ and $8 \times 10^{-13} \mathrm{sec}^{-1}$. Wind resuspension caiculations are made assuming an active wind disturbance depth of $10 \mathrm{~mm}$. The airborne radioactivity is calculated by determining the product of the wind resuspension rate $\left(\mathrm{sec}^{-1}\right)$, the disturbance depth $(0.01 \mathrm{~m})$, the total surface area exposed $\left(\mathrm{m}^{2}\right)$, the total time of exposure to wind (sec), and the specific activity of the associated radionuclide mixture $\left(\mathrm{Ci} / \mathrm{m}^{3}\right)$.

Water sprays containing wetting agents (e.g., detergents) have been used to reduce dust concentrations in air. (6) Fine water sprays or mists increase the surface tension of exposed dusty areas. A resuspension reduction of several orders of magnitude may occur, as suggested by the effect of rain on exposed surfaces. (7) Since the effectiveness of water sprays is a function of the soil/waste form encountered, procedures used, and other site-specific parameters, the reduction of air concentrations by a factor of 10 is felt to be an adequate estimate for this analysis. This assumption is used for wind and mechanical resuspension rates, both inside and outside of the containment enclosure, whenever water sprays are postulated to be used.

When containment enclosures are used for the relocation of TRU waste, airborne releases are calculated assuming a constant airborne dust loading of $10 \mathrm{mg} / \mathrm{m}^{3},(8)$ a building volume of $1,300 \mathrm{~m}^{3}$, and three complete air changes per hour through the building HEPA filter system. Water sprays are assumed to reduce the airborne dust by a factor of 10 , resulting in a level of $1 \mathrm{mg} / \mathrm{m}^{3}$. A total transmission factor of $1 \times 10^{-6}$ is assumed for a roughing and two HEPA fi)ters in series. (9) 
Since a variety of waste forms and package designs are found in burial trenches, it is difficult to estimate package integrity and waste migration in the reference trench. $(6,10,11)$ For this reason, no credit for package integrity is assumed for either the TRU waste or the complete trench exhumation. The slit trench canisters are assumed to have a $1 \%$ failure rate involving either 30-year-old or 1-year-old waste. Calculations are based on the following soil/ waste mixture volumes: $12 \mathrm{~m}^{3}$ for the slit trench, $5 \mathrm{~m}^{3}$ for the partial trench exhumation of TRU waste, and $12,200 \mathrm{~m}^{3}$ for the complete trench exhumation. It is beyond the scope of this study to further quantify these waste mixtures. However, it is felt that not all of the waste encountered will be of correct particle size or physical form for airborne transport. Therefore, it is assumed that only $10 \%$ of the waste is available for atmospheric dispersal. $(6,10,11)$

The following procedure is used to calculate source terms from airborne releases:

1. The airborne radioactivity from mechanical mixing operations is calculated by determining the waste volume disturbed and the total time of disturbance. For this study, it is assumed that waste volumes and times are the same for both sites.

2. The airborne radioactivity from wind resuspension is calculated by determining the area of waste exposed to the wind and the total exposure time. Bad weather is assumed to delay routine operations at the eastern site; thus, the waste is assumed to be exposed to the wind for a $20 \%$ longer time at the eastern site (see Appendix G).

3. The total airborne radioactivity is calculated by suming the mechanical and wind resuspension terms.

\section{I.1.1 Airborne Radioactive Releases from Routine Waste Relocation Operations}

The details of the airborne radioactive release calculations for routine waste relocation operations are presented in this section. Three waste relocation cases are considered: slit trench exhumation, exhumation of a package of TRU waste, and complete trench exhumation. The data used to calculate the 
airborne releases are summarized in Table I.1-1. Calculated airborne releases from mechanical resuspension, wind resuspension, and the total resuspension (mechanical plus wind) for each waste relocation operation are summarized in Table I.1-2.

\subsubsection{Relocation of Waste from a Slit Trench}

Slit trench waste relocation involves movement of canisters containing activated reactor core internals. To estimate the amount of waste that could leak from these canisters, two cases are considered. The first assumes longterm deterioration of a canister buried for 30 years. The more restrictive case assumes accidental rupture of a canister of 1-year-old waste. One canister is involved in each of these cases, and each case is treated independently. Since activation products in large pieces of equipment or structural steel are fixed within a rigid matrix, it is assumed that only $7 \%$ of the waste in the canister can migrate into the soil. Reference radionuclide inventories 1 and 2 for 30-year-old and 1-year-old waste are shown in Tables I.4-1 and I.4-2, respectively. Each inventory is assumed to be mixed in 1/90 of the total trench voiume, or $12 \mathrm{~m}^{3}$, as discussed in Section 1.4. Gantry crane exhumation defined in Section 11.2.4.4 of Volume 1 is assumed as the reference exhumation option. The individual operations involved in slit trench exhumation are discussed below.

Core Drilling and Sampling. Slit trench core drilling is discussed in Section 11.2.1. Since the waste leaked from a s]it trench canister is assumed to contaminate a volume of only $12 \mathrm{~m}^{3}$, it is estimated that only two out of the total 50 cores drilled penetrate mobile waste. Water sprays are assumed during core driliing, but are not maintained on the exposed cores after drilling. With a core depth of $7 \mathrm{~m}$ and a diameter of $0.1 \mathrm{~m}$, the total volume of waste disturbed is about $0.11 \mathrm{~m}^{3}$. The drilling rate is about 20 linear meters per day, so the driliting of two cores results in about 6 hours of mechanical mixing time. The mechanical mixing airborne release is the product of volume, time, specific activity, and resuspension rate. Thus, $0.38 \mu \mathrm{Ci}$ of reference inventory 1 or $7.6 \mathrm{HCi}$ of reference inventory 2 are released. 
TABLE I.1-1. Wind and Mechanical Resuspension Data for Routine Airborne Releases from Waste Relocation Operations at the Reference LLW Burial Ground

\begin{tabular}{|c|c|c|c|c|c|c|c|c|c|}
\hline \multirow[b]{2}{*}{ Operation } & \multirow[b]{2}{*}{$\begin{array}{l}\text { Reference } \\
\text { Radionuclide } \\
\text { Inventory } \\
\text { Number(a) }\end{array}$} & \multicolumn{4}{|c|}{ Western Site } & \multicolumn{4}{|c|}{ Eastern site } \\
\hline & & $\begin{array}{l}\text { Mechanica! } \\
\text { Volume } \\
\text { of Waste } \\
\left.\text { Moved ( } \mathrm{m}^{3}\right) \\
\end{array}$ & $\begin{array}{l}\text { Hours of } \\
\text { Waste } \\
\text { Movement } \\
\text { (hr) }\end{array}$ & $\begin{array}{l}\text { Area of } \\
\text { waste Exposed } \\
\text { to Wind }\left(\mathrm{m}^{2}\right)\end{array}$ & $\begin{array}{l}\text { Hours of } \\
\text { Wind } \\
\text { Exposure } \\
\text { (hr) }\end{array}$ & $\begin{array}{l}\text { Mechanical } \\
\text { Volume } \\
\text { of Waste } \\
\text { Moved }\left(m^{3}\right)\end{array}$ & $\begin{array}{l}\text { Hours of } \\
\text { Waste } \\
\text { Movement } \\
\text { (hr) }\end{array}$ & $\begin{array}{c}\text { Area of } \\
\text { Waste Exposed } \\
\text { to Wind }\left(\mathrm{m}^{2}\right)\end{array}$ & $\begin{array}{l}\text { Hours of } \\
\text { Wind } \\
\text { Exposure } \\
\text { (hr) }\end{array}$ \\
\hline \multicolumn{10}{|l|}{ Slit Trench Exumation } \\
\hline Core Orilling & $\mathrm{i}, 2$ & 0.11 & 6 & 20 & 740 & 0.11 & 6 & 20 & 888 \\
\hline Remove Trench Soil & 1,2 & 12 & 1 & 5 & 3400 & 12 & 1 & 5 & 4100 \\
\hline Replace Trench Soil & 1,2 & 12 & r & $\ldots(b)$ & $\cdots$ & 12 & 1 & $\cdots$ & -- \\
\hline \multicolumn{10}{|l|}{ TRU Waste Exhumation } \\
\hline Core Drilling & $\begin{array}{l}3 \\
4\end{array}$ & $\begin{array}{l}0.0082 \\
0.0020\end{array}$ & $\begin{array}{l}53 \\
14\end{array}$ & $\begin{array}{r}16 \\
4\end{array}$ & $\begin{array}{l}480 \\
480\end{array}$ & $\begin{array}{l}0.0082 \\
0.0020\end{array}$ & $\begin{array}{l}53 \\
14\end{array}$ & $\begin{array}{r}16 \\
4\end{array}$ & $\begin{array}{l}550 \\
550\end{array}$ \\
\hline Renove Trench Soil (non-TRU) & 3 & 600 & 120 & -- & $\ldots$ & 600 & 120 & $\cdots$ & -- \\
\hline Package Contaminated Soil and Waste (TRU) & 4 & 5 & 20 & $\cdots$ &.-- & 5 & 20 & $\cdots$ & -- \\
\hline Remove TRU Waste & 4 & -- & $\cdots$ & -- & $\cdots$ & -- & -- & $\cdots$ & $\cdots$ \\
\hline Return Trench Soil (non-TRU) & 3 & 600 & 120 & -- & -- & 600 & 120 & -- & $\cdots$ \\
\hline Backfill with Overburden & $\cdots$ & $\cdots$ & $\cdots$ & -- & --- & $\cdots$ & -- & -- & -- \\
\hline Equipment Cleanup and Remova 1 & 3 & 1 & 8 &.- & -- & 1 & 8 & --- &.- \\
\hline \multicolumn{10}{|l|}{ Complete Burial Trench waste Exhumation } \\
\hline Core Drilling & 3 & 0.058 & 360 & 115 & 2200 & 0.058 & 360 & 175 & 2700 \\
\hline Remove and Package Waste/Soil & 3 & 12200 & 280 & 230 & 1600 & 12200 & 280 & 230 & 1900 \\
\hline Backfill with Overburden & $\cdots-$ & $\cdots$ & $\cdots$ & -- & -- & --- & -- & $\cdots$ & $\cdots$ \\
\hline Equipment Cleanup and Removal & 3 & 2 & 8 & -- &.-- & 2 & 8 & -- & --- \\
\hline
\end{tabular}

(a) Reference radionuclide inventory numbers refer to the radionuclide mixtures in Tables $1.4-1$ through $1.4-4$. Oniy 10\% of the curies involved are in a form that will permit atmospheric transport.

(b) A dash indicates that the corresponding resuspension pathway is not considered for this operation. 
TABLE I.1-2. Calculated Airborne Releases from Routine Waste Relocation Operations at the Reference LLW Burial Grounds

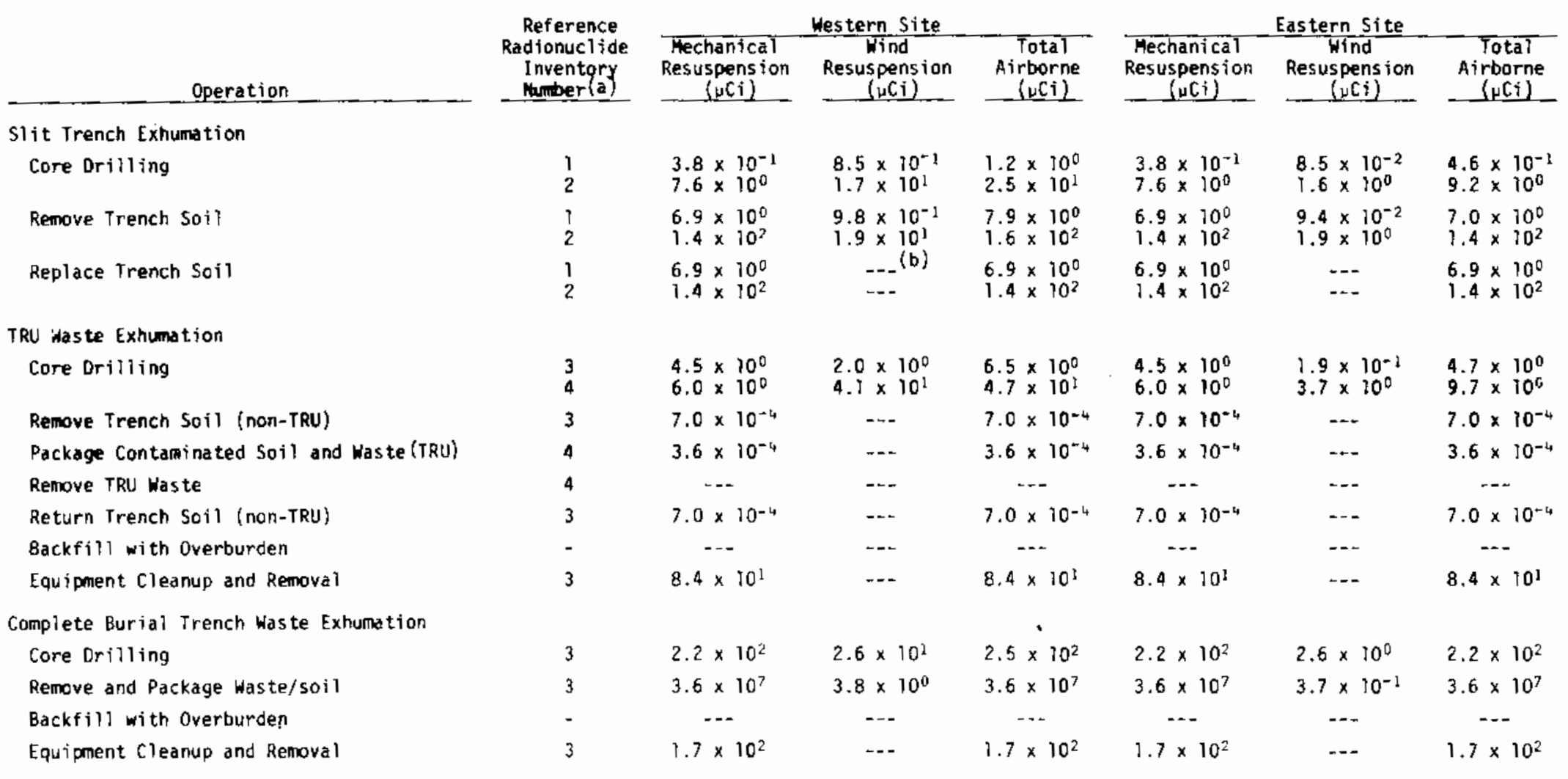

(a) Reference radionuclide inventory numbers refer to the radionuclide mixtures in Tables 1.4-1 through 1.4-4. Only $10 \%$ of the curies involved

are in a form that will pemait a tnospheric transport.
(b) A dash indicates that the corresponding resuspension pathay is not considered for this operation. 
Since the cores are not assumed to require packaging, they are spread over a surface area of $10 \mathrm{~m}^{2}$ per core until the trench overburden is removed and the cores are covered. The total exposed area is $20 \mathrm{~m}^{2}$, with an active wind disturbance depth of $10 \mathrm{~mm}$. From Figures 11.2-2 and 11.2-3, core drilling takes 20 work days for the western site and 24 work days for the eastern site. Assuming that 3 extra work days are required to remove the overburden (thus covering the exposed cores), a total wind exposure time of 31 calendar days (740 hours) for the western site and 37 calendar days (888 hours) for the eastern site is calculated. For the western site, the wind-resuspended radioactivity is calculated to be $0.85 \mu \mathrm{Ci}$ of inventory 1 or $17 \mu \mathrm{Ci}$ of inventory 2 . For the eastern site, $0.085 \mu \mathrm{Ci}$ of inventory 1 or $1.6 \mu \mathrm{Ci}$ of inventory 2 are calculated to be released.

The total airborne release is found by summing the airborne releases for mechanical and wind resuspension. For the western site, the total release is $1.2 \mu \mathrm{Ci}$ of inventory 1 or $25 \mu \mathrm{Ci}$ of inventory 2. For the eastern site, the total release is $0.46 \mu \mathrm{Ci}$ of inventory $\mathrm{l}$ or $9.2 \mu \mathrm{Ci}$ of inventory 2 .

Slit Trench Soil/Waste Removal. A total of $12 \mathrm{~m}^{3}$ of contaminated soil is assumed to be removed during slit trench exhumation. The total mechanical mixing time is assumed to be 1 hour for each site. Water sprays are assumed during removal of the contaminated soil. The total airborne release from mechanical operations is thus $5.9 \mu \mathrm{Ci}$ of inventory 1 or $140 \mu \mathrm{Ci}$ of inventory 2 .

The soil removed from the slit trench is assumed to be stored in an overburden pile along the full $150-\mathrm{m}$ trench length. To contain the volume of material in the trench, the pile requires a radius of about $4.6 \mathrm{~m}$ (assuming a half-cylinder shape). The $12 \mathrm{~m}^{3}$ of waste in such a pile has a surface area of about $5 \mathrm{~m}^{2}$. No water sprays are assumed. For the western site, from Figure 11.2-2, the soil is exposed for a maximum of 100 work days, or about 3,400 consecutive hours. The airborne release is about $0.98 \mu \mathrm{Ci}$ of inventory 1 or $19 \mu \mathrm{Ci}$ of inventory 2. For the eastern site, from Figure 11.2-3, the waste is exposed for up to $20 \%$ longer, or about 4,100 consecutive hours maximum. The airborne release is calculated to be $0.094 \mu \mathrm{Ci}$ of inventory 1 or $1.9 \mu \mathrm{Ci}$ of inventory 2 . 
The total airborne release is the sum of the mechanical and wind resuspension terms. For the western site, this sum is $7.9 \mu \mathrm{Ci}$ of inventory $i$ or $160 \mu \mathrm{Ci}$ of inventory 2. For the eastern site, it is $7.0 \mu \mathrm{Ci}$ of inventory 1 or $340 \mu \mathrm{Ci}$ of inventory 2. Mechanical resuspension dominates the airborne release from slit trench soil/waste removal operations.

Backfill Slit Trench Soil/Waste. A total of $12 \mathrm{~m}^{3}$ of contaminated soil is returned to the slit trench during backfilling. It is assumed that the same amount of time is required for backfilling as for soil removal (i.e., I hour). The release is therefore the same as the mechanical resuspension release calculated for soil/waste removal. The releases are the same for the western and eastern sites: $6.9 \mathrm{HCi}$ of inventory 1 or $140 \mu \mathrm{Ci}$ of inventory 2.

\section{I.1.1.2 Relocation of TRU Waste from a Burial Trench}

Partial trench relocation operations involve the selective removal of TRU waste packages from a burial trench. Thus, reference radionuclide inventories 3 and 4 are encountered in these operations. These inventories are Tisted in Tables I.4-3 and I.4-4, and are discussed in Section 1.4. The reference technology used is assumed to be manual operations inside a singie enclosure building. Only the core drilling occurs outside of the enclosure building.

Core Drilling. Since TRU waste forms are encountered in this operation, a special method is used to contain the radionuclides. This method is described in Section 11.3.1. A total of 20 cores are drilled over an area of $100 \mathrm{~m}^{2}$. A total of four cores are assumed to strike TRU waste (reference inventory 4), and 16 strike normal trench waste (reference inventory 3). Each core is $8 \mathrm{~m}$ long and has an active length of $6.5 \mathrm{~m}$ of waste. Since each core is encased in plastic as it is drilled, the volume of mechanically mixed waste subject to resuspension is assumed to be only 1\% (leakage) of each core. The volume of TRU waste disturbed is calculated to be $0.002 \mathrm{~m}^{3}$, and the volume of non-TRU waste disturbed is calculated to be $0.0082 \mathrm{~m}^{3}$. At a rate of 15 linear meters per day, it takes about 14 working hours to drill the TRU cores and about 53 working hours to drill the non-TRU cores. Water sprays are assumed to reduce the 
mechanical resuspension rate by a factor of 10 for this operation. The total airborne radioactivity released because of mechanical disturbance during core drilling is calculated to be $6 \mu \mathrm{Ci}$ of TRU waste (inventory 4) and $4.5 \mu \mathrm{Ci}$ of non-TRU waste (inventory 3 ).

Because of the special core-containment procedures used, each core drilled is assumed to contaminate only $1 \mathrm{~m}^{2}$ of ground surface. Therefore, only $4 \mathrm{~m}^{2}$ of waste inventory 4 and $16 \mathrm{~m}^{2}$ of waste inventory 3 are exposed to surface winds. No water sprays are assumed. These areas remain on the ground surface until the overburden is removed. From Table 11.3-2, wind exposure for the western site could be as long as 14 work days, or 480 consecutive hours; waste at the eastern site could remain on the surface about 17 work days, or 550 consecutive hours. The airborne radioactivity from wind resuspension for the western site is calculated to be $41 \mu \mathrm{Ci}$ of inventory 4 and $2.0 \mu \mathrm{Ci}$ of inventory 3. For the eastern site it is calculated to be $3.7 \mu \mathrm{Ci}$ of inventory 4 and $0.19 \mu \mathrm{Ci}$ of inventory 3 .

The total airborne release is the sum of the mechanical mixing and wind resuspension terms. Thus, for the western site, a total of $47 \mu \mathrm{Ci}$ of inventory 4 and $6.5 \mu \mathrm{Ci}$ of inventory 3 is released. For the eastern site, $9.7 \mu \mathrm{Ci}$ of inventory 4 and $4.7 \mu \mathrm{Ci}$ of inventory 3 are released as a result of core drilling operations.

Remove Non-TRU Trench Waste/Soil. After the single enclosure building is erected, non-TRU waste removal begins. From Section 11.3.5, approximately $600 \mathrm{~m}^{3}$ of non-TRU waste must be removed before the TRU waste can be removed. This waste is stored inside of the enclosure building. The excavation rate is about $5 \mathrm{~m}^{3} / \mathrm{hr}$, so about 120 hours are required to remove this waste. Water sprays reduce the dust level in the building to $1.0 \mathrm{mg} / \mathrm{m}^{3}$, and 3 total buildingvolume air changes are assumed per hour. Thus, $4.7 \times 10^{5} \mathrm{~m}^{3}$ of air, with a total of $470 \mathrm{~g}$ of soil and waste, assault the HEPA filter system. Assuming a soil density of $2 \mathrm{~g} / \mathrm{cm}^{3}, 240 \mathrm{~cm}^{3}$ (or $2.4 \times 10^{-4} \mathrm{~m}^{3}$ ) of waste inventory 3 strike the HEPA filter system. Assuming a transmission factor of $1 \times 10^{-6}$, (9) $2.4 \times 10^{-10} \mathrm{~m}^{3}$ of waste, or $7.0 \times 10^{-4} \mathrm{\mu Cj}$ of inventory 3 , are released. 
Remove and Package TRU Trench Soil. The TRU waste is assumed to be uniformly mixed with enough soil to fill two waste boxes, as described in Section 11.3.2.1. These boxes have dimensions of $1.2 \mathrm{~m} \times 1.2 \mathrm{~m} \times 1.8 \mathrm{~m}$, with a total volume of about $5 \mathrm{~m}^{3}$, and are Tined with plastic. Extra care is taken in exhuming the TRU waste; thus, the exhumation rate is only about $1 \mathrm{~m}^{3} /$ day (as described in Section 11.3.5). With 4 hours per day of mechanical effort involved, a total of 20 hours are spent exhuming and packaging the TRU waste. Again, a single enclosure building is assumed, with water sprays to reduce dust loading in the air. Using the airflow parameters for this building and an air loading of $1.0 \mathrm{mg} / \mathrm{m}^{3}, 12 \mathrm{~g}$ of waste inventory 4 contact the HEPA filter system. Assuming a soil density of $2 \mathrm{~g} / \mathrm{cm}^{3}, 6.0 \mathrm{~cm}^{3}$ (or $6.0 \times 10^{-6} \mathrm{~m}^{3}$ ) of inventory 4 are involved. With a specific activity of $60 \mathrm{Ci} / \mathrm{m}^{3}$, and a HEPA system transmission factor of $1 \times 10^{-6}$, a total of $3.6 \times 10^{-4} \mu \mathrm{Ci}$ are released during this operation.

Remove TRU Waste. After the waste is packaged, it is removed from the single enclosure building, as described in Section 11.3. The waste boxes are surveyed for smearable surface contamination and, when clean, are loaded (in a Type B container) on a truck for removal to deep geologic disposal, as described in Section 11.3.3. Since no direct waste contact is involved here, no airborne release is expected.

Backfill Non-TRU Trench Waste/Soil. This operation is expected to release, at most, the same amount of contamination as removal of the same material described earlier. Thus, $7.0 \times 10^{-4} \mu \mathrm{Ci}$ of waste inventory 3 are calculated to be released.

Backfill with overburden. Since the movement of clean material is involved in this operation, no radioactive airborne release is anticipated.

Equipment Cleanup and Removal. After exhumation, the equipment used is decontaminated before it is removed from the site. This is part of the demobilizing time shown in Figure 11.3-3, and is assumed to require 8 working hours for the building and equipment. At most, a volume of $1 \mathrm{~m}^{3}$ of waste inventory 3 is handled. Water sprays are assumed to be used, thus reducing the airborne dust concentration. For this operation, the estimated release is $84 \mu \mathrm{Ci}$. 


\section{I.1.1.3 Relocation of all the Waste from a Burial Trench}

Complete burial trench exhumation is discussed in Section 11.4. Excavation from within the trench is assumed for this analysis. Reference radionuclide inventory 3 is assumed to characterize the waste encountered. This inventory is shown in Table 1.4-3.

Core Drilling and Sampling. As described in Section 11.4.7, about 115 cores are required to characterize the trench before waste exhumation. The cores are drilled in the same manner as those for relocation of TRU waste from a burial trench. Therefore, many of the parameters used in this calculation are the same as those defined for TRU waste exhumation. Each core is $0.7 \mathrm{~m}$ in diameter and $8 \mathrm{~m}$ 7ong, with an active waste length of $6.5 \mathrm{~m}$. Each core is encased in plastic as it is drilled; hence, the volume of waste subject to mechanical mixing is assumed to be only $1 \%$ of the total core volume $(5.8 \times$ $\left.10^{-2} \mathrm{~m}^{3}\right)$. Drilling time is expected to be about 6 hours a day and, at a dritling rate of 15 linear meters per day, a total of 60 work days are required. This equals 360 hours of mechanical mixing during drilling, for either site. Water sprays are assumed to reduce the resuspension rate by a factor of 10 . The airborne release from mechanical resuspension is calculated to be $220 \mathrm{\mu Ci}$.

Because of the core-containment procedures used, each core drilled is assumed to contaminate only $1 \mathrm{~m}^{2}$ of ground surface. Therefore, only $115 \mathrm{~m}^{2}$ of contaminated surface result. For the western site, from Figure 11.4-2, the waste could be exposed to surface winds for about 65 work days, or 2,200 consecutive hours, before the overburden is removed. For the eastern site, work delays add $20 \%$ more time, for a total of 2,700 consecutive hours of wind exposure. The totai radioactivity made airborne by wind resuspension is calculated to be $26 \mu \mathrm{Ci}$ for the western site and $2.6 \mu \mathrm{Ci}$ for the eastern site.

The total airborne release is the sum of the mechanical and wind suspension terms. For both sites, this sum is dominated by the mechanical mixing component. Releases for the western and eastern sites are calculated to be $250 \mu \mathrm{Ci}$ and $220 \mu \mathrm{Ci}$, respectively. 
Remove and Package Waste/Soil. The total volume of waste/soil assumed to be packaged per trench is given as $12,200 \mathrm{~m}^{3}$ in Section 11.4.2. No credit for package integrity is assumed in calculating airborne releases. While waste forms will vary greatly within a trench, for this analysis the waste is assumed to be a homogeneous mixture of the radionuclides listed in reference jnventory 3 , and $10 \%$ of the waste is available for resuspension. Work schedules for the in-trench exhumation are based on an excavation rate of $24 \mathrm{~m}^{3} / \mathrm{hr}$ per crew (see Section 11.4.5), with two crews working. Therefore, it takes about 47 work days, or 280 work hours, to remove the waste from a single trench. Water sprays reduce the resuspension rate by a factor of 10 . The total airborne release from mechanical resuspension is calculated to be $36 \mathrm{Ci}$.

The surface area of the exposed waste during complete trench exhumation and waste packaging is calculated on the assumption that two crews work from the trench ends toward the center. (This method is described in Section 11.4.5.) The trench walls and floor are assumed to be free of radioactive contamination as each working face advances. The area of each working face is calculated assuming a working slope of 45 degrees. The average trench width is about $12.5 \mathrm{~m}$, and the working face is about $9.2 \mathrm{~m}$ high along the 45 degree slope. The area of each face is about $115 \mathrm{~m}^{2}$; therefore, the total area exposed is $230 \mathrm{~m}^{2}$. For the western site (from Figure 11.4-2), it takes about 45 work days to exhume and package the waste. This corresponds to about 1,600 hours of continuous wind disturbance to a depth of $0.01 \mathrm{~m}$. For the eastern site (from Figure 11.4-3), about 53 work days, or 1,900 hours of continuous exposure, are required. Water sprays reduce the resuspension rate by a factor of 10 at each site. The airborne releases are calculated to be about $3.8 \mu \mathrm{Ci}$ for the western site and $0.37 \mu \mathrm{Ci}$ for the eastern site.

The total airborne release is the sum of the mechanical and wind resuspension terms. This total is controlled by the mechanical mixing term and is $36 \mathrm{Ci}$ for both sites.

Backfill with overburden. Since clean overburden is assumed to be transported by truck from offsite, and the trench walls and floor are free of contamination, no airborne radioactivity is assumed to be generated by this operation. 
Equipment Cleanup and Removal. After the complete trench is exhumed, the equipment undergoes a radiation survey and decontamination before it is shipped offsite. This operation is part of the work required to demobilize the equipment, as shown in Table 11.4-1. As in the equipment cleanup from partial trench (TRU) waste relocation, it is assumed that $1 \mathrm{~m}^{3}$ per crew, or a total of $2 \mathrm{~m}^{3}$, of waste inventory 3 is handled. Water sprays are used to reduce dust loading. Completion of this operation is estimated to require about 8 working hours, releasing a total of $170 \mu \mathrm{Ci}$.

\section{I.1.2 Airborne Radioactive Releases from Routine Site Stabilization Operations}

Site stabilization operations are described in Section 10 and Appendix $F$. The purpose of these operations is to reduce the extent and rate of radionuclide release from buried wastes left in place in a decommissioned LLW burial ground. The operations are designed to mitigate releases caused by geomorphological, hydrological, biological, and human release mechanisms. None of the techniques in the stabilization plans considered involve direct contact with the waste; thus, there is no anticipated mechanism for airborne releases for the site stabilization operations described. The selection of a set of stabilization plans for a specific site may require procedures that involve contact with waste, but the impact of such operations is anticipated to be small by comparison to waste relocation operations. Therefore, no airborne releases are calculated for stabilization operations.

\subsubsection{Airborne Radioactive Releases from Postulated Decomissioning Accidents}

During routine decommissioning operations, situations may arise leading to accidental airborne releases of radioactivity. Postulated LLW burial ground decomissioning accidents and estimated airborne releases from these accidents are shown in Table I.1-3. The accident scenarios are presented in order of decreasing magnitude of atmospheric release, with the corresponding reference radionuclide inventory listed. Transportation accidents (for waste relocation operations) are included in the table.

An estimate of the frequency of occurrence of each postulated accident is aiso given in Table I.1-3. The frequency of occurrence is listed as being 


\section{TABLE I.T-3. Postulated Accidents During Decomissioning Operations at the Reference LLW Burial Ground}

\begin{tabular}{|c|c|c|c|c|c|}
\hline Operation/incident & $\begin{array}{c}\text { Reference } \\
\text { Radionuclide } \\
\text { Inventory } \\
\text { Mumber(a) }\end{array}$ & $\begin{array}{l}\text { Volume } \\
\text { of Was te } \\
\text { Involved } \\
\left(\mathrm{m}^{3}\right)\end{array}$ & $\begin{array}{l}\text { Duration } \\
\text { of } \\
\text { Accident } \\
\text { (hr) }\end{array}$ & $\begin{array}{c}\text { Total } \\
\text { Airborne } \\
\text { Release } \\
\text { (uCi) }\end{array}$ & $\begin{array}{l}\text { Accident } \\
\text { Frequency }(\mathrm{b})\end{array}$ \\
\hline \multicolumn{6}{|l|}{ Waste Relocation } \\
\hline Severe Transportation Accident (TRU) & 4 & 5.2 & 1 & $3.1 \times 10^{3}$ & Low \\
\hline Spontaneous Combustion of Wastes & $\begin{array}{l}3 \\
4\end{array}$ & 4 & $\begin{array}{l}4 \\
1\end{array}$ & $\begin{array}{l}1.7 \times 10^{9} \\
9.0 \times 10^{-3}\end{array}$ & $\begin{array}{l}\text { Medium } \\
\text { Medium }\end{array}$ \\
\hline Exhumation of Undetected TRU Waste & 4 & 5.2 & 1 & $1.1 \times 10^{3}$ & High \\
\hline Onsite Transportation Accident (non-TRU) & 3 & 10 & I & $1.0 \times 10^{3}$ & Medium \\
\hline Waste Package Handling (TRU) & 4 & 2.6 & 1 & $5.5 \times 10^{2}$ & Low \\
\hline Trench void-Space Coliapse & 3 & 45 & 1 & $4.7 \times 10^{2}$ & Medium \\
\hline Man-Caused Fire & 3 & 1 & 1 & $4.4 \times 10^{2}$ & Medium \\
\hline Severe Transportation Accident (non-TRU) & 3 & 5.2 & 1 & $1.5 \times 10^{2}$ & Medium \\
\hline STit Trench Side-wall Collapse & 2 & 12 & 1 & $1.4 \times 10^{2}$ & Low \\
\hline Failure of HEPA Filters (TRU) & 4 & 1 & 6 & $7.2 \times 10^{1}$ & Low \\
\hline Waste Penetration During Overburden Removal & 3 & $i$ & 960 & $3.4 \times 10^{1}$ & Low \\
\hline Core Encasement Rupture & 3 & 0.051 & i & $5.3 \times 10^{0}$ & High \\
\hline Minor Iransportation Accident (TRU) & 4 & 5.2 & 1 & $3.1 \times 10^{0}$ & Low \\
\hline High wind & 3 & 2.3 & 24 & $5.8 \times 10^{-1}$ & $\mathrm{High}$ \\
\hline Building Leak During TRU Exhumation & $\begin{array}{l}4 \\
3\end{array}$ & $\begin{array}{r}5 \\
200\end{array}$ & $\begin{array}{l}30 \\
40\end{array}$ & $\begin{array}{l}3.6 \times 10^{-1} \\
2.2 \times 10^{-2}\end{array}$ & $\begin{array}{l}\text { High } \\
\text { High }\end{array}$ \\
\hline Undetected TRU Core Orilling & 4 & 0.051 & 2 & $2.1 \times 10^{-1}$ & $\mathrm{High}$ \\
\hline Minor Transportation Accident (non-TRU) & 3 & 5.2 & Y & $1.5 \times 10^{-1}$ & Medium \\
\hline Temporary Loss of Services & 3 & $\ldots$ & $-\cdots$ & $\cdots$ & High \\
\hline Slit Trench Canister Rupture & 2 & $\cdots$ & $\cdots$ & -- & Low \\
\hline Loss of water Spray & 3 & -- & $-\cdots$ & -- & High \\
\hline Natural Phenomena & 3 & $\cdots$ & -- & $-\cdots$ & Low \\
\hline Aircraft Crashes & 3 & --- & $-\cdots$ & -- & Low \\
\hline \multicolumn{6}{|l|}{ Site Stabilization } \\
\hline Trench Void-Space Collapse & 3 & 45 & 1 & $4.7 \times 10^{3}$ & Medium \\
\hline $\begin{array}{l}\text { Waste Penetration During Site } \\
\text { Stabi]ization Operations }\end{array}$ & 3 & 1 & 240 & $8.6 \times 10^{\circ}$ & Low \\
\hline \multicolumn{6}{|c|}{$\begin{array}{l}\text { (a) Reference radionuclide inventory numbers refer to the radionuclide mixtures in Tables } 1.4-1 \text { through } \\
1.4-4 \text {. Only } 10 \% \text { of the curies shown are in a form that permits airborne transport. } \\
\text { (b) Frequence of occurrence: High }>1.0 \times 10^{-2} \text {; Medium } 1.0 \times 10^{-2} \text { to } 1.0 \times 10^{-5} \text {; Low } 1.0 \times 10^{-5} \text { events } \\
\text { per year. } \\
\text { (c) A dash indicates that no estimates of airborne releases are made. }\end{array}$} \\
\hline
\end{tabular}


high if tile occurrence of a release of similar magnitude is greater than $10^{-2}$, medium if between $10^{-2}$ and $10^{-5}$, and low if less than $10^{-5}$ events per year.

Table I.1-3 includes postulated accidents for both waste relocation and site stabilization operations. Most of the listed accidents pertain only to waste relocation operations. None of the site stabilization plans considered in this study involves direct contact with the subsurface waste. Since the waste is normally covered by 1 or $2 \mathrm{~m}$ of overburden, most stabilization accidents would not result in an airborne release of radioactivity.

While it is beyond the scope of this study to identify and evaluate every accident for decomissioning an LLW burial ground, a number of operational, natural phenomena, and indirect man-related accidents are postulated. Multipleevent accidents are not considered; that is, for each accident only one event is analyzed.

Transportation accidents listed in Table I.1-3 are discussed in Section I.3. other accidents are described briefly in the following paragraphs.

Spontaneous Combustion of Waste. Since relatively large volumes of combustible material are buried in LLW burial sites, a spontaneous fire in the waste pile is possible during waste relocation operations. For this analysis, two waste fires are postulated: one during complete trench waste relocation and one during partial waste relocation involving TRU waste.

A spontaneous fire is postulated to occur at night during trench waste relocation operations. Several combustible waste forms (e.g., paper products, plastic products, rubber products, wooden crates, and rags) exist in burial trenches. (12) A fire in these wastes during working hours would be quickiy detected and extinguished; however, a fire occurring at night might burn for a relatively long time. Thus, a fire is postulated to burn undetected for 4 hours and consume $4 \mathrm{~m}^{3}$ of waste. The waste involved is assumed to contain the mixture of radionuclides listed in reference inventory 3 . The reported maximum fractional airborne release during a contaminated waste fire is $1.5 \times 10^{-4}$. (13) Thus, a total of $1,700 \mu \mathrm{Ci}$ is estimated to be released by such a waste fire. 
A spontaneous waste fire involving TRU waste is postulated to occur at night within the confines of the metal enciosure. Since the volume of TRU waste is quite smali (only $5 \mathrm{~m}^{3}$ ), the fire is postulated to consume $1 \mathrm{~m}^{3}$ of waste in 1 hour. Using the same airborne release fraction from fires $\left(1.5 \times 10^{-4}\right)(13)$ and the waste from reference inventory 4, a total of $9000 \mathrm{HCi}$ is airborne in the single-wailed containment building. Assuming a HEPA filter system transmission factor of $1 \times 10^{-6},(9)$ a total of $0.009 \mu \mathrm{Ci}$ is caiculated to be released from this postulated accident.

A medium frequency of occurrence is estimated for fires resulting in the magnitudes of airborne release calculated here.

Exhumation of Undetected TRU Waste. The effectiveness of partial trench waste removal is total7y dependent on the accuracy of burial records and the results of core drilling. Both of these may be subject to error, depending on the site and circumstances involved. It is realistic to postulate that pockets of undetected TRU waste may be encountered during routine exhumation of all the waste from a trench. For this accident, it is postulated that $5 \mathrm{~m}^{3}$ of waste inventory 4 are encountered during in-trench waste exhumation, and that the TRU waste is not detected until packaged and ready for shipment. Therefore, it is handled in the same way as any other waste form in the tranch.

The TRU waste is postulated to be in an exposed condition subject to mechanical mixing for approximateiy one hour. Assuming a mechanical-mixing resuspension rate of $1 \times 10^{-7}$ per second and a water-spray air-concentration reduction factor of 10 (see Section 1.1 ), and the airborne release is estimated to be $1100 \mu \mathrm{Ci}$ of inventory 4 . It is estimated that the frequency of occurrence of an accident with this magnitude of release is high.

TRU Waste Package Handling. After TRU waste is exhumed and packaged, the sealed packages are removed from the work enclosure for transport to another location. It is postulated that one of the two waste boxes is accidentally dropped outside of the metal building, spiling the contents on the ground. Water sprays are assumed to be immediately availabie to reduce the airborne release. The total volume of material involved fills a waste box $(1.2 \mathrm{~m} \times 1.2 \mathrm{~m} \times 1.8 \mathrm{~m})$ with a volume of about $2.6 \mathrm{~m}^{3}$. It is estimated that 
about $l$ hour is required to repackage the contaminated soil. Using the mechanical-mixing resuspension factor of $1 \times 10^{-7}$ per second, the total release is estimated to be $550 \mu \mathrm{Ci}$ of inventory 4 . A low frequency of occurrence is estimated for an event with this amount of airborne release, since special procedures are used and only two boxes of TRU waste are handled for each TRU waste exhumation operation.

Void-Space Collapse. During site stabilization operations or overburden removal operations for trench exhumation, it is postulated that earthmoving equipment encounters a void space and sinks into the waste trench. Assuming that the trench is $30 \%$ void space (see Section F.1.1.1), it is calculated that a void large enough to engulf a medium-sized earthmover could occur if all of the void space of that section of trench were in one location. For this accident, it is postulated that a $90-\mathrm{m}^{3}$ void engulfs an earthmover while it is removing trench overburden. This event, and the subsequent recovery from it, is postulated to disturb a volume of waste equal to one-half the volume of the void, or $45 \mathrm{~m}^{3}$. It is estimated that this volume is disturbed for a maximum of 1 hour. For void-space collapse during stabilization, water sprays are not postulated to be available to reduce airborne dust concentration. However, for collapse during waste relocation, water sprays are assumed to decrease the airborne dust concentration by a factor of 10. Thus, the total airborne release from this event is $4700 \mu \mathrm{Ci}$ of inventory 3 for void-space collapse during stabilization, and $470 \mu \mathrm{Ci}$ of inventory 3 for void-space collapse during waste relocation. It is estimated that events with this magnitude of release have a medium frequency of occurrence.

Man-Caused Fires. Waste fires could occur during working hours as a result of several man-caused events, including explosive accidents involving trench equipment or welding apparatus, as well as less severe human-error events. Because of the presence of the work crew, the fire is quickly detected and extinguished. Therefore, a fire is postulated to burn for 1 hour, consuming $1 \mathrm{~m}^{3}$ of waste inventory 3 . Using a reported maximum release fraction from waste fires of $1.5 \times 10^{-4},(13)$ the total airborne release is estimated to be $440 \mu \mathrm{Ci}$. As with the spontaneous fire, a man-caused fire resulting in this magnitude of release is expected to have a medium frequency of occurrence. 
Slit Trench Side-Wall Collapse. Slit trench exhumation operations are performed after a side wall is constructed from sheet piling. It is postulated that the side wall collapses during soil removal. Such an event results in a potential for airborne release. Assuming that all $12 \mathrm{~m}^{3}$ of waste inventory 2 are involved for a maximum of 1 hour, the estimated airborne release is $140 \mathrm{HCi}$. Water sprays are assumed to be operating for the duration of the accident. A side-wall collapse leading to an airborne release of this magnitude is estimated to have a low frequency of occurrence.

Failure of HEPA Filters During IRU Waste Exhumation. As discussed earlier, TRU waste exhumation is postulated to be performed inside a single enclosure building. This building is equipped with a HEPA filter system with a total transmission factor of $1 \times 1 D^{-6} .(9)$ Such a system could fail because of equipment malfunction or human error and increase the airborne release. It is postulated that a total failure of the filters occurs during a 6 -hour work day when TRU wastes are being handled. The airflow system is assumed to continue operating, giving three building air exchanges per hour. Water sprays are operating, and the air dust loading is $1.0 \mathrm{mg} / \mathrm{m}^{3}$. With a building volume of $1,300 \mathrm{~m}^{3}$, the total airborne release is estimated to be $2.3 \mathrm{~g}$. Assuming a density of $2 \mathrm{~g} / \mathrm{cm}^{3}$, the volume of waste released is $1.2 \mathrm{~cm}^{3}$ (or $1.2 \times 10^{-6} \mathrm{~m}^{3}$ ). Using waste inventory 4 , the total activity released is estimated to be $72 \mu \mathrm{Ci}$. Because of manual inspection procedures and radiation monitoring equipment, a filter failure accident with this magnitude of release is estimated to have a low frequency of occurrence.

Waste Penetration During Overburden Removal. The removal of overburden from the waste trenches is a routine operation for complete trench exhumation. It is postulated that, during this operation, the equipment accidentally penetrates the waste. Such an event is felt to be realistic, especially where burial records are incomplete or inaccurate. It is felt that this event would disturb a small volume of waste. Therefore, it is postulated that about $100 \mathrm{~m}^{2}$ are exposed to the wind by this accident. From Figures $11.4-2$ and $11.4-3$, it is estimated that, if undetected, this area could be exposed for up to 40 days. The worst case of this event would occur at the western site because of the nigher wind resuspension rate at that site. Assuming no water spray is used, 
a wind resuspension rate of $1 \times 10^{-11} \mathrm{sec}^{-1}$ and a disturbance depth of $10 \mathrm{~mm}$, the total airborne release is estimated to be $34 \mu \mathrm{Ci}$ of inventory 3 . Waste penetration events as severe as this are estimated to have a low frequency of occurrence.

Core Encasement Rupture. Core drilling for complete trench exhumation is discussed in Secton 11.4.1. Each core is assumed to be encased in plastic as it is drilled to prevent the spread of radioactivity. For this accident it is postulated that a plastic encasement ruptures and that the waste is exposed for one hour. The rupture is postulated to occur at a location where water sprays are not available. A volume of $0.051 \mathrm{~m}^{3}$ of waste of reference radionuclide inventory 3 is involved. The airborne release is estimated to be $5.3 \mu \mathrm{Ci}$. A core encasement rupture accident resulting in an airborne release of this magnitude is estimated to have a high frequency of occurrence.

High Winds. High winds have a high frequency of occurrence, especially at the western site where dust storms frequently occur. Using a wind resuspension rate based on an average annual ground-level wind speed may result in underestimation of the short-term impact of these winds. For this study, the wind resuspension rate is determined using a power function relationship of the wind speed, as discussed in Section I.1. A high-wind event is postulated to occur at either the western or eastern site, resulting in a 24-hour average ground-level windspeed of $10 \mathrm{~m} / \mathrm{sec}$. This value is chosen because it is twice the highest windspeed used for calculating routine airborne releases. Using Equation 1.1 , the high-wind resuspension rate is calculated to be $1 \times 10^{-10}$ $\mathrm{sec}^{-1}$. In the event of high wind, routine waste relocation operations are suspended. It is further assumed that water sprays are used to reduce airborne dust concentrations by a factor of 10. For complete trench waste relocation, the area of exposed waste is $230 \mathrm{~m}^{2}$, with a wind disturbance depth of $10 \mathrm{~mm}$. Thus, the estimated airborne release from a 24-hour high-wind event is $0.58 \mu \mathrm{Ci}$ of reference inventory 3 . This value compares to a routine 24-hour wind release of $0.058 \mu \mathrm{Ci}$ for the western site and $0.0016 \mu \mathrm{Cj}$ for the eastern site.

Building Leak During Partial Trench Relocation. The reference technology for TRU waste relocation assumes that excavation takes place inside a single 
enclosure. The reference enclosure is a lightweight sheet-metal structure with reinforcing steel beams and diagonal struts. The building is designed to have a negative airflow and a HEPA air-filtration system. Undetected building leaks could be caused by such things as improper design, accidental damage to a wall, or an ineffective ventilation system. It is postulated that a leak exists in the building, permitting $0.1 \%$ of the airborne radioactivity in the building to excape unfiltered.

The airborne concentrations of radioactivity in the reference building are estimated in Section I.1.1.2. For non-TRU waste relocation operations, it is estimated that $7.8 \mathrm{~g}\left(3.9 \times 10^{-6} \mathrm{~m}^{3}\right)$ of waste inventory 3 contact the HEPA system from routine non-TRU waste removal operations. A leak of $0.1 \%$ results in the release of $3.9 \times 10^{-9} \mathrm{~m}^{3}$, or $0.011 \mathrm{\mu Ci}$. The same release occurs when the waste is replaced in the trench. Thus, the total airborne release of inventory 3 is estimated to be $0.022 \mu \mathrm{Ci}$.

For the removal of the $5 \mathrm{~m}^{3}$ of TRU waste (inventory 4), it is estimated that $12 \mathrm{~g}\left(6.0 \times 10^{-6} \mathrm{~m}^{3}\right)$ of waste assault the HEPA filter system. Again, assuming that $0.7 \%$ of the airborne waste leaks from the building, a total of $6.0 \times 10^{-9} \mathrm{~m}^{3}$, or $0.36 \mu \mathrm{Ci}$, of inventory 4 is released from the building. Containment failure of a single enclosure building resulting in an airborne release of this magnitude is estimated to have a high frequency of occurrence.

Undetected TRU Core Drilling. Core drilling for complete trench exhumation is discussed in section 11.4.1. Of the 115 cores predicted to be drilled, it is assumed that one core strikes a pocket of TRU waste. For this accident, it is postulated that the presence of TRU waste is not detected unti] the entire core is drilled. From Section 1.1.1.3, it is estimated that one core disturbs a waste volume of about $0.051 \mathrm{~m}^{3}$. This entire volume is assumed to be inventory 4 waste. Since special core encasement procedures are used, only $1 \%$ of the core is assumed to leak. The drilling rate is expected to be 15 linear meters per day, so, assuming 6 hours of drilling per day, about 2 hours are required to drill the $6.5 \mathrm{~m}$ of active waste in the core. Assuming that the mechanical-mixing resuspension rate is $1 \times 10^{-7} \mathrm{sec}^{-1}$ and that water sprays reduce the air concentration by a factor of 10 , the airborne release is estimated to be $0.21 \mu \mathrm{Ci}$. A core drilling accident resulting in an airborne release of this magnitude is estimated to have a high frequency of occurrence. 
Temporary Loss of Services. Work progress could be interrupted by the loss of support services. Such an interruption stops normal work activities, and no airborne releases are anticipated. While loss of services is estimated to have a high frequency of occurrence, this event is not analyzed further.

Slit Trench Canister Rupture. It is postulated that a slit trench waste canister ruptures during loading into a shipping cask. This rupture spills the waste in the trench. The waste is activated LWR core internals in very large pieces. While the waste contains large quantities of beta-gamma producing activation products, it is not in a form that can be readily made airborne for release. Therefore, no airborne release results. This event is estimated to have a low frequency of occurrence and is not analyzed further.

Loss of Water Spray. As with the loss of other site services, water spray loss is assumed to stop all work. Site work procedures require a water spray for most operations and, while loss of the water spray may have a high frequency of occurrence, no further anatysis of this event is made.

Aircraft Crashes. Each burial ground has its own unique potential risk from aircraft crashes, based on its proximity to airports and air-traffic lanes. The risk of aircraft impact at nuclear reactor sites is concluded to be low, (14) and it is felt that a similar low risk exists for LLW burial sites. The risk is not escalated by decommissioning operations and, thus, is found to be about $10^{-6}$ to $10^{-8}$ events per year. No further analys is is made here.

Waste Penetration During Site Stabilization Operations. For this event, it is postulated that an area of $100 \mathrm{~m}^{2}$ of waste is exposed for about 10 days during site stabilization operations. Such an event may occur at a site where the exact location of the trenches is unknown because of inaccurate or incomplete records. Assuming that no water spray is used, and using the western wind resuspension factor $\left(1 \times 10^{-11} \mathrm{sec}^{-1}\right)$ disturbing the waste to a depth of $10 \mathrm{~mm}$, the airborne release is estimated to be $8.6 \mu \mathrm{Ci}$. Because of radiation monitoring efforts, an event with this release has a low frequency of occurrence.

\subsubsection{Calculated Public Radiation Doses}

First-year doses and 50-year committed dose equivalents are estimated for airborne releases from routine decommissioning operations and decommissioning 
accidents. Dose calculations use the airborne radionuclide concentrations described in Sections 1.1 .1 and 1.1 .3 and the reference radionuclide inventories tabulated in Section I.4. A detailed discussion of dose models is found in Appendix $C$. The dose calculations presented in this section are summarized in Section 13 of Volume 1.

The airborne radioactive releases from routine waste relocation operations, shown in Table 1.1-2 for the western and eastern sites, are used with the corresponding reference radionuclide inventories to calculate the doses shown in Tables 1.1-4 through I.1-7. Tables 1.1-4 and I.1-5 contain the calculated doses to the maximum-exposed individual. Tables I.1-6 and I.1-7 contain the calculated doses to the population residing within an $80-\mathrm{km}$ radius around the reference LLW site, using average individual exposure parameters. For this analysis, identical site parameters for the western and eastern sites are used, except for wind resuspension factors and times required to perform some of the decomissioning tasks.

Table 1.1-8 contains estimates of doses to the maximum-exposed individual for ajrborne releases from decommissioning accidents. Entries in the tabie are ordered in terms of decreasing magnitude of the airborne release. Doses from transportation accidents are included in this table.

\section{I.2 OCCUPATIONAL SAFETY}

Details of the occupational dose calculations for waste relocation, site stabilization, and long-term care are presented in this section.

Section 11 of Volume 1 contains a discussion of methods and procedures for waste relocation. Occupational dose calculations are made for three waste relocation cases:

- relocation of high beta-gamma radioactivity waste from a slit trench by use of the gantry crane exhumation option

- relocation of TRU waste from a burial trench by use of manual excavation techniques inside a singie enclosure

- relocation of all the waste from a burial trench by excavation from within the trench. 


\section{TABLE I.1-4. Radiation Doses to the Maximum-Exposed Individual from Airborne Releases}

During Routine Waste Relocation Operations at the Western Site

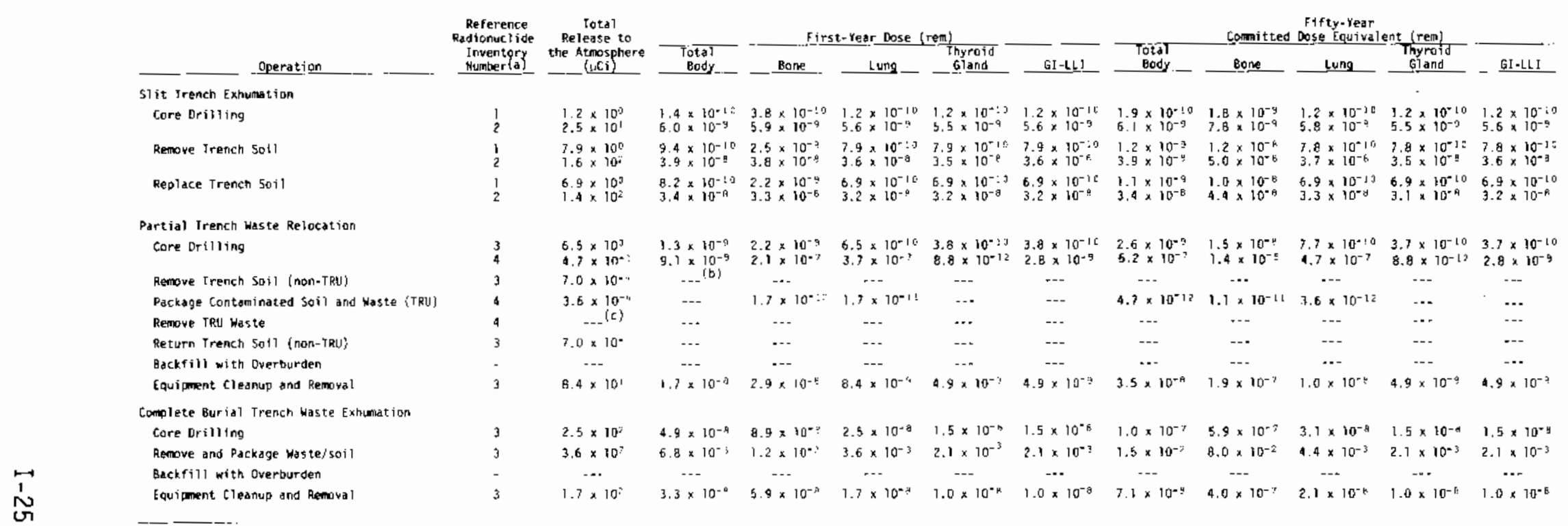

Takpeference rodtonuclide inventory numbers refer to the radionuclide mixtures in iables 3.4-1 through 1.4-4. Only 10\% of the curies

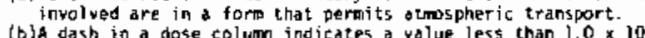

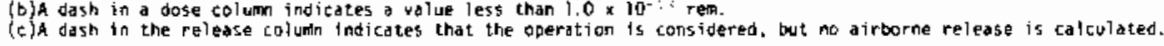


TABLE I.1-5. Radjation Doses to the Maximum-Exposed Individuat from Airborne Releases During Routine Waste Relocation Operations at the Eastern Site

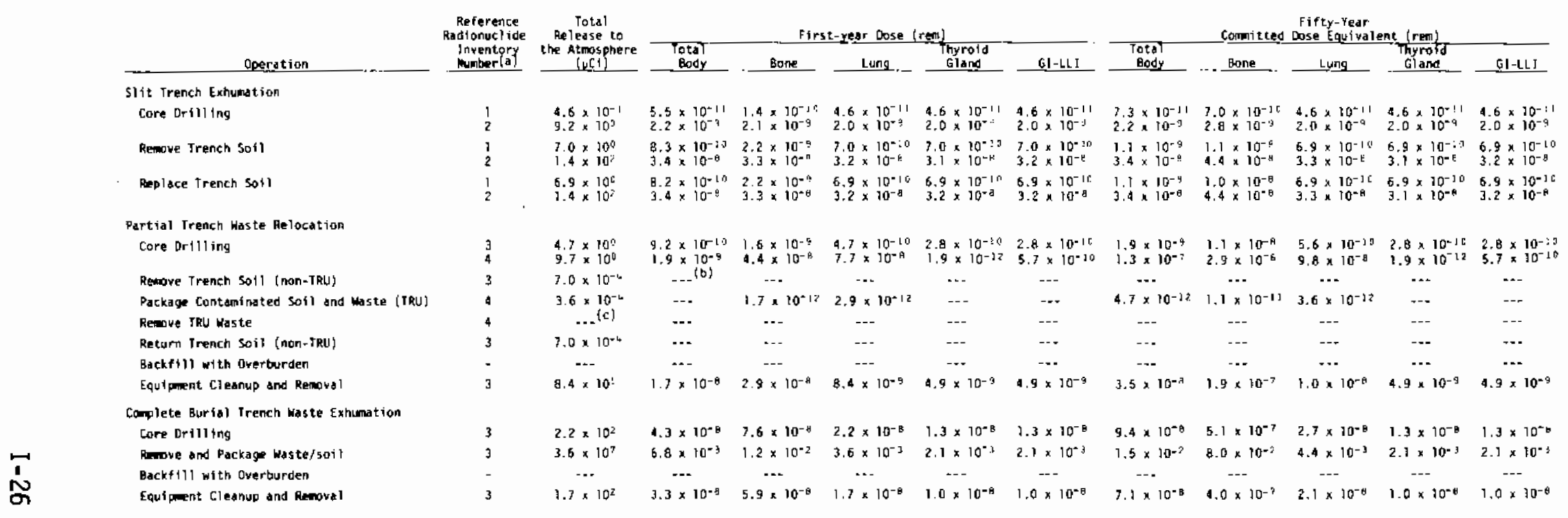

(a) Reference radionucl lde inventory numbers refer to the radianucl ide mixtures in Tabies 1.4-1 through 1.4-4. Only $10 x$ of the curies

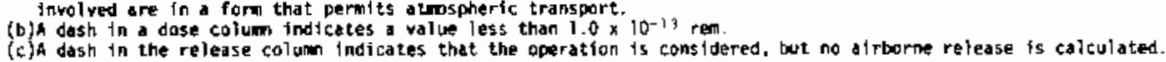


IABLE 1.1-6. Radiation Doses to the Population Residing Within $80 \mathrm{~km}$ from Ajrborne Releases During Routine Waste Relocation Operations at the Western Site(a)

\begin{tabular}{|c|c|c|c|c|c|c|c|c|c|c|c|c|}
\hline \multirow[b]{2}{*}{ Operation. } & \multirow{2}{*}{$\begin{array}{c}\text { Reference } \\
\text { Radionuclide } \\
\text { inventory } \\
\text { Number } \\
\end{array}$} & \multirow{2}{*}{$\begin{array}{c}\text { Total } \\
\text { Release to } \\
\text { the Atmosphere } \\
\text { (uci) }\end{array}$} & \multicolumn{5}{|c|}{ First-Year Dose (man-ren) } & \multicolumn{5}{|c|}{$\begin{array}{l}\text { Fifty-Year } \\
\text { Comitted Dose Equivalent (man-rem) }\end{array}$} \\
\hline & & & $\begin{array}{l}\text { Total } \\
\text { Body }\end{array}$ & Bone & Lung & $\begin{array}{c}\text { Thyro id } \\
\text { Gland }\end{array}$ & GI-LLLI & $\begin{array}{c}\text { Total } \\
\text { Body } \\
\end{array}$ & Bone & Lung & $\begin{array}{l}\text { Thyrotd } \\
\text { Gland } \\
\end{array}$ & G1- \\
\hline \multicolumn{13}{|l|}{ Shit Trench Exhuraation } \\
\hline Core Drilling & $\frac{1}{2}$ & $\begin{array}{l}1.2 \times 10^{0} \\
2.5 \times 10^{1}\end{array}$ & $\begin{array}{l}8 \times 10^{-8} \\
4 \times 10^{-6}\end{array}$ & $\begin{array}{l}3 \times 10^{-7} \\
3 \times 10^{-4}\end{array}$ & $\begin{array}{l}7 \times 10^{-4} \\
3 \times 10^{-6}\end{array}$ & $\begin{array}{l}7 \times 10^{-8} \\
3 \times 10^{-4}\end{array}$ & $\begin{array}{l}7 \times 10^{-4} \\
3 \times 10^{-7}\end{array}$ & $\begin{array}{l}3 \times 10^{-7} \\
4 \times 10^{-6}\end{array}$ & $\begin{array}{l}2 \times 10^{-6} \\
5 \times 10^{-6}\end{array}$ & $\begin{array}{l}7 \times 10^{-8} \\
3 \times 10^{-6}\end{array}$ & $\begin{array}{l}7 \times 10^{-8} \\
3 \times 10^{-6}\end{array}$ & $\begin{array}{l}7 \times 10^{-8} \\
3 \times 10^{-6}\end{array}$ \\
\hline Renove Trench Soil & $\begin{array}{l}1 \\
2\end{array}$ & $\begin{array}{l}7.9 \times 10^{9} \\
1.6 \times 10^{2}\end{array}$ & $\begin{array}{l}5 \times 10^{-7} \\
2 \times 10^{-5}\end{array}$ & $\begin{array}{l}2 \times 10^{-5} \\
2 \times 10^{-4}\end{array}$ & $\begin{array}{l}4 \times 10^{-7} \\
2 \times 10^{-5}\end{array}$ & $\begin{array}{l}4 \times 10^{-7} \\
2 \times 10^{-3}\end{array}$ & $\begin{array}{l}4 \times 10^{-7} \\
2 \times 10^{-5}\end{array}$ & $\begin{array}{l}8 \times 10^{-7} \\
2 \times 10^{-5}\end{array}$ & $\begin{array}{l}9 \times 10^{-6} \\
3 \times 10^{-5}\end{array}$ & $\begin{array}{l}4 \times 10^{-7} \\
2 \times 10^{-5}\end{array}$ & $\begin{array}{l}4 \times 10^{-7} \\
2 \times 10^{-5}\end{array}$ & $\begin{array}{l}5 \times 10^{-7} \\
2 \times 10^{-5}\end{array}$ \\
\hline Replace Trench Soil & $\frac{1}{2}$ & $\begin{array}{l}6.9 \times 10^{0} \\
1.4 \times 10^{2}\end{array}$ & $\begin{array}{l}5 \times 10^{-7} \\
2 \times 10^{-4}\end{array}$ & $\begin{array}{ll}2 \times 10^{-6} \\
2 \times 10^{-1}\end{array}$ & $\begin{array}{l}1 \times 10^{-7} \\
2 \times 10^{-4}\end{array}$ & $\begin{array}{l}4 \times 10^{-7} \\
2 \times 10^{-5}\end{array}$ & $\begin{array}{l}4 \times 10^{-7} \\
2 \times 10^{-5}\end{array}$ & $\begin{array}{l}7 \times 10^{-7} \\
2 \times 10^{-5}\end{array}$ & $\begin{array}{l}9 \times 10^{-6} \\
3 \times 10^{-5}\end{array}$ & $\begin{array}{l}4 \times 10^{-7} \\
2 \times 10^{-5}\end{array}$ & $\begin{array}{l}4 \times 10^{-7} \\
2 \times 10^{-5}\end{array}$ & $\begin{array}{l}4 \times 10^{-3} \\
2 \times 10^{-3}\end{array}$ \\
\hline \multicolumn{13}{|l|}{ Partial Trench Waste Relocation } \\
\hline core Drilling & $\begin{array}{l}3 \\
4\end{array}$ & $\begin{array}{l}6.5 \times 10^{0} \\
4.7 \times 10^{1}\end{array}$ & $\begin{array}{l}9 \times 10^{-7} \\
1 \times 10^{-5}\end{array}$ & $\begin{array}{l}2 \times 10^{-4} \\
3 \times 10^{-4}\end{array}$ & $\begin{array}{l}5 \times 10^{-7} \\
4 \times 10^{-4}\end{array}$ & $\begin{array}{l}2 \times 10^{-7} \\
6 \times 10^{-9}\end{array}$ & $\begin{array}{l}2 \times 10^{-7} \\
1 \times 10^{-6}\end{array}$ & $\begin{array}{l}2 \times 10^{-t} \\
7 \times 10^{-4}\end{array}$ & $\left\{\begin{array}{l}1 \times 10^{-5} \\
1 \times 10^{-2}\end{array}\right.$ & $\begin{array}{l}6 \times 10^{-7} \\
6 \times 10^{-4}\end{array}$ & $\begin{array}{l}2 \times 10^{-7} \\
6 \times 10^{-9}\end{array}$ & $\begin{array}{l}2 \times 10^{-7} \\
1 \times 10^{-6}\end{array}$ \\
\hline Remere Trench Solil (non-TRU) & 3 & $7.0 \times 10^{-4}$ & $1 \times 10^{-10}$ & $2 \times 10^{-10}$ & $5 \times 10^{t l}$ & $3 \times 10^{-11}$ & $3 \times 10^{-11}$ & $3 \times 10-10$ & $1 \times 10^{-9}$ & $7 \times 10^{-11}$ & $3 \times 10^{-11}$ & $3 \times 10^{-11}$ \\
\hline Package Contaminated Soil and Waste (TRU) & 4 & $3.6 \times 10^{-4}$ & $8 \times 10^{-11}$ & $1 \times 10^{-9}$ & $3 \times 10^{-9}$ & --- & $1 \times 10^{-11}$ & $6 \times 10^{-9}$ & $1 \times 10^{-7}$ & $4 \times 10^{-9}$ & --- & $1 \times 10^{-11}$ \\
\hline Remove TRU Wiste & 4 & $\ldots(c)$ & $\ldots(d)$ & -- & $\cdots$ & $\cdots$ & $\cdots$ & --- & $\ldots$ & ... & +- & -- \\
\hline Return Trench Soil (nan-TRU) & 3 & $7.0 \times 10^{-4}$ & $1 \times 10^{-10}$ & $2 \times 10^{-10}$ & $5 \times 10^{-61}$ & $3 \times 10^{-i} i$ & $3 \times 10^{-11}$ & $3 \times 10^{-10}$ & $1 \times 10^{-4}$ & $7 \times 10^{-11}$ & $3 \times 10^{-11}$ & $3 \times 10^{-11}$ \\
\hline Backfill with Overburden & - & --- & $\cdots-$ & $\cdots$ & --- & $\cdots$ & $\cdots$ & $\cdots$ & --- & $\cdots$ & $\cdots$ & ... \\
\hline Equipment Cleanup and Removal & 3 & $8.4 \times 10^{1}$ & $1 \times 10^{-5}$ & $2 \times 10^{-5}$ & $6 \times 10^{-5}$ & $3 \times 10^{-6}$ & $3 \times 10^{-6}$ & $3 \times 10^{-3}$ & $2 \times 10^{-4}$ & $8 \times 10^{-6}$ & $3 \times 10^{-6}$ & $3 \times 10^{-6}$ \\
\hline \multicolumn{13}{|l|}{ Coplete Burlaf Trench Waste Exhumbtion } \\
\hline Core Drtlling & 3 & $2.5 \times 10^{2}$ & $4 \times 10^{-5}$ & $7 \times 10^{-5}$ & $2 \times 10^{-5}$ & $8 \times 10^{-5}$ & $8 \times 10^{-6}$ & $8 \times 10^{-5}$ & $5 \times 10^{-4}$ & $2 \times 10^{-5}$ & $8 \times 10^{-6}$ & $8 \times 10^{-6}$ \\
\hline Rerove and Package Waste/soil & 3 & $3.6 \times 10^{7}$ & $5 \times 10^{\circ}$ & $7 \times 10^{0}$ & $3 \times 10^{\circ}$ & $2 \times 10^{9}$ & $2 \times 10^{0}$ & $2 \times 10^{1}$ & $7 \times 10^{1}$ & $4 \times 10^{0}$ & $2 \times 10^{0}$ & $2 \times 10^{0}$ \\
\hline Backfill with Overburden & - & --- & $\cdots$ & $\cdots$ & $--\cdot$ & $\cdots$ & $\ldots$ & --- & $\cdots$ & --- & $\cdots$ & $\cdots$ \\
\hline Equipent Clesnup and Revoval & 3 & $1.7 \times 10^{2}$ & $2 \times 10^{-3}$ & $5 \times 10^{-2}$ & $1 \times 10^{-5}$ & $6 \times 70^{-4}$ & $6 \times 10^{-6}$ & $5 \times 10^{-5}$ & $3 \times 10^{-4}$ & $2 \times 10^{-.5}$ & $6 \times 10^{-6}$ & $6 \times 10^{-6}$ \\
\hline
\end{tabular}

(a) Population doses are shown to one significant figure.

b) Reference radionuclide inventary numbers refer to the radionuclide mixtures in rables I.4-1 through 1.4-4. Only 70\% of the curies involved are in

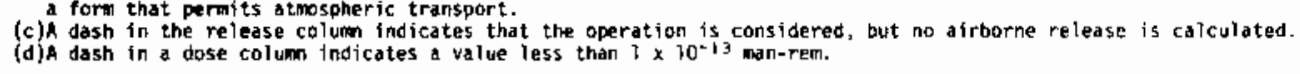


TABLE I.1-7. Radiation Doses to the Population Residing Within $80 \mathrm{~km}$ from Ajrborne Releases During Routine Waste Relocation Operations at the Eastern Site(a)

\begin{tabular}{|c|c|c|c|c|c|c|c|c|c|c|c|c|}
\hline & $\begin{array}{l}\text { Reference } \\
\text { Radionucilde }\end{array}$ & $\begin{array}{l}\text { Total } \\
\text { Release to }\end{array}$ & & First-y & ear Doose in & an-re & & & Conmitted & $\begin{array}{l}\text { Fifty-Year } \\
\text { se Equival }\end{array}$ & $(\operatorname{man}-r e$ & \\
\hline Operation & & & $\begin{array}{l}\text { Total } \\
\text { Body. }\end{array}$ & Bone & Lung .. & G & GI-LLL] & Body_ & Bone. & Luns & Giond & GI-LL] \\
\hline it Trench Exhumation & & & & & & & & & & & & \\
\hline core Orilling & $\begin{array}{l}7 \\
2\end{array}$ & $\begin{array}{l}4.6 \times 10^{-1} \\
9.2 \times 10^{0}\end{array}$ & $\begin{array}{l}3 \times 10^{-8} \\
1 \times 10^{-6}\end{array}$ & $\left\{\begin{array}{l}1 \times 10^{-3} \\
1 \times 10^{-1}\end{array}\right.$ & $\begin{array}{l}3 \times 10^{-A} \\
1 \times 10^{-1}\end{array}$ & $\begin{array}{l}3 \times 10^{-8} \\
1 \times 10^{-6}\end{array}$ & $\begin{array}{l}3 \times 10^{-9} \\
1 \times 10^{-6}\end{array}$ & $\begin{array}{l}5 \times 10^{-5} \\
1 \times 10^{-6}\end{array}$ & $\begin{array}{l}6 \times 10^{-7} \\
2 \times 10^{-6}\end{array}$ & $\begin{array}{l}3 \times 10^{-6} \\
1 \times 10^{-6}\end{array}$ & $\begin{array}{l}3 \times 10^{-8} \\
1 \times 10^{-6}\end{array}$ & $\left\{\begin{array}{l}\times 10^{-8} \\
1 \times 10^{-6}\end{array}\right.$ \\
\hline Remove Trench Soii & 3 & $\begin{array}{l}7.0 \times 10^{6} \\
1.4 \times 10^{2}\end{array}$ & $\begin{array}{l}5 \times 10^{-7} \\
2 \times 10^{-4}\end{array}$ & $\begin{array}{l}2 \times 10^{-6} \\
2 \times 10^{-1}\end{array}$ & $\begin{array}{l}4 \times 10^{-7} \\
2 \times 10^{-1}\end{array}$ & $\begin{array}{l}4 \times 10^{-7} \\
2 \times 10^{-1}\end{array}$ & $\begin{array}{l}4 \times 10^{-7} \\
2 \times 10^{-4}\end{array}$ & $\begin{array}{l}7 \times 10^{-7} \\
2 \times 10^{-5}\end{array}$ & $\begin{array}{l}9 \times 10^{-4} \\
3 \times 10^{-5}\end{array}$ & $\begin{array}{l}4 \times 10^{-7} \\
2 \times 10^{-5}\end{array}$ & $\begin{array}{l}4 \times 10^{-7} \\
2 \times 10^{-5}\end{array}$ & $\begin{array}{l}4 \times 10^{-7} \\
2 \times 10^{-5}\end{array}$ \\
\hline Replace Trench Soil & $\begin{array}{l}1 \\
2\end{array}$ & $\begin{array}{l}6.9 \times 10^{6} \\
1.4 \times 10^{7}\end{array}$ & $\begin{array}{l}5 \times 10^{-7} \\
2 \times 10^{-3}\end{array}$ & $\begin{array}{ll}2 & \times 10^{-6} \\
2 & \times 10^{-6}\end{array}$ & $\begin{array}{l}4 \times 10^{-1} \\
2 \times 10^{-1}\end{array}$ & $\begin{array}{l}4 \times 10^{2} \\
2 \times 10^{-3}\end{array}$ & $\begin{array}{l}4 \times 10^{-1} \\
2 \times 10^{-6}\end{array}$ & $\begin{array}{l}7 \times 10^{-3} \\
2 \times 10^{-5}\end{array}$ & $\begin{array}{l}9 \times 10^{-6} \\
3 \times 10^{-4}\end{array}$ & $\begin{array}{l}4 \times 10^{-7} \\
2 \times 10^{-5}\end{array}$ & $\begin{array}{l}4 \times 10^{-7} \\
2 \times 10^{-5}\end{array}$ & $\begin{array}{l}4 \times 10^{-7} \\
2 \times 10^{-5}\end{array}$ \\
\hline rtial Trench Waste Rel & & & & & & & & & & & & \\
\hline Care orilting & $\begin{array}{l}3 \\
4\end{array}$ & $\begin{array}{l}4.7 \times 10^{2} \\
9.7 \times 10^{0}\end{array}$ & $\begin{array}{l}7 \times 10^{-1} \\
3 \times 10^{-6}\end{array}$ & $\begin{array}{l}1 \times 10^{-4} \\
5 \times 10^{-5}\end{array}$ & $\begin{array}{l}4 \times 10^{-7} \\
8 \times 10^{-5}\end{array}$ & $\begin{array}{l}2 \times 10^{-7} \\
1 \times 10^{-1}\end{array}$ & $\begin{array}{l}2 \times 10^{-7} \\
4 \times 10^{-1}\end{array}$ & $\begin{array}{l}1 \times 10^{-6} \\
1 \times 10^{-4}\end{array}$ & $\begin{array}{l}9 \times 10^{-6} \\
3 \times 10^{-3}\end{array}$ & $\begin{array}{l}4 \times 10^{-7} \\
1 \times 10^{-4}\end{array}$ & $\begin{array}{l}2 \times 10^{-7} \\
1 \times 10^{-9}\end{array}$ & $\begin{array}{l}2 \times 10^{-7} \\
4 \times 10^{-7}\end{array}$ \\
\hline Remave Trench soit (non-TRu) & 3 & $7.0 \times 10^{-16}$ & $1 \times 10^{-13}$ & $2 \times 10^{-110}$ & $5 \times 10^{-i i}$ & $3 \times 10^{-11}$ & $3 \times 10^{-11}$ & $3 \times 10^{-10}$ & $1 \times 10^{-4}$ & $6 \times 10^{-11}$ & $3 \times 10^{-11}$ & $3 \times 10^{-11}$ \\
\hline Package Contaminated So 11 and Waste (TRU) & 4 & $3.6 \times 10^{-4}$ & $8 \times 10^{-34}$ & $1 \times 10^{-4}$ & $3 \times 10^{-9}$ & $4 \times 10^{-14}$ & $1 \times 10^{-11}$ & $6 \times 10^{-9}$ & $1 \times 10^{-3}$ & $4 \times 10^{-4}$ & $4 \times 10^{-14}$ & $1 \times 10^{-11}$ \\
\hline Renove TRU Haste & 4 & $\ldots(c)$ & $\ldots$ (d) & -.- & $\cdots$ & $\cdots$ & --- & -.. & $\cdots$ & $\cdots$ & $\cdots$ & $\cdots$ \\
\hline Return Trench Sail (non-TRU) & 3 & $1.0 \times 10^{-4}$ & $1 \times 10^{016}$ & $2 \times 10^{-19}$ & $5 \times 10^{-1}:$ & $3 \times 10^{-11}$ & $3 \times 10^{-11}$ & $3 \times 10^{-11}$ & $1 \times 10^{-3}$ & $6 \times 10^{-11}$ & $3 \times 10^{-11}$ & $3 \times 10^{-11}$ \\
\hline Backfild with Overburden & - & -- & $\cdots$ & $\cdots$ & $-\cdot-$ & $\cdots$ & $--\cdot$ & $\cdots$ & $\cdots$ & -- & $\cdots$ & $\cdots$ \\
\hline Equipment Cleanup and Renoval & 3 & $8.4 \times 10^{3}$ & $1 \times 10^{-5}$ & $2 \times 10^{-4}$ & $6 \times 10^{-6}$ & $3 \times 10^{-6}$ & $3 \times 10^{-i}$ & $3 \times 10^{-5}$ & $2 \times 10^{-4}$ & $8 \times 10^{-6}$ & $3 \times 10^{-6}$ & $3 \times 10^{-6}$ \\
\hline Complet & & & & & & & & & & & & \\
\hline core ortlling & 3 & $2.2 \times 10^{2}$ & $3 \times 10^{-2}$ & $6 \times 10^{-4}$ & $2 \times 10^{-5}$ & $3 \times 10^{-6}$ & $8 \times 10^{-6}$ & $7 \times 10^{-5}$ & $5 \times 10^{-4}$ & $2 \times 10^{-5}$ & $8 \times 10^{-6}$ & $8 \times 10^{-6}$ \\
\hline Remove and Package & 3 & $3.6 \times 10^{7}$ & $5 \times 10^{0}$ & $7 \times 10=$ & $3 \times 10^{1 !}$ & $2 \times 10^{\prime \prime}$ & $2 \times 10^{11}$ & $2 \times 10^{1}$ & $7 \times 10^{3}$ & $4 \times 10^{0}$ & $2 \times 10^{0}$ & $2 \times 10^{0}$ \\
\hline Backfill with Overburden & - & $\cdots$ & -- & --- & --- & $\cdots$ & --- & $\cdots$ & $\cdots$ & $\cdots$ & $\cdots$ & $\cdots$ \\
\hline Equipment Cleanup and Removal & 3 & $1.7 \times 10^{2}$ & $2 \times 10^{-3}$ & $5 \times 10^{-6}$ & $1 \times 10^{-1}$ & $6 \times 10^{-11}$ & $6 \times 10^{-t}$ & $5 \times 10^{-5}$ & $3 \times 10^{-4}$ & $2 \times 10^{-5}$ & $6 \times 10^{-6}$ & $6 \times 10^{-6}$ \\
\hline
\end{tabular}

(a) Population doses are shown to one significant figure.

the radionuclide mixtures in Tables I. 4-1 through 1.4-4. Only 10: of the curies involved are in

a form that permits atmospheric transport.

(c) A dash in the release colunn indicates that the operation 15 considered, but no dirborne release is calculated.

(d) A dash in a dose column indicates a value less than $1 \times 10^{-! 3}$ man-rem. 


\section{TABLE 1.1-8. Radiation Doses to the Maximum-Exposed Individual from Airborne Releases from Decommissioning Accidents}

\begin{tabular}{|c|c|c|c|c|c|c|c|c|c|c|c|c|}
\hline & $\begin{array}{l}\text { Reference } \\
\text { Radionucl ide }\end{array}$ & Totat & & $\mathrm{F} 1+\mathrm{S}$ & t-Year tose & & & & -Yearc & dose Equ & $\frac{\text { ivalent (rent) }}{\text { Thyre id }}$ & \\
\hline - 0perationfincident & & 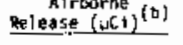 & Body. & lone & Lung & Gland & $\rightarrow$ Gl-LLI & $\begin{array}{l}\text { Total } \\
\text { Bady }\end{array}$ & Eone & Lung._- & $\begin{array}{l}\text { Thyre id } \\
\text { Giland. }\end{array}$ & GI-LII \\
\hline Haste Relocation & & & & & & & & & & & & \\
\hline Severe Transportation Accident $\{\mathrm{TRU}\}$ & 4 & $3.1 \times 10^{3}$ & $6.1 \times 10^{-3}$ & $1.4 \times 10^{-1}$ & $1.5 \times 10^{-1}$ & $---^{\{c\}}$ & $1.3 \times 10^{-4}$ & $2.0 \times 10^{-1}$ & $4.6 \times 10^{3}$ & $1.5 \times 10^{-1}$ & $\cdots$ & $1.3 \times 10^{-4}$ \\
\hline Spontaneous combust ion of Wastes & 3 & $\begin{array}{l}1.7 \times 10^{3} \\
9.0 \times 10^{-4}\end{array}$ & $\begin{array}{l}3.1 \times 10^{-6} \\
3.9 \times 10^{-11}\end{array}$ & $\begin{array}{l}2.2 \times 10^{-5} \\
8.8 \times 10^{-9}\end{array}$ & $\begin{array}{l}5.9 \times 10^{-6} \\
9.2 \times 10^{-9}\end{array}$ & $\begin{array}{c}5.0 \times 10^{-9} \\
--\end{array}$ & $\begin{array}{l}3.5 \times 10^{-1} \\
8.0 \times 10^{-9}\end{array}$ & $\begin{array}{l}1.2 \times 10^{-5} \\
1.2 \times 10^{-8}\end{array}$ & $\begin{array}{l}1.9 \times 10^{-4} \\
2.8 \times 10^{-7}\end{array}$ & $\begin{array}{l}6.0 \times 10^{-5} \\
9.2 \times 10^{-9}\end{array}$ & $5.8 \times 10^{-3}$ & $\begin{array}{l}3.5 \times 10^{-7} \\
8.0 \times 10^{-4}\end{array}$ \\
\hline Exhumation of Undetected IRO waste & 4 & $1.1 \times 10^{3}$ & $4.8 \times 10^{-5}$ & $1.6 \times 10^{-3}$ & $1.2 \times 10^{-3}$ & --- & $1.0 \times 10^{-6}$ & $1.6 \times 10^{-3}$ & $3.6 \times 10^{-2}$ & $1.2 \times 10^{-3}$ & --- & $1.0 \times 10^{-6}$ \\
\hline Onsite Transportation Accident (non-TRU) & 3 & $1.0 \times 10^{3}$ & $8.9 \times 10^{-5}$ & $5.3 \times 10^{-4}$ & $1.8 \times 10^{-4}$ & $1.4 \times 10^{-7}$ & $1.0 \times 10^{-5}$ & $3.5 \times 10^{-4}$ & $5.3 \times 10^{-3}$ & $1.7 \times 10^{-4}$ & $1.6 \times 10^{-7}$ & $1.0 \times 10^{-5}$ \\
\hline Waste Packege Handling (TRU) & 4 & $5.6 \times 70^{2}$ & $2.4 \times 10^{-5}$ & $5.5 \times 10^{-11}$ & $5.8 \times 10^{-4}$ & --- & $5.0 \times 10^{-7}$ & $7.8 \times 10^{-4}$ & $1.7 \times 10^{-2}$ & $5.8 \times 10^{-4}$ & $\cdots$ & $5.0 \times 10^{-7}$ \\
\hline Trench vold-space collapse & 3 & $4.7 \times 10^{2}$ & $8.6 \times 10^{-3}$ & $6.1 \times 10^{-6}$ & $1.6 \times 10^{-6}$ & $1.4 \times 10^{-9}$ & $9.8 \times 10^{-8}$ & $3.4 \times 10^{-6}$ & $5.2 \times 10^{-5}$ & $1.7 \times 10^{-6}$ & $1.6 \times 10^{-9}$ & $9.8 \times 10^{-8}$ \\
\hline Man-Caused Fire & 3 & $4.4 \times 10^{2}$ & $8.1 \times 10^{-7}$ & $5.7 \times 10^{-6}$ & $1.5 \times 10^{-6}$ & $1.3 \times 10^{-9}$ & $9.2 \times 10^{-8}$ & $3.2 \times 10^{-6}$ & $4.9 \times 10^{-5}$ & $1.6 \times 10^{-6}$ & $1.5 \times 10^{-7}$ & $9.2 \times 10^{-8}$ \\
\hline Severe Transportation Accident (non-TRU) & 3 & $1.5 \times 10^{2}$ & $1.3 \times 10^{-5}$ & $9.1 \times 10^{-5}$ & $2.4 \times 10^{-4}$ & $2.1 \times 10^{-\mu}$ & $1.4 \times 10^{\circ} \mathrm{6}$ & $5.1 \times 10^{-3}$ & $7.7 \times 10^{-4}$ & $2.5 \times 10^{-5}$ & $2.4 \times 10^{\circ} \stackrel{9}{1}=0$ & $1.4 \times 10^{-6}$ \\
\hline 5lit Trench side-mall tollapse & $?$ & $1.4 \times 10^{7}$ & $1.1 \times 10^{\circ}$ & $1.1 \times 10^{-3}$ & $9.5 \times 10^{-4}$ & $--\cdot$ & $8.5 \times 10^{-\mathrm{A}}$ & $1.3 \times 10^{-3}$ & $3.9 \times 10^{\circ} \%$ & $1.4 \times 10^{-3}$ & -- & $8.5 \times 10^{-8}$ \\
\hline Failure of HEPA filters $\{T R U\}$ & 4 & $7.2 \times 10$. & $3.1 \times 10^{-6}$ & $7.2 \times 10^{-1}$ & $7.5 \times 10^{-4}$ & $\cdots$ & $6.5 \times 10^{-5}$ & $1.0 \times 10^{-4}$ & $2.3 \times 10^{-3}$ & $7.6 \times 10^{-5}$ & $\cdots$ & $6.5 \times 10^{-5}$ \\
\hline waste Penetration during Overburden Remaval & 3 & $3.4 \times 10^{1}$ & $6.2 \times 10^{-5}$ & $4.4 \times 10^{-1}$ & $1.2 \times 10^{-1}$ & $1.0 \times 10^{-10}$ & $7.1 \times 10^{-9}$ & $2.5 \times 10^{-7}$ & $3.7 \times 10^{-5}$ & $1.2 \times 10^{-7}$ & $1.2 \times .10^{-20}$ & $7.1 \times 10^{-3}$ \\
\hline Core Encasement Rypture & 3 & $5.3 \times 10^{3}$ & $9.7 \times 10^{-5}$ & $6.9 \times 10^{-13}$ & $1.9 \times 10^{54}$ & $1.6 \times 10^{-11}$ & $1.8 \times 10^{-4}$ & $3.9 \times 10^{-4}$ & $5.8 \times 10^{-7}$ & $1.9 \times 10^{-8}$ & $1.9 \times 10^{-11}$ & $1.1 \times 10^{-3}$ \\
\hline Minor Transportat 10 Accident (TRU) & 4 & $3.1 \times 10^{10}$ & $6.1 \times 10^{-6}$ & $1.4 \times 10^{-6}$ & $1.5 \times 10^{-6}$ & -- & $1.3 \times 10^{-7}$ & $2.0 \times 10^{-4}$ & $4.6 \times 10^{-3}$ & $1.5 \times 10^{-4}$ & $\cdots$ & $1.3 \times 10^{-7}$ \\
\hline High wind & 3 & $5.8 \times 10^{-1}$ & $1.1 \times 10^{-4}$ & $7.6 \times 10^{.9}$ & $2.0 \times 10^{-9}$ & $1.7 \times 10^{-12}$ & $1.2 \times 10^{-13}$ & $4.2 \times 10^{-9}$ & $6.4 \times 10^{-2}$ & $2.1 \times 10^{-4}$ & $2.0 \times 10^{-12}$ & $7.2 \times 10^{-1} ! 6$ \\
\hline Building Leak During TRU Exhumation & $\begin{array}{l}a \\
3\end{array}$ & $\begin{array}{l}3.6 \times 10^{-1} \\
2.2 \times 10^{-2}\end{array}$ & $\begin{array}{l}1.5 \times 10^{-n} \\
4.0 \times 10^{-11}\end{array}$ & $\begin{array}{l}3.6 \times 10^{-7} \\
2.9 \times 10^{-1}: 0\end{array}$ & $\begin{array}{l}3.7 \times 10^{-7} \\
3.7 \times 10^{-11}\end{array}$ & -- & $\begin{array}{l}3.3 \times 10^{-16} \\
4.6 \times 10^{-12}\end{array}$ & $\begin{array}{l}5.1 \times 10^{-3} \\
1.6 \times 10^{-10}\end{array}$ & $\begin{array}{l}1.2 \times 10^{-5} \\
2.4 \times 10^{-7}\end{array}$ & $\begin{array}{l}3.7 \times 10^{-6} \\
7.8 \times 10^{-11}\end{array}$ & --- & $\begin{array}{l}3.3 \times 10^{-0}: 0 \\
4.6 \times 10^{-32}\end{array}$ \\
\hline Undetected TRU Core drilling & 4 & $2.4 \times 10^{-1}:$ & $4.1 \times 10^{-9}$ & $2.1 \times 10^{-3}$ & $2.2 \times 10^{-7}$ & -.. & $2.0 \times 10^{-10}$ & $3.0 \times 10^{-7}$ & $6.8 \times 10^{-6}$ & $2.2 \times 10^{-7}$ & --- & $2.0 \times 10^{-10}$ \\
\hline Minor Transportation Accident (non-TRU) & 3 & $1.5 \times 70^{\circ}:$ & $1.3 \times 10^{-4}$ & $9.1 \times 10^{-4}$ & $2.4 \times 10^{-9}$ & $2.1 \times 10^{-1}: 1$ & $1.4 \times 10^{-9}$ & $5.1 \times 10^{-6}$ & $7.7 \times 10^{-1}$ & $2.5 \times 10^{-3}$ & $2.4 \times 10^{-11}$ & $1,4 \times 10^{-1}$ \\
\hline Temporary Loss of Services & 3 & $--{ }^{(0)}$ & $--\cdot$ & $\cdots$ & $\cdots$ & -- & $\cdots$ & $\cdots$ & $\cdots$ & --- & $\cdots$ & --- \\
\hline Slit Irench caniscer Ruplure & 2 & --- & $\cdots$ & $\cdots$ & $\cdots$ & $\cdots$ & $\cdots$ & $\cdots$ & --- & $\cdots$ & $\cdots$ & $\cdots$ \\
\hline Loss of Water Spray & 3 & $\cdots$ & $\cdots$ & $\cdots$ & $\cdots$ & $\cdots$ & $\cdots$ & $\cdots$ & -- & $\cdots$ & --- & $\cdots$ \\
\hline Natural Phemomena & 3 & $\cdots$ & --- & $\cdots$ & $\cdots$ & $\cdots$ & $\cdots$ & $\cdots$ & --- & $\cdots$ & --- & $\cdots$ \\
\hline Alrtraft Crashes & 3 & --- & $\cdots$ & $\cdots$ & $-\cdot$ & $\cdots$ & $\cdots$ & $\cdots$ & --- & $\cdots$ & $\cdots$ & --- \\
\hline ation & & & & & & & & & & & & \\
\hline Trench void-5pate coll & 3 & $4.7 \times 10^{3}$ & $8.6 \times 10^{-6}$ & $6.1 \times 10^{-5}$ & $1.5 \times 10^{-5}$ & $1.4 \times 10^{-8}$ & $9.8 \times 10^{-7}$ & $3.4 \times 10^{-5}$ & $5.2 \times 10^{-4}$ & $1.7 \times 10^{-5}$ & $1.6 \times 10^{-8}$ & $9.8 \times 10^{-7}$ \\
\hline $\begin{array}{l}\text { Waste Penetration Durting } \\
\text { stabilization Operations }\end{array}$ & 3 & $8.6 \times 10^{0}$ & $1.6 \times 10^{-8}$ & $1.1 \times 10^{-7}$ & $3.0 \times 10^{-4}$ & $2.6 \times 10^{-11}$ & $1.8 \times 10^{-9}$ & $5.3 \times 10^{\circ} \mathrm{H}$ & $9.5 \times 10^{-9}$ & $3.1 \times 10^{-8}$ & $2.9 \times 10^{-11}$ & $1.8 \times 10^{-9}$ \\
\hline
\end{tabular}

(a) Reference radionucl ide inventory numbers refer to the radionuctide mixtures in Tables 1.4-i through 1.4-4. Only 10\% of the curies shom are in a form that permits dirborne etansport.
(b) Transportation accipents are included in this table and discussed in section I.3.2.

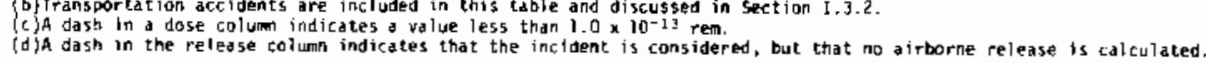


Site stabilization and Tong-term care procedures for which occupational dose calculations are made are discussed in Section 10 of volume 1.

To calculate occupational doses from external exposure, it is necessary to compute an exposure rate, determine a quality factor for the radiation present, and estimate the amount of time each crew member actually spends in the radiation field during the various phases of decommissioning.

Exposure rates from non-transuranic (non-TRU) waste are calculated using the computer code ISOSHLO $(15,16)$ The ISOSHLD program uses a point-kernel integration technique to evaluate exposure rates at the detector. Photonenergy flux is calculated for 25 energy groups with average energies ranging from $15 \mathrm{keV}$ to $3.0 \mathrm{MeV}$. Twelve source/detector geometries are available. For these calculations, the conventional burial trench (described in Section 7.2 of Volume 1) is approximated by a rectangular parallelepiped, with the detector on the centerline and slab shields representing the soil. To simplify the geometric description of the source term, it is assumed that the radioactive material is homogeneously distributed throughout the entire trench volume. The slit trench canisters are represented as cylindrical sources with slab shields. For the siit trench, it is assumed that the radioactive material is distributed uniformly throughout the canisters that are located according to the description given in Section 7.2.2.

Dose rates from the TRU waste are computed using the code PUSHLO. PUSHLD is specifically designed to correctly handle the low-energy photons from plutonium and its daughters. The plutonium source consists of a $40 \mathrm{~g} \mathrm{PuO} \mathrm{P}_{2}$ cylinder with an oxide density of $2 \mathrm{~g} / \mathrm{cm}^{3}$, centered in a 208- $\downarrow$ waste drum with 16-gauge steel walis. The soil that covers the drum is considered to have a composition similar to that of concrete and a density of $2 \mathrm{~g} / \mathrm{cm}^{3}$.

Both ISOSHLO and PUSHLD are used to calculate dose rates in terms of Roentgens per unit time. One Roentgen of gamma radiation is equivalent to 0.956 rads; ${ }^{(18)}$ for this study a direct conversion from Roentgen to rad is used. Since the major radiation from the waste is high-energy beta and garma, a quality factor of 1.0 is used to convert the exposure rate to a dose-equivalent rate. For brevity, all dose-equivalent rates are called dose rates. 
The manpower and man-hours required for each waste relocation operation are 1isted in Sections 11.2 through 11.4 of Volume 1 . Estimates are made of the fraction of the work day that each crew member spends in the radiation field. A work day is defined as being 6 hours long, except for operations involving special clothing such as bubble suits, where the work day is assumed to be 4 hours. Waste relocation operations are estimated to take $20 \%$ longer to complete at the eastern site than at the western site due to delays caused by unfavorable weather conditions. Work progress is limited by these delays, but the actual workers' exposure time for both sites is approximately equal. Therefore, in computing the external occupational doses for waste relocation operations, the man-days required for the western site are used.

Sections I.2.1 through 1.2.3 describe assumptions and procedures used to calculate external doses to decommissioning workers for the three waste relocation cases. Sections I.2.4 and I.2.5 describe the occupational dose analyses for site stabilization and long-term care, respectively.

\section{I.2.1 Relocation of High Beta-Gamma Radioactivity Waste from a Slit Trench}

A description of the slit trench is given in Section 7.2.2 of Volume 1 . The technologies for waste exhumation from a slit trench are described in Section 11.2. The reference waste exhumation technology used for estimating occupational doses is the mobile gantry crane. It is assumed that one-half of the 90 canisters in the trench contain 1-year-old waste while the remaining canisters contain 30-year-old waste, thus approximating a gradually filling trench over a 30-year period. These wastes are characterized by reference radionuclide inventories 1 and 2, shown in Tables I.4-1 and I.4-2. Table I.2-1 contains a summary of occupational doses received during waste relocation from a slit trench. The assumptions and calculational details for these dose calculations are discussed below.

\section{I.2.1.1 Core Drilling and Sampling}

Slit trench core drilling and sampling operations are described in Section 11.2.2. Two sources of potential occupational exposure from these activities are considered: contaminated core drilling samples and the external dose from the waste canisters themselves. 
TABLE I.2-1. Occupational Doses and Data for Slit Trench Waste Relocation Operations $(a)$

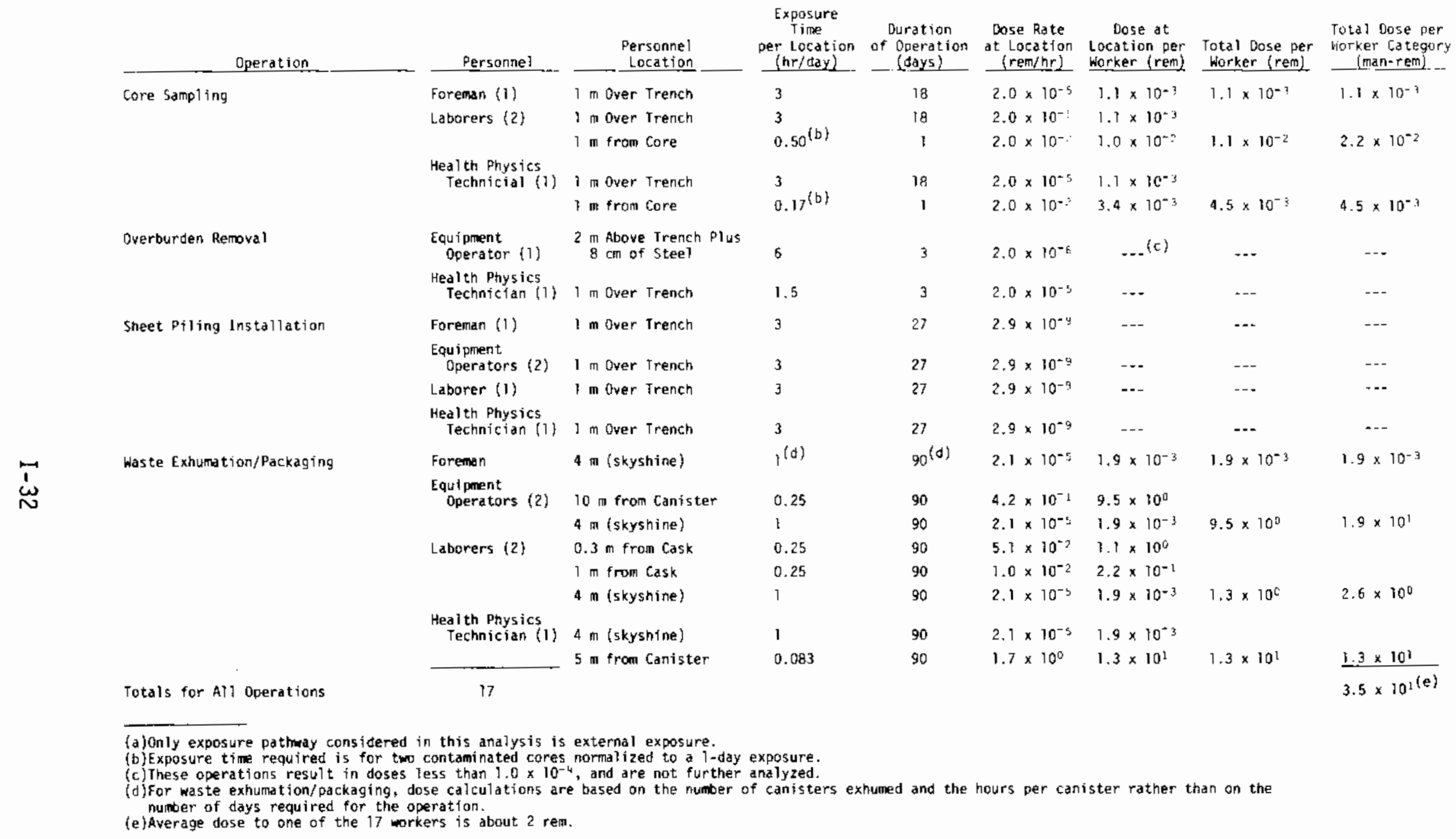


Since the leaked waste from any canister is assumed to contaminate a volume of only $12 \mathrm{~m}^{3}$, it is estimated that only two out of 50 cores penetrate mobile waste. Assuming a $1 \%$ leak fraction, a homogeneous mixture of waste throughout the $12 \mathrm{~m}^{3}$, and a core volume of $0.055 \mathrm{~m}^{3}$, approximately $15 \mathrm{mC} i$ of 1-year-old waste or $0.73 \mathrm{mci}$ of 30 -year-oid waste are contained in each contaminated core sample. These amounts result in dose rates at $1 \mathrm{~m}$ of $2 \times 10^{-2}$ rem/hr for 1 -year-0ld waste and $1 \times 10^{-3}$ rem/hr for 30-year-old waste. It is assumed that each contaminated core sample is handled by two laborers for 15 minutes total and that each sample is surveyed by the health physics technician for 5 minutes, with these workers at a distance of $1 \mathrm{~m}$ from the core.

External dose calculations from the buried canisters are performed for two cases: core driliting before and after overburden removal. With $2.2 \mathrm{~m}$ of soil overburden (for the case of core drilling before overburden removal), the dose rate $1 \mathrm{~m}$ above the ground surface is $1.9 \times 10^{-10} \mathrm{rem} / \mathrm{hr}$. With $1.2 \mathrm{~m}$ of soit overburden (for the case of core drilling after overburden removal), the dose rate is $2.0 \times 10^{-5} \mathrm{rem} / \mathrm{hr}$. It is assumed that the work crew is over the trench for $50 \%$ of each work day. Occupational exposure from core drilling prior to overburden removal is considered to be negligible when compared to other doses accumulated during slit trench exhumation.

\section{I.2.1.2 Overburden Remova?}

The overburden removal process for the sit trench is described in Section 11.2.1. One meter of overburden is removed, leaving $1.2 \mathrm{~m}$ of soil remaining over the upper layer of canisters. The operation is estimated to take 3 days. The work crew includes one equipment operator and a health physics technician. It is assumed that the equipment operator works over the trench a full day at a distance of $2 \mathrm{~m}$ above the ground surface, with a minimum of $80 \mathrm{~mm}$ of steel shielding. The health physics technician is assumed to be over the trench $25 \%$ of each work day at a distance of $1 \mathrm{~m}$ above the ground surface. The dose rate at $1 \mathrm{~m}$ above the ground surface is computed to be $2.0 \times 10^{-5} \mathrm{rem} / \mathrm{hr}$. Assuming a plane source and a shielding attenuation factor of 0.1 , as determined from the Radiological Health Handbook, (19) a dose rate 
of $2.0 \times 10^{-6} \mathrm{rem} / \mathrm{hr}$ to the equipment operator is calculated. Doses for this operation are calculated to be iess than 0.1 mrem for each worker, and are therefore considered to be insignificant.

\section{I.2.1.3 Sheet Piling Installation}

Sheet piling is installed along the sides of the trench before excavation operations begin. The placement of the sheet piling is described in Section 11.2.3. Since the sheet piling is installed $1.2 \mathrm{~m}$ back from the side of the trench, it is assumed that a minimum of $2 \mathrm{~m}$ of soil shielding exists between the waste canisters and the workers during this operation. It is also assumed that workers rotate jobs, that their dose reference point is $1 \mathrm{~m}$ above the ground surface, and that the entire crew is at this location for $50 \%$ of the work day. The dose rate through $2 \mathrm{~m}$ of soil and $1 \mathrm{~m}$ of air is calculated to be $3.0 \times 10^{-9} \mathrm{rem} / \mathrm{hr}$. Occupationai exposure during sheet piling installation is therefore considered to be insignificant.

\subsubsection{Trench Excavation and Waste Exhumation}

Trench excavation and waste canister retrieval requires remote operations because of the high dose rates within the slit trench. Trench excavation using a mobile gantry crane is briefly described in Section 11.2.4.5. This operation involves removal of the soil surrounding the waste canister. When a canister is exposed, the digging stops and canister exhumation begins. Exhumation consists of lifting the canister using a boom crane, loading the canister into a cask placed in the trench, replacing and manually fastening the cask 1 id, and removing the cask from the trench.

During excavation it is assumed that the dose rate is negligible to most of the crew, since they are at least several meters from the sheet piling and there are several meters of soil shielding. Even though the operations are remotely monitored with TV cameras, the gantry crane operator may require some visual contact with the excavation area in order to manipulate the equipment. It is assumed that the operator is at an average distance of $10 \mathrm{~m}$ from the canisters and that approximately 2 hours are required to excavate a section of trench and expose a waste canister. It is further assumed that, for 15 minutes of this time, enough of the canister is exposed so that a significant 
dose may be received by the crane operator. Conservatively, it is assumed that the canister is completely exposed during this 15 -minute period. The dose rate at $10 \mathrm{~m}$ from a bare 1 -year-old canister is estimated to be $8.2 \times 10^{-1} \mathrm{rem} / \mathrm{hr}$, and the dose rate at $10 \mathrm{~m}$ from a bare 30 -year-old canister is estimated to be $1.8 \times 10^{-2} \mathrm{rem} / \mathrm{hr}$. Therefore, an average dose rate of $4.2 \times 10^{-1} \mathrm{rem} / \mathrm{hr}$ is used.

It is estimated to take 2 hours to transfer a canister into a cask, seai the cask, and remove the cask from the trench. During part of this timie, until the canister is inside the cask, the canister is compietely exposed. The time during which the canister is completely exposed is assumed to be 1 hour. Still, the direct dose to most of the working crew is minimal, except to the boom-crane operator and to the health physics technician who must take smear samples of the canister surface to check for possible contamination.

Cask loading is performed at a location in the trench where a shield wall is erected. It is assumed that the boom-crane operator is $10 \mathrm{~m}$ from an unshielded canister for only 15 minutes during each 2-hour cask loading period.

The health physics technician uses an extending device at least $5 \mathrm{~m}$ long to check for smearable contamination on the canister surface. It is assumed that 5 minutes are required to monitor each canister. The dose rate at $5 \mathrm{~m}$ from a 7 -year-old waste canister is estimated to be $3.3 \mathrm{rem} / \mathrm{hr}$, and the dose rate at $5 \mathrm{~m}$ from a 30 -year-old waste canister is estimated to be $7.1 \times 10^{-2}$ $\mathrm{rem} / \mathrm{hr}$. The average dose rate is therefore $1.7 \mathrm{rem} / \mathrm{hr}$.

Other crew members are assumed to be exposed only as a result of scattering from trench walls (skyshine). Although there are 3 layers of canisters, the skyshine calculation is made on the basis of a fixed canister location in a trench. The reference canister is assumed to be $2 \mathrm{~m}$ below the top of the trench, at the approximate location of the top layer of canisters. The skyshine contribution is calculated by using an equation from the Reactor Shielding Design Manual. (20) The dose rate to personnel located $4 \mathrm{~m}$ from the edge of the trench is calculated to be $2 \times 10^{-5} \mathrm{rem} / \mathrm{hr}$.

After the canister is placed inside a cask and the cask lid is remotely placed on top, the lid must be manually fastened down. This is the only time during the entire excavation/exhumation operation that anyone is assumed to 
be in the trench. It is assumed that this task requires two laborers one-half hour each per cask. Two sources of radiation doses to these workers are considered: the cask itself and the canisters remaining in the trench.

The dose rate from the transport cask is assumed to be the maximum allowable according to federai regulations in 10 CFR 49. (21) This maximum allowable dose rate is $200 \mathrm{mrem} / \mathrm{hr}$ at the cask surface and $10 \mathrm{mrem} / \mathrm{hr}$ at 3 feet (1 $\mathrm{m}$ ) away. Assuming that a cask containing a l-year-oid waste canister exhibits these dose rates, a cask containing a 30-year-old waste canister would exhibit dose rates that are about 50 times smalier, or about $4 \mathrm{mrem} / \mathrm{hr}$ on the surface and $0.2 \mathrm{mrem} / \mathrm{hr}$ at $i \mathrm{~m}$. The average dose rates are therefore about $1.0 \times 10^{-i}$ $\mathrm{rem} / \mathrm{hr}$ and $5.1 \times 10^{-3} \mathrm{rem} / \mathrm{hr}$ at the cask surface and $1 \mathrm{~m}$ away, respectively. The two laborers are generally assumed to be $1 \mathrm{~m}$ away from a cask, with their extremities as close as $0.3 \mathrm{~m}$ from the cask surface about haif the time. At a distance of $0.3 \mathrm{~m}$, the average dose rate is estimated to be $5.1 \times 10^{-2} \mathrm{rem} / \mathrm{hr}$, assuming the cask is a point source.

In estimating dose rates from nearby canisters, the worst case exists when the first cask iid is fastened down. At this time the cask is nearest the remaining canisters in the trench. The canisters are $3.6 \mathrm{~m}$ long and are piaced end to end in the trench, with $1.4 \mathrm{~m}$ of soit between canister ends. Assuming that excavation removes half the soil between the canisters and that sheet piling is used for soil stabilization, $0.7 \mathrm{~m}$ of soil and $6 \mathrm{~mm}$ of steel shields the first set of canisters. If the first four sets of canisters nearest the cask all contain l-year-old waste, a dose rate of $1.0 \times 10^{-2} \mathrm{rem} / \mathrm{hr}$ to iaborers fastening down the first cask lid is estimated. As each succeeding canister is removed, the dose rate decreases because the cask is further away from the remaining canisters. After the first three coiumns of canisters are removed, the dose rate decreases to about $? \times 10^{-3} \mathrm{rem} / \mathrm{hr}$. Dose rates are calculated to laborers fastening the lids on the first nine casks and sumed to compute an average dose rate of $5.2 \times 10^{-3}$ rem/hr during cask iid fastening. This average dose rate from nearby canisters is approximately the same as that received from the cask on which the workers are fastening the lid. 


\section{I.2.2 Relocation of TRU Waste from a Burial Trench}

A description of methods and procedures for exhumation of a package of TRU waste from a burial trench is found in Section 11.3 of Volume 1. The burial trench is described in Section 7.2 of Volume 1. For the calculation of the occupational radiation dose from this operation, the reference technology is assumed to be manual excavation inside a single enclosure. During excavation and exhumation, all personnel working inside the enclosure are required to wear bubble suits. Therefore, the only dose calculated is that due to external exposure. A worker is assumed to spend 4 hours inside the enclosure during a normal work day.

For external dose rate calculations, the TRU waste package is assumed to have a volume of $1 \mathrm{~m}^{3}$ and to contain $40 \mathrm{~g}$ of plutonium. The isotopic composition of the plutonium is given in reference inventory 4 of Section I.4. The non-TRU waste that must be removed to reach the TRU waste package has an average activity of $2.9 \mathrm{Ci} / \mathrm{m}^{3}$ and an isotopic composition given in reference inventory 3 of Section I.4.

Dose rates from non-TRU waste exhumation are calculated using the code ISOSHLD, and those from TRU waste exhumation are calculated using the code PUSHLD.

A summary of the data and calculated occupational doses for TRU waste relocation is shown in Table I.2-2. The assumptions and calculational details for this operation are discussed below.

\section{I.2.2.l Core Drilling and Sampling}

Core drilling and sampling is described in Section 11.3.1 of Volume 1. It is estimated that 20 cores are required to precisely locate the position of the TRU waste and to identify the extent of radionuclide migration from the waste. It is estimated to take 14 days to complete the core drilling.

Two sources of radiation exposure are considered: the non-TRU waste

beneath the overburden, and the contaminated core samples. The dose rate from the non-TRU waste through $2 \mathrm{~m}$ of soil at a point $1 \mathrm{~m}$ above the ground is 


\section{TABLE 1.2-2. Occupational Doses and Data for Partial Trench (TRU) Waste}

\section{Exhumation/Relocation}

\begin{tabular}{|c|c|c|c|c|c|c|c|c|}
\hline ... .. operation. ... ... & Persorine 1... & 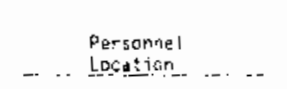 & 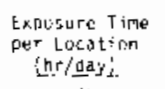 & $\begin{array}{l}\text { Ouration of } \\
\text { Operdtior } \\
\text { (days) }\end{array}$ & $\begin{array}{l}\text { Dose Rxce at } \\
\text { cocicition } \\
\text { (renthly. }\end{array}$ & $\begin{array}{l}\text { Deuse dt Locatior } \\
\text { per Worker } \\
\text { - fren }) . .\end{array}$ & $\begin{array}{l}\text { Tota: Dase } \\
\text { DPT Worker } \\
\text { - Erem! ... }\end{array}$ & 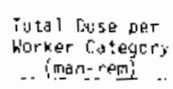 \\
\hline \multirow[t]{3}{*}{ Core Sampling } & foreman: I! & to m from core & $3.3^{(b)}$ & 1 & $1.1 \times 1 \cdots$ & $3.7 \times 10^{-}$ & $3.7 \times 10^{-}$ & $3.7 \times 1 \%$ \\
\hline & aborers (?) & I m from Core & $5 . g^{(b)}$ & i & $1.1 \times 1 \ldots-$ & $3.5 \times 20^{-1}$ & $5.5 \times 10^{-:}$ & $1.1 \times 19=$ \\
\hline & $\begin{array}{l}\text { Hearth Physics } \\
\text { Technician (1) }\end{array}$ & $1 \mathrm{~m}$ from Care & $1.7^{i b !}$ & 1 & $\therefore 1 \times 10^{-}$ & i.s $\times 10^{-!}$ & $1.8 \times 10^{-}$ & $1.8 \times 1 y^{-:}$ \\
\hline Dverburten Rerioval & $\ldots(c)$ & $\ldots$ & $\ldots$ & -.. & .. & ..- & $\cdots$ & $\ldots$ \\
\hline Sheet $p i l i n g$ Instailation & ...(c) & $\cdots$ & $\cdots$ & $\cdots$ & ... & ... & $\cdots$ & $\cdots$ \\
\hline \multirow[t]{4}{*}{ frastall Enclostire butiding } & Forennith 11 ! & 1 m sbove Ground Surface & 6 & 5 & $2.3 \times 13$ & $\therefore \hat{5} \times 15$ & $7.0 \times: 0$ & $7 \because \because \times 10^{-}$ \\
\hline & $\begin{array}{l}\text { Equ ipment } \\
\text { Operators (Q) }\end{array}$ & $\begin{array}{l}\text { 2.m Above Ground Surface } \\
\text { piys } 80 \text { min' of Steg: }\end{array}$ & i & 5 & $2.3 \times 10^{-i}$ & $\gamma .0 \times 10^{-}$ & $7.0 \times 10^{-}$ & $\mathrm{i} .4 \times \mathrm{ir}: \cdots$ \\
\hline & Laborars 12 i & In Above Ground Surface & 6 & : & $2.3 \times 10^{-}$ & $3.0 \times 10-6$ & $3.6 \times 10^{-}$ & $(.1) \times 10^{-\cdots}$ \\
\hline & $\begin{array}{l}\text { Health Physics } \\
\text { Tec, hnician i?: }\end{array}$ & $\therefore$ ar Above Graund Surface & $\varepsilon$ & 5 & $2.3 \times 10^{-}$ & $7.8 \times 10^{\cdots}$ & $1.0 \times 10^{-}$ & $7.5 \times 190$ \\
\hline \multirow[t]{6}{*}{ Exsivuate Non-TRU Wíst.t } & Furenian : I: & ib hi from kis te file & 4 & 31 & $3 . i j \times 10^{-}$ & $8.4 \times 10$ & $2.4 \times 1 i j$. & $9.4 \times i 0$ \\
\hline & $\begin{array}{l}\text { Eouiprent } \\
\text { Operators }\end{array}$ & $5 \mathrm{~m}$ from waste pile & 4 & 30 & $1.6 \times 1$. & $4.4 \times 1 \%$ & $8.4 \times 10$ & $1.8 \times 10$ \\
\hline & iaborers izi & $5 \mathrm{~m}$ from waste file & $\left.3.63^{1}\right)^{3}$ & 30 & $7.5 \times 1:=$ & E. $0 \times 1 ;$ & & \\
\hline & & Wremin pit & $3.17^{i d ;}$ & 36 & $7.2 \times 11^{-}$ & $3.7 \times 1.2$ & $1.2 \times: 0$ & $2.4 \times 19:$ \\
\hline & 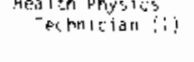 & E in frum kaste five & 3. $.4 ! ! c !$ & 30 & $7.01 \times 10^{-}$ & $8.11 \times 10:$ & & \\
\hline & & Within Pit & & 30 & $7.8 \times 10^{-}$ & $3.7: 00$ & $1.2 \times 10$ & $i .2 \times 10:$ \\
\hline \multirow{8}{*}{ Exhume/Parkaye TSUl Nast } & forenar \{1; & $\begin{array}{l}5 \mathrm{~m} \text { from haste Fule } \\
\text { withron pit }\end{array}$ & ? & 5 & $1.9 \times 10^{-1}$ & $1.4 \times 19$ & & \\
\hline & Equipmen: & & z & 5 & $7.4 \times 10^{-}$ & $7.6 \times 10^{\circ}$ & $8.8 \times 11$ & $8.4 \times 10$ \\
\hline & Operators & 5 ni frorl waste "iles & i & b & $1.4 \times 1:-i$ & $.4 \times 10$. & & \\
\hline & & Within Pit & 2 & ؛ & $2.4 \times 10^{-:}$ & $7.4 \times 10^{0}$ & $8.8 \times 111$ & i. $.8 \times 10 ! 1$ \\
\hline & Labiarers (?) & $5 \pi$ fronl tascerifie & ? & 5 & $1.6 \times 120$ & $1.4 \times 10=$ & & \\
\hline & & Wienin Pit & $\therefore$ & s & $7.6 \times 15=$ & $2.4 \times 10$ & B. $8 \times 10$ & $\therefore .8 \times: 0^{1}$ \\
\hline & $\begin{array}{l}\text { Hedeth Phosics } \\
\text { Techrocian (1! }\end{array}$ & 5 m from Waste Jile & $?$ & $\therefore$ & $18 \times 10^{-}$ & $1.4 \times 10^{0}$ & & \\
\hline & & within Pit & 7 & is & $7.0 \times 13^{-}$ & $7.4 \times$ in & $8.8 \times 10$ & E. $9 \times 10$ \\
\hline \multirow[t]{8}{*}{ Clent Lp and Remove Ens :osure } & foreman (?) & 5 m froil waste bille & $\mathrm{i}$ & z & $8.0 \times 10^{-}$ & $8.4 \times 1 \%:$ & & \\
\hline & & $1 \mathrm{~m}$ Above Ground Surfice & c & 3 & $3 \div \times ? 0^{-1}$ & $0.1 \times 10^{-}$. & $3.4 \times 1 \%$ & $0.4 \times 10^{-1}$ \\
\hline & $\begin{array}{l}\text { Equl onitent } \\
\text { Queritars (n) }\end{array}$ & 5 in fromi haste fine & 6 & $?$ & $7 . .8 \times 10^{-}$ & $8.4 \times: 0$ & & \\
\hline & & 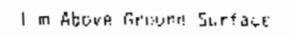 & fi & 3 & $2.3 \times 15-$ & $41 \times 10^{\cdots}$ & $8.4 \times 10^{-i}$ & $i .7 \times 12$ \\
\hline & Labarers :7: & s m fror haste pile & $\mathrm{f}$ & 2 & $\therefore \therefore \times 10$ & $8.4 \times 10^{-}$ & & \\
\hline & & $1 \mathrm{~m}$ Above Ground Surtake & f & 3 & $2.3 \times 10^{-}$ & $4.1 \times ? 0^{-1}$ & $8.4 \times 10^{-2}$ & $1.2 \times 1=$. \\
\hline & $\begin{array}{l}\text { Health Physies } \\
\text { Technician (1) }\end{array}$ & Som fram haste pile & 3 & 2 & $7.0 \times \mathrm{in}^{-}$ & $5.4 \times 10^{-1}$ & & \\
\hline & $\ldots \ldots \ldots$ & $? \pi$ Rogue firound Surface & 6 & $?$ & $2.3 \times 10^{-1}$ & $9.1 \times 10^{4}$ & 8.4 $410^{-}:$ & 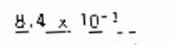 \\
\hline Tutals fur Ali Qperatians & ру & & & & & & & $1.2 \times \operatorname{in}^{2}(e)$ \\
\hline
\end{tabular}


computed to be $2.1 \times 10^{-10} \mathrm{rem} / \mathrm{hr}$. Thus, the occupational dose from this source is considered to be negiigible compared to other sources considered in this study.

Some of the core samples contain non-TRU waste with an isotopic composition of reference inventory 3 and an average curie content of $2.9 \mathrm{ci} / \mathrm{m}^{3}$. This number is based on the assumption that the waste is homogeneously mixed throughout the entire trench volume. Assuming that $4 \mathrm{~m}$ of the 8-m-long core is non-TRU waste, and using a core volume of $0.055 \mathrm{~m}^{3}$, approximately $80 \mathrm{mCi}$ of radionuclide inventory 3 is contained in each core sample. This corresponds to a dose rate of $1.1 \times 10^{-1}$ rem/hr at a distance of $1 \mathrm{~m}$. All 20 core samples are assumed to contain the same amount of non-TRU waste.

It is assumed that two laborers handle each core for 15 minutes. The health physics technician surveys each core for 5 minutes at a distance of $1 \mathrm{~m}$. The drilling foreman is assumed to be $10 \mathrm{~m}$ away for 10 minutes per core. At a distance of $10 \mathrm{~m}$, the core sample is treated as a point source and the dose rate is estimated to be $1.1 \times 10^{-3} \mathrm{rem} / \mathrm{hr}$.

\subsubsection{Overburden Removal}

One meter of overburden is removed from a $30-\mathrm{m}^{2}$ area, requiring only 1 day at each site. The crew consists of one equipment operator and one health physics technician. There is still $1 \mathrm{~m}$ of soil covering the waste after overburden removal. The dose rate through $1 \mathrm{~m}$ of soil is $2.3 \times 10^{-5} \mathrm{rem} / \mathrm{hr}$ in air $1 \mathrm{~m}$ above the soil. Since this operation is of such short duration, the dose accumulation is negigible and is not further analyzed.

\section{I.2.2.3 Sheet Piling Installation}

Sheet piling is installed to provide a square pit with 10-m sides. A minimum of 1 m of soil is assumed between the crew personnel and radioactive material in the pit. It is estimated to require only 4 days to install the sheet piling, including a day each for mobilization and demobilization. The occupational dose for this operation is estimated to be negiigible and is not further analyzed. 


\section{I.2.2.4 Trench Excavation and Waste Exhumation}

Trench excavation and waste exhumation operations for TRU waste removal are divided into four phases:

1. Insta71 enclosure (5 days)

2. Excavate non-TRU waste (30 days)

3. Exhume TRU waste ( 5 days)

4. Clean up and demobilize (5 days).

The dose calculations for these operations are discussed below.

1. Instal1 Enciosure - The work enciosure is a lightweight sheet-metal buitding $12 \mathrm{~m}$ by $18 \mathrm{~m}$ by $6 \mathrm{~m}$ high. It is assumed that the work crew is over the trench the entire 6 -hour work day at a distance of $1 \mathrm{~m}$ above ground. The dose rate from the TRU waste is insignificant since this waste is covered by about $6 \mathrm{~m}$ of soil. The dose rate from the non-TRU waste, with $1 \mathrm{~m}$ of overburden, is $2.3 \times 10^{-5} \mathrm{rem} / \mathrm{hr}$. The equipment operator is assumed to have about $80 \mathrm{~mm}$ of steel shielding; thus, this operator receives a dose of $2.3 \times 10^{-6} \mathrm{rem} / \mathrm{hr}$.

2. Excavate non-TRU Waste - Approximately $600 \mathrm{~m}^{3}$ of non-TRU waste is removed from the upper $6 \mathrm{~m}$ of the pit area in order to reach the TRU waste. A remova? rate of $5 \mathrm{~m}^{3} / \mathrm{hr}$ and a 4-hour work day are assumed. A backhoe is assumed to be used to remove the non-TRU waste, with assistance from the laborers only when necessary. It is assumed that the entire crew is above the pit during this phase, except for the laborers and the health physics technician, who spend about half an hour in the pit each day during the final 2 weeks of non-TRU waste excavation.

For work above the pit, two sources of radiation are considered: the nonTRU waste pile and the waste beneath the $1 \mathrm{~m}$ of overburden. For the entire $600-m^{3}$ non-TRU waste pile, ISOSHLD is used to compute a dose rate of $1.4 \times 10^{-1} \mathrm{rem} / \mathrm{hr}$ at a distance of $5 \mathrm{~m}$. For an average dose rate over the 30 days of excavation operations, this dose rate is reduced by a factor of 2 to give $7.0 \times 10^{-2} \mathrm{rem} / \mathrm{hr}$. For operations above the pit, the dose rate from the waste beneath the overburden is negigible compared to the waste-pile dose rate. 
For work within the pit volume, dose rates are computed for the non-TRU waste behind the sheet piling and the TRU waste beneath the pit bottom. ISOSHLD is again used to calculate a dose rate of $3.6 \times 10^{-1} \mathrm{rem} / \mathrm{hr}$ in the pit at a distance of $1 \mathrm{~m}$ from the nearest wa 11 . The pit walls are treated as an infinite plane, so this dose rate is doubled to obtain a dose rate of $7.2 \times 10^{-1} \mathrm{rem} / \mathrm{hr}$ from the non-TRU waste. The dose rate from the TRU waste is calculated, using PUSHLD, to be $2.0 \times 10^{-3} \mathrm{rem} / \mathrm{hr}$ at a distance of $1 \mathrm{~m}$ above the surface of the waste without soil shielding. The total dose rate for in-pit activities is therefore about $7.2 \times 10^{-1} \mathrm{rem} / \mathrm{hr}$.

3. Exhume TRU Waste - It is assumed that half of the crew is in the pit and the other half is above the pit during this phase of operations. Since the TRU waste is handled in the pit, a waste surface dose rate of $2.0 \times 10^{-2} \mathrm{rem} / \mathrm{hr}$ is added to the non-TRU dose rate in the pit, making the total dose rate to workers in the pit $7.4 \times 10^{-1} \mathrm{rem} / \mathrm{hr}$.

The total dose rate to workers above the pit comes from two sources. Ali $600 \mathrm{~m}^{3}$ of the non-TRU waste pile is above the pit during exhumation of the TRU waste, contributing $1.4 \times 10^{-1} \mathrm{rem} / \mathrm{hr}$ at a distance of $5 \mathrm{~m}$. It is assumed that, in lifting the TRU waste from the pit and preparing it for transportation offsite, the workers above the pit are an average distance of $1 \mathrm{~m}$ from the waste package. The dose rate from the TRU waste package at this distance is $2.0 \times 10^{-3} \mathrm{rem} / \mathrm{hr}$. Thus, the total dose rate to workers above the pit is $1.4 \times 10^{-1} \mathrm{rem} / \mathrm{hr}$.

4. Cleanup and Demobilization - Prior to this phase of operation, all of the TRU waste is packaged and removed from the enclosure. A smali bulldozer is used to push the non-TRU waste back into the pit. This operation requires 2 days for completion. It is assumed that the entire crew is above the pit during this operation and that the average dose rate is $7.0 \times 10^{-2} \mathrm{rem} / \mathrm{hr}$ (one-half of the maximum dose rate at a distance of $5 \mathrm{~m}$ from the non-TRU waste pile).

Three days are required to remove the work enclosure and stabilize the ground surface after the non-TRU waste is returned to the pit. The dose rate for this operation is the same as that calculated for installation of the enclosure $\left(2.3 \times 10^{-5} \mathrm{rem} / \mathrm{hr}\right)$. 


\section{I.2.3 Relocation of all the Waste from a Single Burial Trench}

Section 11.4 of volume 1 contains a discussion of methods and procedures for complete exhumation and reiocation of the waste from a single reference burial trench. It is assumed that high beta-gama radioactivity waste and TRU waste have aiready been removed from the burial trench. Complete trench reiocation operations involve the exhumation of wastes of reference radionuclide inventory 3, shown in Table 1.4-3. The reference technology used for occupational dose calculations is excavation and exhumation from within the trench (i.e., from the trench floor), as described in Section 11.4.2.2.

A summary of external doses to decommissioning workers for relocation of al1 the waste from a single burial trench is given in Table 1.2-3. The total occupational dose for this waste relocation operation includes both an external and an inhalation dose. A discussion of the magnitude of the inhalation dose and of the use of respiratory equipment to reduce this dose is included in Section 13.3 of Volume 1; hence, the inhalation dose is not discussed here. Assumptions and calculational details for external dose estimates are given beiow.

\section{I.2.3.1 Core Drilling and Sampling}

Core drilling and sampling operations related to this waste relocation operation are discussed in Section 11.4.1. An estimated 115 cores are to be taken, with several of these being sent to the laboratory for analysis. It is estimated that the core drilling program requires 62 days.

To calculate occupational doses, two sources of radiation are considered: the trench waste itself and the radioactive core samples. The dose rate from the trench waste through $2 \mathrm{~m}$ of soil overburden is computed to be $2.1 \times 10^{-10} \mathrm{rem} / \mathrm{hr} 1 \mathrm{~m}$ above the ground surface in air. The occupationa? dose from this source is negligible during the core dritling and sampling program.

The core samples contain some radioactive waste. Aithough the amount varies, an average content is caiculated based on the average curie content of the trench waste. Reference inventory 3 is used, with an average specific activity of $2.9 \mathrm{Ci} / \mathrm{m}^{\hat{3}}$. It is assumed that $4 \mathrm{~m}$ of each $8-\mathrm{m}-1$ ong core sample 
TABLE 1.2-3. Occupational Doses and Data for Exhumation of the Waste from One Burial Trench ${ }^{(a)}$

\begin{tabular}{|c|c|c|c|c|c|c|c|c|}
\hline ... - Operation ... .. & _- Personnei $\ldots$ & $\begin{array}{l}\text { L'ersonnel } \\
\ldots . \quad \text { Lncation }\end{array}$ & $\begin{array}{l}\text { Lxposure iime } \\
\text { per Lucation } \\
\text { [nriday)... }\end{array}$ & $\begin{array}{l}\text { Duration of } \\
\text { Operation } \\
\text { Idysy }\end{array}$ & 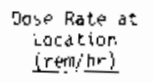 & $\begin{array}{l}\text { Jose at iacation } \\
\text { Der worker } \\
\text { - rell. }\end{array}$ & $\begin{array}{l}\text { Tatal Rose } \\
\text { per Worker } \\
\text {. (rean!) - }\end{array}$ & 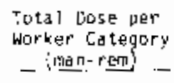 \\
\hline \multirow[t]{3}{*}{ Core Sampi iny } & Foremar (1) & In in frapp Care & $19.2^{\{b]}$ & ! & $1.1 \times 10^{-:}$ & $2.1 \times 10^{-}:$ & $2, i \times 10^{-}$ & $2.3 \times 10^{-}$ \\
\hline & Laborers $\{2\}$ & in from core & $28.8^{\{\mathrm{t} !}$ & 1 & 1. $\therefore \times 10^{-1}$ & $3.7 \times 10^{2}$ & $3.2 \times 10=$ & $6.4 \times 10:$ \\
\hline & $\begin{array}{l}\text { Health Physics } \\
\text { Tectinicidri (1) }\end{array}$ & $1 \mathrm{~m}$ from core & $9.6^{\left(\mathrm{t}^{\mathrm{j}}\right.}$ & 1 & $1.2 \times 10^{-1}$ & $1 . \therefore \times 10$ & $\therefore .1 \times 10^{0}$ & $1,1 \times 10=$ \\
\hline \multirow[t]{2}{*}{ Dverburden Remival } & $\begin{array}{l}\text { Equiganent } \\
\text { Opera tors (2) }\end{array}$ & $\begin{array}{l}\text { 2. In Above Oyerburden } \\
\text { Plus \&D mir of Stee } 1\end{array}$ & 6 & 3 & $1.0 \times 10^{-}$ & $1.8 \times 10$ & $1.8 \times 10^{-2}$ & $3.6 \times 10^{-2}:$ \\
\hline & $\begin{array}{l}\text { Heal th Physics } \\
\text { :echnicider }(i)\end{array}$ & I mabcive Overburden & $i$ & 3 & $1.0 \times 10^{-}$ & $3.2 \times 10^{-}$ & $3.2 \times 10^{-}$ & $3.8 \times 10^{\circ}$ \\
\hline \multirow{5}{*}{$\begin{array}{l}\text { Mubilize for ixcavation } \\
\text { (2 Crews) }\end{array}$} & foremen (z) & I nl Above Ground surtace & 6 & 3 & $1 . n \times 10^{-}$ & $1.2 \times 1.2-1$ & $1.8 \times 10^{-}$ & $3.5 \times 10^{-}$ \\
\hline & $\begin{array}{l}\text { Enlipnent } \\
\text { Operators }\{B\}\end{array}$ & $1 \pi$ Äbove Ground Surface & G & 3 & $1 . \because \times 10^{-}$ & $1.8 \times 10^{-}:$ & $1.8 \times 10^{-1}$ & $i .4 \times 19$ \\
\hline & laburers $(8)$ & Im Above Bround Surface & 6 & 3 & $1, n \times i y^{-}$ & $.8 \times 10^{-}$ & $1.8 \times 0^{-1}:$ & $1.4 \times 1.0=$ \\
\hline & Truck Drivers [?] & 1 T Abave Ground Surface & E & 3 & $1.0 \times 10$ & $1.8 \times 10^{-2}:$ & $1.8 \times 1:-!$ & $2.6 \times 10^{-1}$ \\
\hline & $\begin{array}{l}\text { hed lter, physics } \\
\text { iecchrifcians (z) }\end{array}$ & I if Abnve Ground Surface & 6 & 3 & $1.2 \times 15=$ & $1.8 \times 10^{-}$ & $1.8 \times 10^{-i}$ & $3.6 \times 10^{-:}$ \\
\hline \multirow{18}{*}{$\begin{array}{l}\text { Waste Extumaticn/Pákagirg } \\
\text { \{? [rews\} }\end{array}$} & Forenter $\{2\}$ & $1 \mathrm{~m}$ Above Ground Surface & 3 & 4ं & $10 \times 1 n$ & $1.3 \times 102$ & & \\
\hline & & 10 m from Excavation Face & 3 & 42 & $4.8 \times 10^{-}$ & $6.0 \times 10$. & $3.3 \times 10^{0}$ & $1.5 \times 101$ \\
\hline & $\begin{array}{l}\text { Fquipment } \\
\text { Operd tors (B) }\end{array}$ & 1 in Abuve Ground Surface & 3 & औ? & $\therefore 0 \times 10^{-}$ & $i .3 \times 10^{3}$ & & \\
\hline & & $3 \pi$ trom Excavatior Face & 0.15 & $\$ 2$. & $2.1 \times 10^{-1}$ & $1.3 \times 10^{\circ}$ & & \\
\hline & & S $\pi$ from Excayation Face & $\therefore 45$ & 42 & $1.3 \times 10^{-1}$ & $2.4 \times 15:$ & & \\
\hline & & $10 \mathrm{~m}$ from Excavation face & 2.6 & 4: & $4.8 \times 10^{-}$ & $4.8 \times 10^{n}$ & $9.8 \times 10^{\circ}$ & $7.8 \times 10^{1}$ \\
\hline & laburers $\{B\}$ & 1 m. Aboye Ground Surface & 3 & 42 & $1.0 \times 10^{-}$ & $1.3 \times 10^{10}$ & & \\
\hline & & I n) from Fxcovasion face & 0.15 & 42 & $3.6 \times 10^{-1}$ & $2.3 \times 10^{2}$ & & \\
\hline & & $2 \mathrm{~m}$ from $\underline{x}$ xcavation fose & 0. 13 & 42 & $2.8 \times 10^{-1}$ & $1.8 \times 10^{n}$ & & \\
\hline & & 3 n: Frem Excavation face & 8.3 & 42 & $2.1 \times 10^{-2}:$ & $2.6 \times 10=$ & & \\
\hline & & 5 nil from Excavatian face & 0.9 & 42 & $\therefore .3 \times 10^{-1}$ & $4.9 \times 10^{3}$ & & \\
\hline & & in m trom Excavation Face & 1.6 & 42 & $4.8 \times 10^{\circ}$ & $3.0 \times 10^{n}$ & $1.6 \times 10^{1}$ & $1.3 \times 10$ \\
\hline & irbock Driqers $(8)$ & $1 \mathrm{~m}$ Above Ground Surface & 6 & 42 & $1.0 \times 10^{-}$ & $2.5 \times 10^{5}$ & $2.5 \times 10 \%$ & $3.0 \times 10^{2}$ \\
\hline & $\begin{array}{l}\text { Health Physics } \\
\text { Techricians }(2)\end{array}$ & I in hoove Ground Surface & 3 & 42 & $1.0 \times 10^{2}=$ & $1.3 \times 30$ & & \\
\hline & & 3 in from Excavation Face & 0.3 & $4 ?$ & $2.2 * 10^{-1}$ & $2,6 \times 10^{n}$ & & \\
\hline & & $5 \mathrm{~m}$ from Excayation Face & 0.3 & 42 & $1.3 \times 10^{\circ}:$ & $1.6 \times 10^{0}$ & & \\
\hline & & $10 \mathrm{~m}$ from Excaystion Face & $i .5$ & 42 & $4.8 \times 10^{-i}$ & $3.0 \times 20=$ & & \\
\hline & $\ldots-\ldots$ & 2is $\mathrm{m}$ from Excavation. Face & 0.9 & 42 & $1.4 \times 10^{-1}$ & $5.3 \times 70^{-1}$ & $9.0 \times 10^{4}$ & $1.9 \times 101$ \\
\hline iotals for \&ll Operations & 29 & & & & & & & $2.6 \times 10^{2}$ \\
\hline
\end{tabular}

Taithe only exposure pathway considered in this analysis is external exposure.

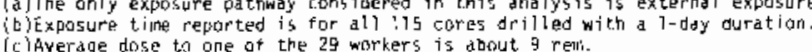


contain radioactive waste. Using a core volume of $0.055 \mathrm{~m}^{3}$, approximately $80 \mathrm{mCi}$ of radioactive waste is contained in each core. This corresponds to a dose rate of $1.1 \times 10^{-1}$ rem/hr at a distance of $1 \mathrm{~m}$ in air. At a distance of $10 \mathrm{~m}$ in air, the core sample appears similar to a point source, and the dose rate is estimated to be $1.1 \times 10^{-3} \mathrm{rem} / \mathrm{hr}$. sThe same personnel locations and exposure times are assumed as for the TRU core drilling operation (see Section $(.2 .2 .1)$.

\section{I.2.3.2 Overburden Removal}

For complete waste relocation from a conventional trench, $2 \mathrm{~m}$ of overburden is removed, down to the active waste level of the trench. The entire operation is estimated to require about 3 days. The work crew includes two equipment operators and a hearth physics technician. It is assumed that the equipment operators are $2 \mathrm{~m}$ above the ground surface, with about $80 \mathrm{~mm}$ of steel shielding, and that the heaith physics technician is $1 \mathrm{~m}$ above the ground surface for 7 hour each day.

The dose rate above the ground surface increases logarithmically as the overburden is removed. Using numerical integration and an overburden removal rate of $0.11 \mathrm{~m} / \mathrm{hr}$, an accumulated dose is computed for various overburden thicknesses. For each equipment operator, the total dose is calculated to be $1.8 \times 10^{-2}$ rem. To simplify calculations it is assumed that the time periods during which the health physics technician is over the trench are distributed uniformly throughout the day; his total dose is computed to be $3.0 \times 10^{-2}$ rem.

\subsubsection{Trench Excavation and Waste Exhumation}

Excavation is performed with a front-end loader operating on the floor of the trench. Large intact containers are removed from the trench with a crane and grappling hooks. Sma 11 boxes, 208-l drums, and loose waste are fed into a vibrating hopper over a large metal bin $(1.2 \mathrm{~m} \times 1.2 \mathrm{~m} \times 1.8 \mathrm{~m})$. After a bin is filled, the lid is secured. The bin is then lifted from the trench and prepared for transport. Laborers in each crew assist equipment operators in grappling onto waste containers, attaching cables to waste bins, and performing manual excavation tasks. Two crews are assumed to work from either end of the trench toward the middle. It is assumed that one-half of each crew is above 
the trench, with workers rotating assignments so that each worker spends the same amount of time in the trench. Trench excavation and waste exhumation is estimated to require a total of 42 days.

External doses to decommissioning workers are based on assumptions about the time spent by various workers at different work locations and the radiation dose rates at these locations. As noted above, each worker is assumed to spend one-half his work day above the trench at a location where the average dose rate is $1.0 \times 10^{-2} \mathrm{rem} / \mathrm{hr}$. Dose rates at positions within the excavated portion of a trench are computed, using the ISOSHLD code, for several distances from the face of the waste. The computed dose rates are assumed to be constant throughout the trench excavation and waste exhumation process.

Table I.2-3 contains a list of crew-member distances from the face of the waste, the times spent at these distances, the corresponding dose rates, and the total dose for each worker during waste exhumation operations. In practice, a crew member would probably spend 1 or more days at one task before being assigned to another task. However, in Table I.2-3, an "average" worker is assumed who rotates to each of the possible work assignments in his category during the 6-hour period spent each day in decommissioning operations. For example, during one 6-hour period, an equipment operator is assumed to spend 3 hours operating the crane and fork lift at ground level above the trench, 1.5 hours operating the front-end loader, and 1.5 hours operating the tractordozer within the trench.

\section{I.2.4 Occupational Exposure from Site Stabilization Operations}

Site stabilization operations for this study are designed to avoid contact with the waste in the trenches. Since there is assumed to be an overburden layer of 1 to $2 \mathrm{~m}$ above the buried waste, occupational doses for stabilization operations will be significantly less than those calculated for waste relocation operations. An estimate of occupational doses for stabilization operations is made here.

Information obtained from dosimeters at an operating burial ground indicates that an average dose rate of about 1 mrem per 24-hour day may be conservative (see Section 0.7 ). In Section 12.1 it is estimated that 1.5 to 23 man-years of decomissioning worker labor are required for site stabilization operations. 
The number of man-years depends on the site stabilization plan selected and on site-specific parameters. Assuming that there are about 250 man-days per man-year, with 8-hour work days, the total occupational dose to site stabilization workers is estimated to be between 0.12 and 1.9 man-rem.

\subsubsection{Occupational Exposure from Long-Term Care Operations}

Long-term care operations for this study are designed to occur after site stabilization. For these operations, the amount and condition of the trench overburden is determined by the specific site stabilization plan selected. An estimate of the annual occupational doses for long-term care is made here.

Information obtained from dosimeters at an operating buria? ground indicates that an average dose rate at the site is about 1 mrem per 24-hour day (see Section 0.1). It is conservative to assume this same dose rate during long-term care, since it does not take into account potential reductions in dose rate from extra overburden or radioactive decay. The number of man-years required on an annual basis for long-term care at both the western and eastern sites is given in Tables H.3-l through H.3-4. Manpower requirements range from 0.7 to 3.2 man-years per year. Assuming that there are 250 man-days per year, with 8-hour work days, the annual occupational dose to lang-term care workers is estimated to be between 0.06 and 0.27 man-rem per year of long-term care.

\section{I.3 TRANSPORTATION SAFETY}

Waste relocation involves the exhumation of buried waste and its shipment to another disposal location. Relocated wastes can be moved to another trench at the same burial site, or offsite to another shallow-land burial ground or to a deep geologic repository. Transportation requirements for each of the waste relocation cases evaluated in this study are described in Section H.4. Shiprnents are made in accordance with federal and state regulations summarized in Sections 5.2.2 and G.4.2. Section 13.4 summarizes the transportation safety impacts of radioactive waste shipments for the waste relocation decomissioning mode. 
This section provides supporting details needed to calculate the radiological effects of routine transportation activities and transportation accidents. To provide a basis for the discussion that follows, shipment requirements for waste relocation are summarized in Table 1.3-1. Transportation requirements are assumed to be the same for waste shipments from either the western or the eastern reference sites.

TABLE 1.3-1. Waste Shipping Requirements

\begin{tabular}{|c|c|c|c|c|}
\hline Option & $\begin{array}{c}\text { Shipment } \\
\text { Destination }\end{array}$ & $\begin{array}{l}\text { No. of } \\
\text { Shipments }\end{array}$ & $\begin{array}{c}\text { Distance } \\
(\mathrm{km})\end{array}$ & $\begin{array}{c}\text { Avg. Speed } \\
(\mathrm{km} / \mathrm{hr})\end{array}$ \\
\hline TRU Waste & Geologic Repository & 1 & 2400 & 65 \\
\hline Slit Trench & Geologic Repository & 90 & 2400 & 65 \\
\hline Slit Trench & Shallow-Land Burial & 90 & 2400 & 65 \\
\hline Entire Trench & Geologic Repository & 970 & 2400 & 35 \\
\hline Entire Trench & Shallow-Land Burial & 970 & 2400 & 35 \\
\hline Entire Trench & Onsite Relocation & 1220 & 0.5 & 10 \\
\hline
\end{tabular}

\section{I.3.1 Assumptions for Routine Transportation Calculations}

The method used to estimate routine radiation doses to occupationaliy exposed workers and members of the general public from truck transport of waste is based on that given in WASH-1238. (22) In addition, the following assumptions are made:

1. Dose rates for radioactive shipments are assumed to be the maximum allowed by federal regulations. These dose rates are sumarized in Section G.4.2. Use of these dose rates results in conservatively high estimates of doses to the general public and to transportation workers from routine transport of radioactive waste.

2. The population density along the transportation corridors from the western site is 40 persons $/ \mathrm{km}^{2}$. The population density along the transportation corridors from the eastern site is 120 persons $/ \mathrm{km}^{2}$. 
3. For shipments of TRU waste or slit trench canisters, two drivers per truck are assumed. For a 2,400-km trip, each driver is assumed to spend 36 hours inside the cab, and 3 hours outside at an average distance of $2 \mathrm{~m}$ from the truck. With two drivers alternating, the truck can maintain an average speed of $65 \mathrm{~km} / \mathrm{hr}$.

4. For offsite shipments during reiocation of an entire trench, one driver per truck is assumed to spend 36 hours in the cab, and 3 hours outside at an average distance of $2 \mathrm{~m}$ from the truck. With only one driver, the truck can maintain an average speed of $35 \mathrm{~km} / \mathrm{hr}$.

5. The cumulative dose to the general population from truck shipments is dependent on the population density and the speed of the shipment. Shipments from the western site result in doses of $7.7 \times 10^{-7}$ man-rem $/ \mathrm{km}$ for shipments averaging $65 \mathrm{~km} / \mathrm{hr}$ and $1.4 \times 10^{-6}$ man-rem/ $\mathrm{km}$ for shioments averaging $35 \mathrm{~km} / \mathrm{hr}$. From the eastern site, doses are $2.3 \times 10^{-6} \mathrm{man}-\mathrm{rem} / \mathrm{km}$ and $4.2 \times 10^{-6}$ man-rem/ $\mathrm{km}$ for shipments averaging 65 and $35 \mathrm{~km} / \mathrm{hr}$, respectively.

6. When the truck stops for fuel, service attendants are exposed to the shipment. Six garagemen are assumed to spend 10 minutes apiece at an average distance of $2 \mathrm{~m}$ from the truck per 2,400-km shipment.

7. Onlookers from the general public might be exposed to radiation when the truck stops for fuel or for the drivers to eat. The onlooker dose per shipment is calculated on the basis that 24 peopie each spend 3 minutes at an average distance of $2 m$ from a shipment.

8. Onsite relocation of the waste is accompitished with $10-m^{3}$ dump trucks lined with plastic. The waste is removed to a new trench $0.5 \mathrm{~km}$ from the original trench. For each shipment one driver is assumed to average $10 \mathrm{~km} / \mathrm{hr}$ between trenches, with a $0.25-\mathrm{hr}$ loading time at each end.

Direct radiation doses to transport workers and members of the genera? public from routine transport of exhumed radioactive waste, calculated using these assumptions, are presented in Table 1.3-2. 
TABLE I.3-2. Direct Radiation Doses to Transportation Workers and Members of the General Public During Routine Transport of Exhumed Waste

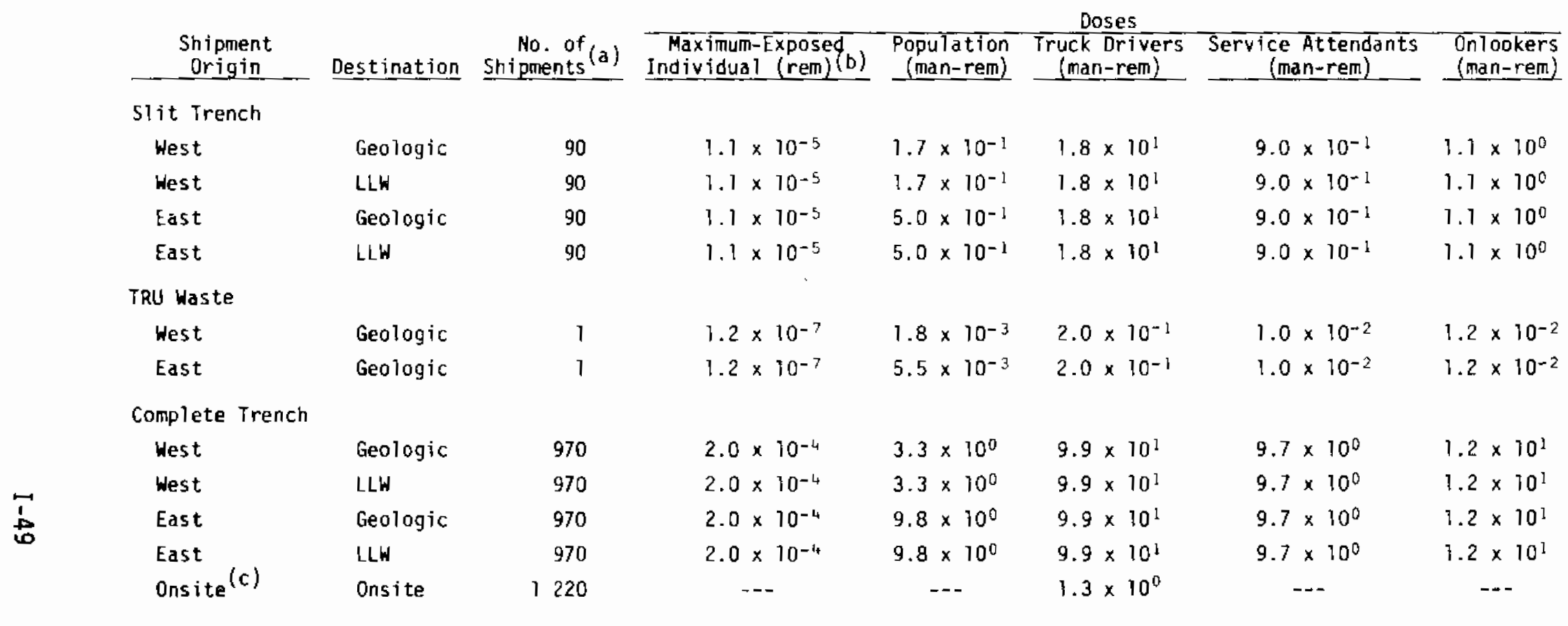

(a)A1] shipments are assumed to be $2,400 \mathrm{~km}$, except onsite shipments that are $0.5 \mathrm{~km}$.

(b)All shipments are assumed to follow the same route, therefore the maximum-exposed individual is exposed to ah shipments.

(c) Since onsite shipments do not use public highways, only truck drivers are involved. 


\section{I.3.2 Assumptions for Postulated Transportation Accidents}

Transportation accidents have a wide range of severities. Most accidents occur at low vehicle speeds and have relatively minor consequences. In genera?, as speed increases, accident severity aiso increases. However, accident severity is not a function of vehicle speed only. Other factors (e.g., the type of accident, the kind of equipment involved, and the location of the accident) can have an important bearing on accident severity.

Furthermore, damage to a package in a transportation accident is not directly related to accident severity. In a series of accidents of the same severity, or in a singie accident involving a number of packages, damage to individual packages may vary from none to extensive. In relatively minor accidents, serious damage to packages can occur from impacts on sharp objects or from being struck by other cargo. Conversely, even in very severe accidents, damage to some packages may be minimal.

In this study, the probabilities of truck accidents are based on accident data suppiied by the U.S. Department of Transportation. (22) Accidents are classified by severity into three categories as functions of truck speed and fire duration. These categories and their associated probabilities are shown in Table I.3-3.

Accidents involving trucks carrying waste from the burial ground might result in the release of radioactive material. A number of potential accident classes are identified. The accident descriptions are derived from those described for similar shipping circumstances in Technology for Commercial Radioactive Waste Management. (23) These accidents are described in Tabies 1.3-4 and I.3-5 for offsite waste shipments in special containers and in Table 1.3-6 for onsite shipments in dump trucks. The waste shipped offsite is packaged in steel boxes and shipped in overpacks that meet Type 8 package standards. The accident protection provided by these overpacks enables a shipment to withstand all but very severe, highty unusual accidents. Only improper packaging or severe impact and fire are assumed to provide a mechanism for airborne radioactive release. The material being transported is solid and, for the most part, noncombustible; hence, even the fraction of respirable materiai released in a severe accident that punctures a container is expected to be small. 
TABLE I.3-3. Transportation Accident Severity Categories

$\begin{array}{cccc}\text { Severity } & \begin{array}{c}\text { Vehicie } \\ \text { Speed }(\mathrm{km} / \mathrm{hr})\end{array} & \begin{array}{c}\text { Fire } \\ \text { Duration }(\mathrm{hr})\end{array} & \begin{array}{c}\text { Probability per } \\ \text { Vehicle km }\end{array} \\ \text { Minor } & 0-50 & 0 & 2 \times 10^{-7} \\ & 0-50 & <0.5 & 4 \times 10^{-9} \\ \text { Moderate } & 50-80 & 0 & 6 \times 10^{-7} \\ & 0-50 & 0.5-1.0 & 3 \times 10^{-11} \\ & 50-80 & <0.5 & 6 \times 10^{-9} \\ \text { Severe } & 80-110 & 0 & 2 \times 10^{-7} \\ & 80-110 & <0.5 & 3 \times 10^{-9} \\ & 0-50 & >1.0 & 3 \times 10^{-12} \\ & 50-80 & >1.0 & 6 \times 10^{-12} \\ & 50-80 & 0.5-1.0 & 4 \times 10^{-12} \\ & 80-110 & 0.5-1.0 & 4 \times 10^{-12} \\ & >110 & 0 & 6 \times 10^{-11} \\ & >110 & <0.5 & 6 \times 10^{-11}\end{array}$

Because wastes exhumed from a slit trench are massive metal pieces shipped in large shielded casks, an airborne release from an accident involving these wastes is considered to be extremely unlikely. Therefore, no accidents involving cask transport are evaluated.

Radiation doses to the maximum-exposed individual from these accidents are included in Table 1.1-8, and are based on the release scenarios in Tables 1.3-4 through I.3-6 for reference radionuclide inventories 3 and 4 . The concentrations of radionuclides in the air breathed by the maximum-exposed individual are calculated using the assumptions presented in Section I.3.3. 


\section{TABLE I.3-4. Minor Offsite Transportation Accidents}

.. Accident Description

Truck collision or over turn involves waste container's.

ruch colijsion ar coerLuri and $1 / 2$ hour (cr cuntainers. es5) rire invalves waste

Sequence of Events.

1. Collision or overturn accident occurs.

2. Truck leaves roadway and may overturn.

3. Confinenent barriers of Type overpack remain intact.

4. Accident is reported to loca and federal officials.

5. Package recovered

1. Collision or overturn accident occurs.

2. Truck leaves roddway and ilay overturn.

3. Pon-high-level TRU waste container is involved in $1 / \%$ nour ior lessifire.

$\therefore$ Accicent is reportes to local and federa: off $\{$ icials.

- Packate recoveres.

vidste shiprlent. liede ir ilproperiy closed fork waste is lickde with imbroperly

$$
\text { Safety Systeir }
$$

Release.

1. Radiation warning signs on over. None pack cdution onlookers to keep distance.

2. interagency radiciocical assis. tance personnel available to assist local public safety and transport carrier officials to control site and recover over pack.

3. Continement barriers of Type overpack contuin all radicactive idteria!.

1. Radiation warnine signs on over. Ponr pack cautior in?ookers to keep distarice.

2. interajercy radiolngical assistance nersmonel available to assist iocal public safety and transport carrier officials to contrial sito and recover averidsk.

3. Confinerent barriers of Type F? ivereack contalis: ull radioactive Wateria?.

1. A shiplient of nor-high-level Ils closed packacjes.

2. Sole redioastive rliateriul is releaced fror! tho packages to the interior of the cucruack.

3. A sliali fraction of the trate rial reisasce from the waste packaces escapes from the confirencht of the overpack durin the urio.
. Radiation werrinc sions on over valck caution rowokers to keep distarice.

?. Qua:ity assuranes and packitie?

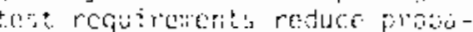
bility uf shingets with improperly closed packages

3. Sealec overpack provents releds to the environment of lideriai soilled from: inproberly ciosed i)ackages.
Rearase fraction is $10^{-}$of shiplent. inventory. Assule release of respirable patrticles at cround if?vel for one rour at a truckservice stop.

Releabes are rroil invertury a for liku shipuents, anc from inventory 3 for others 


\section{TABLE I.3-5. Severe Offsite Transportation Accidents}

\section{Accident Description}

Truck collision or overturn subjects waste containers to severe impact and fire.
I. Collision or overturn accident occurs at high speed.

2. Overpack strikes massive object and decelerates almost instantaneously.

3. Overpack is involved in fire Tasting longer than I hour.

4. Waste packages are breached by force of accident.

5. Only rips or holes are created in overpack; waste packages are retained within the confines of retained withir

6. Accident is reported to local and federal officials.

7. Packaue is sedled.

8. Area is decontaminated.

9. Package is recovered.

\author{
Safety System
}

1. Interagency radiological assistance personflel available to assist local public safety and transport carrier officials to control site and recover overpack.

2. Only small openings exist in overpack. Accident does not result in gross breach of containment.
Release

Release fraction is $10^{-6}$ of shipment inventory.

Assume release of respirable particles at ground level for one hour.

Releases are from inventory 4 for TRU shipments, and froril inventory 3 for others.

\section{TABLE 1.3-6. Onsite Transportation Accident}

\begin{tabular}{|c|c|c|c|}
\hline Accident Jescription & Sequence of Events & Safety.. System & Release \\
\hline $\begin{array}{l}\text { Dump truck overturn } \\
\text { results in spill of waste } \\
\text { onsite. }\end{array}$ & $\begin{array}{l}\text { 1. [ymp truck leaves roadway and } \\
\text { overturns. } \\
\text { 2. } 10 \mathrm{~m}^{3} \text { of waste spill on ground. } \\
\text { 3. Site workers respond with water } \\
\text { sprays. }\end{array}$ & $\begin{array}{l}\text { 1. Accident is onsite, distant from } \\
\text { general public. } \\
\text { 2. Water sprays are quickly brought } \\
\text { to accident scene. } \\
\text { 3. Loading crew is within } 0.5 \mathrm{~km} \text {. }\end{array}$ & $\begin{array}{l}10 \text { in: of average concentration } \\
\text { waste spilled. Mechanical resus- } \\
\text { pension factor is } 10^{-7} \text { sec } \\
\text { Water sprays reduce release one } \\
\text { order of magnitude. Releases are } \\
\text { from inventory } 4 \text { for TRU shipment.s, } \\
\text { and from inventory } 3 \text { for others. }\end{array}$ \\
\hline
\end{tabular}

4. Spilled material is reloaded onto truck with onsite equipment. 


\section{I.3.3 Calculations of Airborne Radioactive Concentration During Transportation Accidents}

The estimation of radionuclide concentrations in air for short-term airborne releases at distances closer than $1.0 \mathrm{~km}$ requires special attention. Regulatory Guide $1.4^{(24)}$ contains a discussion of acceptable assumptions for evaluating design-basis, loss-of-coolant accidents (LOCA) at a PWR. For accidents with a duration of less than 8 hours, a Pasquill Type $F$ atmospheric stability and a windspeed of $1 \mathrm{~m} / \mathrm{sec}$ in a uniform direction are assumed. In Figure 2(A) of Regulatory Guide 1.4, the diffusion factor $x / Q^{\prime}$ (in units of $\mathrm{sec} / \mathrm{m}^{3}$ ) is shown as a function of both distance from a point source and accident duration. For a 0 - to 8-hr duration accident, the value closest to the release source shown in Figure $2(A)$ is about $10^{-\%}\left(\mathrm{sec} / \mathrm{m}^{3}\right)$ at a distance of about $200 \mathrm{~m}$. Extension of the curve beyond the border of the figure results in an estimated $x / Q^{\prime}$ value of about $0.1\left(\mathrm{sec} / \mathrm{m}^{3}\right)$ at $100 \mathrm{~m}$. Using a building-wake correction factor of 3 (from Figure $]$ of Regulatory Guide 1.4) gives an accident $x / Q^{\prime}$ value of about $3 \times 10^{-2}\left(\mathrm{sec} / \mathrm{m}^{3}\right)$ at $100 \mathrm{~m}$. Because of the difficulty in modeling the air concentrations at close distances, the maximum-exposed individual is assumed to be located $100 \mathrm{~m}$ from transportation accidents.

At distances close to the release source, the diffusion of the downwind plume is influenced by the cross-sectional area of the release source. For this reason, a comparison of the $x / Q^{\prime}$ value extrapolated from Regulatory Guide 1.4 is made with $X / Q^{\prime}$ values calculated using a building-wake model. Assuming complete reflection of the plume by the ground plane, the groundlevel centerline air concentration from a ground-level release is calculated using Equation I.2:

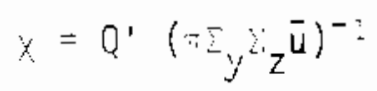

where:

Q' - rate of release from the source, corrected for decay during transit to the exposure point, $\mathrm{Ci} / \mathrm{sec}$ 


$$
\begin{gathered}
\bar{u}-\text { average ground-level wind speed in the direction of travel, } \mathrm{m} / \mathrm{s} \\
\Sigma_{y}, \Sigma_{z} \text { building-wake diffusion coefficients calculated by: } \\
\Sigma_{y}=\left(\sigma_{y}^{2}+\mathrm{cA} / \pi\right)^{1 / 2} \\
\Sigma_{z}=\left(\sigma_{z}^{2}+\mathrm{cA} / \pi\right)^{1 / 2}
\end{gathered}
$$

where:

A - cross-sectional area of the release source normal to the wind direction, $\mathrm{m}^{2}$

c a factor estimating the relation of the cross-sectional area to pressure wakes ( 0.5 for this study)

$\sigma_{y}$ - crosswind lateral standard deviation of the cloud concentration, $m$

$\sigma_{z}$ - crosswind vertical standard deviation of the cloud concentration, $m$. A minimum value of $\sigma_{y}$ and $\sigma_{z}$ of $\sqrt{A} / 6$ is assumed for this study.

Using Equation I.2, Pasquill Type $F$ centerline air concentrations at various distances for selected release source cross-sectional areas are shown in Figure 1.3-1. At about $500 \mathrm{~m}$ downwind, the curves converge. The close-in dependence of the building-wake modification is illustrated by the divergence of the area-dependent curves.

From Figure 1.3-1, it can be seen that the value of $x / Q^{\prime}$ extrapolated from Regulatory Guide 1.4 corresponds to an exposed cross-sectional area of about $30 \mathrm{~m}^{2}$. This appears to be a reasonable comparison; therefore, a value of $3 \times 10^{-2}\left(\mathrm{sec} / \mathrm{m}^{3}\right)$ is used as the transportation accident $x / Q^{\prime}$ for an individua? located $100 \mathrm{~m}$ downwind.

\section{I.4 REFERENCE RADIONUCLIDE INVENTORIES}

The residual radionuclide inventories associated with the various waste forms encountered during LLW decommissioning are presented in Section 7 of Volume 1. They are repeated here, with a brief discussion, to help illustrate 


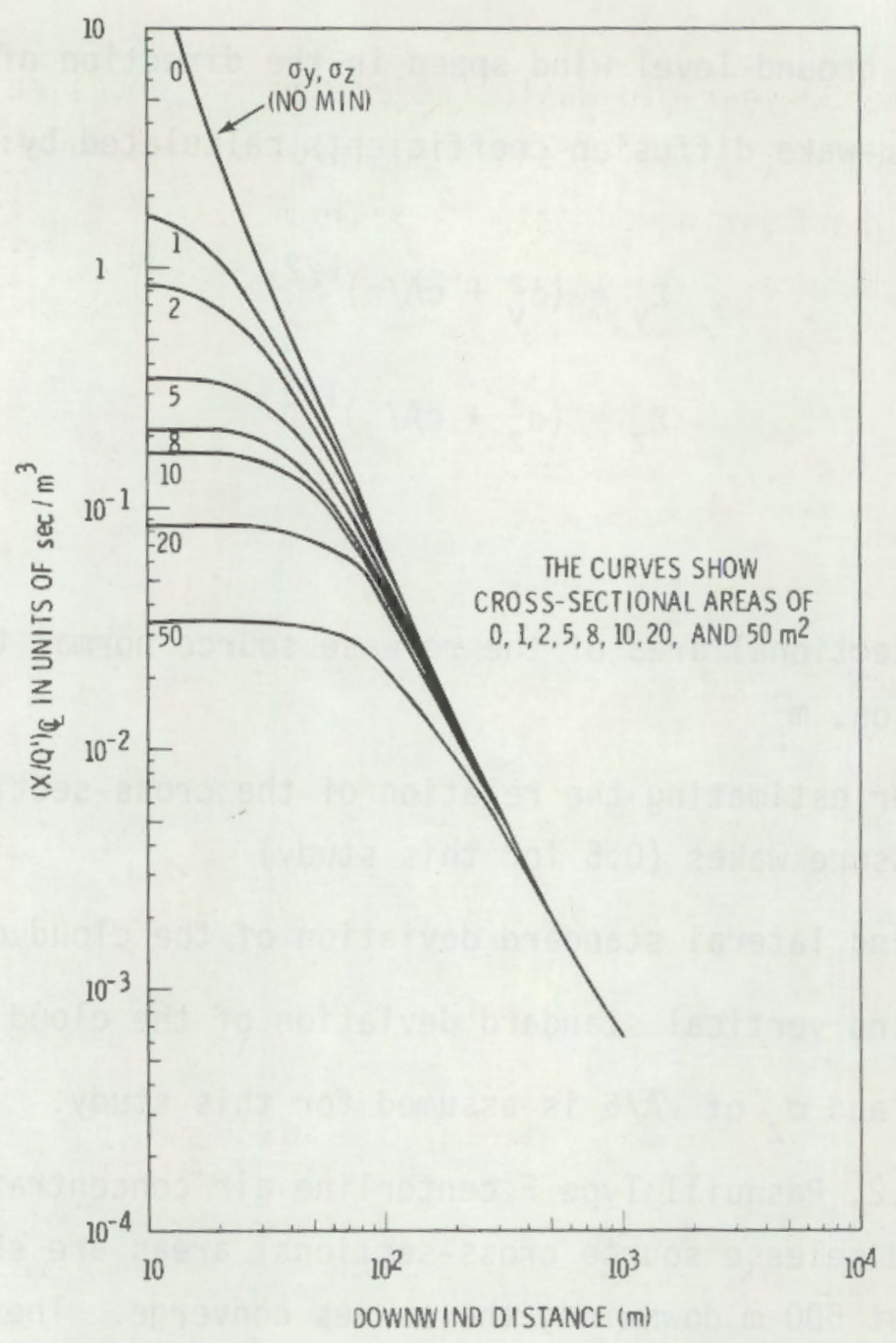

FIGURE I.3-1. Pasquil1 Type $F$ Centerline $\times / Q^{\prime}$ Values for Building-Wake Modification Factors Versus Downwind Distance

the relationships between the calculated airborne releases and the resulting radiation doses. These inventories are also the basis for the dose rate estimates used to calculate occupational exposures during decommissioning. A reference number is assigned to each inventory to aid in relating the airborne release, the radionuclide mixture, and the radiation doses for each decommissioning operation.

The slit trench contains activated reactor core internals packaged in cylindrical steel canisters. Two modes of radioactive release from these canisters are postulated. The first involves a loss of canister integrity as a result of some long-term process such as corrosion. The radionuclide 
mixture involved is the 30-year-01d waste (reference radionuclide inventory 1) shown in Table 1.4-1. The second mode involves a canister rupture as a result of an accident during burial. A maximum case for this mode is the 1-year-old waste mixture (reference radionuclide inventory 2) shown in Table I.4-2.

\section{TABLE I.4-1. Reference Radionuclide Inventory, 1, 30-Year-01d Slit Trench Waste/Soil Mixture(a)}

\begin{tabular}{|c|c|c|c|c|c|}
\hline Radionuclide & $\begin{array}{c}\text { Half Life } \\
\text { (years) }\end{array}$ & $\begin{array}{c}\text { Radioactivity } \\
\text { per } \\
\text { Canister at } \\
\text { Burial (Ci) }\end{array}$ & $\begin{array}{c}\text { Radioactivity } \\
\text { per } \\
\text { Canister at } \\
\text { Site Closure (ci) } \\
\end{array}$ & $\begin{array}{r}\text { Total Leaked } \\
\text { Radioactivity } \\
\text { at Site } \\
\text { Closure (Ci) } \\
\end{array}$ & $\begin{array}{c}\text { Average } \\
\text { Soil/Waste } \\
\text { Concentration } \\
\left(\mathrm{C} i / \mathrm{m}^{3}\right)(\mathrm{c}) \\
\end{array}$ \\
\hline${ }^{54} \mathrm{Mn}$ & $8.3 \times 10^{-1}$ & $2.0 \times 10^{2}$ & $2.6 \times 10^{-9}$ & $2.6 \times 10^{-11}$ & $2.2 \times 10^{-12}$ \\
\hline${ }^{55} \mathrm{Fe}$ & $2.6 \times 10^{0}$ & $2.5 \times 10^{3}$ & $8.4 \times 10^{-1}$ & $8.4 \times 10^{-3}$ & $7.0 \times 10^{-4}$ \\
\hline${ }^{59} \mathrm{Fe}$ & $1.2 \times 10^{-1}$ & $1.0 \times 10^{2}$ & $\ldots(d)$ & $\ldots$ & $\ldots$ \\
\hline${ }^{58} \mathrm{Co}$ & $2.0 \times 10^{-1}$ & $2.5 \times 10^{2}$ & $\ldots$ &.- & $\ldots$ \\
\hline${ }^{60} \mathrm{Co}$ & $5.3 \times 10^{0}$ & $1.8 \times 10^{3}$ & $3.6 \times 10^{1}$ & $3.6 \times 10^{-1}$ & $3.0 \times 10^{-2}$ \\
\hline $59 \mathrm{Ni}$ & $8.0 \times 10^{4}$ & $1.5 \times 10^{0}$ & $1.5 \times 10^{0}$ & $1.5 \times 10^{-2}$ & $1.2 \times 10^{-3}$ \\
\hline $63 \mathrm{Ni}$ & $9.2 \times 10^{1}$ & $2.0 \times 10^{2}$ & $1.6 \times 10^{2}$ & $1.6 \times 10^{0}$ & $1.3 \times 10^{-1}$ \\
\hline Totals & & $\overline{5.0 \times 10^{3}}$ & $2.0 \times 10^{2}$ & $2.0 \times 10^{0}$ & $\overline{1.6 \times 10^{-1}}$ \\
\hline
\end{tabular}

(a) Based on 5,000 $\mathrm{Ci}$ per canister of the radioactivity shown in Table 7.3-4 of volume 1.

(b) Assuming that one of the capsules buried in the first year of operation has leaked $1 \%$ of the radioactivity it contains.

(c) The released activity is assumed to be mixed in $1 / 90$ of the slit trench volume $\left(12 \mathrm{~m}^{3}\right)$.

(d) A dash indicates values less than $1.0 \times 10^{-12} \mathrm{Ci}$.

\section{TABLE 1.4-2. Reference Radionuc1ide Inventory 2, 1-Year-01d S1it Trench Waste/Soil Mixture(a)}

\begin{tabular}{|c|c|c|c|c|c|}
\hline idionuclide & $\begin{array}{c}\text { Half Life } \\
\text { (years) }\end{array}$ & $\begin{array}{c}\text { Radioactivity } \\
\text { per } \\
\text { Canister at } \\
\text { Burial (Ci) } \\
\end{array}$ & $\begin{array}{l}\text { Radioactivity } \\
\text { per } \\
\text { Canister at } \\
\text { Site Closure (Ci) }\end{array}$ & $\begin{array}{r}\text { Total Leaked } \\
\text { Radioactivity } \\
\text { at Site (b) } \\
\text { Closure (Ci) }\end{array}$ & $\begin{array}{c}\text { Average } \\
\text { Soil/Waste } \\
\text { Concentratjon } \\
\left(\mathrm{Ci} / \mathrm{m}^{3}\right)(\mathrm{c}) \\
\end{array}$ \\
\hline${ }^{54} \mathrm{Mn}$ & $8.3 \times 10^{1}$ & $2.0 \times 10^{2}$ & $2.0 \times 10^{2}$ & $2.0 \times 10^{0}$ & $1.7 \times 10^{-1}$ \\
\hline${ }^{55} \mathrm{Fe}$ & $2.6 \times 10^{0}$ & $2.5 \times 10^{3}$ & $1.9 \times 10^{3}$ & $1.9 \times 10^{1}$ & $1.6 \times 10^{0}$ \\
\hline${ }^{59} \mathrm{Fe}$ & $1.2 \times 10^{-1}$ & $1.0 \times 10^{2}$ & $3.1 \times 10^{-1}$ & $3.1 \times 10^{-3}$ & $2.6 \times 10^{-4}$ \\
\hline${ }^{58} \mathrm{Co}$ & $2.0 \times 10^{-1}$ & $2.5 \times 10^{2}$ & $7.8 \times 10^{0}$ & $7.8 \times 10^{-2}$ & $6.5 \times 10^{-3}$ \\
\hline${ }^{60} \mathrm{Co}$ & $5.3 \times 10^{0}$ & $1.8 \times 10^{3}$ & $1.6 \times 10^{3}$ & $1.6 \times 10^{1}$ & $1.3 \times 10^{0}$ \\
\hline${ }^{59} \mathrm{Ni}$ & $8.0 \times 10^{4}$ & $1.5 \times 10^{0}$ & $1.5 \times 10^{0}$ & $1.5 \times 10^{-2}$ & $1.2 \times 10^{-3}$ \\
\hline${ }^{6}{ }^{3} \mathrm{Ni}$ & $9.2 \times 10^{1}$ & $2.0 \times 10^{2}$ & $2.0 \times 10^{2}$ & $2.0 \times 10^{0}$ & $1.7 \times 10^{-1}$ \\
\hline Totals & & $5.0 \times 10^{3}$ & $3.9 \times 10^{3}$ & $3.9 \times 10^{1}$ & $3.2 \times 10^{0}$ \\
\hline
\end{tabular}

(a) Based on 5,000 Ci per canister of the radioactivity shown in Table 7.3-4 of Volume 1.

(b)Assuming that one of the capsules buried in the last year of operation has leaked

$1 \%$ of the radioactivity it contains.

(c) The released activity is assumed to be mixed in $1 / 90$ of the slit trench volume (12 $\left.\mathrm{m}^{3}\right)$. 
Since a low failure rate is assumed for these canisters, because of design features and burial procedures, only one canister of either waste form is assumed to leak. The slit trench analysis compares the airborne releases for these two inventories. The waste in the canisters is assumed to be activation products in a fixed matrix. Therefore, only $1 \%$ of the waste in either canister is assumed to be mobile, and only a fraction $\left(1 / 90\right.$, or $\left.12 \mathrm{~m}^{3}\right)$ of the total trench volume is contaminated in either case.

Reference radionuclide inventory 3 , shown in Table $1.4-3$, is a listing of the average concentration of radioactivity in the reference trench at the time of site closure. The average radioactivity per trench is found by dividing the total burial ground inventory (at site closure) by the total number of trenches. The trench radionuclide concentration is found by dividing the average radioactivity per trench by the total volume of the trench waste/soil mixture $\left(12,200 \mathrm{~m}^{3}\right)$.

Reference radionuclide inventory 4 , the TRU waste inventory for burial trench relocation, is shown in Table I.4-4. The mixture of actinides in the complete trench is used as a basis for determining the radionuclide inventory associated with $40 \mathrm{~g}$ of plutonium isotopes. This waste is assumed to be mixed in enough volume to fill two waste boxes $\left(\sim 5 \mathrm{~m}^{3}\right)$.

No direct credit is taken for the effect of waste package integrity, except in the case of the slit trench. However, it is assumed that only $10 \%$ of the waste is of the correct physical form and particle size to permit atmospheric transport from excavation operations. Airborne releases from transport accidents are found using release fractions given in the literature, as discussed in Section I.3. 
TABLE I.4-3. Reference Radionuclide Inventory 3, Average
Waste/Soil Radioactivity at Site Closure(a)

\begin{tabular}{|c|c|c|c|c|}
\hline Radionucl ide & $\begin{array}{c}\text { Half Life } \\
\text { (years) } \\
\end{array}$ & $\begin{array}{c}\text { Total Burial } \\
\text { Ground } \\
\text { Inventory at } \\
\text { Site Closure (Ci) } \\
\end{array}$ & $\begin{array}{c}\text { Average } \\
\text { Radioactivity } \\
\text { per Trench at }(b) \\
\text { Site Closure (ci) }\end{array}$ & $\begin{array}{c}\text { Average } \\
\text { Trench } \\
\text { Concentration } \\
\left(\mathrm{Ci} / \mathrm{m}^{3}\right)(\mathrm{c}) \\
\end{array}$ \\
\hline${ }^{3} \mathrm{H}$ & $1.2 \times 10^{1}$ & $1.1 \times 10^{5}$ & $6.1 \times 10^{2}$ & $5.0 \times 10^{-2}$ \\
\hline${ }^{14} \mathrm{C}$ & $5.7 \times 10^{3}$ & $7.6 \times 10^{3}$ & $4.2 \times 10^{1}$ & $3.4 \times 10^{-3}$ \\
\hline${ }^{51} \mathrm{Cr}$ & $7.6 \times 10^{-2}$ & $3.0 \times 10^{2}$ & $1.6 \times 10^{0}$ & $1.3 \times 10^{-4}$ \\
\hline${ }^{54} \mathrm{Mn}$ & $8.3 \times 10^{-1}$ & $1.9 \times 10^{4}$ & $1.0 \times 10^{2}$ & $8.2 \times 10^{-3}$ \\
\hline${ }^{55} \mathrm{Fe}$ & $2.6 \times 10^{0}$ & $1.0 \times 10^{5}$ & $5.6 \times 10^{2}$ & $4.6 \times 10^{-2}$ \\
\hline${ }^{58} \mathrm{Co}$ & $2.0 \times 10^{-1}$ & $5.2 \times 10^{3}$ & $2.9 \times 10^{1}$ & $2.4 \times 10^{-3}$ \\
\hline${ }^{60} \mathrm{CO}$ & $5.3 \times 10^{0}$ & $6.2 \times 10^{5}$ & $3.4 \times 10^{3}$ & $2.8 \times 10^{-1}$ \\
\hline $59 \mathrm{Ni}$ & $8.0 \times 10^{4}$ & $2.5 \times 10^{4}$ & $1.4 \times 10^{2}$ & $1.2 \times 10^{-2}$ \\
\hline${ }^{6} \mathrm{Ni}$ & $9.2 \times 10^{1}$ & $4.2 \times 10^{6}$ & $2.3 \times 10^{4}$ & $1.9 \times 10^{0}$ \\
\hline${ }^{65} \mathrm{Zn}$ & $6.7 \times 10^{-1}$ & $1.2 \times 10^{3}$ & $6.7 \times 10^{0}$ & $5.5 \times 10^{-4}$ \\
\hline${ }^{90} \mathrm{Sr}$ & $2.8 \times 10^{1}$ & $6.7 \times 10^{3}$ & $3.7 \times 10^{1}$ & $3.0 \times 10^{-3}$ \\
\hline $90 \mathrm{Y}$ & $7.3 \times 10^{-3}$ & $6.7 \times 10^{3}$ & $3.7 \times 10^{1}$ & $3.0 \times 10^{-3}$ \\
\hline${ }^{95} \mathrm{Zr}$ & $1.8 \times 10^{-1}$ & $2.0 \times 10^{2}$ & $1.1 \times 10^{0}$ & $9.0 \times 10^{-5}$ \\
\hline${ }^{99} \mathrm{TC}$ & $2.1 \times 10^{5}$ & $6.5 \times 10^{1}$ & $3.6 \times 10^{-1}$ & $3.0 \times 10^{-5}$ \\
\hline${ }^{106} \mathrm{Ru}$ & $1.0 \times 10^{0}$ & $1.9 \times 10^{3}$ & $1.1 \times 10^{1}$ & $9.0 \times 10^{-4}$ \\
\hline${ }^{106} \mathrm{Rh}$ & $9.5 \times 10^{-7}$ & $1.9 \times 10^{3}$ & $1.1 \times 10^{1}$ & $9.0 \times 10^{-4}$ \\
\hline $124 \mathrm{Sb}$ & $1.6 \times 10^{-1}$ & $3.8 \times 10^{1}$ & $2.1 \times 10^{-1}$ & $1.7 \times 10^{-5}$ \\
\hline${ }^{125} \mathrm{Sb}$ & $2.7 \times 10^{0}$ & $1.3 \times 10^{3}$ & $7.2 \times 10^{0}$ & $5.9 \times 10^{-4}$ \\
\hline 1291 & $1.7 \times 10^{7}$ & $1.3 \times 10^{1}$ & $7.2 \times 10^{-2}$ & $5.9 \times 10^{-6}$ \\
\hline${ }^{134} \mathrm{Cs}$ & $2.0 \times 10^{0}$ & $9.4 \times 10^{4}$ & $5.2 \times 10^{2}$ & $4.3 \times 10^{-2}$ \\
\hline${ }^{136} \mathrm{Cs}$ & $3.0 \times 10^{E}$ & $6.8 \times 10^{2}$ & $3.8 \times 10^{0}$ & $3.1 \times 10^{-4}$ \\
\hline${ }^{137} \mathrm{Cs}$ & $3.0 \times 10^{1}$ & $1.2 \times 10^{6}$ & $6.7 \times 10^{3}$ & $5.5 \times 10^{-1}$ \\
\hline${ }^{144} \mathrm{Ce}$ & $7.8 \times 10^{-1}$ & $1.4 \times 10^{3}$ & $7.8 \times 10^{0}$ & $6.4 \times 10^{-4}$ \\
\hline${ }^{144} \mathrm{Pr}$ & $3.0 \times 10^{-5}$ & $1.4 \times 10^{3}$ & $7.8 \times 10^{0}$ & $6.4 \times 10^{-4}$ \\
\hline${ }^{222} R n$ & $1.0 \times 10^{-2}$ & $2.1 \times 10^{2}$ & $1.2 \times 10^{0}$ & $9.8 \times 10^{-5}$ \\
\hline $226 \mathrm{Ra}$ & $1.6 \times 10^{3}$ & $2.1 \times 10^{2}$ & $1.2 \times 10^{0}$ & $9.8 \times 10^{-5}$ \\
\hline${ }^{230} \mathrm{Th}$ & $8.0 \times 10^{4}$ & $1.4 \times 10^{2}$ & $7.8 \times 10^{-1}$ & $6.4 \times 10^{-5}$ \\
\hline $232 \mathrm{Th}$ & $1.4 \times 10^{10}$ & $1.6 \times 10^{1}$ & $8.9 \times 10^{-2}$ & $7.3 \times 10^{-6}$ \\
\hline $235 \mathrm{U}$ & $7.1 \times 10^{8}$ & $6.5 \times 10^{3}$ & $3.6 \times 10^{-1}$ & $3.0 \times 10^{-5}$ \\
\hline $238 \mathrm{U}$ & $4.5 \times 10^{9}$ & $1.4 \times 10^{-3}$ & $7.8 \times 10^{-6}$ & $6.2 \times 10^{-10}$ \\
\hline $23{ }^{3} \mathrm{~Np}$ & $2.1 \times 10^{6}$ & $9.2 \times 10^{-2}$ & $5.1 \times 10^{-4}$ & $4.2 \times 10^{-8}$ \\
\hline${ }^{238} \mathrm{Pu}$ & $8.6 \times 10^{1}$ & $6.0 \times 10^{2}$ & $3.3 \times 10^{-4}$ & $2.7 \times 10^{-8}$ \\
\hline${ }^{239} \mathrm{Pu}$ & $2.4 \times 10^{4}$ & $8.5 \times 10^{1}$ & $4.7 \times 10^{-1}$ & $3.8 \times 10^{-5}$ \\
\hline${ }^{240} \mathrm{Pu}$ & $6.6 \times 10^{3}$ & $1.3 \times 10^{2}$ & $7.2 \times 10^{-1}$ & $5.9 \times 10^{-5}$ \\
\hline $24 ! \mathrm{Pu}$ & $1.3 \times 10^{1}$ & $1.6 \times 10^{4}$ & $8.9 \times 10^{1}$ & $7.3 \times 10^{-3}$ \\
\hline${ }^{24} 2 \mathrm{Pu}$ & $3.8 \times 10^{5}$ & $4.7 \times 10^{-1}$ & $2.6 \times 10^{-3}$ & $2.1 \times 10^{-7}$ \\
\hline $241 \mathrm{Am}$ & $4.6 \times 10^{2}$ & $5.1 \times 10^{2}$ & $2.8 \times 10^{0}$ & $2.3 \times 10^{-2}$ \\
\hline $243 \mathrm{Am}$ & $8.0 \times 10^{3}$ & $4.1 \times 10^{0}$ & $2.3 \times 10^{-2}$ & $1.9 \times 10^{-6}$ \\
\hline${ }^{242} \mathrm{Cm}$ & $4.4 \times 10^{-1}$ & $9.4 \times 10^{1}$ & $5.2 \times 10^{-1}$ & $4.3 \times 10^{-5}$ \\
\hline${ }^{244} \mathrm{~cm}$ & $1.8 \times 10^{1}$ & $2.2 \times 10^{2}$ & $1.2 \times 10^{0}$ & $9.8 \times 10^{-5}$ \\
\hline Total & & $6.4 \times 10^{5}$ & $3.5 \times 10^{4}$ & $2.9 \times 10^{0}$ \\
\hline
\end{tabular}

(a) Based on the total burial ground inventory in Table 7.3-3 of Volume 1 .

(b) The total burial ground inventory divided by 780 trenches gives the average radioactivity per trench.

(c) The average trench activity divided by a trench waste/soil volume of $12,200 \mathrm{~m}^{3}$. 

TABLE I.4-4. Reference Radionuclide Inventory 4, TRU Waste Actiyity at
Site Closure Associated with $40 \mathrm{~g}$ of Pu Isotopes(a)

\begin{tabular}{|c|c|c|c|c|}
\hline Radionuclide & $\begin{array}{c}\text { Half Life } \\
\text { (years) } \\
\end{array}$ & $\begin{array}{l}\text { Total Burial } \\
\text { Ground Inventory } \\
\text { (Ci) }\end{array}$ & $\begin{array}{c}40 \mathrm{~g} \mathrm{Pu} \\
\text { Radioactivity of } \\
\text { TRU Mixture } \\
(\mathrm{Ci}) \\
\end{array}$ & $\begin{array}{c}\text { Average } \\
\text { Concentration } \\
\text { of TRU Waste } \\
\text { for Relocation } \\
\left(\mathrm{Ci} / \mathrm{m}^{3}\right)(\mathrm{b}) \\
\end{array}$ \\
\hline $237 \mathrm{~Np}$ & $2.1 \times 10^{6}$ & $9.2 \times 10^{-2}$ & $1.6 \times 10^{-3}$ & $3.1 \times 10^{-4}$ \\
\hline $238 \mathrm{Pu}$ & $8.6 \times 10^{1}$ & $6.0 \times 10^{2}$ & $1.1 \times 10^{1}$ & $2.1 \times 10^{0}$ \\
\hline $239 \mathrm{pu}$ & $2.4 \times 10^{4}$ & $8.5 \times 10^{1}$ & $1.5 \times 10^{0}$ & $2.9 \times 10^{-1}$ \\
\hline $240 \mathrm{Pu}$ & $6.6 \times 10^{3}$ & $1.3 \times 10^{2}$ & $2.3 \times 10^{0}$ & $4.4 \times 10^{-1}$ \\
\hline $241 \mathrm{Pu}$ & $1.3 \times 10^{1}$ & $1.6 \times 10^{4}$ & $2.8 \times 10^{2}$ & $5.4 \times 10^{1}$ \\
\hline $241 \mathrm{Am}$ & $4.6 \times 10^{2}$ & $5.1 \times 10^{2}$ & $9.1 \times 10^{0}$ & $1.8 \times 10^{0}$ \\
\hline $242 \mathrm{Pu}$ & $3.8 \times 10^{5}$ & $4.7 \times 10^{-1}$ & $8.4 \times 10^{-3}$ & $1.6 \times 10^{-3}$ \\
\hline $243 \mathrm{Am}$ & $8.0 \times 10^{3}$ & $4.1 \times 10^{0}$ & $7.2 \times 10^{-2}$ & $1.4 \times 10^{-2}$ \\
\hline${ }^{242} \mathrm{Cm}$ & $4.4 \times 10^{-1}$ & $9.4 \times 10^{1}$ & $1.6 \times 10^{0}$ & $3.1 \times 10^{-1}$ \\
\hline${ }^{244} \mathrm{Cm}$ & $1.8 \times 10^{1}$ & $2.2 \times 10^{2}$ & $3.9 \times 10^{0}$ & $7.5 \times 10^{-1}$ \\
\hline Totals & & $1.8 \times 10^{4}$ & $3.1 \times 10^{2}$ & $6.0 \times 10^{1}$ \\
\hline
\end{tabular}

(a) The values calculated associated with the radioactivity in a mixture containing $40 \mathrm{~g}$ of $\mathrm{Pu}$ are assumed to be in the same ratios as the total burial ground inventory found in Table 7.3-3 of Volume 1.

(b) Based on two waste packages of TRU waste $(1.2 \mathrm{~m} \times 1.2 \mathrm{~m} \times 1.8 \mathrm{~m}$ per package) containing $40 \mathrm{~g}$ of $\mathrm{Pu}$ isotopes. 


\section{REFERENCES}

1. K. J. Schneider and C. E. Jenkins, Technology, Safety and Costs of Decommissioning a Reference Nuclear Fuel Reprocessing Plant, NUREG-0278, Prepared by Pacific Northwest Laboratory for the U.S. Nuclear Regulatory Commission, October 1977.*

2. R. I. Smith, G. J. Konzek and W. E. Kennedy, Jr., Technology, Safety and Costs of Decommissioning a Reference Pressurized Water Reactor Power Station, NUREG/CR-0130, Prepared by Pacific Northwest Laboratory for the U.S. Nuclear Regulatory Commission, June 1978. $\star \star$

3. C. E. Jenkins, E. S. Murphy and K. J. Schneider, Technology, Safety and Costs of Decommissioning a Reference Small Mixed Oxide Fuel Fabrication Plant, NUREG/CR-0129, Prepared by Pacific Northwest Laboratory for the U.S. Nuclear Regulatory Commission, February 1979.**

4. R. C. Milham, J. F. Schubert, J. R. Watts, A. L. Boni and J. C. Corey, "Measured Plutonium Resuspension and Resulting Dose from Agricultural Operations on an 01d Field at the Savannah River Plant in the Southeastern United States," IAEA/USERDA International Symposium on Transuranium Nuclides in the Environment, pp. 17-21, November 1975.

5. J. W. Healy, An Examination of the Pathways from Soil to Man for Plutonium, Los Alamos Scientific Laboratory, LA-6741-MS, pp. 28-50, 1977.

6. D. H. Card, Early Waste Retrieval Interim Report, TREE-1047, Idaho National Engineering Laboratory, EG \& G Idaho, Inc., Pp. 19-40, February 1977.

7. B. L. Cohen, "Hazards from Plutonium Toxicity," Health Physics $\underline{32}(5): 359-379,1977$.

8. Final Elk River Reactor Program Report, CO0-651-93, Revised, P. F-9, United Power Association, Elk River, MN, November 1974.

9. Technology for Commercial Radioactive Waste Management, DOE/ET-0028/2, Pacific Northwest Laboratory, for the Department of Energy, Volume 2 of 5, Section 4.8, 1979.

10. J. H. Horton, Exhumation of Radioactive Solid Wastes Buried for Fourteen Years, DP-1456, E. I. DuPont de Nemours and Company, Savannah River Laboratory, pp. 5-11, Aiken, SC 29801, 1977.

11. H. P. Holcomb, Radionuclide Content of an Exhumed Canyon Vessel and Neighboring Soi $\overline{1}$, OP-1446, E. I. Oupont de Nemours and Company, Savannah River Laboratory, pp. 5-27, Aiken, SC 29801, 1976. 
12. The Shallow Land Burial of Low-Level Radioactively Contaminated Solid Waste, National Research Council, National Academy of Sciences, Washington, DC, pp. 32-79, 1976.

13. J. Mishima and L. C. Schwendiman, Fractional Airborne Release of Uranium (Representing Plutonium) During the Burning of Contaminated Waste, BNWL-1730, Battelle, Pacific Northwest Laboratories, Richland, WA, April 1973.

14. I. B. Wa11, "Probabilistic Assessment of Aircraft Risk for Nuclear Power Plants," Nuclear Safety 15(3):276-284, May-June 1974 .

15. R. L. Engel, J. Greenborg and M. M. Hendrickson, ISOSHLD - A Computer Code for General Purpose Isotope Shielding Analysis, BNWL-236, Battelle, Pacific Northwest Laboratories, June 1966.

16. G. L. Simmons et a1., ISOSHLD II Code Revision to Include Calculation of Dose Rates from Shielded Bremsstrahlung Sources, BNWL-236, SuppleAppendices ment 1, Battelle, Pacific Northwest Laboratories, March 1967.

17. J. N. Strode and H. H. Van Tuy1, PUSHLD - A Code for Calculations of Gamma Dose Rates from Plutonium in Various Geometries, HEDL-TME-73-89, Hanford Engineering Development Laboratory, Richland, WA, 1970.

18. F. H. Attix and W. C. Roesch, Radiation Dosimetry, Vol. 1, Academic Press, Inc., 1968.

19. Radiological Health Handbook, Public Health Service, Revised Edition, 1970.

20. T. Rockwell III, Editor, Reactor Shielding Design Manual, D. Van Norstrand Company, Inc., 1st Edition, p. 40, 1956.

21. U.S. Code of Federal Regulations, Title 49, Parts 170-189, "Transportation." Superintendent of Documents, GPO, Washington, DC 20555, January 1977.

22. Directorate of Regulatory Standards, Environmental Survey of Transportation of Radioactive Materials to and from Nuclear Power Plants, WASH-1238, U.S. Atomic Energy Commission, Washington, DC, 1972.

23. Technology for Commercial Radioactive Waste Management, D0E/ET-0028/4, Pacific Northwest Laboratory, for the Department of Energy, Volume 4 of 5 , Section 6.6.1, 1979.

24. U.S. NRC, Assumptions Used for Evaluating the Potential Radiological Consequences of a Loss of Coolant Accident for Pressurized Water Reactors, Regulatory Guide 1.4, Revision 2, June 1974.

25. D. H. Slade, Editor, Meteorology and Atomic Energy, U.S. AEC, Division of Technical Information, 1968.

\#Available for purchase from the National Technical Information Service, Springfield, Virginia 22161.

**Available for purchase from the NRC/GPO Sales Program, U.S. Nuclear Regulatory Commission, Washington, D.C. 20555, and the National Technical Information Service, Springfieid, Virginia 22161. 


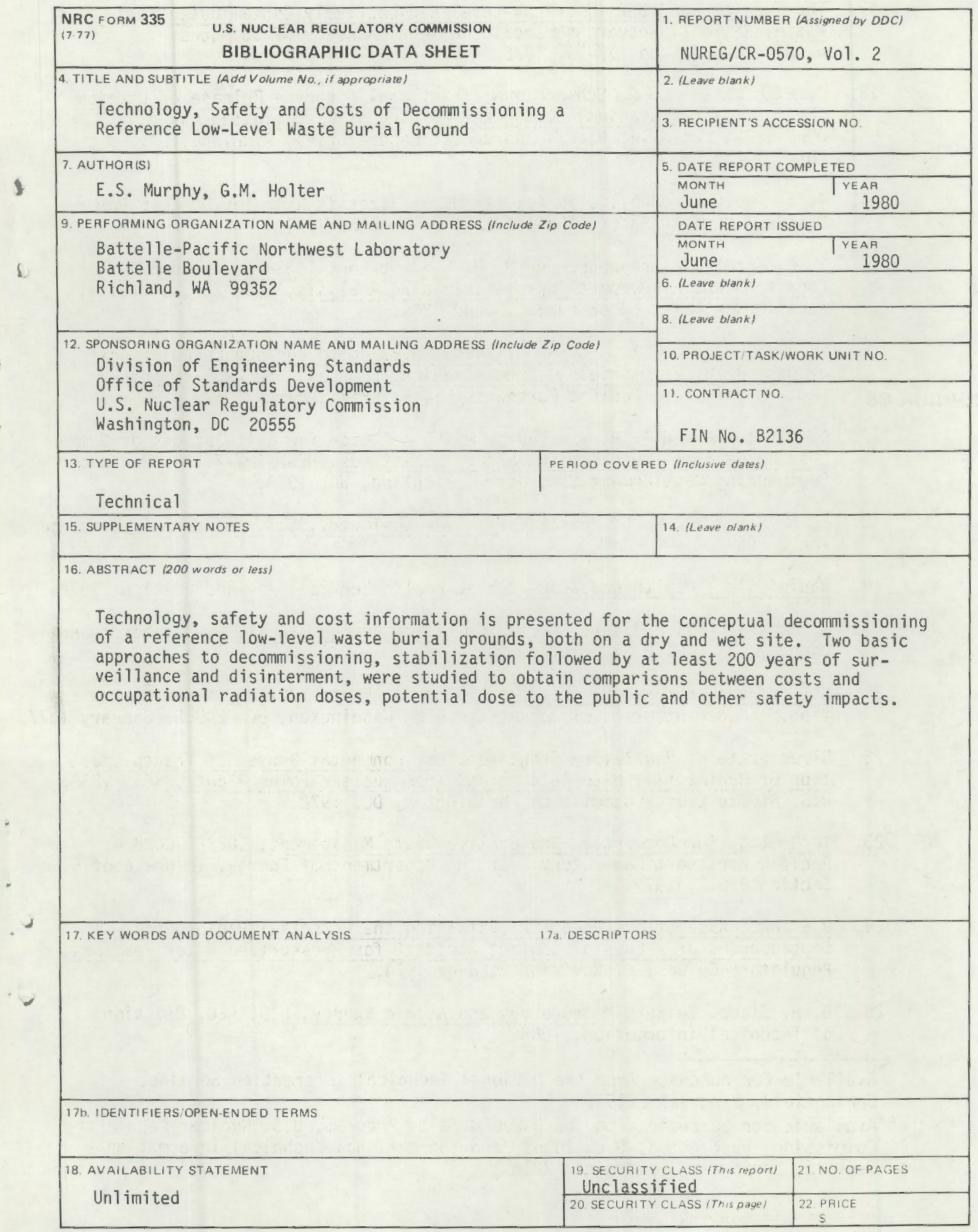


